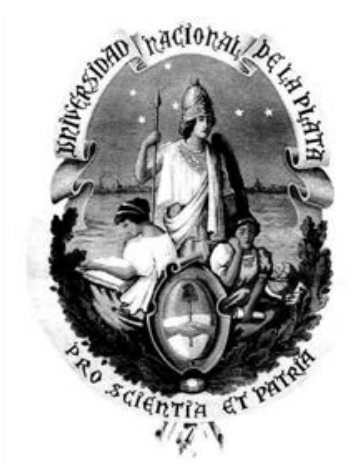

Universidad Nacional de La Plata

Facultad de Ciencias Astronómicas y Geofísicas

\title{
Estudio multiespectral de nebulosas anillo alrededor de estrellas Wolf-Rayet
}

\author{
Lic. Javier Vasquez \\ Directora: Dra. Cristina E. Cappa
}

Tesis presentada para optar al grado de

Doctor en Astronomía

Marzo de 2008 



\section{Resumen}

Las estrellas Wolf-Rayet (WR) constituyen la última etapa evolutiva de las estrellas de gran masa. Los vientos estelares generados en esta fase se caracterizan por sus altas velocidades terminales y tasas de pérdida de masa. Estos vientos interactúan con el medio interestelar que los rodea modelándolo e inyectando energía mecánica. Esa interacción puede ser observada y analizada en diferentes rangos del espectro electromagnético (EE). Las zonas más ricas para estudiar esas interacciones son los rangos rangos óptico, infrarrojo y radio. De observaciones en cada una de esta franjas del espectro se puede obtener información valiosa de la interacción entre el campo de radiación estelar y el material circundante, y entre el material expulsado de las estrellas de gran masa y el material interestelar barrido. En muchos casos, esa interacción crea diferentes estructuras interestelares. Nosotros dedicamos este trabajo al estudio de las contrapartes en distintas franjas del EE asociadas a las nebulosas anillo observadas en el rango óptico. Esas estructuras particulares se llaman burbujas interestelares (BI).

Este trabajo se desarrolla de la siguiente manera: en primer término, damos un introducción teórica de los principales modelos que explican la estructura y evolución de las BI, sin tener en cuenta la evolución de las estrellas que le dan origen. Luego, consideramos modelos más realistas que incluyen también la evolución de las estrellas de gran masa, desde la fase de secuencia principal hasta la fase WR. En el Capítulo 3 se muestran algunos ejemplos de BI, damos sus principales parámetros como masa, densidad y tamaño lineal, y se explican los mecanismos que dan origen a la radiación en cada una de las franjas del EE. En los Capítulos 4, 5 y 6 encaramos el análisis multifrecuencia de las regiones de interés. El Capítulo 7 está dedicado al estudio de la formación estelar secuencial en las cáscaras en expansión de las BI asociadas a la acción de los vientos de WR 157 y a WR 153ab. Este estudio es novedoso ya que hasta el momento no hay una cantidad apreciable de trabajos referidos a este tema. Finalmente, en el Capítulo 8 enunciamos los resultados generales, puntos en común y particularidades de las regiones analizadas.

Los datos utilizados han sido obtenidos con diferentes instrumentos, en varios casos contamos con datos propios (SEST) o surgidos a través de convenios con otros grupos de investigación (DRAO), y en otros casos, con datos públicos obtenidos de diferentes bases de datos (2 MASS, IRAS, MSX, etc).

Los resultados del estudio del continuo de radio en el entorno de WR 157, WR 152 y WR 153ab indican que podemos descartar que el origen de esta radiación es no térmica y el responsable de este tipo de radiación sería la interacción free-free (térmica). Existen similitudes morfológicas entre las distribuciones del gas ionizado y el polvo interestelar. El hidrógeno neutro no presenta correlación con la mayoría de la estructuras analizadas (excepto aquella asociada a WR 152), mientras que el hidrógeno molecular guarda vinculación con el polvo interestelar, y generalmente está ubicado en los bordes de las nebulosas anillo. Esa correlación, junto con la emisión de radiación de los hidrocarburos aromáticos policíclicos (PAHs) en esas zonas, dan la pauta de la existencia de regiones de fotodisociación en los bordes de las nebulosas.

La formación estelar secuencial se da en las dos BI estudiadas, pero no con la intensidad 
que se lleva a cabo en la región H II clásica Gum 31. 


\section{Índice general}

1. Introducción y objetivos de esta tesis 4

2. Burbujas Interestelares: estructura y evolución 8

2.1. Modelos evolutivos de BI para estrellas de secuencia principal 10

2.1.1. Fase de expansión libre 11

2.1.2. Fase de expansión adiabática 11

2.1.3. Fase de "barredora de nieve" 13

2.1.4. Fase terminal en la vida de las BI 18

2.2. Modelo evolutivo de las BI con viento estelar variable 18

2.2.1. Evolución de una BI durante la fase en SP de la estrella central 18

2.2.2. Fase supergigante roja (SGR) 20

2.2.3. Fase Wolf-Rayet (WR) 20

2.2.4. Energía 21

2.2.5. Masa 24

2.3. Eficiencia de conversión de energía y momento 25

3. ¿Por qué observar en radiofrecuencias y en IR? 29

3.1. Observaciones en el rango óptico 29

3.2. Observaciones en el infrarrojo 34

3.2.1. Emisión del polvo interestelar 37

3.2.2. Análisis en el mediano y lejano IR 38

3.3. Emisión en el continuo de radio 40

3.4. La línea de $21 \mathrm{~cm} \quad 46$

3.4.1. Obtención de la densidad de columna y masa de H I 49

3.5. Observaciones moleculares: parámetros físicos 52

3.5.1. Temperatura de excitación 53

3.5.2. Cálculo de la densidad de columna 54

3.5.3. Cálculo de la masa y de la densidad media de una nube molecular 58

3.6. Distancia cinemática 59

4. El entorno de la nebulosa SG $13 \quad 62$

4.1. WR 157 y la nebulosa óptica SG 13

4.2. Observaciones 64

4.2.1. Observaciones en radio 64

4.2.2. Datos IRAS y MSX 64

4.3. Distribución de gas y polvo 66

4.3.1. Emisión del gas ionizado 66

4.3.2. Emisión del polvo interestelar 69 
4.3.3. Emisión del gas atómico y molecular 69

4.4. Discusión $\quad 72$

4.4.1. Análisis del medio interestelar $\quad 72$

4.4.2. Principales parámetros de la nebulosa anillo $\quad 75$

$\begin{array}{ll}\text { 4.5. Conclusiones } & 77\end{array}$

5. El medio interestelar modelado por los vientos de las estrellas WR 152 y WR 153ab $\quad 83$

5.1. Introducción y antecedentes $\quad 83$

5.2. Base de datos utilizada 86

5.3. Estudio del H I en gran escala $\quad 87$

5.4. Análisis multifrecuencia en dirección a WR $152 \quad 90$

5.4.1. Radiación en el continuo de radio $\quad 92$

5.4.2. Emisión del H i hacia WR 152

5.4.3. Emisión en el lejano IR $\quad 97$

5.5. Análisis multifrecuencia en dirección a WR 153ab 100

5.5.1. Emisión en el continuo de radio e IR 100

5.5.2. Distribución y morfología del ${ }^{12} \mathrm{CO} \quad 102$

5.6. Discusión 102

5.6.1. Distancia a las estructuras 102

5.6.2. Conexión entre las estructuras de H I 104

5.6.3. Parámetos de las estructuras 105

5.7. Escenario 108

5.8. Conclusiones 110

6. La componente molecular del MIE asociada a WR 113

6.1. Antecedentes 114

6.2. Parámetros observacionales 116

6.3. Cálculo de $T_{\text {exc }}$ y $\tau \quad 118$

6.4. Distribución de CO en dirección a WR $113 \quad 119$

6.4.1. Cociente $R_{2-1 / 1-0} \quad 122$

6.5. Determinación de la distancia cinemática y

$\begin{array}{lr}\text { parámetros físicos de la estructura } & 129\end{array}$

6.6. Conclusiones 131

7. Análisis de la posible formación estelar inducida por los vientos de las estrellas WR

7.1. Introducción 133

7.2. Análisis de catálogos infrarrojos para detectar YSOs 136

7.2.1. Criterios de selección y análisis de las fuentes 2 MASS 136

7.2.2. Criterios de selección para las fuentes MSX 138

7.2.3. Criterios de selección para las fuentes IRAS 138

7.3. Búsqueda de candidatos a YSOs en la vecindad de nebulosas anillo 139

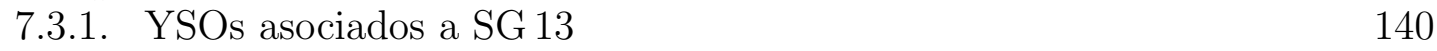

7.3.2. YSOs asociados a Sh2-132 145

7.3.3. Contrapartes moleculares de los YSOs 145

7.4. YSOs en la región H II Gum 31

7.4.1. Análisis de la distribución del ${ }^{12} \mathrm{CO} \quad 151$ 
7.4.2. Distribución y características de los candidatos a YSOs 152

7.5. Discusión

155

7.6. Resumen y conclusiones

159

8. Conclusiones 162

8.1. Trabajo futuro 164

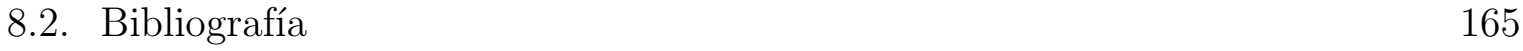

A. Conceptos de instrumentación radioastronómica $\quad 166$

A.1. Algunas nociones radioastronómicas 166

A.2. Conceptos básicos de interferometría 169

$\begin{array}{ll}\text { A.3. Bibliografía } & 176\end{array}$

$\begin{array}{ll}\text { B. Lista de trabajos publicados } & 177\end{array}$ 


\section{Capítulo 1}

\section{Introducción y objetivos de esta tesis}

La estrellas de gran masa interactúan con el medio interestelar (MIE) circundante básicamente de dos maneras: a través de fotones ultravioletas (UV) y transfiriendo materia, momento y energía a través de vientos estelares. Los fotones UV ionizan el gas atómico y disocian moléculas en los alrededores de las estrellas, mientras que los vientos estelares empujan el material circundante formando burbujas interestelares (BI). Dado que la tasa de fotones ionizantes de las estrellas de gran masa es alta (Osterbrock 1989), se forman en sus alrededores regiones H II con un determinado radio, que llamamos radio de Strömgren. Por medio de los vientos estelares, una buena porción de la masa inicial de las estrellas de gran masa es "devuelta" al MIE, contribuyendo a su enriquecimiento químico.

La evolución de las estrellas con masas mayores a $25 \mathrm{M}_{\odot}$ esencialmente sigue la secuencia (García-Segura et al. 1996a, García-Segura et al. 1996b)

$$
\text { Estrella tipo } \mathrm{O} \rightarrow \mathrm{VLA} \text { o } \mathrm{SGR} \rightarrow \mathrm{WR} \rightarrow \text { supernova }
$$

donde las siglas VLA, SGR y WR corresponden a estrellas variables luminosas azules (del inglés LBV, luminous blue variable), supergigantes rojas (del inglés RSG, red supergiants) y estrellas Wolf-Rayet, respectivamente.

Las estrellas WR son el último eslabón en la cadena evolutiva de estrellas de gran masa, antes de la fase de supernova (Maeder, 1990), por eso su estudio es vital para el conocimiento de la supernova subsiguiente, y el análisis del MIE alrededor de estas estrellas es importante porque allí evolucionará el remanente de supernova. Las estrellas WR de Población I se concentran en los brazos espirales de la Galaxia (van der Hucht 2001). En la Fig. 1.1 se puede ver un gráfico donde se muestra la distribución de estrellas WR sobre el plano galáctico en los cuatro cuadrantes.

Las WR presentan en sus espectros líneas de emisión de carbono, nitrógeno y oxígeno en diferentes estados de ionización (presentes, básicamente desde la región del UV hasta la región IR del espectro) que determinan su tipo espectral. De esta forma encontramos 

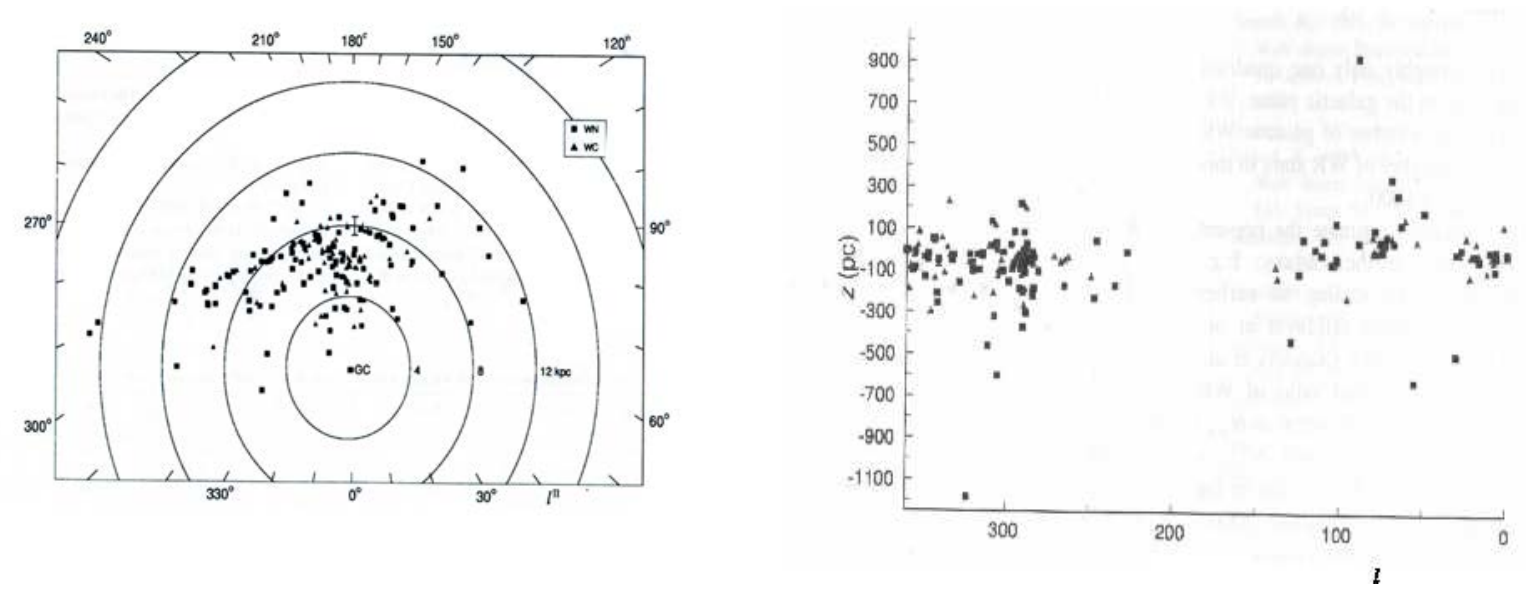

Figura 1.1: Distribución de estrellas WR sobre el plano galáctico (van der Hucht 2001).

estrellas WR clasificadas como ricas en nitrógeno (WN), carbono (WC) y oxígeno (WO).

Las estrellas WR están en la etapa de quema de helio, poseen un núcleo convectivo y han perdido gran parte de las capas exteriores de hidrógeno. Por lo tanto, se puede considerar a estos objetos como los núcleos de estrellas masivas, de forma tal que su análisis brinda información crucial sobre la nucleosíntesis estelar. Los modelos de evolución estelar (por ej. Maeder 1990) sugieren una secuencia evolutiva dentro de la fase WR de la forma $\mathrm{WN} \longrightarrow \mathrm{WC} \longrightarrow \mathrm{WO}$.

Dos parámetros caracterizan a los vientos estelares: la cantidad de masa estelar que es arrojada al medio interestelar por unidad de tiempo, llamada tasa de pérdida de masa $\dot{M}$, y la velocidad máxima que adquiere el material expulsado por la estrella, la velocidad terminal $v_{\infty}$.

Diferentes modelos de vientos estelares predicen distintas tasas de pérdida de masa y velocidades terminales. La comparación de estos valores con los observados nos permite estudiar qué mecanismos son los responsables del viento estelar.

La masa estelar perdida por las estrellas WR a través de los vientos estelares contribuye al enriquecimiento del MIE, ya que devuelven al MIE material procesado en el interior de las estrellas a través de procesos nucleares. Las estrellas WR ricas en carbono, además, producen granos de polvo. Tanto el gas estelar como los granos de polvo enriquecerán el MIE que dará origen a sucesivas generaciones de estrellas.

El material perdido por las estrellas junto con el gas interestelar ionizado por los fotones estelares origina las nebulosas ópticas alrededor de estas estrellas (Chu et al. 1983), evidencia en el rango óptico de la presencia de una burbuja interestelar.

En este trabajo de tesis se llevó a cabo un estudio multiespectral de algunas nebulosas anillo ópticas asociadas a estrellas WR galácticas con el fin de analizar la interacción de 
las estrellas con el medio interestelar circundante.

Entre los objetivos que nos propusimos alcanzar, los puntos más destacados fueron:

- Analizar la emisión de nebulosas anillo en el continuo de radio a fin de conocer la distribución del gas ionizado, su densidad electrónica y masa

- Estudiar la distribución del polvo en las nebulosas a partir de la emisión en la banda infrarroja del espectro

- Analizar la distribución del hidrógeno neutro en la vecindad de las nebulosas seleccionadas, por medio de datos de la línea de $21 \mathrm{~cm}$. El objetivo fue identificar las estructuras atómicas neutras presentes a diferentes velocidades y estudiar su posible vinculación con las nebulosas y las estrellas WR, analizando la distribución y cinemática del gas atómico neutro asociado.

- Conocer la distribución y características físicas del material molecular vinculado a la nebulosa, a fin de identificar probables regiones de fotodisociación en la interfase entre el gas ionizado y molecular

- Analizar si en las cáscaras moleculares asociadas a estas nebulosas se dan las condiciones para la formación estelar inducida por los frentes de choque originados en los vientos estelares

Estos estudios contribuyen a conocer en cierto detalle la interacción de las estrellas WR con el MIE y a establecer las condiciones energéticas de las nebulosas seleccionadas y su estado evolutivo. La confrontación de los resultados observacionales con los modelos teóricos de evolución de burbujas interestelares ayuda a mejorar los modelos evolutivos.

En el siguiente capítulo se hará una introducción teórica referida a la interacción entre estrellas de gran masa con el medio interestelar circundante. Enfocaremos nuestra atención en los resultados correspondientes a los modelos evolutivos de estrellas con masas superiores a $35 \mathrm{M}_{\odot}$. En el Capítulo 3 se resaltará la importancia de estudiar estas estructuras en los rangos infrarrojo y de radio, concentrándonos en la determinación de los parámetros físicos que se obtienen a partir de estas observaciones. En los Capítulos 4, 5 y 6 se analiza el MIE en la vecindad de las estrellas WR 157, WR 152 y WR 153ab, y WR 113, asociadas a las nebulosas SG 13, Sh2-132 y Anon(WR 113), respectivamente. Se describen los métodos utilizados y los resultados del estudio multifrecuencia de cada una de las estructuras generadas por los fuertes vientos de estas estrellas. Finalmente, en el Capítulo 7 se trata de establecer qué tan efectivos son los procesos de formación estelar inducida por vientos generados por estas estrellas. 


\section{Bibliografía}

Chu Y.-H., Treffers R.R., Kwitter K., 1983, ApJS, 53, 937

García-Segura G., Langer N. \& MacLow M.M., 1996a, 316, 133

García-Segura G., MacLow M.M. \& Langer N., 1996b, 305, 229

Maeder A., 1990, A\&AS, 84, 139

Osterbrock D. E., 1989, S\&T, 78, 491

van der Hucht K.A., 2001, New Astronomy Rev., 45, 135 


\section{Capítulo 2}

\section{Burbujas Interestelares: estructura y evolución}

\section{Resumen}

En el siguente Capítulo daremos una breve introdución teórica acerca de la interacción entre las estrellas de gran masa y el medio interestelar.

En primer término desarrollaremos el análisis teórico de la estructura y evolución de una burbuja interestelar generada por una estrella de gran masa en la fase de secuencia principal. Esta situación implica que en una primera aproximación los parámetros principales del viento, es decir, la tasa de pérdida de masa y la velocidad terminal se mantienen constantes durante todo el período en consideración.

Luego, desarrollaremos un análisis similar, pero con un viento variable generado por estrellas de 35 y $60 \mathrm{M}_{\odot}$, a lo largo de toda su vida y atravesando por cada fase evolutiva.

La interación entre el viento estelar y el MIE cirundante modifica la dinámica de ese medio. La colisión del viento con el MIE da lugar a la generación de una burbuja interestelar (BI). Una de las descripciones más claras de BI está dada por Weaver et al. (1977), quien enuncia que una BI es una cavidad de baja densidad y alta temperatura, rodeada por una envoltura o cáscara constituida por gas estelar desacelerado y gas interestelar barrido. Esta cáscara está formada por una región externa de material neutro si el frente de ionización queda atrapado en la envoltura. La forma que puede adquirir este tipo de estructuras, idealmente esféricas, dependen fuertemente de las características del viento y de las condiciones en las que se encuentra el MIE en el que evolucionan. Particularmente, las estrellas tempranas modifican drásticamente su entorno debido a las altas tasas de pérdida de masa y altas velocidades terminales de los vientos que en ellas se generan. Baste decir que las estrellas masivas arrojan al MIE durante su vida $\left(\sim(1-10) \times 10^{6}\right.$ años $)$ una cantidad de energía similar a la entregada en un evento de supernova $\left(\sim 10^{51} \mathrm{erg}\right)$.

Las BI alrededor de estrellas WR se detectaron primero en el rango óptico, como nebu- 
losas anillo, llamadas así por su aspecto anular. Los primeros investigadores que prestaron atención a esta clase de estructuras fueron Johnson y Hogg (1965), quienes analizaron dos nebulas anillo ópticas típicas alrededor de estrellas WR: NGC 2359 y NGC 3199, asociadas a las estrellas WR 7 y WR 18, respectivamente. Estos autores estimaron sus masas en base a observaciones en el continuo de radio, y sugirieron que la estructura de cáscara de las nebulosas se originaba cuando el fuerte viento estelar empujaba el medio interestelar circundante. Smith (1968) encontró siete anillos nebulares alrededor de estrellas WR galácticas. Subsecuentes búsquedas triplicaron el número de estrellas con nebulosas asociadas. Al presente se sabe que alrededor del $\sim 30 \%$ de las estrellas WR en la galaxia presenta nebulosas anillo ópticas asociadas (ver Marston 1994a, Marston et al. 1994b y referencias allí citadas, Marston 1997), aunque en varios casos las estructuras observadas poco tienen de "anulares". Las nebulosas que se encuentran en torno a las estrellas WN son más numerosas que las que se encuentran en torno a estrellas WC (Marston et al. 1994b), un hecho compatible con el camino evolutivo propuesto dentro de la fase WR.

Las características espectrales de estas nebulosas pueden ser usadas para diagnosticar propiedades estelares, tales como luminosidad o temperatura efectiva, además de ser útiles para evaluar escenarios de evolución estelar.

La teoría básica de interacción entre el MIE y los vientos estelares fue desarrollada analíticamente por Castor et al. (1975) y Weaver et al. (1977).

En esta sección describiremos la estructura y evolución de las BI en el MIE siguiendo el análisis de Lamers \& Cassinelli (1999). Estos autores asumieron un viento estelar constante y esféricamente simétrico; y un medio interestelar estático y con densidad constante, sin grumos, sin campos magnéticos y sin fases de ionización.

Cuando el viento estelar se expande en el MIE genera una cáscara de material denso a alta temperatura formada por gas estelar y gas del MIE que ha sido empujado por el frente de choque del viento. Esta capa de material se mueve en dos direcciones: una en el mismo sentido que el viento y la otra, en sentido opuesto, originando dos frentes de choque, uno en el borde interno y otro en el borde externo de la cáscara. En la zona que queda entre esos dos frentes, la energía cinética del viento estelar es convertida en calor y el gas adquiere temperaturas del orden de $10^{6} \mathrm{~K}$. Esta temperatura es mucho más elevada que la producida en una región $\mathrm{H}$ II por el campo de radiación de la estrella $\left(\sim 10^{4} \mathrm{~K}\right)$. De esta manera la región de interacción entre el viento y el MIE determina condiciones de ionización y excitación que son características de este tipo de estructuras.

La parte superior de la Figura 2.1 muestra esquemáticamente la estructura de la región de interacción entre el viento estelar y el MIE. Esta región está separada en cuatro zonas que, desde el interior hacia el exterior, son :

[1. Zona 1: En esta región el viento estelar avanza casi libremente a velocidad supersónica.

- Zona 2: Corresponde a la parte más interna de la cáscara, formada por viento estelar calentado y comprimido por la onda de choque. 


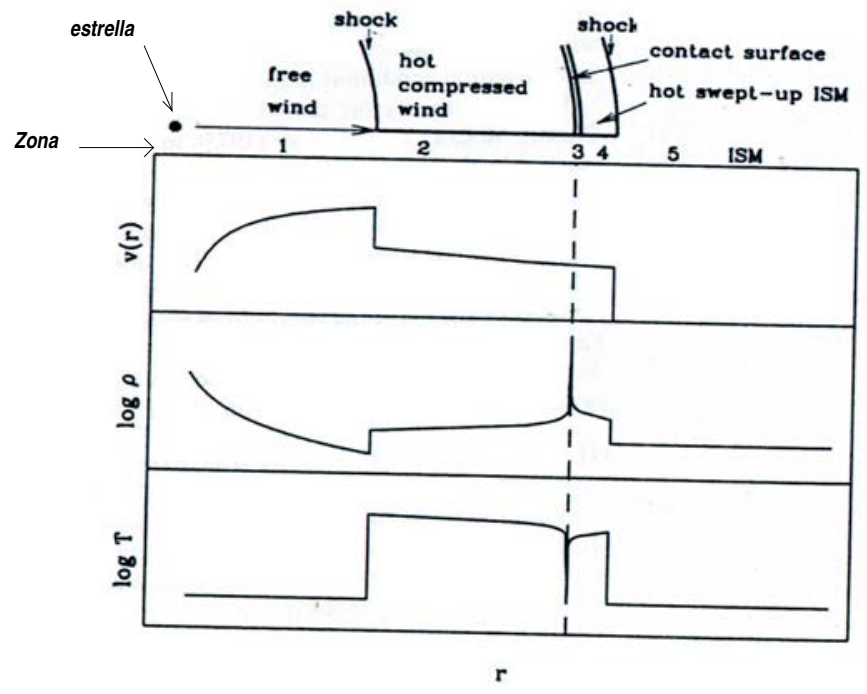

Figura 2.1: Estructura de una Burbuja Interestelar y comportamiento de la velocidad, densidad y temperatura en sus distintas zonas.

- Zona 3: Separa las zonas 2 y 4 y se denomina superficie de contacto. Está compuesta mayoritariamente por material interestelar barrido, comprimido y enfriado radiativamente.

- Zona 4: Compuesta de material del MIE barrido por el frente de choque externo. El gas del MIE atraviesa este frente de choque, donde el gas es comprimido y calentado.

Rodeando a la región de interacción se encuentra material interestelar que todavía no ha sido afectado por el frente de choque externo (a esta región la llamaremos Zona 5 en la descripción siguiente).

\subsection{Modelos evolutivos de BI para estrellas de se- cuencia principal}

A continuación discutiremos las tres fases evolutivas de las cuatro zonas mostradas en la Figura 2.1, por las que atraviesa una BI:

- fase de expansión libre del viento.

- fase de expansión adiabática.

- fase de "barredora de nieve" ("snowplow"). 
Para entender la evolución de la región de interacción entre el viento estelar y el MIE asumiremos que una estrella se "enciende" automáticamente cuando comienza la quema de hidrógeno en el núcleo. Adoptaremos una tasa de pérdida de masa $\dot{M}=10^{-6}$ $\mathrm{M}_{\odot}$ año ${ }^{-1}$, con una velocidad terminal $v_{\infty}=2000 \mathrm{~km} \mathrm{~s}^{-1}$. Estos parámetros son típicos de una estrella $\mathrm{O}$ en su fase de secuencia principal (ver por ej. Chlebowki \& Garmany 1990). La luminosidad mecánica del viento es $L_{w}=\frac{1}{2} \dot{M} v_{\infty}{ }^{2}=10^{36}$ erg $s^{-1}$, que se considera constante durante la evolución de la BI. Consideraremos que el MIE alrededor de la estrella es homogéneo, con una densidad ambiental $\rho_{0} \simeq 2 \times 10^{-24} \mathrm{~g} \mathrm{~cm}^{-3}$ correspondiente a un valor típico $n_{0} \simeq 1 \mathrm{~cm}^{-3}$.

\subsubsection{Fase de expansión libre}

Inicialmente el viento se expande libremente en el MIE. En esta fase el frente de choque interno no contribuye a la disminución de la velocidad del viento. El frente de choque externo se mueve hacia afuera a la misma velocidad del viento, que es aproximadamente la misma con la que el material interestelar es barrido. Debido a ésto, esta fase es llamada de expansión libre.

La cantidad de material barrido aumenta a medida que transcurre el tiempo, y el impulso que lleva el viento hace que éste no pueda empujar a la cáscara con la misma velocidad. De esta manera la velocidad de expansión de la cáscara disminuye.

La fase de expansión libre finaliza luego de un tiempo $\tau_{1}$, cuando la masa de material barrido en la Zona 4 es comparable a la masa del material del viento estelar en la Zona 2.

La masa perdida por la estrella es $\dot{M} \tau_{1}$, y la masa del MIE barrida es $\frac{4 \pi}{3}\left(v_{\infty} \tau_{1}\right)^{3} \rho_{0}$. Esas dos masas se igualan cuando:

$$
\tau_{1}=\sqrt{\frac{3}{4 \pi} \frac{\dot{M}}{\rho_{0} v_{\infty}^{3}}}
$$

Teniendo en cuenta los parámetros del viento estelar y del MIE dados al comienzo de esta sección, $\tau_{1} \sim 100$ años. Durante este tiempo, la burbuja alcanza un radio $r=$ $v_{\infty} \tau_{1} \approx 0.2 \mathrm{pc}$. Al final de esta etapa, tanto la Zona 2 (viento estelar calentado por la onda de choque), como la 4 (MIE barrido), alcanzan una temperatura muy elevada. En la Figura 2.2 se ve el comportamiento de la velocidad y la temperatura del material en la BI al término de la fase de expansión libre.

\subsubsection{Fase de expansión adiabática}

Cuando la fase de expansión libre termina, la burbuja tiene la siguiente estructura:

- El viento se expande libremente a una velocidad supersónica hasta un radio $R_{1}$, donde encuentra el frente de onda interno. 


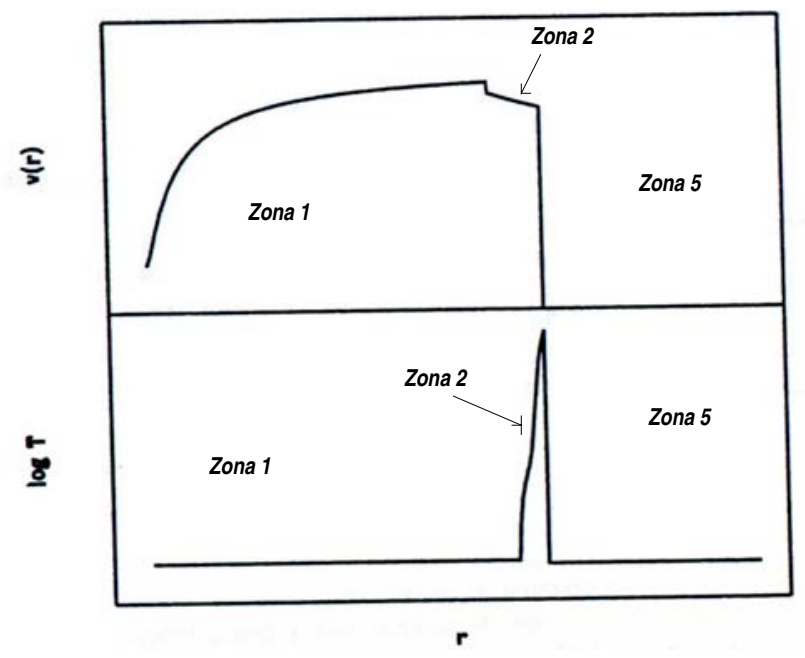

Figura 2.2: Comportamiento de la velocidad y temperatura del material estelar al término de la fase de expansión libre.

- La región que contiene el material estelar "golpeado" por el frente de choque tiene un radio externo $R_{2}$. La energía cinética del viento es depositada en esta región en forma de calor. Esto genera temperaturas del orden de $10^{7} \mathrm{~K}$. Toda la materia estelar que ha atravesado el frente de choque interno se encuentra en esta región y es $M_{2} \approx \dot{M} \tau_{1}$. Como esta región está a una temperatura muy elevada, la superficie de contacto se expande hacia afuera a una velocidad $v_{2}=d R_{2} / d t$.

- Rodeando la Zona 2 hay una cáscara de material interestelar barrido que se extiende hasta un radio $R_{4}$. Como ésta contiene todo el material barrido, su masa es $M_{4}=\frac{4 \pi R_{4}{ }^{3} \rho_{0}}{3}$. El límite externo de esta zona es el frente de choque externo.

La estructura es básicamente la misma que se ve en la Figura 2.1, excepto que la temperatura es muy alta en la cáscara y no hay todavía una densidad muy alta en la Zona 3.

Durante esta fase, el material que atraviesa cualquiera de los dos frentes de choque está muy caliente y no hay pérdidas significativas de energía por radiación.

Aunque el enfriamiento radiativo aún no es importante, la temperatura de la burbuja disminuirá ya que la energía es transformada en trabajo y se utiliza para aumentar el volumen de la BI. Cuando la zona de material barrido se enfría adiabáticamente a $10^{6} \mathrm{~K}$, el mecanismo de enfriamiento dominante es radiación por líneas de emisión, y la temperatura de la cáscara disminuye hasta $\sim 10^{4} \mathrm{~K}$.

Esta fase termina cuando $T \sim 10^{6} \mathrm{~K}$. Su duración puede ser estimada calculando el tiempo que le toma a la cáscara en expansión enfriarse de $10^{7}$ a $10^{6} \mathrm{~K}$. 
La temperatura detrás del frente de choque externo $T_{\text {shock}}$, puede ser determinada utilizando las expresiones para un frente de choque adiabático:

$$
T_{\text {shock }}=\frac{3}{16} \frac{\mu m_{\mathrm{H}} k^{2}}{\left(v_{\text {shock }}\right)}=1.4 \times 10^{5}\left(\frac{v_{\text {shock }}}{100 \mathrm{kms}^{-1}}\right)^{2} \quad K
$$

donde $\mu$ es el peso molecular medio, $k$ es la constante de Boltzman, $m_{\mathrm{H}}$ la masa del átomo de hidrógeno y $v_{\text {shock }}$ es la velocidad del frente de choque externo.

De esta ecuación vemos que el cambio de temperatura de $10^{7} \mathrm{~K}$ a $10^{6} \mathrm{~K}$ corresponde a un cambio en la velocidad del frente de choque de 840 a $270 \mathrm{~km} \mathrm{~s}^{-1}$.

Aunque las fases de expansión libre y expansión adiabática son importantes desde el punto de vista dinámico, no tienen relevancia desde el punto de vista observacional, ya que su duración es muy corta $\left(10^{2}\right.$ y $10^{3}$ años, respectivamente).

\subsubsection{Fase de "barredora de nieve"}

El material interestelar no perturbado entrante en el frente de choque externo adquiere una $\mathrm{T} \sim 10^{6} \mathrm{~K}$, y rápidamente se enfría hasta llegar a $10^{4} \mathrm{~K}$, temperatura que puede ser mantenida por el campo de radiación de la estrella. Esta fase es llamada "barredora de nieve" o snowplow debido a que hay una cáscara de material "frío" y comprimido que está siendo empujada.

En este momento, el límite entre la cáscara externa y el MIE es esencialmente un frente de choque isotérmico. La densidad de la cáscara aumenta de $\sim 10$ a $10^{3} \mathrm{~cm}^{-3}$, y en consecuencia ésta será más fina.

La duración de esta fase dependerá del tiempo que el viento persista, que para una estrella masiva es de $\sim(1-10) \times 10^{6}$ años (Lamers \& Cassinelli, 1999). Debido a su mayor duración, las burbujas interestelares se observan más fácilmente en esta fase.

La fase de snowplow puede ser dividida en dos etapas:

- una etapa de conservación de la energía, en la cual el material en la Zona 2 se mantiene caliente y no sufre pérdidas significativas de energía por radiación. Esta zona es extendida pues contiene un gas de baja densidad y alta temperatura $(T \sim$ $\left.10^{7} \mathrm{~K}\right)$.

- una etapa de conservación del momento, en la que el material de la Zona 2 se enfría radiativamente y por lo tanto esta región es fina.

Durante la fase snowplow, la masa de material interestelar barrido $M_{s}(t)$ supera a la masa del viento estelar, $M_{s}(t)>>\dot{M} t$, donde $M_{s}(t)$ se puede expresar como:

$$
M_{s}(t)=(4 / 3) \pi R^{3}(t) \rho_{0}
$$


siendo $R(t)$ el radio exterior de la burbuja al tiempo $t$.

La burbuja se expande porque la presión del interior es mayor que la del MIE que la rodea. La expansión es descripta por la ecuación de momento:

$$
d\left[M_{s}(t) v(t)\right] / d t=4 \pi R^{2} p_{\mathrm{B}}
$$

donde $v(t)=\frac{d R(t)}{d t}$ es la tasa de expansión de la burbuja y $p_{\mathrm{B}}$ es la presión interna de la burbuja generada por el viento, de la cual se hacen suposiciones que nos llevan a las fases de conservación de la energía y de conservación del momento.

- Para el modelo de conservación de la energía, $p_{\mathrm{B}}$ está determinada por la presión del gas a temperaturas $\geq 10^{6} \mathrm{~K}$ en la Zona 2. Este gas es calentado por la energía cinética del material estelar incidente. Este modelo fue desarrollado analíticamente por Castor et al. (1975) y Weaver et al. (1977).

- Para el modelo de conservación del momento, se asume que la energía térmica en la Zona 2 se pierde por enfriamiento radiativo, y que el viento impacta directamente sobre la cara interna de la cáscara. De este modo hay una transferencia directa del momento del viento sobre la cáscara, lo que provoca la expansión.

\section{Descripción del modelo de conservación de la energía}

La estructura de la BI en esta etapa está representada en la Figura 2.3.

El material en la Zona 2 tiene una temperatura $\geq 10^{6} \mathrm{~K}$ y el enfriamiento radiativo es insignificante. La tasa de enfriamiento es baja y la estructura se expande adiabáticamente.

La energía cinética inyectada en la cáscara por el viento, al tiempo $t$, está dada por $E_{w}=L_{w} t$, donde $L_{w}$ es la luminosidad mecánica del viento estelar, que se supone constante.

Por otro lado, la energía interna de la burbuja $E_{i}$, es igual al producto entre la energía por gramo de material $\left(\frac{3}{2} n k T / \rho_{\mathrm{B}}=\frac{3}{2} p_{\mathrm{B}} / \rho_{\mathrm{B}}\right)$, y la masa total de la burbuja $\left(\frac{4}{3} \pi R^{3} \rho_{\mathrm{B}}\right)$. Como la energía total de la burbuja proviene de la energía del viento, $E_{i}=E_{w} \mathrm{y}$

$$
p_{\mathrm{B}}=\frac{L_{w} t}{2 \pi R^{3}}
$$

Si reemplazamos esta expresión en la ecuación (2.3) e integramos, obtendremos para la expansión de la burbuja durante la fase adiabática:

$$
R(t)=\left(\frac{25 L_{w}}{14 \pi \rho_{0}}\right)^{1 / 5} t^{3 / 5}
$$




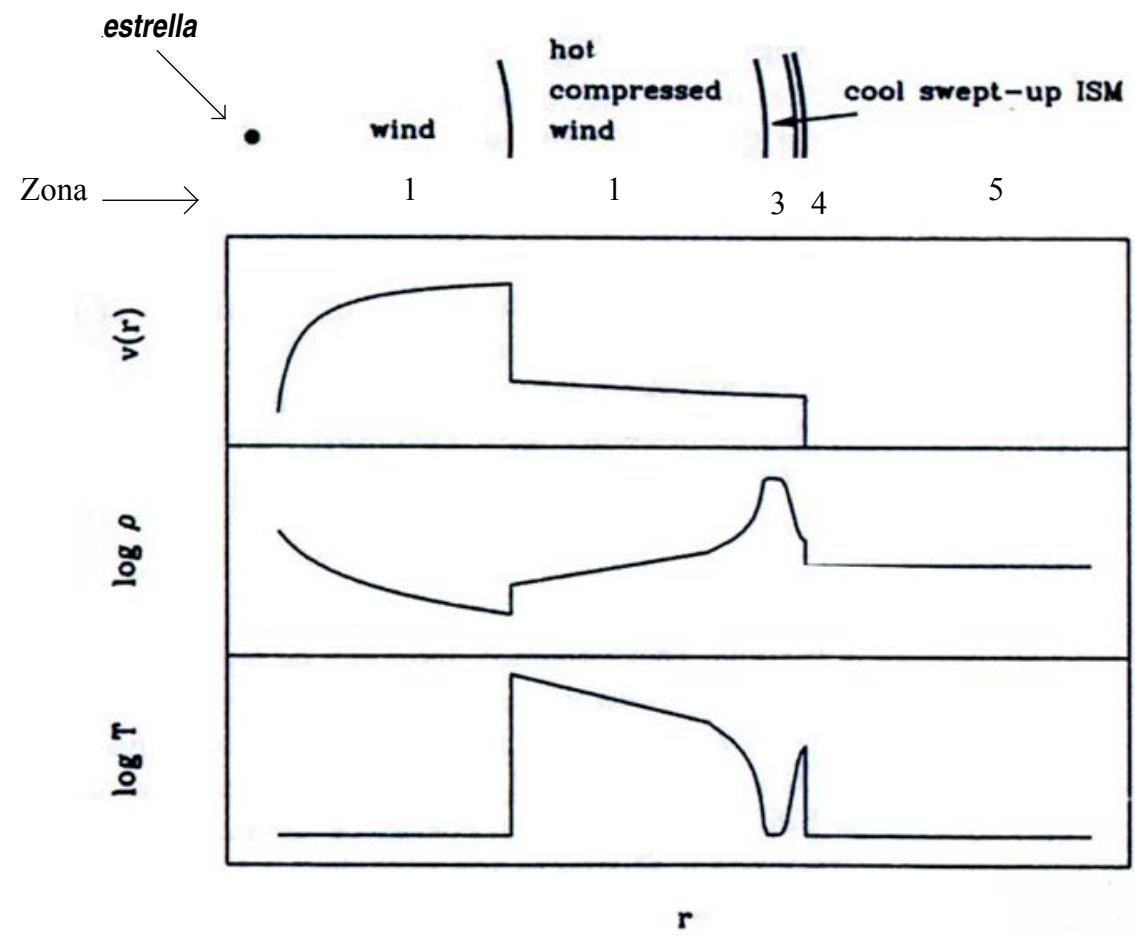

Figura 2.3: Estructura de la cáscara durante la fase de conservación de la energía. 
Esta expresión muestra que la cáscara se expande más lentamente que en el caso de expansión libre, donde $R(t) \propto t$. A partir de esta expresión, se pueden obtener los radios de las Zonas 2 y 3 :

$$
R_{2} \simeq R_{3}=28\left(\frac{L_{36}}{\mu n_{0}}\right)^{1 / 5} t_{6}^{3 / 5} \quad \mathrm{pc}
$$

donde $n_{0}$ es la densidad de partículas del MIE no perturbado (densidad ambiental), $L_{36}$ es la luminosidad mecánica $L_{w}$ en unidades de $10^{36}$ erg y $t_{6}$, la edad dinánica de la BI en unidades de $10^{6}$ años.

Se pueden obtener las velocidades de expansión de estas dos zonas, derivando (2.5) con respecto a $t$

$$
v_{2} \simeq v_{3}=17\left(\frac{L_{36}}{\mu n_{0}}\right)^{1 / 5} t_{6}{ }^{-2 / 5} \mathrm{~km} \mathrm{~s}^{-1}
$$

La edad dinámica de la estructura puede estimarse en base a (2.6) y (2.7) y resulta:

$$
t_{d}=0.6 \frac{R_{3}}{v_{3}} \times 10^{6} \quad \text { años }
$$

Aplicando el modelo de conservación de la energía, para una burbuja típica correspondiente a una estrella de $50 \mathrm{M}_{\odot}$, se tendrá un radio de $\sim 60$ pc y una velocidad de expansión de $10 \mathrm{~km} \mathrm{~s}^{-1}$ al cabo de $\sim 4 \times 10^{6}$ años.

En el límite entre la burbuja caliente y la cáscara fría, el gradiente de temperatura es muy alto. Esto genera transporte de energía por conducción de electrones de la Zona 2 hacia la Zona 3. A medida que la burbuja se expande, su temperatura disminuye a $10^{6}$ $\mathrm{K}$, las pérdidas de energía por radiación se vuelven muy grandes, y de esta forma la fase de conservación de energía finaliza.

La transición entre esta fase y la fase de conservación del momento ocurre en un tiempo $t=t_{\text {rad }}$

$$
t_{\text {rad }}=15.5 \times 10^{6}\left(L_{36}^{8} n_{0}^{2}\right)^{1 / 6} \quad \text { años }
$$

\section{Descripción del modelo de conservación del momento}

Si la tasa de enfriamiento radiativo es comparable o mayor a la tasa de calentamiento generada por el viento estelar, la Zona 2 se enfriará aún más, su densidad aumentará, y 


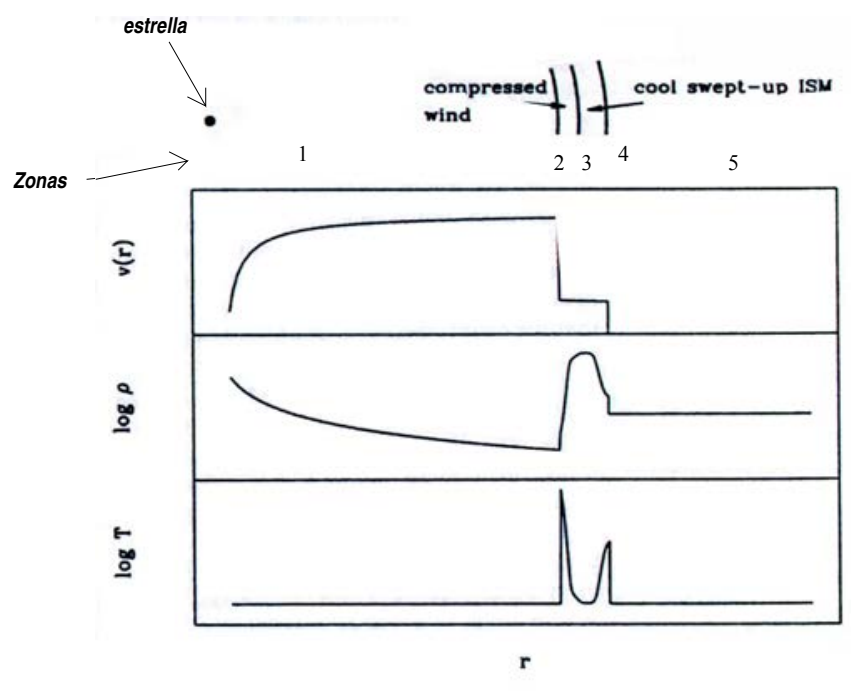

Figura 2.4: Estructura de la cáscara según el modelo de conservación del momento.

su espesor disminuirá. La burbuja entrará en la fase de conservación del momento, en la cual $R_{1} \approx R_{2}$. La estructura de la cáscara en esta fase está ilustrada en la Figura 2.4.

Durante esta etapa, la presión sobre el lado interno de la cáscara es la presión dinámica del viento $\rho v_{\infty}^{2}$. El radio $R(t)$ será entonces:

$$
R(t)=\left(\frac{3 \dot{M} v_{\infty}}{2 \pi \rho_{0}}\right)^{1 / 4} t^{1 / 2}=16\left(\frac{L_{36}}{v_{3} n_{0}}\right)^{1 / 4} t_{6}^{1 / 2} \quad \mathrm{pc}
$$

donde $v_{3} \equiv\left(v_{\infty} / 1000 \mathrm{~km} \mathrm{~s}^{-1}\right)$.

La velocidad de expansión de la cáscara será:

$$
v_{e x p}(t)=7.9\left(\frac{L_{36}}{v_{3} n_{0}}\right)^{1 / 4} t_{6}{ }^{-1 / 2} \mathrm{~km} \mathrm{~s}^{-1}
$$

La edad dinámica de la BI en esta fase será:

$$
t_{d}=0.5 \frac{R}{v_{\text {exp }}} \times 10^{6} \quad \text { años }
$$

Nótese que las expresiones que dan la edad dinámica en los casos de conservación de energía 2.8 y conservación de momento 2.11 son similares. 


\subsubsection{Fase terminal en la vida de las BI}

La velocidad de expansión de la BI disminuye hasta valores comparables a la velocidad de turbulencia del MIE ( $\sim 5 \mathrm{~km} \mathrm{~s}^{-1}$, Verschuur \& Kellerman 1988) y la burbuja interestelar se confunde con el medio circundante.

\subsection{Modelo evolutivo de las BI con viento estelar variable}

En la sección precedente, hemos descripto la estructura y la evolución de una BI asociada a una estrella de secuencia principal considerando que los parámetros del viento estelar no variaban. A continuación, describiremos un modelo de evolución de BI que incluye las diferentes etapas evolutivas de la estrella central y los diferentes parámetros del viento estelar correspondientes a cada fase, mostrándose la interacción entre diferentes vientos.

Se han realizado numerosas simulaciones numéricas de estructura y evolución de la acción de los vientos estelares para estrellas evolucionadas con masas mayores a $35 \mathrm{M}_{\odot}$. En esta sección vamos a realizar un breve resumen conceptual de la evolución del medio interestelar (MIE) asociado a las estrellas de gran masa, tratando de resaltar los resultados de simulaciones realizados por García-Segura et al. (1996a), García-Segura et al. (1996b) y Arthur (2006).

Se consideran tres fases evolutivas estelares claras: de secuencia principal (SP), de supergigante roja (SGR) y, finalmente, de estrella WR. No se incluye la fase final de supernova. Se asume que la tasa de pérdida de masa y la velocidad terminal del viento estelar se mantienen constantes en cada una de estas fases y se incluyen los mecanismos de calentamiento por fotoionización y de enfriamiento radiativo. Por otro lado, no se tiene en cuenta la conducción térmica como mecanismo de calentamiento ni la acción de los campos magnéticos. El medio ambiente tiene temperatura y densidad constantes. Todas estas consideraciones son comunes a la mayoría de las simulaciones de evolución de BI.

\subsubsection{Evolución de una BI durante la fase en SP de la estrella central}

Las condiciones iniciales planteadas por Arthur (2006) para la evolución del MIE en torno a estrellas con masas mayores a $35 \mathrm{M}_{\odot}$ son: un medio interestelar ionizado (región H II), con un radio de Strömgren de $\sim 4.5$ pc si la densidad del medio neutro adyacente a la región H II es $n_{\mathrm{H}}=15 \mathrm{~cm}^{-3}$. La tasa de pérdida de masa es de $\dot{M}=9.1 \times 10^{-7} \mathrm{M}_{\odot}$ años ${ }^{-1}$ y la velocidad terminal del viento es $v_{\infty}=890 \mathrm{~km} \mathrm{~s}^{-1}$. Por otro lado, la tasa de fotones ionizantes de la estrella es $S_{*}=6.34 \times 10^{47} \mathrm{~s}^{-1}$ (Schaller et al. 1992, van Marle et al. 2005).

Delante del frente de ionización, se forma un frente de choque isotérmico que provoca 


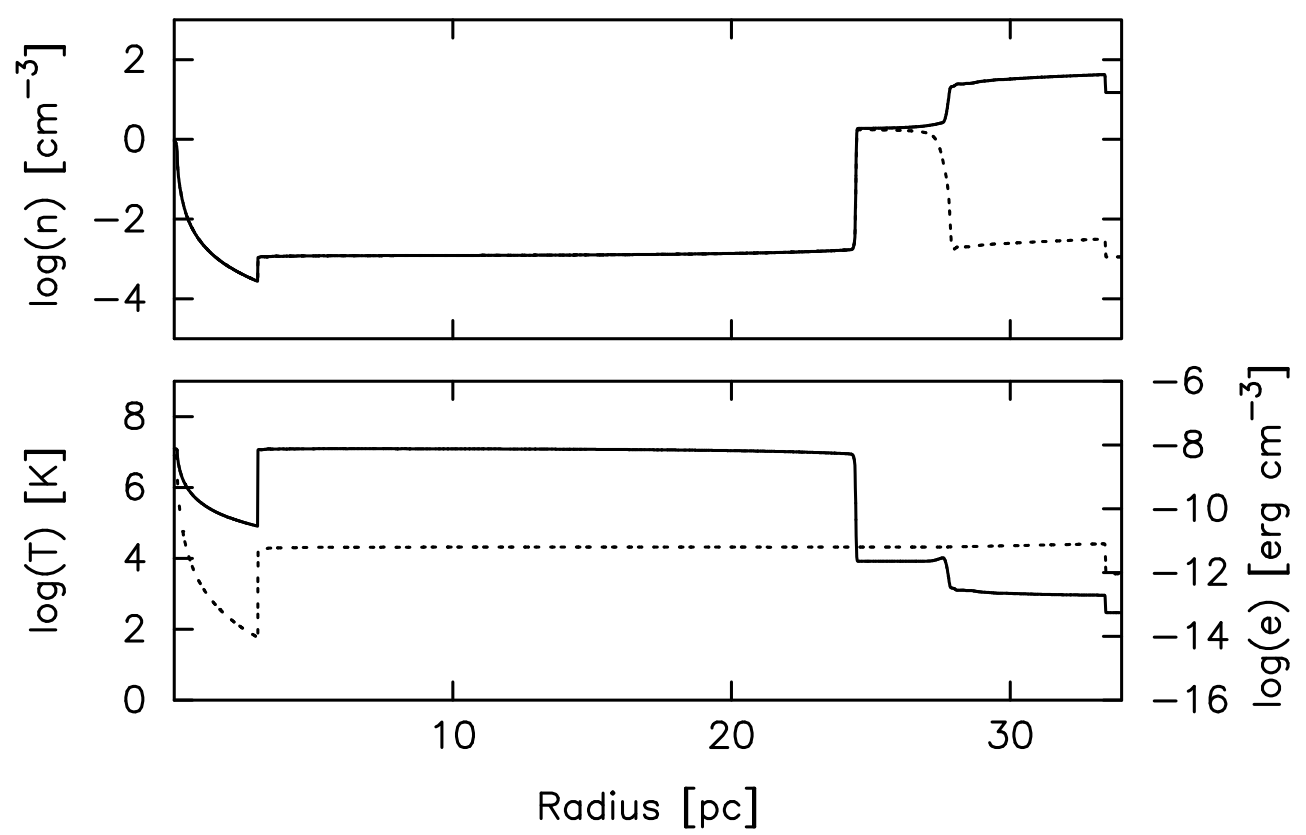

Figura 2.5: Perfil de densidad y temperatura de la BI al final de la fase de SP. En el panel superior se muestra, en línea continua, la densidad total de partículas, mientras que en línea punteada, la densidad de material ionizado. En el panel inferior, en línea continua, se muestra el perfil de la temperatura a lo largo de la BI, y en línea punteada, la densidad de energía (Arthur 2006).

la expansión de la región H II en el gas neutro. El viento estelar origina una BI dentro de la región H II.

A medida que transcurre el tiempo, el enfriamiento en la zona ionizada comienza a ser eficiente y genera la formación de una cáscara fina y densa. El frente de ionización queda atrapado en esta cáscara. Entre el frente isotérmico y esta cáscara, hay una región ocupada por el gas ionizado original que, como está apantallado por esta cáscara, comienza a recombinarse con un tiempo de recombinación típico $\sim 10^{5} / n$. Esto hace que el frente isotérmico se desplace a una velocidad $<10 \mathrm{~km} \mathrm{~s}^{-1}$ en el medio neutro. Los resultados de las simulaciones indican que el enfriamiento radiativo en esta zona favorece la formación de inestabildades, cuyo resultado es la creación de "grumos" de material neutro en la región ionizada.

La Fig. 2.5 muestra los perfiles de densidad, temperatura y energía térmica de la BI y de la región H iı, luego de $4.8 \times 10^{6}$ años de evolución.

Luego, la cáscara de material barrido alcanza el frente de choque externo. En este momento, la densidad en la cáscara disminuye debido a que la presión en la cáscara es la misma que en el interior de la burbuja, la cual decrece a medida que el frente de onda interno avanza. La temperatura de la cáscara de material barrido está determinada por la fotoionización, y es de $\sim 10^{4} \mathrm{~K}$. El frente de choque interno continuará moviéndose hasta 


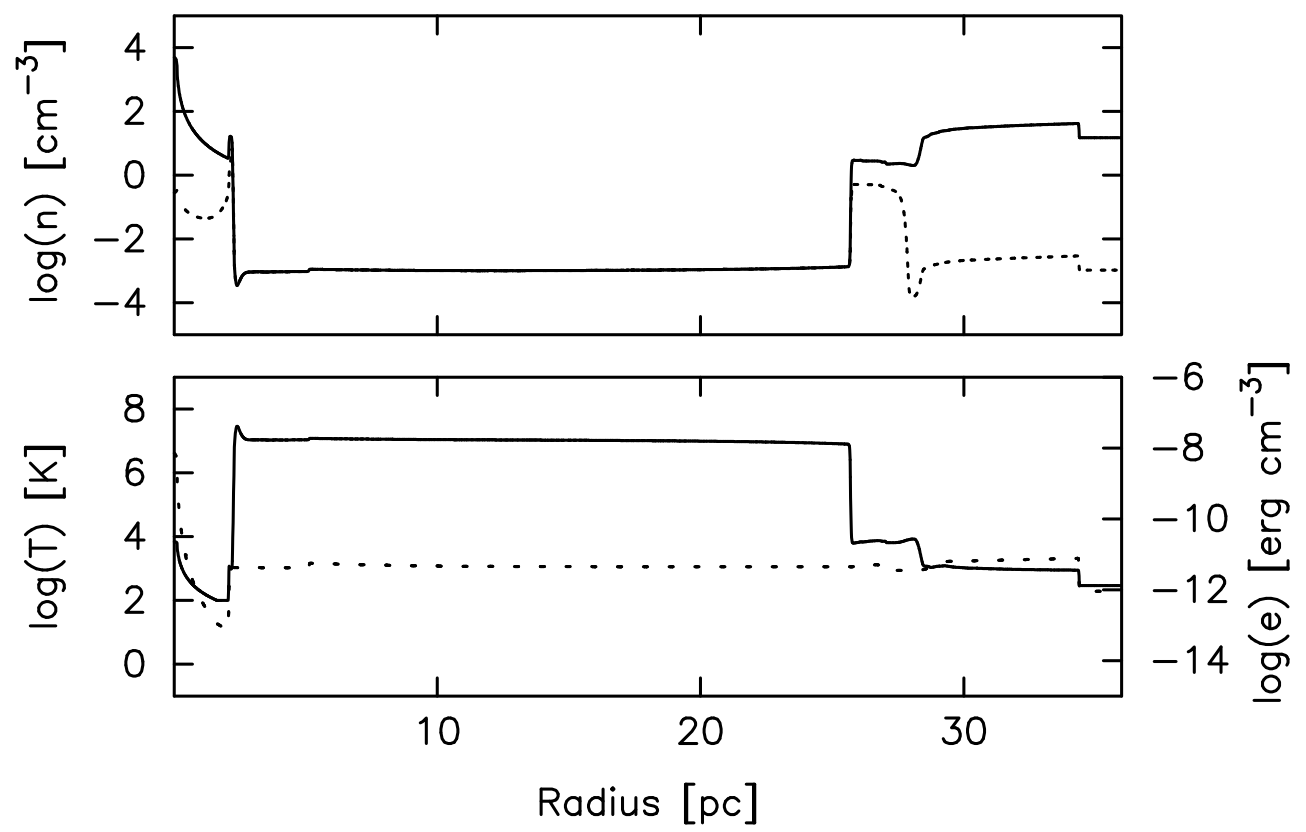

Figura 2.6: Perfil de densidad y temperatura de la BI al final de la fase SGR, es decir, luego de $5.0 \times 10^{6}$ años. Los diferentes tipos de línea tienen el mismo significado que en la Fig. 2.5.

que la presión del viento estelar iguale a la presión del MIE.

\subsubsection{Fase supergigante roja (SGR)}

Esta fase dura aproximadamente $2 \times 10^{5}$ años. En este lapso de tiempo, la luminosidad de la estrella disminuye a $3.1 \times 10^{41}$ fotones $\mathrm{s}^{-1}$, la velocidad terminal del viento estelar es de $15 \mathrm{~km} \mathrm{~s}^{-1}$ y la tasa de pérdida de masa aumenta a $8.3 \times 10^{-5} \mathrm{M}_{\odot}$ años ${ }^{-1}$. Los valores elegidos por Arthur (2006) son típicos de estrellas en esta fase. Este viento lento y denso se expande dentro de la estructura formada por la acción del viento en la etapa de SP de la estrella. Como la luminosidad de la estrella decrece en esta etapa, la burbuja empieza a recombinarse y la región H II tiende a desaparecer. Por lo tanto, se dice que el viento generado en la etapa SGR de la estrella es neutro. En la Fig. 2.6 se muestra la estructura en densidad y temperatura de la BI al término de esta fase.

\subsubsection{Fase Wolf-Rayet (WR)}

El viento generado en la fase WR de la estrella, se expande dentro de la estructura formada durante los dos períodos anteriores. En esta fase, el viento se acelera y $v_{\infty} \simeq 2160$ $\mathrm{km} \mathrm{s}^{-1}$, la tasa de pérdida de masa se mantiene del orden de $4 \times 10^{-5} \mathrm{M}_{\odot}$ años ${ }^{-1}$, mientras que la tasa de fotones ionizantes aumenta a $S_{*}=3.86 \times 10^{47} \mathrm{~s}^{-1}$. Nuevamente, los valores 
elegidos para $\dot{M}$ y $v_{\infty}$ son compatibles con valores observados para esta fase (van der Hucht 2001, Cappa et al. 2004). La transición de la fase SGR a la WR, involucra una aceleración del viento, que se desarrolla en un medio con una distribución de densidad que varía con $r^{-2}$ (originada en la fase anterior), generando una situación dinámicamente inestable, llamada inestabilidad de Rayleigh-Taylor. Estas inestabilidades originan acumulaciones de material frío, que se hacen más notorias cuando el fuerte viento de la estrella WR impacta en el viento de la etapa previa. Así se forman estructuras "rizadas" que eventualmente "rompen" la cáscara original formada en la fase de SP. La Fig. 2.7 muestra el resultado de la colisión entre los vientos de las fases WR (zona interna) y SGR (zona externa) para $t=15 \times 10^{3}, 18 \times 10^{3}, 21 \times 10^{3}$ y $24 \times 10^{3}$ años (simulación a,b,c y d, respectivamente) posteriores al comienzo del viento de la estrella WR. Los paneles ubicados a la derecha de cada una de las cuatro figuras indican, en escala de grises, las temperaturas que se alcanzan en cada sector de la burbuja. La temperatura del gas en la zona de colisión (zona blanca) alcanza valores $>10^{7} \mathrm{~K}$, originando la emisión en rayos $\mathrm{X}$ del gas.

La Fig. 2.8 muestra cómo la burbuja original formada en la fase de SP, ha sido "represurizada" por el viento de la fase WR. El material que ha atravesado el frente de choque se ioniza y se forma nuevamente una región H II en el interior de la BI.

\subsubsection{Energía}

Con respecto a la variación de la energía durante las diferentes etapas evolutivas de las BI, debemos tener en cuenta que la energía mecánica total del viento, $\dot{E}_{w} t$, se irá transformando en energía térmica, principalmente en las áreas de colisión entre diferentes vientos, en energía cinética de las cáscara en expansión, y por supuesto, en radiación.

En la Fig. 2.9 se observa la evolución de la luminosidad mecánica del viento estelar a medida que la estrella evoluciona. A efectos de comparación, se agregó, con línea punteada, la luminosidad estelar. Se observa que durante la mayor parte de la evolución, la luminosidad del viento se mantiene por encima de $\sim 10^{37}$ erg. La energía cinética total depositada por la estrella durante toda su vida es $\sim 10^{51} \mathrm{erg}$, similar a la depositada en una explosión de supernova (Castelletti 2005).

La Fig. 2.10 muestra la evolución de las energías cinética y térmica contenidas en el medio adyacente a la estrella hasta un radio de 70 pc. Lo que se indica como energía total es la suma de ambas. Se observa que la energía térmica es superior a la cinética a lo largo de toda la evolución. Los principales responsables de esto son los choques entre vientos de diferentes etapas, que hacen que la temperatura en esas zonas se eleve fuertemente. Los valores mostrados son cotas superiores, ya que se ha despreciado el efecto de evaporación debido a la conducción térmica.

De los $\sim 10^{51}$ erg depositados en el MIE por el viento estelar, al menos el $56 \%$ es radiado, quedando sólo el $26 \%$ como energía térmica y el $18 \%$ como energía cinética. Estos valores corresponden a un modelo de evolución para una estrella de $60 \mathrm{M}_{\odot}$ (García-Segura et al. 1996b). 

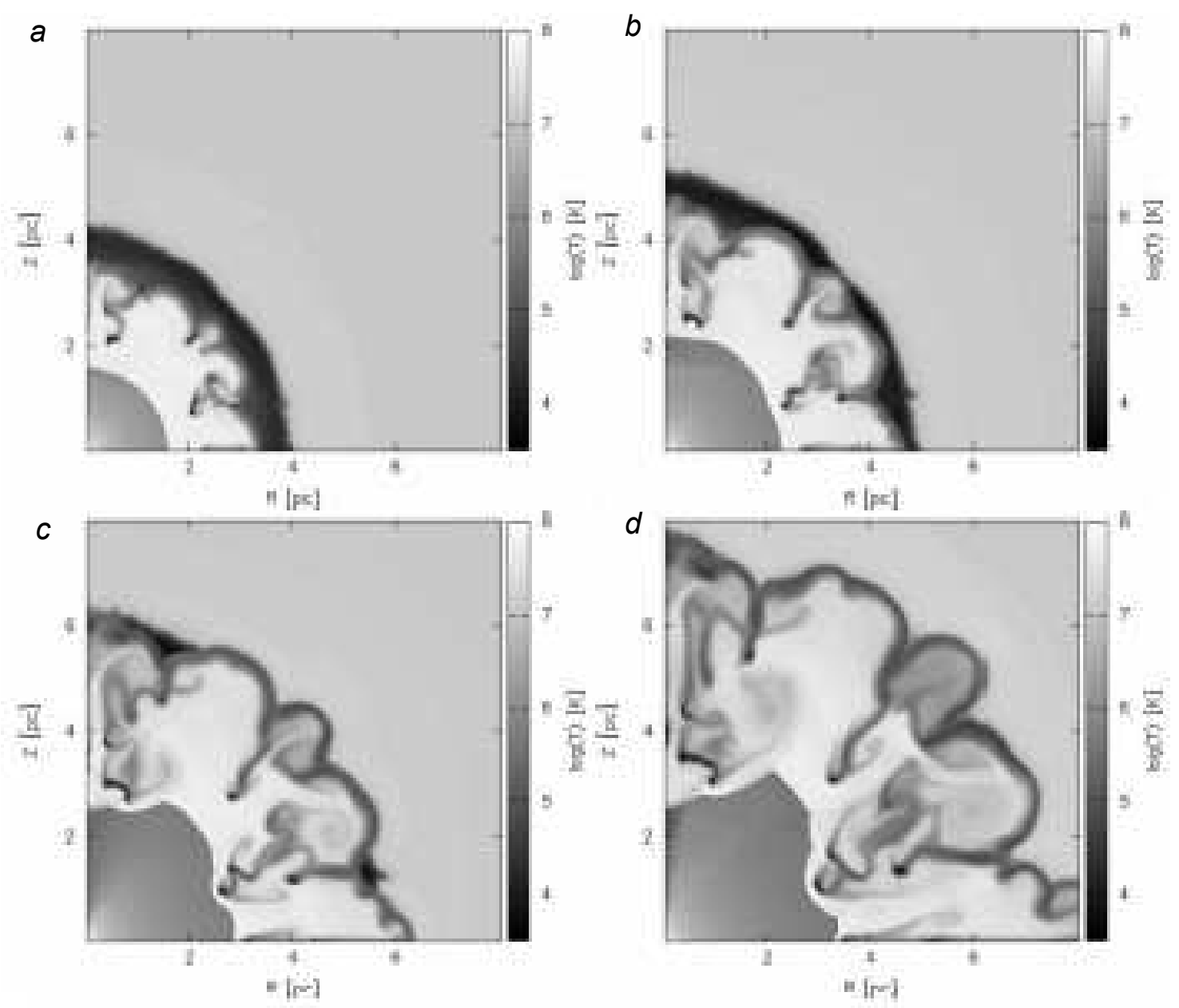

Figura 2.7: Interacción entre los vientos de las fase WR y SGR para $15 \times 10^{3}, 18 \times 10^{3}$, $21 \times 10^{3}$ y $24 \times 10^{3}$ años (a,b,c y d, respectivamente) posteriores al comienzo del viento de la estrella WR. Los ejes indican el radio de la burbuja interestelar R (pc) (abcisas) y la distancia perpendicular al plano ecuatorial en donde se desarrolla el viento, z (pc) (ordenadas). A la izquierda de cada gráfico está indicado en una barra lateral las intensidades en temperatura. 


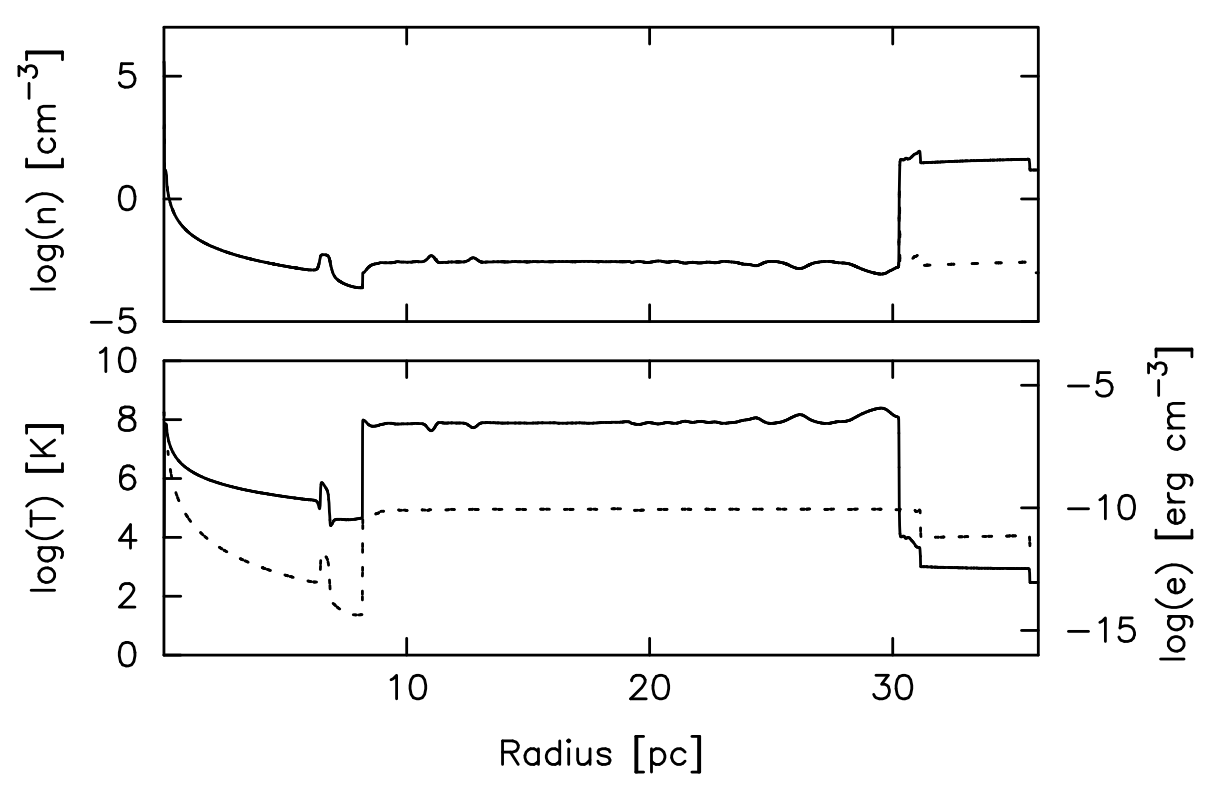

Figura 2.8: Perfil de densidad y temperatura de la BI al término de la fase WR o sea, luego de $5.5 \times 10^{6}$ años. Los tipos de línea corresponden a los mismos parámetros que en la Fig. 2.5.

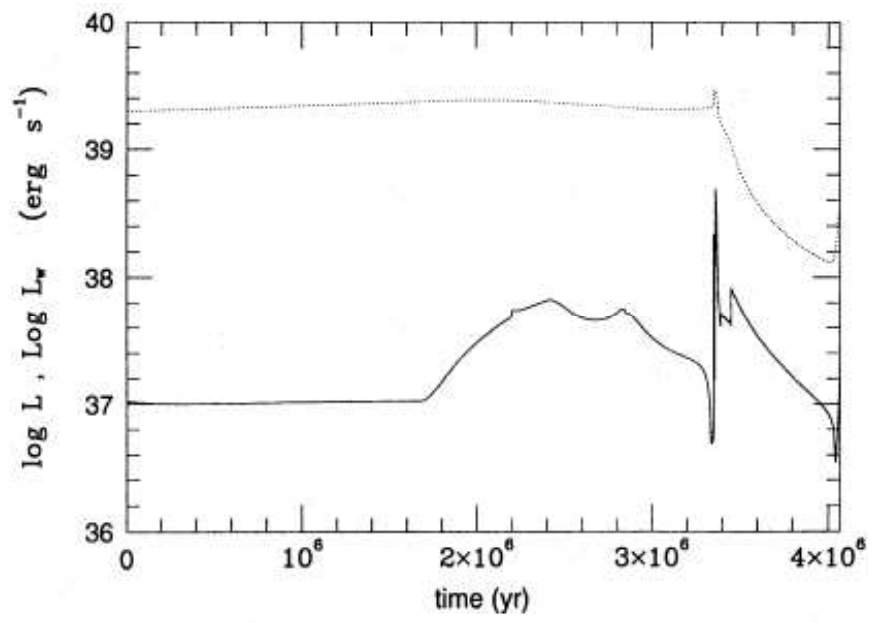

Figura 2.9: Evolución de la luminosidad del viento estelar para una estrella de $60 \mathrm{M}_{\odot}$ (línea continua). A modo de comparación, se grafica el luminosidad estelar en línea punteada (García-Segura et al. 1996b). 


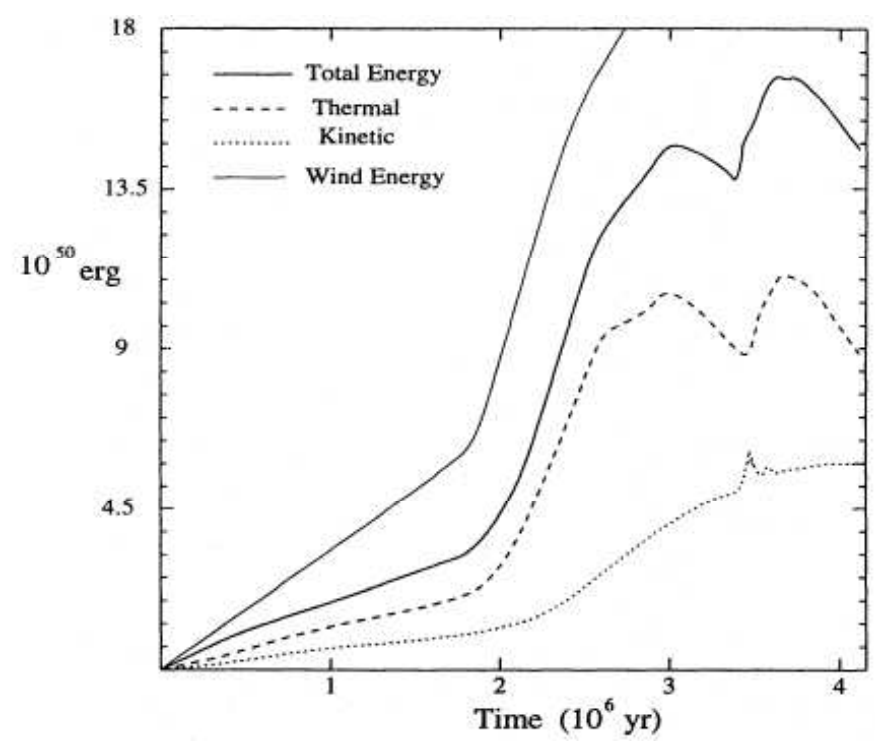

Figura 2.10: Evolución de la energía cinética y térmica de una BI de un radio de 70 pc, para el mismo ejemplo que el de la Fig 2.9. Además se grafica la suma de ambas energías, mostrada como energía total, y la energía cinética del viento (García-Segura et al. 1996b).

La mayoría de los modelos consideran que la primera etapa de expansión de las cáscaras generadas en la fase SP corresponderá a vientos "empujados por energía". La elevada energía interna de la burbuja hace que ésta se expanda por la gran diferencia de presión con respecto a la presión externa del MIE, a través de un medio más frio. La energía cinética de la cáscara de material neutro barrido es del orden del $25 \%$ de la energía mecánica en este estadío. Por otro lado, al comenzar a actuar el viento de la SGR, los fotones ionizantes quedan atrapados en la cáscara densa, y el material ionizado que todavía no ha sido alcanzado por esta cáscara comienza a recombinarse. Como la velocidad de este viento es menor que la del viento de la fase SP, tanto la fracción de energía térmica como la energía cinética decrecen.

Durante la fase WR, el material que empieza a recombinarse es nuevamente ionizado, y la cáscara de la SGR que se desplazaba lentamente, es impulsada por el fuerte viento de la nueva fase.

Por lo visto antes, los modelos no pueden explicar hasta el momento y de manera clara, cuáles son los mecanismos que empujan a los vientos en diferentes etapas evolutivas de las BI.

\subsubsection{Masa}

Para una estrella de $35 \mathrm{M}_{\odot}$, en el momento en que los vientos de las fases SGR y WR colisionan (que, por otra parte, es uno de los momentos en que las cáscaras de las 
burbujas pueden detectarse más fácilmente), los modelos muestran que la estrella central tiene todavía una masa de $13 \mathrm{M}_{\odot}$. En este momento, la luminosidad es de $10^{5.5} \mathrm{~L}_{\odot}$ y la temperatura efectiva del orden de $6 \times 10^{4} \mathrm{~K}$. La estrella ha perdido hasta acá $\sim 2.5$ $\mathrm{M}_{\odot}$ en la fase de $\mathrm{SP}, \sim 18.5 \mathrm{M}_{\odot}$ en el estadío de $\mathrm{SGR}$ y $\sim 1 \mathrm{M}_{\odot}$ en la etapa de $\mathrm{WR}$, es decir, un total de $\sim 22 \mathrm{M}_{\odot}$. Cerca del $85 \%$ de la masa previamente perdida por la estrella se encuentra en las cáscaras o filamentos de la BI. Observacionalmente, esto es de suma importancia, ya que en algunos casos la determinación de las masas de nebulosas asociadas a estrellas WR, permite estimar la cantidad total de masa perdida por la estrella en fases previas. Este tipo de estimaciones debe ir acompañado de estudios de abundancias químicas de las nebulosas anillo (ver Esteban et al. 1993), que muestran si la nebulosa está preferentemente formada por material enriquecido por los procesos de nucleosíntesis estelar, o, por material estelar

\subsection{Eficiencia de conversión de energía y momento}

Si conocemos la masa barrida $M_{s}(t)$, la velocidad de expansión de la BI, $v_{\text {exp }}(t)$, la velocidad terminal $v_{\infty}$ del viento, la tasa de pérdida de masa $\dot{M}(t)$ y el tiempo durante el cual ha soplado el viento estelar, podemos conocer la eficiencia de conversión de energía y momento del viento estelar en energía y momento de la BI en base a estos cocientes:

$$
\begin{gathered}
\epsilon=\frac{\text { Energía cinética de la cáscara }}{\text { Energía del viento estelar }}=\frac{E_{k}}{E_{w}}=\frac{1 / 2 M_{s}(t) v_{\text {exp }}(t)^{2}}{1 / 2 \dot{M}(t) v_{\infty}^{2} t} \\
\pi=\frac{\text { Momento de la cáscara }}{\text { Momento impartido por el viento }}=\frac{M_{s}(t) v_{\text {exp }}(t)}{\dot{M}(t) v_{\infty} t}
\end{gathered}
$$

donde $\epsilon$ se denomina eficiencia de conversión de energía y $\pi$, eficiencia de conversión de momento. Estos cocientes ayudan a determinar si la burbuja está en la etapa de conservación de la energía o de conservación del momento. El modelo de conservación de energía predice $\epsilon \approx 0.2$ y $\pi \geq 1$. Para el caso de conservación de momento se espera $\epsilon \ll 0.2$ y $\pi=1$. Estos parámetros, sin embargo, deben usarse con cuidado, ya que pueden alterarse si, por ejemplo, la burbuja se "despresuriza" (Cooper et al. 2004).

No debe olvidarse que la masa barrida incluye tanto la masa estelar perdida por la estrella a través del viento estelar como material del medio interestelar. La cantidad de masa entregada al MIE por una estrella, a lo largo de sus diferntes etapas evolutivas puede obtenerse si se conoce, para cada una de las fases, la tasa de pérdida de masa y la luminosidad $N$, entonces

$$
\left(\frac{d M(t)}{d t}\right)_{M I E}=\sum_{j} N_{j} \dot{M}_{j}(t)
$$

donde la suma es sobre todas las fases evolutivas de una estrella. La cantidad de energía 
entregada por una estrella de gran masa durante toda su vida es del orden de la entregada en un evento de supernova. Esa cantidad de energía puede ser calculada a partir de la tasa de energía devuelta al MIE como:

$$
\left(\frac{d E(t)}{d t}\right)_{M I E}=\sum_{j} N_{j} \dot{M}_{j}(t) \frac{v_{\infty}^{2}}{2}
$$

Como veremos en el Capítulo $3, M_{s}$ y $v_{\exp }$ pueden obtenerse de observaciones en los rango infrarrojo y de radio.

En el siguiente capítulo haremos un breve resumen acerca de cómo se manifiestan las BI en el MIE, particularmente las asociadas a estrellas WR, cuáles son sus rasgos característicos observados en cada región del espectro, cuál es la importancia del estudio multifrecuencia de estas estructuras, y cómo se confrontan las observaciones con los modelos teóricos ya descriptos en este capítulo. 


\section{Bibliografía}

Arthur S.J., 2006, astro-ph/0605533

Cappa C.E, Niemela V.S., Martin M.C., McClure-Griffiths N.M., 2005, A\&A, 436, 155

Cappa C., Goss W.M., van der Hucht K.A., 2004, AJ, 127, 2885

Castelletti G., 2005, Tesis doctoral, p.2

Castor J.I., Mc Cray R., Weaver R., 1975, ApJ, 195, 157

Chlebowski T., Garmany C.D., 1991, ApJ, 368, 241

Cooper R.L., Guerrero M.A., Chu Y.-H., Chen C.-H.R., Dunne B.C., 2004, ApJ, 605,751

Esteban C., Vilchez J.M., Smith L.J., Clegg R.E.S., 1992, A\&A, 259, 629

García-Segura G., Langer N. \& MacLow M.M., 1996a, 316, 133

García-Segura G., MacLow M.M. \& Langer N., 1996b, 305, 229

Johnson F.S., Hogg D.E., 1965, ApJ, 142, 1033

Lamers H.J.G.L.M., Cassinelli J.P., 1999, En "Introduction to Stellar Winds", Cambridge University Press

Marston A.P., 1997, ApJ, 475, 188

Marston A.P., 1996, AJ, 112, 2828

Marston A.P., Yocum D. R., García-Segura G., Chu Y.-H., 1994a, ApJS, 95, 151

Marston A.P., Chu Y.-H., García-Segura G., 1994b, ApJS, 93, 229

Prinja R.K., Fullerton A.W., Crowther P.A., 1996, A\&A, 331, 264

Schaller G., Schaerer D., Meynet G. \& Maeder A., 1992, A\&AS, 96, 269

Smith L. F., 1968, MNRAS, 138, 109

van Marle A.J., Langer N., García-Segura G., 2005, A\&A, 444, 837

Verschuur G.L., Kellermann K.L., 1988, Springer-Verlag, p.101

Weaver, R. P., McCray R., Castor J., Shapiro P., Moore R., 1977, ApJ, 218, 377 


\section{Capítulo 3}

\section{¿Por qué observar en radiofrecuencias y en IR?}

\section{Resumen}

En esta sección daremos una breve descripción de las características de las burbujas interetelares $(\mathrm{BI})$ detectadas en diferentes intervalos del espectro electromagnético junto a los procedimientos que nos permiten conocer los parámetros físicos del gas ionizado, neutro, molecular y del polvo interestelar asociados a estas estructuras. Comenzaremos por comentar los rasgos observados en el rango óptico, luego en el IR, y finalmente el aspecto que presentan estas estructuras en radiofrecuencias.

\subsection{Observaciones en el rango óptico}

En la Figura 3.1 se muestran algunas nebulosas anillo ópticas asociadas a estrellas WR galácticas. Por su aspecto anular Johnson \& Hogg 1965) las denominaron (en este rango del espectro) nebulosas anillo. Estos autores atribuyeron su origen a los vientos estelares.

Los primeros intentos por determinar los mecanismos de formación de las nebulosas anillo ópticas alrededor de estrellas WR fueron llevados a cabo por Chu y colaboradores, quienes estudiaron la morfología y dinámica de muchas estructuras asociadas a estrellas WR en nuestra galaxia y en la Nube Mayor de Magallanes (Chu 1981, Chu 1982a, Chu 1982b, Chu et al. 1982; Chu \& Treffers 1981a, Treffers \& Chu 1981b). Sus procesos de formación dieron pie a la siguiente clasificación (Chu 1991):

- tipo $\boldsymbol{W}$, en el que la nebulosa está modelada por el viento estelar y principalmente constituida por material del MIE barrido.

- tipo $\boldsymbol{E}$, en el caso de nebulosas formadas principalmente por material estelar. Son las más pequeñas y las de mayor velocidad de expansión. 
- tipo $\boldsymbol{R}_{s}$, cuando la escala de tiempo dinámico de la nebulosa óptica es mayor que la duración de la fase WR de la estrella asociada. Algunas tienen morfología de cáscara mientras que otras son amorfas. Estas nebulosas se expanden generalmente con velocidades $\leq 10 \mathrm{~km} \mathrm{~s}^{-1}$.

Notemos que este esquema de clasificación no es único, y algunos de estos tipos pueden darse simultáneamente en cualquier nebulosa real.

El análisis de burbujas interestelares ópticas provee información tanto de la estrella central como del material interestelar circundante. Las nebulosas anillo, sobre todo las de tipo E, constituidas por material estelar procesado, tienen abundancias anómalas con respecto a las abundancias típicas de regiones H iI por lo que dan información acerca de la nucleosíntesis estelar. Si se hace un modelo de estructura de fotoionización de la nebulosa, tal que reproduzca las líneas y flujos nebulares observados, se puede obtener información sobre $T_{\text {eff }}$. Trabajos de este tipo realizados por Mathis (1982), Mathis (1985), Evans \& Dopita (1985), Smith \& Clegg (1990) y Esteban et al. (1990) mostraron un amplio rango en $T_{\text {eff }}$, que va desde los $5 \times 10^{4}$ hasta los $8 \times 10^{4} \mathrm{~K}$. Esta gran incerteza se debe principalmente a que el valor de este parámetro físico depende del modelo de atmósfera estelar.

García-Segura et al. (1996a) y García-Segura et al. 1996b) mostraron que las estrellas WR pueden estar rodeadas por dos burbujas interestelares, una interna o circumestelar, y otra externa, asociadas a los vientos en diferentes etapas evolutivas estelares. La exterior habría sido "soplada" por la estrella progenitora en la fase de secuencia principal, mientras que la interna se originaría en las fases RSG o LBV (ver Capítulo 2). Por lo tanto, según la clasificación, las nebulosas tipo $E$ y $W$ deberían estar asociadas a burbujas circumestelares.

Alrededor del $35 \%$ de las estrellas WR están rodeadas por nebulosas anillo ópticas (van der Hucht 2001). Ellas tienen tamaños angulares menores a 30', velocidades de expansión entre 15 y $80 \mathrm{~km} \mathrm{~s}^{-1}$ y edades dinámicas del orden de $10^{5}$ años (Chu et al. 1982).

En la Fig. 3.1 se muestran tres nebulosas anillo asociadas a estrellas WR. La nebulosa NGC 6888 (panel a) asociada a WR 136, es de tipo W; RCW 58, asociada a WR 40, es E y NGC 3199, asociada a WR 18, es W. Como se puede advertir, la morfología anular predomina en los tres casos. Por otro lado, vemos también que la distribución de intensidad no es homogénea en ninguna de las burbujas y que la estrella (indicada con una cruz), no siempre ocupa una posición central. Estos efectos podrían deberse a que han evolucionado en diferentes ambientes interestelares. Un entorno no homogéneo, la anisotropía en los vientos de las estrellas excitatrices, o los movimientos espaciales de la estrella central alejarían de la esfericidad a la nebulosa asociada.

En la Fig. 3.2 vemos una serie de imágenes en diferentes líneas de las nebulosas anillo ópticas NGC 2359 (panel superior) asociada a la estrella WR 7 y G 2.4+1.4 (panel inferior), asociada a WR 102. De izquierda a derecha las imágenes muestran las distribuciones en $\mathrm{H} \alpha$, [OIII] y la resta de ambas imágenes. La posición de las estrellas está indicada con una cruz. En NGC 2359 se ven muchos filamentos que adquieren formas de cáscaras parabólicas 

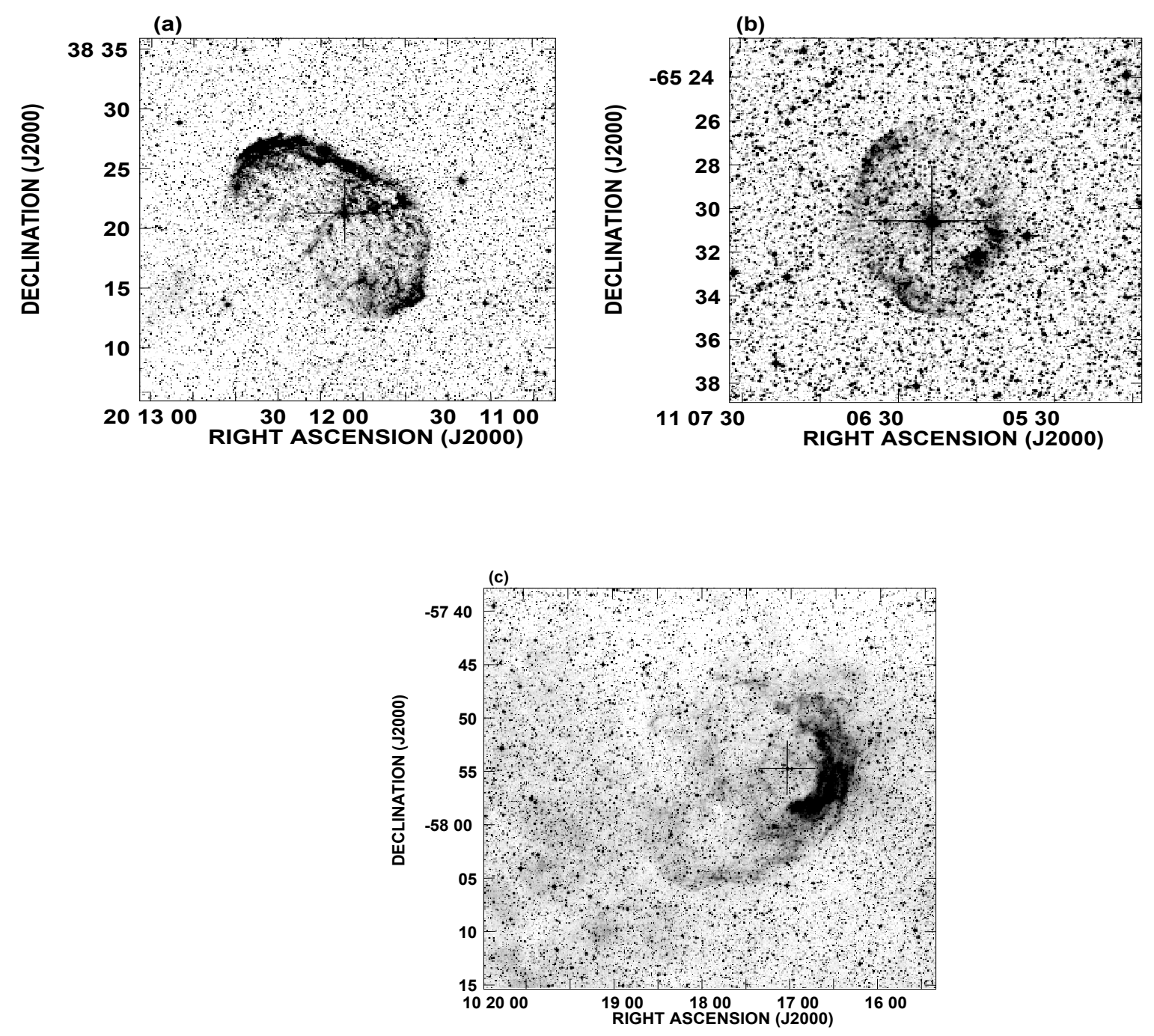

Figura 3.1: Nebulosas anillo asociadas a estrellas WR. a) NGC 6888 asociada a WR 136, b) RCW 58 asociada a WR 40, c) NGC 3199 asociada a WR18. Las imágenes fueron tomadas del Digitized Sky Survey (placas R). Las cruces marcan la posición de las estrellas WR 

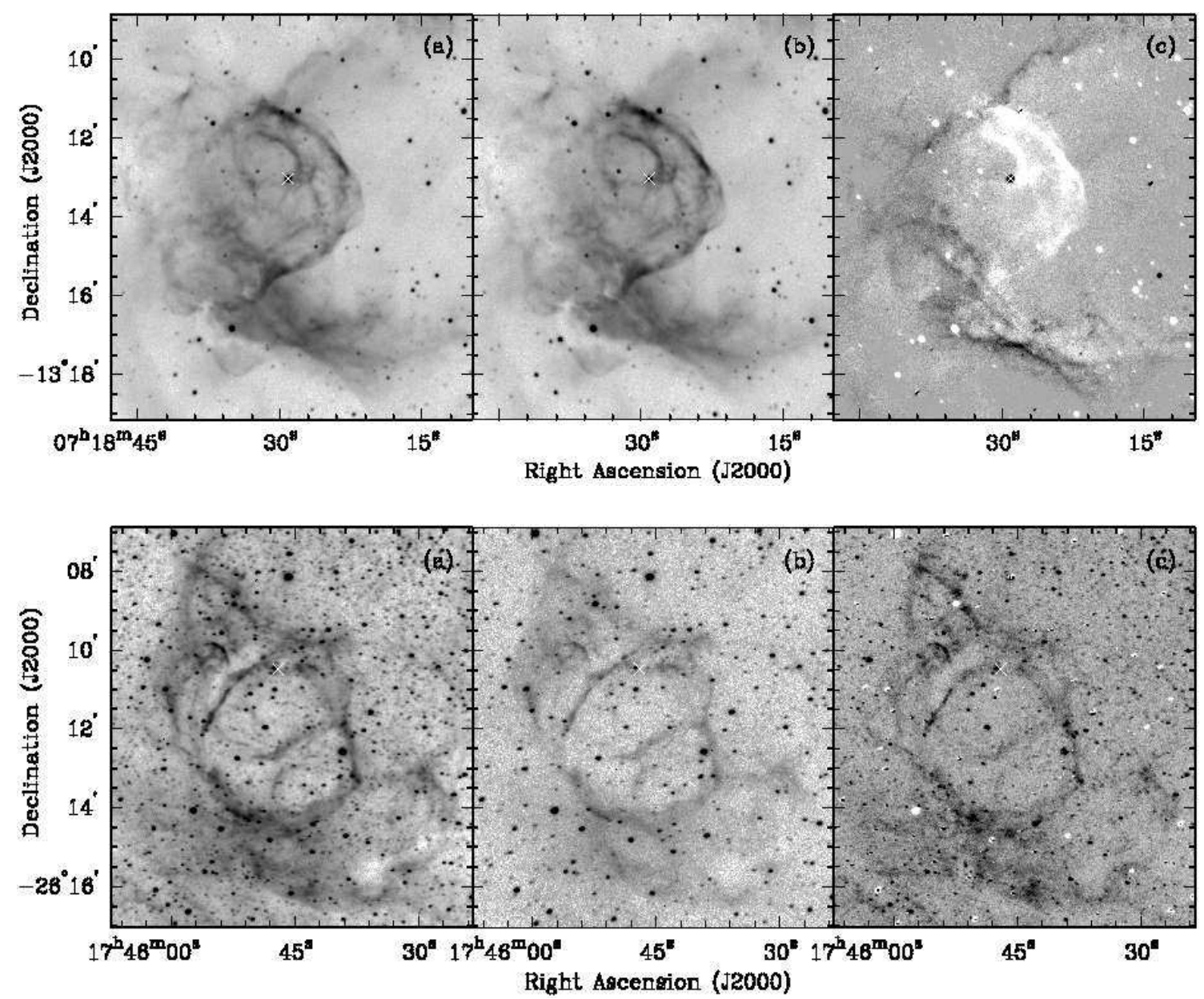

Figura 3.2: Nebulosa anillo óptica NGC 2359 (panel superior) asociada a la estrella WR 7; y G 2.4+1.4 (panel inferior), asociada a WR 102. De izquierda a derecha: distribuciones en $\mathrm{H} \alpha$, [OIII] y resta entre ambas imágenes

con ejes principales en sentido antiparalelo. La distribución de [OIII] aparece casi encima de la posición de estrella y desplazada de la emisión en $\mathrm{H} \alpha$ al suroeste de la estrella. Esto puede tener dos explicaciones: (i) efecto de proyección de la nebulosa sobre el plano del cielo, o (ii) el material está realmente muy cercano a la estrella. Esto puede justificarse dado que la línea de [OIII] es indicadora de zonas donde el material se encuentra altamente ionizado. G 2.4+1.4 presenta un aspecto circular, con filamentos internos que rodean la posición de la estrella WR. La distribución en ambas líneas es similar.

El panel superior de la Fig. 3.3 muestra la nebulosa anillo asociada a WR 23, que presenta una red de filamentos. La nebulosa anillo del panel inferior está asociada a LSS 1887, estrella de tipo O8.5. En general, las estructuras alrededor de estrellas O son menos definidas y tienen tamaños lineales menores que las asociadas a estrellas WR. 

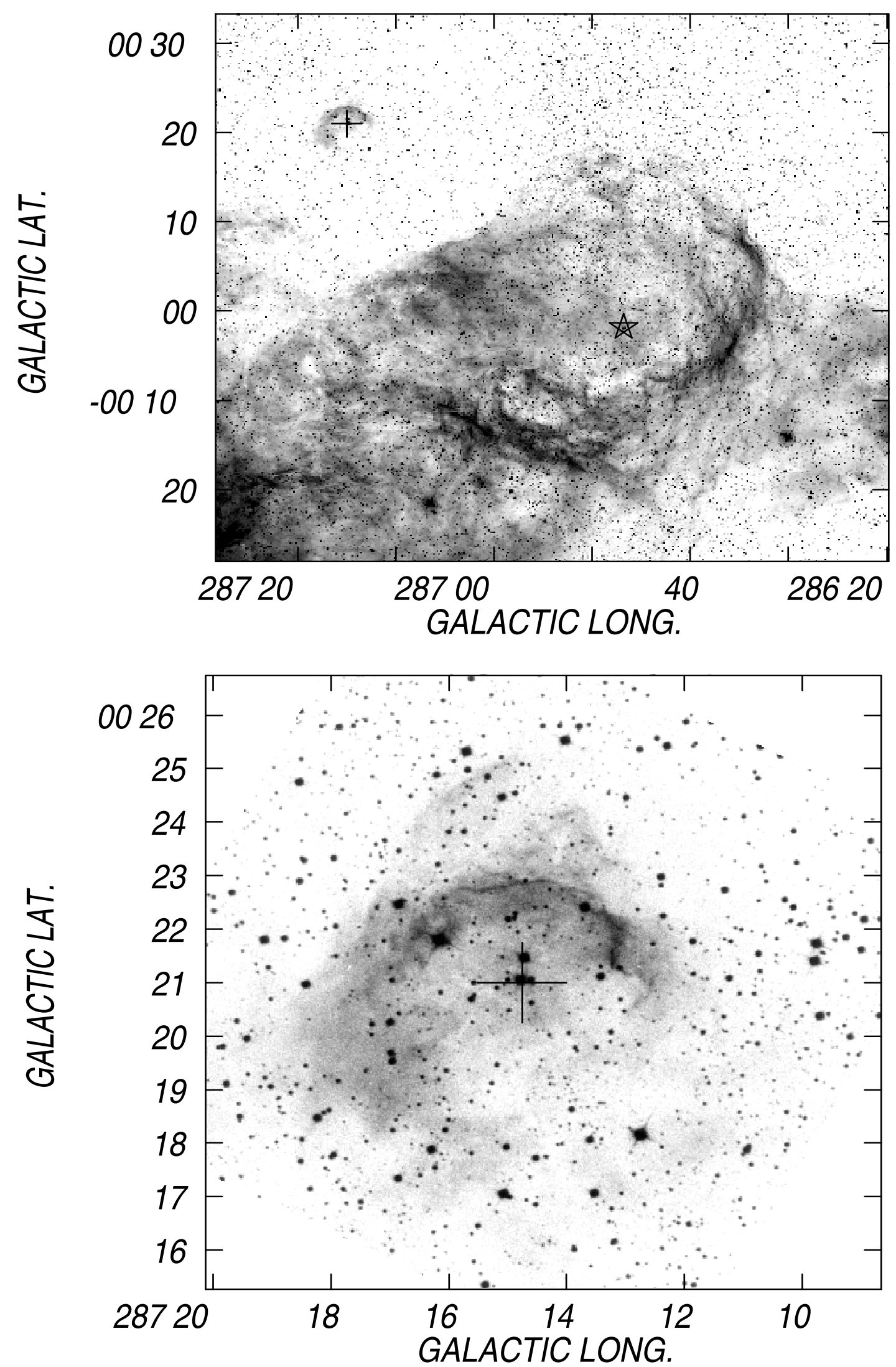

Figura 3.3: Imágenes de las nebulosas anillo ópticas asociadas a WR 23 y a LSS 1887 (O8.5) (Cappa et al. 2005). La estrella y la cruz indican la posición de WR 23 y LSS 1887, respectivamente. 

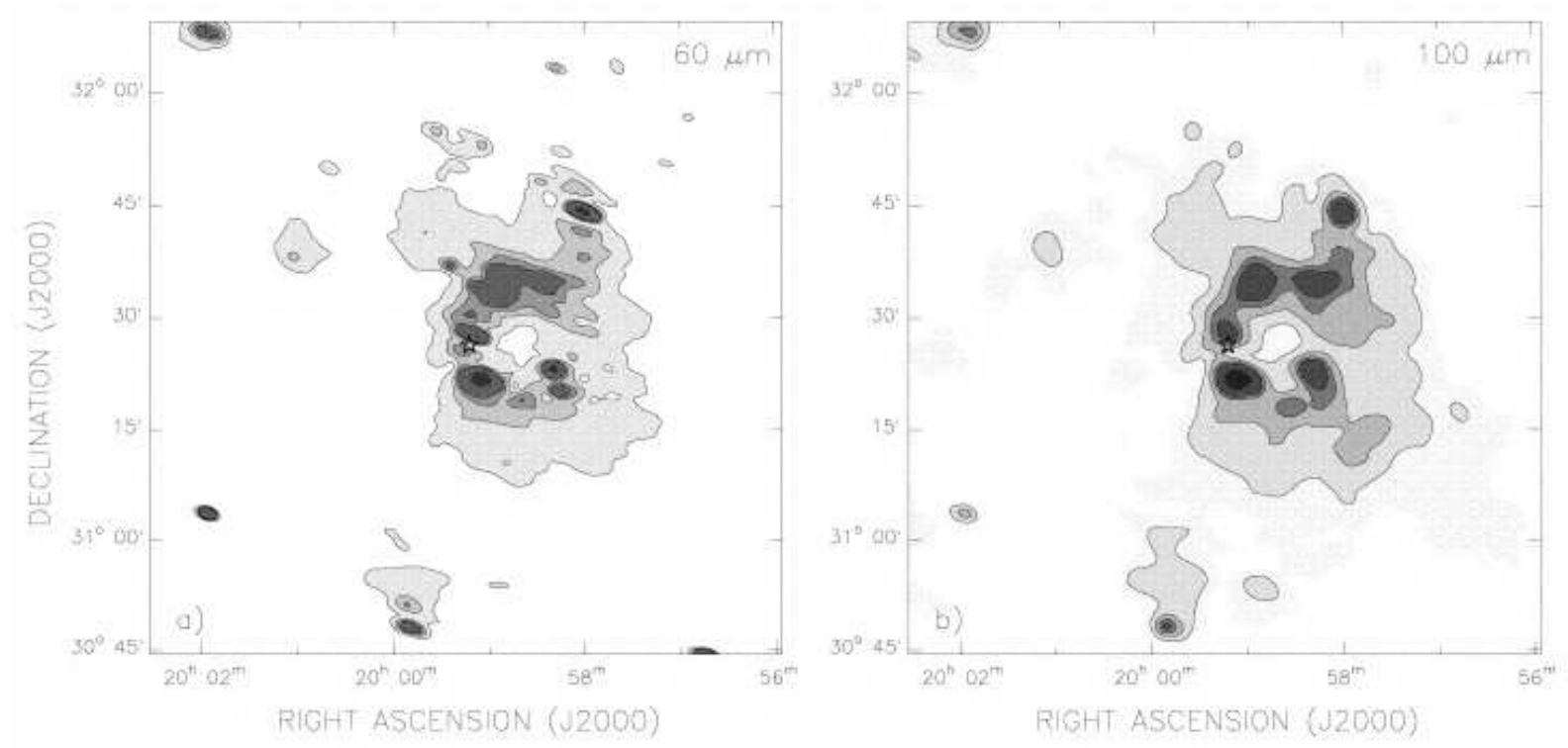

Figura 3.4: Imágenes HIRES (del inglés HIgh RESolution) en $60 \mu \mathrm{m}$ (panel izquierdo) y $100 \mu \mathrm{m}$ (panel derecho) que muestran la distribución de polvo interestelar asociado a la estrella WR 130 (Cichowolski et al. 2001).

\subsection{Observaciones en el infrarrojo}

Van de Hulst (1946) sugirió que el agente responsable de la absorción en el rango óptico del espectro electromagnético es el polvo interestelar. De esta forma, la energía absorbida por los granos de polvo, es reemitida en el IR.

La emisión del polvo constituye $\approx 10-30 \%$ de la radiación total emitida por la Galaxia, teniendo así importancia en el balance de energía detallado del disco galáctico. De esta manera, observaciones de la emisión difusa en el IR proveen importante información sobre la distribución espacial del polvo en el medio interestelar, así como sobre las propiedades de los granos (Hildebrand 1983).

Una partícula de polvo gana energía principalmente por absorción de fotones UV del campo de radiación interestelar (CRI). Se establece un estado estacionario cuando los granos emiten una energía igual a la absorbida, a alguna temperatura $T_{p}$, la cual dependerá de su tamaño y composición. Van de Hulst (1946) mostró que para esferas dieléctricas de radio $a \approx 0.1 \mu \mathrm{m}$ se esperan temperaturas del polvo en el rango $10-20 \mathrm{~K}$ y que estas partículas emitirían en el lejano infrarrojo (FIR, entre 30 y $300 \mu \mathrm{m}$ ).

La emisión en el infrarrojo mediano (MIR, entre 5 y $30 \mu m$ ) indica la presencia de una componente del polvo con mayor temperatura (100-500 K). Estudios de continuo y de líneas de emisión en el cercano infrarrojo (NIR, entre 1 y $5 \mu m$ ) muestran la existencia de granos de polvo con temperaturas mucho mayores que las esperadas para las partículas 
clásicas (radio $a \gtrsim 0.1 \mu \mathrm{m}$ ) en equilibrio térmico con su medio ambiente. Esto llevó a desarrollar modelos que incluyeran emisión de granos de polvo mucho más pequeños sujetos a calentamiento.

El origen de los granos de polvo presentes en BI puede deberse a diferentes procesos (Marston 1991):

- Durante la fase de supergigante roja, el polvo se forma en las capas exteriores de las atmósferas estelares y es dispersado por el viento lento característico de esta fase formando "grumos". Luego, y si eventualmente la estrella evoluciona como WR, estos grumos son barridos por el rápido viento estelar de esta fase. Cabe destacar que las estrellas gigantes rojas y supergigantes son las mayores productoras de polvo (Whittet 1992).

- El polvo forma parte de las capas estelares exteriores que son eyectadas al inicio de la fase WR.

- El polvo es parte del MIE circundante a la estrella, que es barrido por el viento estelar y que, por lo tanto, se expande junto con la cáscara.

La Fig. 3.4 muestra la distribución de radiación asociada a WR 130 en 60 y $100 \mu \mathrm{m}$. La morfología es circular, con la posición de la estrella sobre la envoltura de polvo. A partir del análisis del polvo, tanto en 60 como en $100 \mu \mathrm{m}$, se obtuvieron valores de la temperatura de color $T_{p}=34 \mathrm{~K}$ y de la masa de polvo $M_{p}=7 \mathrm{M}_{\odot}$. La luminosidad IR se obtuvo a partir de las densidades de flujo en las cuatro bandas IRAS, con un valor de $5.1 \pm 10^{4} \mathrm{~L}_{\odot}($ Cichowolski et al. 2001).

La apariencia de estas nebulosas en el IR es similar a la que presentan en el rango óptico y en el continuo de radio (Cappa et al. 2003), indicando la convivencia entre granos de polvo y los electrones responsables de esa emisión. Puede contribuir a la similitud entre ambas emisiones la ionización de electrones pertenecientes a los granos de polvo debido a las colisiones con electrones libres.

En el NIR aparecen las intensas bandas de emisión centradas en 3.3, 6.2, 7.7, 8.6 y 11.3 $\mu \mathrm{m}$. Su origen proviene de la emisión vibracional de moléculas complejas llamadas "hidrocarburos aromáticos policíclicos" (PAH, del inglés "Polycyclic Aromatic Hydrocarbons"). Estas moléculas pueden llegar a contener hasta 80 átomos de carbono (Léger \& Puget 1984, Allamandola et al. 1985, Allamandola et al. 1989, Puget \& Léger 1989, Tielens et al. 2004).

En la Fig. 3.5 se muestran cuatro ejemplos de burbujas interestelares generadas por la emisión de PAHs, observadas por el telescopio espacial "Galactic Legacy Infrared Midplane Survey Extraordinaire" (GLIMPSE). Este instrumento observó las bandas IR centradas en $3.6,4.5,5.8$ y $8.0 \mu \mathrm{m}$.

Estas estructuras generalmente están asociadas a los bordes de regiones H iI, y encierran estrellas de gran masa. Las imágenes que vemos son el resultado de la combinación de tres filtros centrados en $4.5 \mu \mathrm{m}$ (azul), $5.8 \mu \mathrm{m}$ (verde) y en $8.0 \mu \mathrm{m}$ (rojo). En el 
(a)

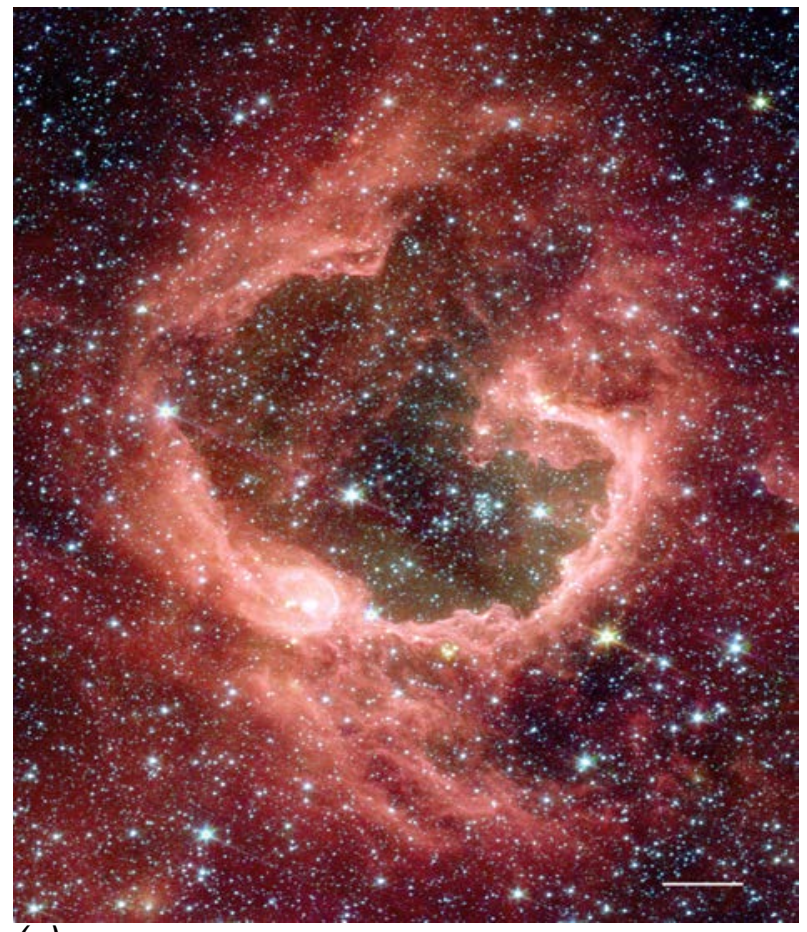

(c)

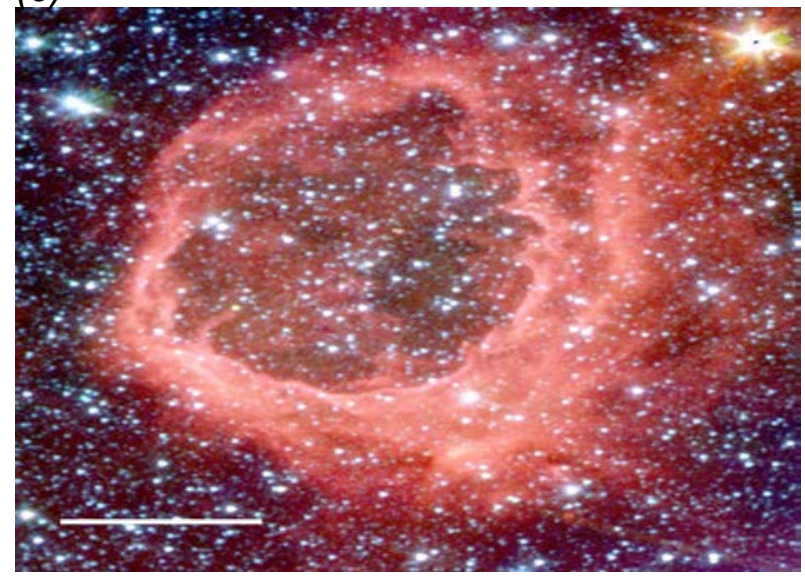

(b)

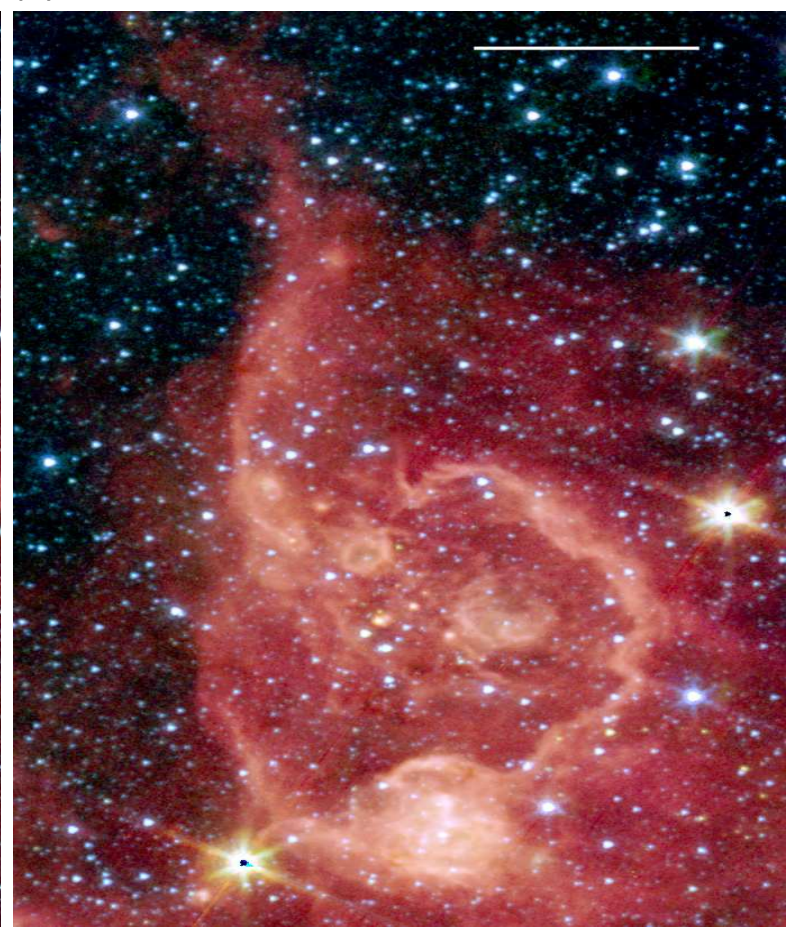

(d)

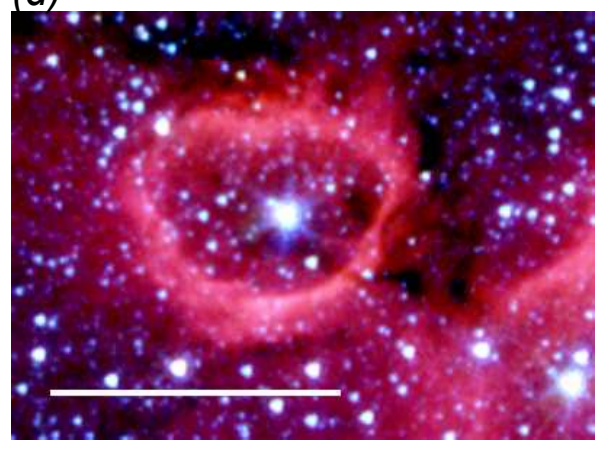

Figura 3.5: Burbujas IR observadas con GLIMPSE. (a) S145, (b) S133, (c) S 44 y (d) S 21 (Churchwell et al. 2006). 
panel (a) se muestra la region S 145, clasificada como burbuja "rota" por estar abierta en su parte superior. Está asociada a la región H II RCW 79. En el panel (b) se muestra la burbuja S 133 clasificada como "burbuja múltiple" por sus filametos internos. El panel (c) exhibe la burbuja S 44, clasificada como burbuja completa por estar cerrada. Esta estructura no tiene asociada estrellas de gran masa. Finalmente, se observa en el panel (d) la burbuja S 21 que es completa y estaría asociada a un objeto estelar.

Un aspecto muy importante de esta emisión es que es muy intensa en la interfase entre zonas ionizadas y nubes moleculares. En estas regiones el material molecular está disociado debido a la exposición a los fuertes campos de radiación UV generados por estrellas tempranas. El rango de energía de estos fotones es $6 \mathrm{eV}<h \nu<13.6 \mathrm{eV}$, debido a que en este rango energético los fotones disocian el hidrógeno molecular, pero no ionizan el H I. Este tipo de ambientes son llamados regiones de fotoionización (PDRs, "photo dissociation regions" (Tielens \& Hollenbach 1985), y se dan frecuentemente en los bordes de regiones HiI. En este escenario, el estudio de la emisión de los PAH sirve como una excelente herramienta en el diagnóstico de formación estelar inducida por frentes de choque de regiones H II impactando en nubes moleculares. Típicamente entre el $0.1-1 \%$ de la energía del FUV es convertida en energía cinética de los electrones eyectados de los PAHs a través del mecanismo de calentamiento fotoeléctrico (Stahler \& Palla 2004).

\subsubsection{Emisión del polvo interestelar}

Los granos de polvo interestelar intercambian energía con su medio ambiente como resultado de la absorción y emisión de la radiación, de colisiones, y de reacciones exotérmicas en la superficie, como la recombinación del hidrógeno. Sin embargo, la temperatura de equilibrio (en estado estacionario), está determinada por los procesos radiativos.

Asumiendo que los granos de polvo se comportan como un cuerpo negro esférico, su temperatura de equilibrio $T_{b}$ la da la Ley de Stefan-Boltzmann, resultando $T_{b} \simeq 3.1 \mathrm{~K}$ (Eddington 1926).

Consideremos un grano de polvo esférico de radio $a \approx 0.1 \mu \mathrm{m}$. La potencia absorbida del CRI es,

$$
W_{a b s}=c\left(\pi a^{2}\right) \int_{0}^{\infty} Q_{a b s}(\lambda) u_{\lambda} d \lambda
$$

donde $Q_{a b s}$ es el factor de eficiencia para la absorción por los granos y $u_{\lambda}$ es la densidad de energía del CRI en función de la longitud de onda $\lambda$.

Por otro lado, la potencia radiada por el grano de polvo es,

$$
W_{\text {rad }}=4 \pi\left(\pi a^{2}\right) \int_{0}^{\infty} Q_{\text {rad }}(\lambda) B_{\lambda}\left(T_{p}\right) d \lambda
$$

donde $Q_{\text {rad }}(\lambda)$ es emisividad del grano, y $B_{\lambda}(T)$ es la función de Planck. Se desprende de 
la ley de Kirchhoff que $Q_{a b s}$ y $Q_{\text {rad }}$ son idénticas a una dada longitud de onda, por lo que serán reemplazadas por la función $Q_{\lambda}$. En equilibrio, las tasas de ganancia y pérdida de energía se igualan,

$$
\int_{0}^{\infty} Q_{\lambda} u_{\lambda} d \lambda=\frac{4 \pi}{c} \int_{0}^{\infty} Q_{\lambda} B_{\lambda}\left(T_{p}\right) d \lambda
$$

Esta ecuación puede ser usada para deducir la temperatura $T_{p}$ de los granos de polvo si se conoce $Q_{\lambda}$.

Pueden, de hecho, darse temperaturas del polvo mayores que $T_{b}$, dado que la absorción ocurre predominantemente en el UV y la emisión en el FIR. En general, $Q_{\lambda}$ sigue una ley de potencia en el FIR (para $a \ll \lambda$ ) y

$$
Q_{F I R} \propto \lambda^{-\beta}
$$

donde $\beta$ dependerá de la naturaleza del material y su valor está entre $1 \leq \beta \leq 2$ (Whittet 1992).

Granos de polvo en diferentes entornos dentro del medio interestelar tienen $T_{p}$ diferente. En el interior de una nube molecular calentada sólo por la CRI externa, el flujo UV visible está atenuado y los granos se calientan predominantemente por absorción de radiación infrarroja. Mediante modelos de transporte de radiación dentro de nubes densas, se ha llegado a calcular la temperatura del polvo como función de la profundidad óptica (Leung 1975, Mathis et al. 1983), así por ejemplo, en una nube esférica con extinción visual $A_{V}=10 \mathrm{mag}$ hacia su centro, $T_{p} \gtrsim 15 \mathrm{~K}$ en las regiones externas de la nube y $T_{p} \gtrsim$ $7 \mathrm{~K}$ en la zona central. $T_{p} \approx 20-30 \mathrm{~K}$ en el polvo de nubes típicas del medio interestelar y $T_{p} \approx 30-40 \mathrm{~K}$ son típicas de regiones H II (ver por ejemplo Chan \& Fich, 1995).

En la inmediata vecindad de una estrella temprana, el alto flujo de fotones UV hace que $T_{p} \gtrsim 500 \mathrm{~K}$. Sin embargo, la temperatura de un grano en estos entornos está limitada por su temperatura de sublimación $\left(T_{p} \approx 1000-1500 \mathrm{~K}\right)$.

\subsubsection{Análisis en el mediano y lejano IR}

En esta sección mostraremos una serie de expresiones que son especialmente útiles en el análisis de los datos IR obtenidos con el satélite astronómico infrarrojo IRAS.

Las luminosidades derivadas de las observaciones en las cuatro bandas de IRAS (12, 25, 60 y $100 \mu \mathrm{m})$ son, por definición,

$$
L_{\nu}=\Delta \nu S_{\nu} 4 \pi d^{2}
$$

siendo $\Delta \nu$ el ancho de banda correspondiente a un frecuencia dada, $S_{\nu}$ el flujo en esa frecuencia y $d$ la distancia a la fuente. Si normalizados estos parámetros, $S_{\nu}$ se expresa 
en Jy, $\Delta \nu=\Delta \nu_{12} 10^{12} \mathrm{~Hz}$ y $d=d_{\mathrm{kpc}} 3.08 \times 10^{22} \mathrm{~m}$, esta expresión resulta:

$$
L_{\nu}\left(L_{\odot}\right)=3.14 \times 10^{5} \Delta \nu_{12}\left(\frac{S_{\nu}}{\mathrm{Jy}}\right)\left(\frac{d}{\mathrm{kpc}}\right)^{2}
$$

donde $L_{\nu}$ es la luminosidad en unidades solares. Si queremos obtener la luminosidad bolométrica en el IR, recurrimos a la siguiente expresión:

$$
L_{\mathrm{IR}}\left(\mathrm{L}_{\odot}\right)=1.58\left(\frac{\mathrm{S}_{\mathrm{IR}}}{\mathrm{Jy}}\right)\left(\frac{\mathrm{d}}{\mathrm{kpc}}\right)^{2}
$$

donde $S_{\mathrm{IR}}=1.3\left(S_{12}+S_{25}\right)+0.7\left(S_{25}+S_{60}\right)+0.2\left(S_{60}+S_{100}\right)($ Chan \& Fich 1995).

Por otra parte, se puede derivar la temperatura y la masa del polvo utilizando las propiedades espectrales de éste, considerando sólo la emisión en las bandas de 60 y 100 $\mu \mathrm{m}$, y que las densidades de flujo de IRAS son monocromáticas (lo cual está lejos de ser cierto, si se examinan las respuestas de los anchos de banda). El coeficiente de absorción del polvo es (Hildebrand 1983):

$$
\kappa_{\nu}=4\left(\frac{\nu}{3 \times 10^{12} \mathrm{~Hz}}\right)^{n} \mathrm{~m}^{2} \mathrm{~kg}^{-1}
$$

donde $1 \leq n \leq 1.5$ es el índice espectral.

La temperatura de color del polvo puede obtenerse como:

$$
T_{p}(\mathrm{~K})=\frac{95.94}{\ln \left[(1.67)^{3+\mathrm{n}} \frac{\mathrm{S}_{\nu}(100)}{\mathrm{S}_{\nu}(60)}\right]}
$$

Si se conoce $T_{p}$, puede derivarse la masa de polvo expresada para un medio ópticamente delgado (caso usual en 60 y $100 \mu \mathrm{m}$ ), como

$$
M_{p, \nu}=\frac{S_{\nu} d^{2}}{k_{\nu} B_{\nu}\left(T_{p}\right)}
$$

donde

$$
B_{\nu}\left(T_{p}\right)=\frac{2 \pi h \nu^{3}}{c^{2}} \frac{1}{e^{\left(h \nu / k T_{p}\right)}-1}
$$

es la función de Planck. Luego de normalizar en frecuencia, se obtiene

$$
M_{p, \nu}\left(\mathrm{M}_{\odot}\right)=25.83^{\mathrm{n}} \nu^{-(3+\mathrm{n})} \mathrm{S}_{\nu}(\mathrm{Jy}) \mathrm{d}^{2}{ }_{\mathrm{Mpc}}\left[\left[(1.67)^{3+\mathrm{n}} \frac{\mathrm{S}_{\nu}(100)}{\mathrm{S}_{\nu}(60)}\right]^{0.5 \nu}-1\right]
$$




\subsection{Emisión en el continuo de radio}

Para interpretar cuantitativamente las observaciones en el continuo de radio es necesario entender cómo viaja la radiación a través del medio a partir de la ecuación de transporte radiativo, planteada para la radiación proveniente de la nebulosa

$$
\frac{d I_{\nu}}{d \tau_{\nu}}=-I_{\nu}+B_{\nu}\left(T_{e}\right)
$$

cuya solución es

$$
I_{\nu}=\int_{0}^{\tau_{\nu}} B_{\nu}\left(T_{e}\right) \exp \left(-\tau_{\nu}\right) d \tau_{\nu}
$$

donde $I_{\nu}$ es la intensidad de la radiación emitida y $B_{\nu}\left(T_{e}\right)=j_{\nu} / k_{\nu}$ es la función fuente que en $L T E$ estará bien representada por una función de Planck, $T_{e}$ la temperatura electrónica y $\tau_{\nu}$ la profundidad óptica, definida como la inversa del camino libre medio de un fotón de frecuencia $\nu$, y expresada a través de

$$
\tau_{\nu}=\int \kappa_{\nu} d l
$$

siendo $d l$ el camino atravesado a lo largo de la línea de la visual.

Considerando la región de radiofrecuencias, esta función puede aproximarse como

$$
B_{\nu}\left(T_{e}\right) \approx \frac{2 k T_{e} \nu^{2}}{c^{2}}
$$

La intensidad de la radiación emitida en un punto de la superficie de la región H iı es descripta en términos de la temperatura de brillo $T_{b}$,

$$
T_{b}=\int_{0}^{\tau_{\nu}} T_{e} \exp \left(-\tau_{\nu}\right) d \tau_{\nu}
$$

que para una nebulosa isotérmica y ópticamente delgada $\left(\tau_{c} \ll 1\right)$, es

$$
T_{b}=T_{e}\left[1-\exp \left(-\tau_{c}\right)\right] \approx T_{e} \tau_{c}
$$

con $\tau_{c} \equiv \tau_{\nu}$ y donde $T_{e}$ es la temperatura electrónica de la fuente. Esta última depende sólo levemente de la temperatura efectiva de la estrella ionizante (Osterbrock 1965) y se puede calcular a partir de observaciones en líneas de recombinación en radio o en el rango óptico.

Mediante observaciones en el continuo de radio, se puede determinar la densidad de flujo integrada sobre la fuente $S_{\nu}$, que puede definirse como

$$
S_{\nu}=\int I\left(\nu, T_{b}\right) d \Omega
$$


donde $I\left(\nu, T_{b}\right)$ es la distribución de brillo de la fuente y la integral se extiende sobre el ángulo sólido subtendido por la fuente.

En condiciones de LTE, la intensidad específica de la radiación obedece la Ley de Planck. En el rango de longitudes de onda centimétricas, $h \nu \ll k T_{b}$ y $I\left(\nu, T_{b}\right)$ puede aproximarse mediante la expresión de Rayleigh-Jeans,

$$
I\left(\nu, T_{b}\right)=\frac{2 h \nu^{3}}{c^{2}} \frac{k T_{b}}{h \nu}=\frac{2 \nu^{2}}{c^{2}} k T_{b}
$$

donde $T_{b}$ es la temperatura de brillo de la fuente. Así, la densidad de flujo medida en términos de $T_{b}$ queda definida como :

$$
S_{\nu}=\frac{2 k \nu^{2}}{c^{2}} \int T_{b} d \Omega
$$

Si la temperatura de brillo es constante sobre toda la fuente, la ecuación (2.36) queda

$$
S_{\nu}=\frac{2 k \nu^{2}}{c^{2}} T_{b} \Omega_{f}
$$

donde $\Omega_{f}$ es el ángulo sólido subtendido por la fuente y es un dato proporcionado por las observaciones en el continuo de radio.

La profundidad óptica para la emisión libre-libre viene dada por (Oster 1961)

$$
\begin{aligned}
\tau_{c}(\text { Oster })= & 3.014 \times 10^{-2}\left(\frac{T_{e}}{\mathrm{~K}}\right)^{-1.5}\left(\frac{\nu}{\mathrm{GHz}}\right)^{-2.0}\left\{\ln \left[4.955 \times 10^{-2}\left(\frac{\nu}{\mathrm{GHz}}\right)^{-1}\right]\right. \\
& \left.+1.5 \ln \left(\frac{T_{e}}{\mathrm{~K}}\right)\right\}\left(\frac{E M}{\mathrm{pc} \mathrm{cm}^{-6}}\right)
\end{aligned}
$$

que puede aproximarse por (Altenhoff et al. 1960)

$$
\tau_{c}(A M W W)=8.235 \times 10^{-2}\left(\frac{T_{e}}{\mathrm{~K}}\right)^{-1.35}\left(\frac{\nu}{\mathrm{GHz}}\right)^{-2.1}\left(\frac{E M}{\mathrm{pc} \mathrm{cm}}\right)
$$

En ambas ecuaciones $n_{i}=n_{e}$ y la medida de emisión $E M=\int n_{e}{ }^{2} d s$ tiene dimensiones de $\mathrm{pc} \mathrm{cm}^{-6}$. Se define al cociente entre $\tau($ Oster $) / \tau(A M W W)$ como :

$$
\begin{aligned}
a\left(\nu, T_{e}\right)= & \frac{\tau_{c}(\text { Oster })}{\tau_{c}(A M W W)}=0.366\left(\frac{T_{e}}{\mathrm{~K}}\right)^{-0.15}\left(\frac{\nu}{\mathrm{GHz}}\right)^{0.1}\left\{\ln \left[4.955 \times 10^{-2}\left(\frac{\nu}{\mathrm{GHz}}\right)^{-1}\right]\right. \\
& \left.+1.5 \ln \left(\frac{T_{e}}{\mathrm{~K}}\right)\right\}
\end{aligned}
$$

Este factor mide la desviación entre el valor exacto y su aproximación. Teniendo en cuenta esto y habiendo asumido $T_{e}=$ cte para toda la región, sustituyendo en (3.18)

$$
T_{b}=8.235 \times 10^{-2} a\left(\nu, T_{e}\right)\left(\frac{T_{e}}{\mathrm{~K}}\right)^{-0.35}\left(\frac{\nu}{\mathrm{GHz}}\right)^{-2.1} \int n_{e}{ }^{2}(x, y, r) d r
$$


donde se ha especificado la variación de $n_{e}$ con la posición dentro de la nebulosa; $x, y$ son las coordenadas cartesianas en la superficie y $r$ es la profundidad en la dirección de la línea de la visual a la nube.

Volviendo a la ecuación (3.22) y teniendo en cuenta (3.21), para $\tau \ll 1$

$$
S_{\nu}=\frac{2 k \nu^{2}}{c^{2}} T_{e} \tau_{c} \Omega_{f}
$$

$S_{\nu} \propto \nu^{\alpha}$, donde $\alpha$ es el índice espectral de la fuente. El valor de este índice depende de la naturaleza de la radiación que se observa.

- Para fuentes térmicas, como es el caso de las nebulosas anillo alrededor de estrellas de alta masa, el mecanismo que origina la radiación es la emisión libre-libre y el índice espectral es $\alpha=2$ para $\tau_{c} \gg 1$ y $\alpha=-0.1$ para $\tau_{c} \ll 1$, esto es, a bajas y altas frecuencias (dentro del rango centimétrico), respectivamente. La inversión de la pendiente se produce alrededor de $1 \mathrm{GHz}$, frecuencia llamada turn-over. La Fig. 3.6 muestra este comportamiento para una región H II.

- Para fuentes no térmicas en general se tiene $\alpha \leq-0.5$.

El índice espectral puede determinarse a partir de dos observaciones en el continuo de radio a distintas frecuencias, mediante,

$$
\alpha=\frac{\log \left(S_{1} / S_{2}\right)}{\log \left(\nu_{1} / \nu_{2}\right)}
$$

donde $S_{1}$ y $S_{2}$ son las densidades de flujo a $\nu_{1}$ y $\nu_{2}$, respectivamente.

Para determinar parámetros de la nebulosa, como la medida de emisión $E M$, la densidad electrónica $n_{e}$, masa $M_{e}$, etc, necesariamente debemos proponer una geometría para la nube. Estos valores dependerán fuertemente del modelo adoptado. Generalmente se usa el trabajo de Mezger \& Henderson (1967) que propone tres tipos de geometría para las regiones H II :

- (a) un modelo esférico de densidad uniforme $n_{0}$ dentro de una esfera de diámetro aparente $\theta_{\text {sph }}$ y cero fuera de ella

- (b) un modelo cilíndrico de densidad uniforme $n_{0}$ dentro de un cilindro de diámetro aparente $\theta_{c y l}$, cuyo eje de simetría está en la dirección de la visual y cuya longitud es igual a su diámetro, siendo cero la densidad fuera del cilindro

- (c) un modelo que asume una distribución exponencial tridimensional, cuyo máximo en densidad es $n_{0}$ y donde el ancho a potencia mitad ( $H P B W$ ) de esta distribución es $\theta_{G}$ 


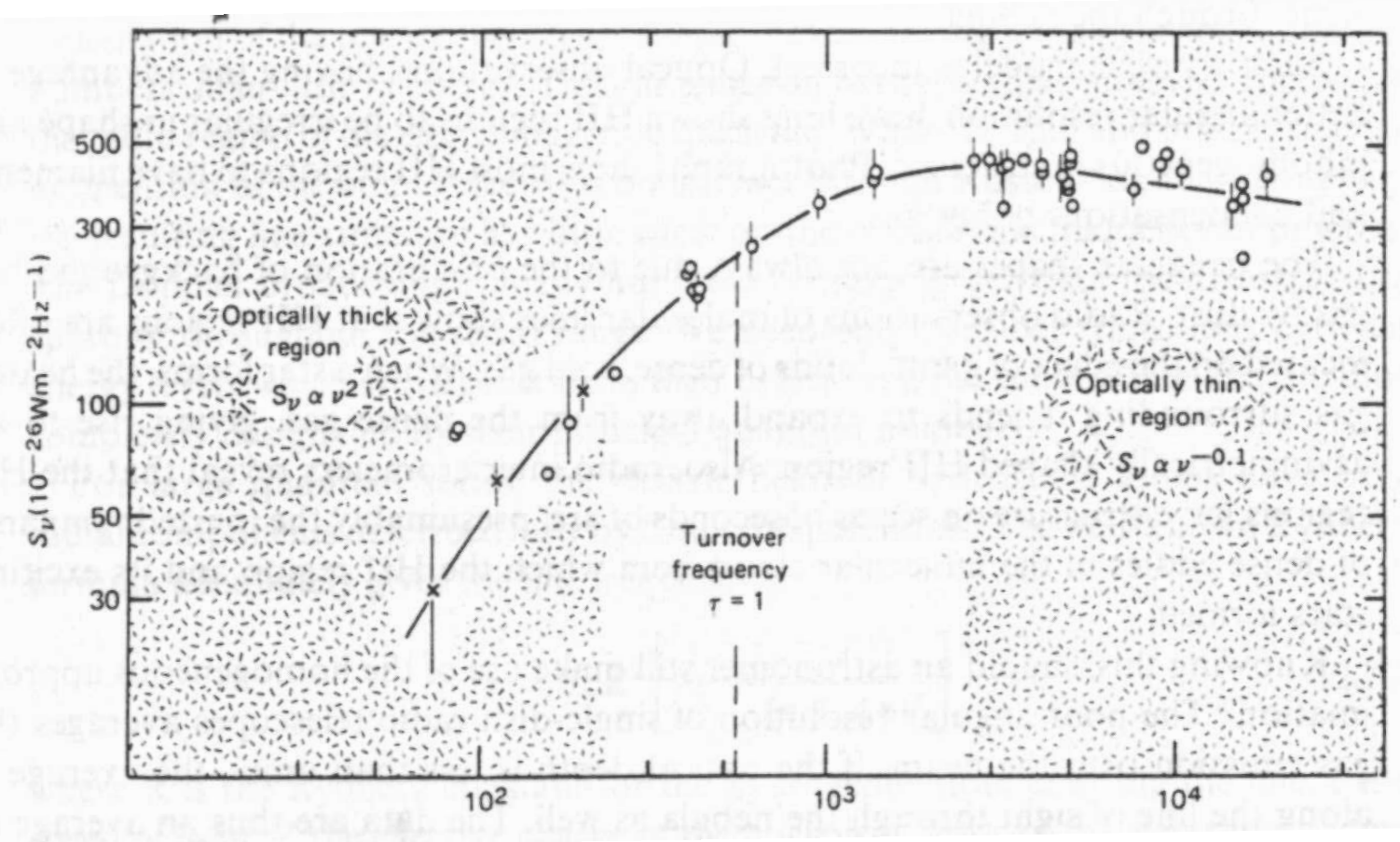

Figura 3.6: Comportamiento de la densidad de flujo con la frecuencia (en escala logarítmica) para la nebulosa de Orión (fuente térmica) (Terzian \& Parrish 1970).

Nuestro trabajo nos ha llevado analizar nebulosas con geometría anular, que puede obtenerse a partir de un modelo esférico con densidad uniforme de Mezger y Henderson (1967). Por este motivo veremos en más detalle nebulosas con esta geometría.

Reemplazamos las dimensiones lineales por ángulos aparentes a través de las relaciones

$$
\theta=\left(x^{2}+y^{2}\right)^{1 / 2} / d ; \quad \phi=r / d
$$

siendo $d$ la distancia a la región H II, la ecuación (3.26) toma la forma

$$
T_{b}=82.35 a\left(\nu, T_{e}\right)\left(\frac{\nu}{\mathrm{GHz}}\right)^{-2.1}\left(\frac{T_{e}}{\mathrm{~K}}\right)^{-0.35}\left(\frac{D}{\mathrm{Kpc}}\right) \int n^{2}(\theta, \phi) d \phi
$$

Evaluando la integral del segundo miembro,

$$
\begin{aligned}
n(\theta, \phi) & =n_{0} & & \text { para } \sqrt{\theta^{2}+\phi^{2}} \leq \frac{\theta_{\text {sph }}}{2} \\
& =0 & & \text { para el resto }
\end{aligned}
$$


obtenemos

$$
\int n^{2}(\theta, \phi) d \phi=n_{0}^{2} \theta_{s p h}\left(1-4 \theta^{2} / \theta^{2}{ }_{s p h}\right)=n_{0}^{2} \theta_{s p h} \psi_{s}(\theta)
$$

La función $\psi_{s}(\theta)$ es la distribución de temperatura de brillo normalizada, $\left(\psi_{\max }\right)=1$. Con la notación definida, podemos escribir para el ángulo sólido de la fuente

$$
\Omega_{f}=2 \pi \int_{0}^{\infty} d \theta \theta \psi(\theta)
$$

el cual, una vez calculado, nos da para nuestro modelo $\Omega_{f}=\frac{\pi}{6} \theta^{2}{ }_{s p h}=1.133 \theta_{G}{ }^{2}$, donde $\theta_{s p h}$ es el diámetro aparente de la fuente y $\theta_{G}$ el ancho a potencia mitad de una distribucion gaussiana que ajusta a la distribución de temperatura de brillo de la fuente. La relación entre ambas es $\theta_{s p h}=1.471 \theta_{G}$. Incluyendo los modelos en las ecuaciones que involucran las cantidades observables $S_{\nu}, T_{e}$ y $d$, se encuentran expresiones para la densidad electrónica promedio de una región H II

$$
\left(\frac{n_{e}}{\mathrm{~cm}^{-3}}\right)=u_{1} a^{1 / 2} 6.351 \times 10^{2}\left(\frac{T_{e}}{10^{4} \mathrm{k}}\right)^{0.175}\left(\frac{\nu}{\mathrm{GHz}}\right)^{0.05}\left(\frac{S_{\nu}}{\mathrm{Jy}}\right)^{0.5}\left(\frac{d}{\mathrm{Kpc}}\right)^{-0.5}\left(\frac{\theta_{G}}{\operatorname{arcmin}}\right)^{-1.5}
$$

y para la masa de hidrógeno ionizado

$$
\left(\frac{M_{H I I}}{\mathrm{M}_{\odot}}\right)=u_{2} a^{1 / 2} 0.3864\left(\frac{T_{e}}{10^{4} \mathrm{k}}\right)^{0.175}\left(\frac{\nu}{\mathrm{GHz}}\right)^{0.05}\left(\frac{S_{\nu}}{\mathrm{Jy}}\right)^{0.5}\left(\frac{d}{\mathrm{Kpc}}\right)^{2.5}\left(\frac{\theta_{G}}{\operatorname{arcmin}}\right)^{1.5}
$$

donde $u_{1} y u_{2}$ dependen en particular del modelo elegido para la distribución de densidad de la región H II. Los valores de $u_{1}$ y $u_{2}$ para los modelos a), b) y c) se listan en la Tabla 3.1 (Mezger \& Henderson 1967).

Tabla 3.1: Factores de conversión de los modelos para calcular la masa total y densidad electrónica

\begin{tabular}{llcc}
\hline & Distribución & $\begin{array}{c}u_{1} \\
(\text { densidad })\end{array}$ & $\begin{array}{c}u_{2} \\
(\text { masa })\end{array}$ \\
\hline (a) & Esférica & 0.775 & 1.291 \\
(b) & Cilíndrica & 0.857 & 1.167 \\
(c) & Gaussiana & 0.911 & 3.106 \\
\hline
\end{tabular}

En las nebulosas existen fluctuaciones en densidad que no son tenidas en cuenta por el modelo adoptado para calcular los parámetros. Los valores de $T_{b}$ medidos observacionalmente resultan más pequeños que los predichos por la ecuación (3.30), típicamente en un factor del orden de diez, cuando se considera $n_{e}$ obtenido a partir de cociente de líneas 
ópticas. Esta diferencia puede sólo ser entendida en términos de fluctuaciones en $n_{e} \mathrm{y}$ se debe a que su determinación en base, por ejemplo, a cocientes de líneas de [SII $] \lambda \lambda$ 6731, 6716 muestran las regiones de alta densidad de las nebulosas. Estas fluctuaciones deben ser tomadas en cuenta en la descripción de la estructura nebular. Podemos definir un factor de llenado si consideramos que la nebulosa presenta una geometría anular con radio interno $R_{\text {int }}$ y radio externo $R_{e x t}$, formada por pequeñas condensaciones o grumos entre ambos radios, con una densidad electrónica $n_{e}^{\prime}$. El factor de llenado $f$ es la fracción del volumen total ocupado por el plasma referido al volumen total en el que éste está distribuído. Puede ser expresado como:

$$
f=\frac{4 / 3 \pi\left(R_{\text {ext }}^{3}-R_{\text {int }}{ }^{3}\right)}{4 / 3 \pi R_{\text {ext }}{ }^{3}} a / 100
$$

con $a$ un factor que considera el porcentaje de ocupación del anillo por el plasma.

Las regiones no ocupadas por el plasma ionizado no generarán ninguna contribución a la emisión de la nebulosa. Al ser la densidad de flujo $S_{\nu}$ una propiedad integral, de su invarianza obtenemos que

$$
n_{e}^{\prime}=\frac{1}{\sqrt{f}} n_{e} \quad y \quad M_{\mathrm{HII}}^{\prime}=\sqrt{f} M_{\mathrm{HII}}
$$

donde $n_{e}^{\prime}$ y $M_{\mathrm{HII}}^{\prime}$ son las nuevas densidades electrónicas y masas del hidrógeno ionizado. Como se ve de las expresiones, la densidad $n_{e}$, calculada sin tener en cuenta las condensaciones, resulta una cota inferior (también llamada densidad electrónica rms) de la densidad electrónica real de la nebulosa, mientras que la masa $M_{\mathrm{HII}}$ resulta una cota superior para la masa total de gas real de la nube. Considerando al He ionizado una vez (HeII), y su abundancia de $\sim 10 \%$ por número de partículas, $M_{\mathrm{HII}}$ debe multiplicarse por 1.27 para obtener la masa ionizada total $\left(M_{i}{ }^{\prime}=1.27 \times M_{\mathrm{HII}}{ }^{\prime}\right)$. Se ha despreciado la contribución de otros elementos.

Buenos ejemplos de BI observadas en el continuo de radio son las mostradas en las Figuras 3.7 y 3.8 .

La Fig. 3.7 muestra la emisión en continuo de radio en $1465 \mathrm{MHz}$ asociada a WR 101 (indicada con una cruz), observada con el Very Large Array (VLA) (Cappa et al. 2002). Esta estructura presenta forma anular con un tamaño de $\sim 12^{\prime}$ de diámetro. El flujo a esta frecuencia es $3.1 \pm 0.3 \mathrm{Jy}$. A partir de una distancia de $3.2 \mathrm{kpc}$, los autores obtuvieron un tamaño lineal de $\sim 8 \mathrm{pc}$, una densidad electrónica $n_{e}=21 \mathrm{~cm}^{-3}$ y una masa ionizada $M_{\mathrm{HII}}=500 \mathrm{M}_{\odot}$. Por otro lado, la Fig. 3.8 muestra una serie de cuatro imágenes del continuo de radio asociadas a WR 130 (Cichowolski et al. 2001). En los cuatro casos se observa una distribución circular en torno a la estrella central. En el caso de la imagen en $8350 \mathrm{MHz}$, la distribución deja de tener el aspecto circular. La naturaleza de la radiación del gas es térmica, con un índice espectral promedio $\alpha=0.0 \pm 0.1$. 


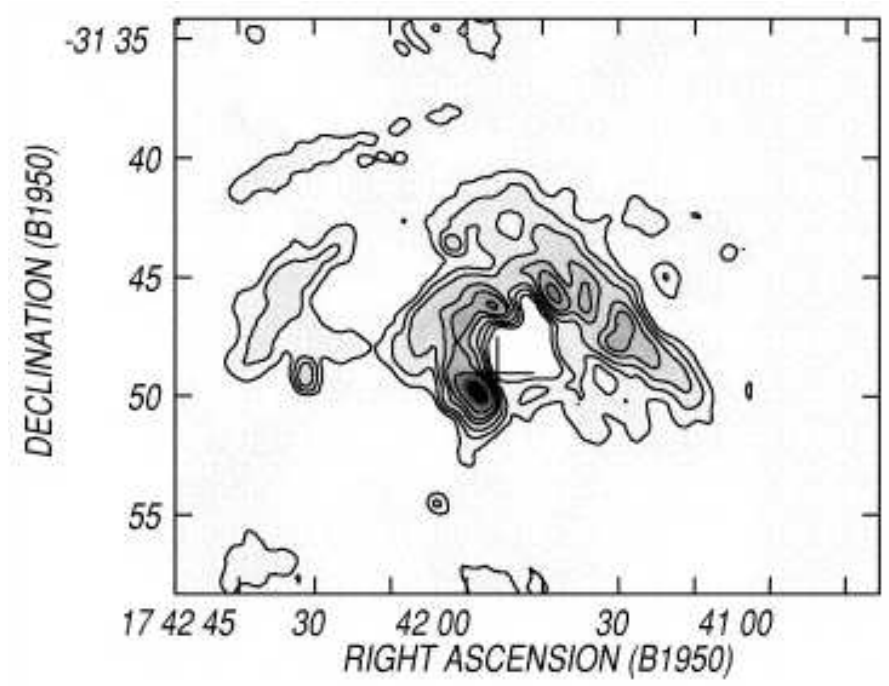

Figura 3.7: Distribución en continuo de radio en $1465 \mathrm{MHz}$ asociada a la estrella WR 101. La cruz indica la posición de la estrellas WR (Cappa et al. 2002).

\subsection{La línea de $21 \mathrm{~cm}$}

Las burbujas interestelares se identifican en la línea de 21 cm como cavidades o mínimos en la distribución de H I, rodeadas de envolturas o cáscaras en expansión.

En el panel superior de la Fig 3.9 se observa una burbuja interestelar en H I encerrando la posición de la estrella WR 23. La escala de intensidades está dada en términos de la densidad columnar promedio. La escala de grises va de $13.0 \times 10^{20}$ a $21.0 \times 10^{20} \mathrm{~cm}^{-2}$. La envoltura de la BI neutra está determinada por el alto gradiente en densidad columnar. Su morfología en circular y encierra la cavidad central, donde se observa la estrella WR. En el panel inferior de esta misma imagen vemos la superposición de la imagen de H I (contornos) y la distribución óptica observada en $\mathrm{H} \alpha$ (grisados). Se puede observar la correlación entre la envoltura de H y y los filamentos ópticos. La distribución de ambas fases del medio está indicando la acción de los vientos de la estrella WR 23.

El panel superior de la Fig 3.10 muestra el aspecto de la burbuja de H I asociada a la estrella WR 85 (Vasquez et al. 2005). Las zonas más intensas reflejan mayor intensidad de la emisión, y corresponden a la envoltura de H I. La posición de la estrella está indicada con una estrella de cinco puntas y se encuentra en la cavidad de la burbuja. Esta estructura se encuentra ubicada a una distancia de $2.8 \pm 1.1 \mathrm{kpc}$, con un radio lineal de $21 \pm 8$ pc y una velocidad de expansión de $9 \pm 2 \mathrm{~km} \mathrm{~s}^{-1}$. La masa en la burbuja de H I es de $530 \pm 400 \mathrm{M}_{\odot}$ y la edad dinámica de $\sim(1.1 \pm 0.5) \times 10^{6}$ años. En el panel inferior de la Fig 3.10 mostramos la superposición entre la magen de H I (contornos) y la nebulosa anillo óptica RCW 118, asociada a WR 85 (grisados). Notamos que el filamento óptico intenso se encuentra bordeado externamente por la envoltura neutra, situación acorde con los 


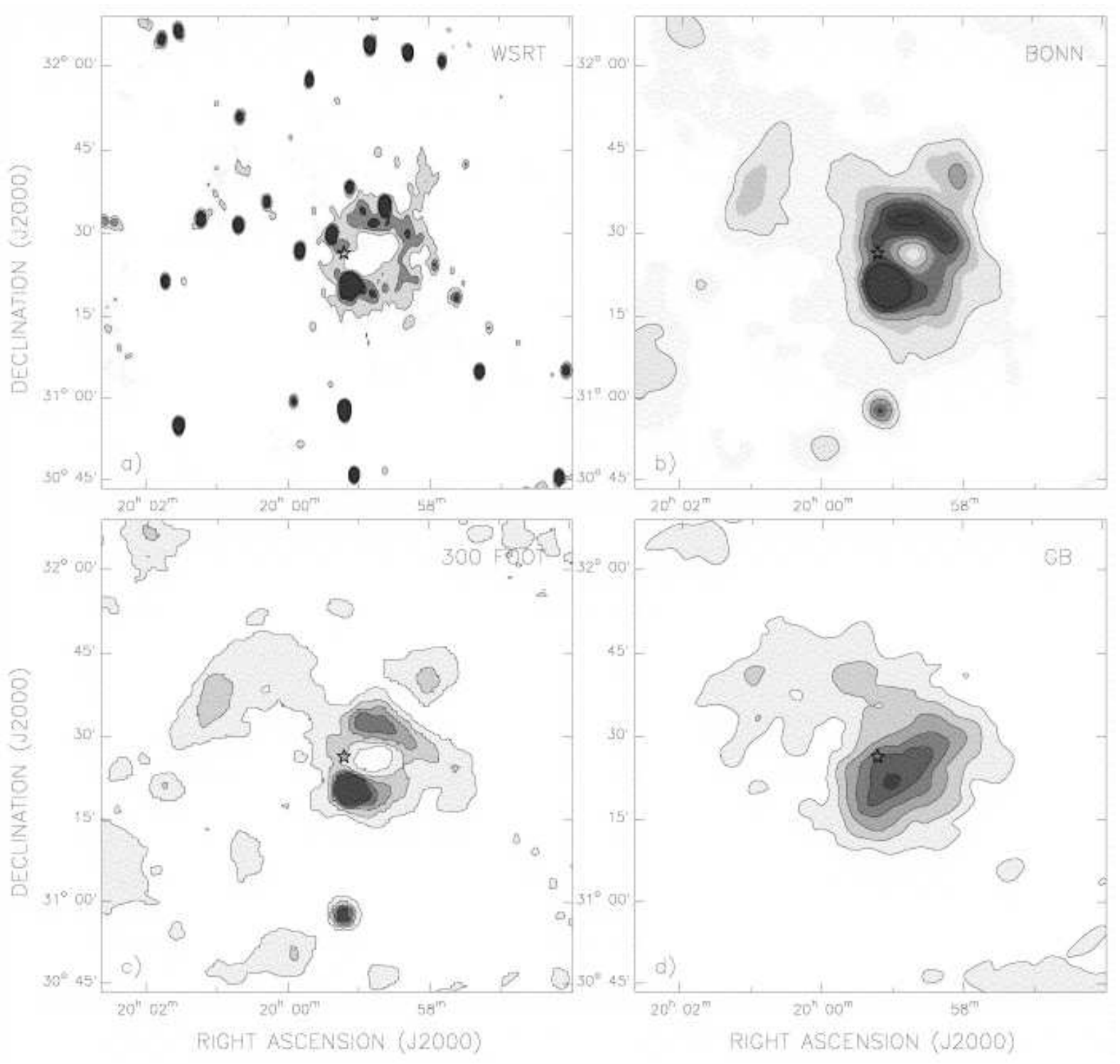

Figura 3.8: Imágenes en continuo de radio. (a) $327 \mathrm{MHz}$. (b) $2695 \mathrm{MHz}$. (c) $4850 \mathrm{MHz}$. (d) $8350 \mathrm{MHz}$ (Cichowolski et al. 2001). 

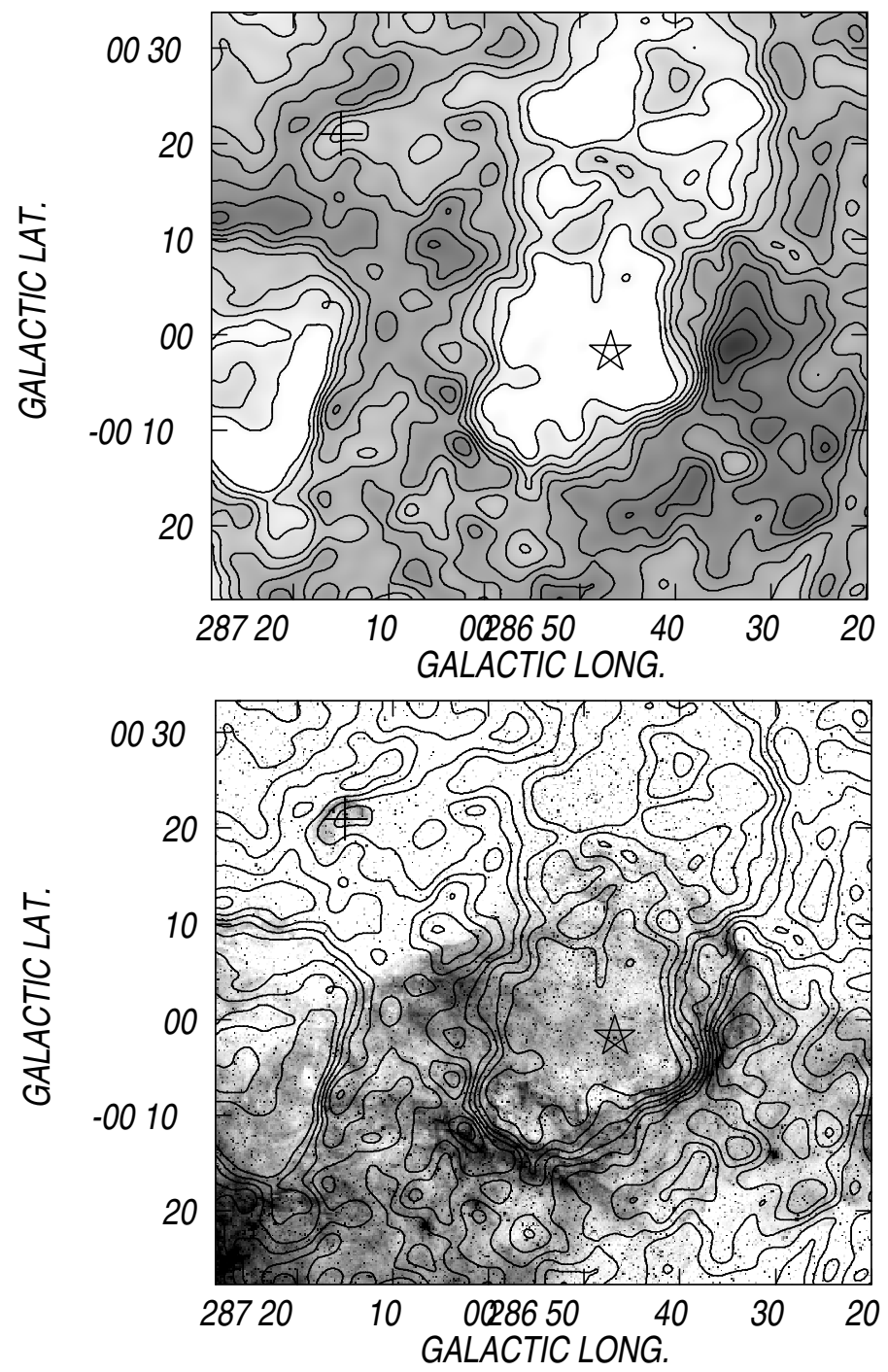

Figura 3.9: Panel superior: Distribución de H I asociado a la estrella WR 23. Panel inferior: Superposición entre la imagen en $\mathrm{H} \alpha$ (grisados) y el hidrógeno neutro (contornos) (Cappa et al. 2005). 
modelos de burbujas interestelares.

Teniendo las características antes mencionadas en cuenta, se analizan las imágenes de H i buscando mínimos y envolturas en la distribución del gas atómico.

Para identificar estructuras en las imágenes de H I se adoptó el siguiente criterio básico:

- Las cavidades y envolturas deben detectarse en un intervalo de velocidades $\Delta v>7$ $\mathrm{km} \mathrm{s}^{-1}$. Teniendo en cuenta que la velocidad de turbulencia en el MIE es $\sim 6.4$ $\mathrm{kms}^{-1}$ (Blitz et al. (1980), Fich et al. (1989)), este criterio nos asegura que las estructuras identificadas tengan sentido físico y no sean meras irregularidades al azar en el MIE.

- Los mínimos deben estar total o parcialmente rodeados por máximos de emisión.

Nosotros buscamos que las cáscaras de H I estén asociadas morfológica y físicamente con nebulosas anillo ópticas y particularemente con la o las estrellas que las generaron. Por este motivo, se adopta una serie de criterios para encontrar esa conexión:

- La estrella debe estar ubicada dentro de la cavidad o en el borde interior de la envoltura.

- El material ionizado o la nebulosa anillo óptica asociada (si está presente), debe estar proyectada sobre la cavidad de H I o sobre los bordes internos de la envoltura neutra.

- La distancia espectrofotométrica a la estrella debe ser compatible, dentro de los errores, con la distancia cinemática de la cavidad.

\subsubsection{Obtención de la densidad de columna y masa de $\mathrm{H}$ I}

La solución de la ecuación de transporte (expresión 3.13), en términos de la temperatura de brillo $T_{b}$ está dada por

$$
T_{b}=T_{s}\left(1-e^{-\tau}\right)
$$

siendo $T_{s}$ la temperatura de spin. A partir de esta expresión podemos decir que si la profundida óptica del H I es $\tau \gg 1$, la expresión (3.38) se puede aproximar como $T_{b}=T_{s}$. Si el medio es ópticamente delgado, (3.38) se puede aproximar como $T_{b} \simeq T_{s} \tau_{\nu}$.

El número total de átomos de hidrógeno en la dirección de la visual, por unidad de área transversal o densidad columnar $N_{\mathrm{HI}}$, se define como:

$$
N_{\mathrm{HI}}(l, b)=1.823 \times 10^{18} \int_{-\infty}^{\infty} T_{s}(v) \tau_{\nu} d v
$$



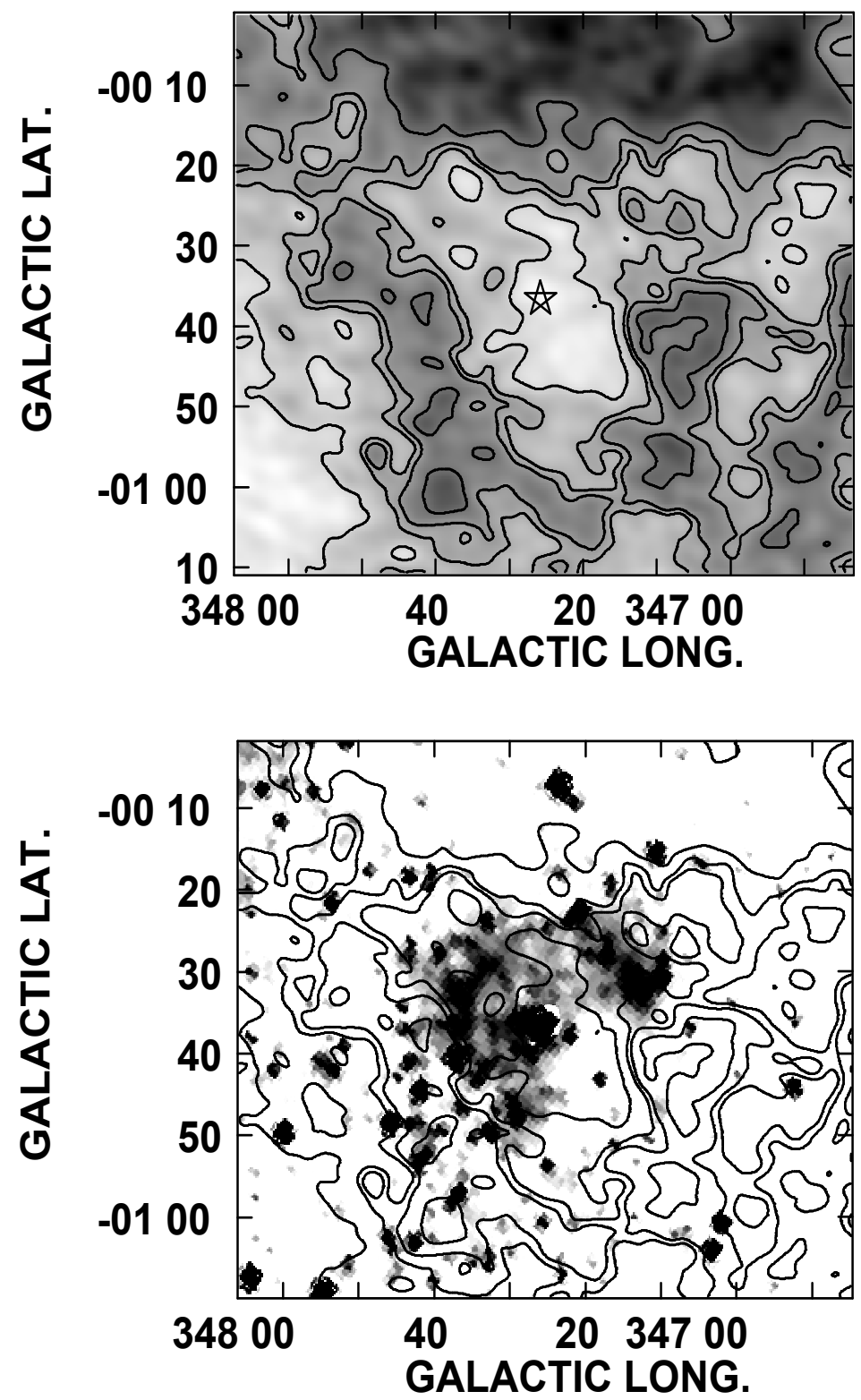

Figura 3.10: Panel superior: Distribución de H I asociado a la estrella WR 85 y a su nebulosa anillo RCW 118. Panel inferior: Superposición entre la imagen óptica de la nebulosa en grisados, con el hidrógeno neutro en contornos (Vasquez et al. 2005). 
donde $d v$ es el diferencial de velocidad radial y $N_{\mathrm{HI}}(l, b)$ está medido en unidades de partícula por $\mathrm{cm}^{-2}$. Esta expresión es válida si la profundidad óptica $\tau \ll 1$. Por lo mencionado anteriormente, podemos aproximar el integrando de la expresión (3.39) por $T_{b}$.

A menos que la suposición de $\tau \ll 1$ represente exactamente la realidad, debemos tener en claro que los resultados obtenidos observacionalmente de $N_{\mathrm{HI}}$ corresponden a límites inferiores de los valores reales de la densidad columnar, ya que sólo podemos observar la parte externa de la nube ópticamente gruesa, suponiendo lo contrario. Generalmente $\tau \simeq 1$ en regiones pequeñas particulares del plano galáctico.

Para el cálculo numérico de $N_{\mathrm{HI}}$ se reemplaza la integral por una sumatoria sobre las velocidades en las que se distingue la estructura. Esta sumatoria representa el área debajo del perfil de $\mathrm{H}$ I correspondiente a una dada posición $(l, b)$ o $(\alpha, \delta)$ dentro del intervalo de velocidades $v_{1}, v_{2}$, a una dada $l$ y $b$. Asumiendo una resolución en velocidad $\Delta v$ constante, entonces la densidad columnar correspondiente a una cierta estructura será,

$$
\frac{N_{\mathrm{HI}}(l, b)}{\mathrm{cm}^{-2}}=1.823 \times 10^{18} \Delta v \sum_{v_{r}=v 1}^{v 2} T_{b}(l, b)
$$

Para obtener la masa de $\mathrm{H}$ I de la estructura de interés $M_{\mathrm{HI}}$ recurrimos a

$$
M_{\mathrm{HI}}=m_{\mathrm{HI}} \widetilde{N_{H I}} A_{f}
$$

donde $m_{\mathrm{HI}}$ es la masa del átomo de hidrógeno, $\widetilde{N_{\mathrm{HI}}}$ la densidad columnar media y $A_{f}$ es el área proyectada de la fuente, siendo $\Omega_{f}=A_{f} / d^{2}$ el ángulo sólido subtendido por la fuente y $d$ su distancia.

Como en general nos vamos a encontrar con estructuras con una envoltura que encierra una cavidad central, nuestro interés estará en determinar los valores de las masas de ambas partes. Una característica importante es definir un valor límite de la densidad columnar (o, en forma equivalente, en temperatura de brillo) en el cual separar ambas partes. La densidad columnar media $\widetilde{\mathrm{N}_{\mathrm{HI}}}$ de la envoltura se obtiene como el valor promedio de $N_{\mathrm{HI}}(l, b)$ dentro del área de la envoltura, menos el nivel de emisión límite entre la envoltura y la cavidad de H I, $N_{\text {HI corte, }}$

$$
\widetilde{N_{\mathrm{HI}}}=\frac{\sum_{1}^{n_{p i x}} N_{\mathrm{HI}}(l, b)}{n_{\text {pix }}}-N_{\mathrm{HI} \text { corte }}
$$

donde $n_{\text {pix }}$ es el número de pixels que encierra la fuente. Para calcular el valor de la densidad columnar de la cavidad consideraremos el valor promedio debajo del valor de corte.

De esta manera, se obtiene la cantidad de masa en la envoltura $M_{e n v}$, y la masa faltante en la cavidad $M_{c a v}$. 


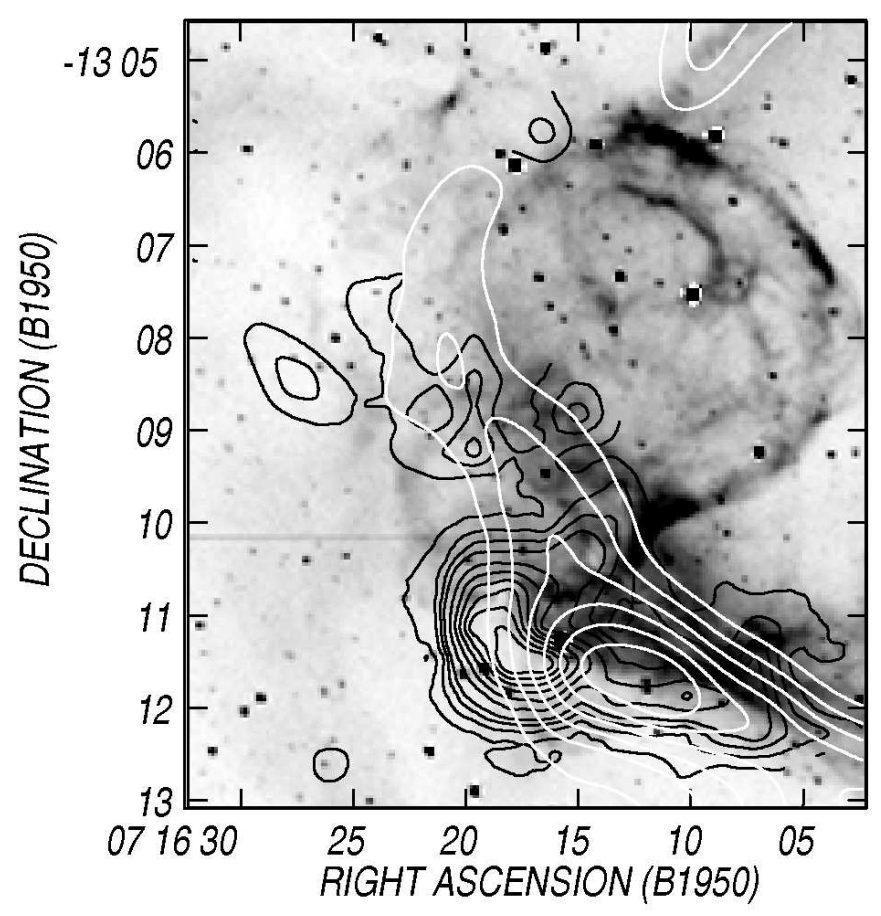

Figura 3.11: Distribución de material molecular (contornos negros) asociado a la estrella WR, superpuesto a la región H II NGC 2359 y a la imagen promedio de H i (contornos blancos).

\subsection{Observaciones moleculares: parámetros físicos}

Una imagen representativa de la distribución de hidrógeno molecular en torno a una nebulosa anillo óptica se muestra en la Fig. 3.11. Aquí se muestra una superposición de la nebulosa anillo óptica NGC 2359, en grisados y la emisión molecular de ${ }^{12} \mathrm{CO}(2-1)$ en $+54 \mathrm{~km} \mathrm{~s}^{-1}$, en contornos negros. Además se muestra la distribución de H i integrada entre $+51.4 \mathrm{y}+57.9 \mathrm{~km} \mathrm{~s}^{-1}$, en contornos blancos. Hacia $\alpha \sim 7^{h} 16^{\text {min }} 18^{\text {seg }}$ y $-13^{\circ} 11.5^{\prime}$, se ve que el máximo de ${ }^{12} \mathrm{CO}(2-1)$ bordea externamente al gas ionizado, de tal manera que se encuentra en convivencia con éste formando una PDR. La forma alargada del H I, con su máximo adyacente a la zona molecular más intensa, sugiere que el gas ionizado está interactuando con el hidrógeno neutro (Cappa et al. 2001). Adoptada una distancia de $5 \mathrm{kpc}$, esta estructura molecular tiene una masa de $1200 \pm 500 \mathrm{M}_{\odot}$.

En las siguientes secciones se verá cómo en base a observaciones de transiciones rotacionales del nivel vibracional inferior de una especie molecular determinada, se pueden derivar los parámetros físicos que caracterizan a una nube molecular dada.

En particular, se verá que se puede inferir la temperatura cinética, la densidad de columna de la molécula y la masa de la nube en la que se encuentra inmersa, a partir de 
la observación de transiciones rotacionales de diferentes isótopos de CO.

\subsubsection{Temperatura de excitación}

Nuevamente, vamos a utilizar la ecuación de transporte dada en la expresión (3.13), aplicada en este caso a una nube molecular que emite radiación generada por la transición rotacional $J=1 \rightarrow 0$. Si la integramos desde la región de emisión hasta el detector, asumiendo que los coeficientes de emisión $j_{\nu}$ y de absorción $\kappa_{\nu}$ son constantes, se llega a que la intensidad específica recibida está dada por:

$$
I_{\nu}\left(l_{0}\right)=I_{\nu}(0) e^{-\tau_{\nu}\left(l_{0}\right)}+\frac{j_{\nu}}{\kappa_{\nu}}\left(1-e^{-\tau_{\nu}\left(l_{0}\right)}\right)
$$

donde $l_{0}$ es una distancia medida desde la nube molecular en dirección de la visual. Sustrayendo $I_{\nu}(0)$ de la ecuación anterior, que representa la emisión de continuo, y definiendo $\Delta I_{\nu}=I_{\nu}\left(l_{0}\right)-I_{\nu}(0)$, la expresión anterior queda

$$
\Delta I_{\nu}=\left(\frac{j_{\nu}}{k_{\nu}}-I_{\nu}(0)\right)\left(1-e^{-\tau_{\nu}\left(l_{0}\right)}\right)
$$

Suponiendo que la intensidad incidente sobre la nube molecular y la recibida por el instrumento corresponden a dos cuerpos negros con $T_{\text {rad }}$ y $T_{b}$, respectivamente, entonces $I_{\nu}(0)$ y $\Delta I_{\nu}(0)$ pueden escribirse como:

$$
\begin{gathered}
I_{\nu}(0)=B_{\nu}\left(T_{r a d}\right)=\frac{2 h \nu^{3}}{c^{2}} \frac{1}{e^{\frac{T^{*}}{T_{r a d}}}-1} \\
\Delta I_{\nu}(0)=B_{\nu}\left(T_{b}\right)=\frac{2 h \nu^{3}}{c^{2}} \frac{1}{e^{\frac{T^{*}}{T_{b}}}-1}
\end{gathered}
$$

siendo $T^{*}=h \nu / k$. Si no hay ninguna fuente de radiación próxima a la concentración molecular, la única presente será la de fondo cósmico cuyo valor es de $T_{\text {rad }}=2.7 \mathrm{~K}$. Finalmente, reemplazando las ecuaciones (3.45) y (3.46) en (3.44), se obtiene

$$
B_{\nu}\left(T_{b}\right)=\left[B_{\nu}\left(T_{e x c}\right)-B_{\nu}\left(T_{r a d}\right)\right]\left(1-e^{-\tau_{\nu}\left(l_{0}\right)}\right)
$$

recordando que $B_{\nu}\left(T_{\text {exc }}\right)=\frac{j_{\nu}}{k_{\nu}}$ es la función fuente y $T_{\text {exc }}$ es la temperatura de excitación, definida como aquella que domina las transiciones entre niveles energéticos.

A partir de esta expresión, se obtiene:

$$
T_{b}(\nu)=T^{*}\left(\frac{1}{e^{\frac{T^{*}}{T_{e x c}}}-1}-\frac{1}{e^{\frac{T^{*}}{T_{\text {rad }}}}-1}\right)\left(1-e^{-\tau_{\nu}\left(l_{0}\right)}\right)
$$


Si la línea es ópticamente gruesa $\left(\tau_{\nu}\left(l_{0}\right) \gg 1\right)$ la ecuación (3.48) se reduce a

$$
T_{b}(\nu)=T^{*}\left(\frac{1}{e^{\frac{T^{*}}{T_{e x c}}}-1}-\frac{1}{e^{\frac{T^{*}}{T_{\text {rad }}}}-1}\right)
$$

A partir de la ecuación (3.49), conociendo $T_{b}(\nu)$ y $T_{\text {rad }}$, se obtiene la temperatura de excitación.

Como ejemplo, consideremos un medio en el que la distribución de velocidades de la especie molecular $H_{2}$ se encuentra caracterizada por una temperatura cinética $T_{\text {cin }} \sim 10$ $\mathrm{K}$ y donde el único campo de radiación presente es el correspondiente a los $2.7 \mathrm{~K}$. En el caso en que las colisiones predominen, $T_{\text {exc }}=T_{\text {cin }} \sim 10 \mathrm{~K}$ y $T_{b} \sim 6.7 \mathrm{~K}$. En cambio, si predominan los procesos radiativos, $T_{\text {exc }}=T_{\text {rad }} \sim 2.7 \mathrm{~K}$ y de la ecuación (3.48) se deriva que la línea será muy débil para ser observada. Entonces, cuanto mayor sea $T_{e x c}$, más fácilmente podrá ser detectada la emisión molecular.

Con el ejemplo anterior se mostró que $T_{\text {exc }}$ se incrementa con el predominio de los procesos colisionales frente a los radiativos. Como dominan los procesos colisionales en el caso del ${ }^{12} \mathrm{CO}, T_{\text {exc }}=T_{\text {cin }}$.

En conclusión, la observación de una línea intensa y ópticamente gruesa, permite inferir un parámetro físico característico de la nube, su temperatura cinética $\left(T_{\text {cin }}\right)$.

\subsubsection{Cálculo de la densidad de columna}

Si queremos calcular la densidad de columna $N_{i}$ en base a una serie de líneas pertenecientes a un mismo elemento, debemos tener en cuenta todas las transiciones entre niveles energéticos. Podemos asumir que la densidad de columna de un nivel energético $n_{i}$ está dado por

$$
N_{i}=\int n_{i} d l
$$

Si la relación de poblaciones entre distintos niveles de energía obedece la distribución de Boltzmann, entonces

$$
\frac{n_{i}}{n_{j}}=\frac{g_{i}}{g_{j}} e^{-\frac{h \nu}{k T_{e x c}}}
$$

donde $g_{i}$ y $g_{j}$ son los pesos estadísticos.

Reemplazando (3.51) en (3.50) y suponiendo que $T_{\text {exc }}$ es constante:

$$
N_{i}=N_{j} \frac{g_{i}}{g_{j}} e^{-\frac{h \nu}{k T e x c}}
$$


Si queremos derivar la densidad de columna de la molécula incluyendo todos los niveles y todas las especies isotópicas, $N_{\text {total }}$, la misma está relacionada con $N_{i}$, a través de la función de partición, Q

$$
\frac{N_{i}}{N_{\text {total }}}=\frac{g_{i}}{Q}\left(1-e^{-\frac{h \nu}{k T e x c}}\right)
$$

$\operatorname{dados} \tau_{\nu}$ y $T_{\text {exc }}$.

Para obtener $\tau$ y $T_{\text {exc }}$ deberíamos contar al menos con observaciones correspondientes a la transición rotacional $J=1-0$, proveniente de dos especies isotópicas del monóxido de carbono, ${ }^{12} \mathrm{CO} \mathrm{y}{ }^{13} \mathrm{CO}$. Particularmente, como se verá en los capítulos siguientes, nosotros contamos con observaciones en ${ }^{12} \mathrm{CO}$ en dirección a las nebulosas anillo SG 13 y Sh2-132. En el caso del estudio de la nebulosa Anon(WR 113) (ver Capítulo 6) contamos además con una observacion de ${ }^{13} \mathrm{CO}(2-1)$ y (1-0) en dirección a WR 113. Por este motivo es que daremos una introducción teórica acerca de cómo obtener diferentes parámetros de las nubes moleculares con observaciones de una o dos especies isotópicas, donde una es ópticamente gruesa $\left({ }^{12} \mathrm{CO}\right)$ y la otra, ópticamente delgada $\left({ }^{13} \mathrm{CO}\right)$.

\section{Líneas de ${ }^{12} \mathrm{CO}$ y ${ }^{13} \mathrm{CO}$ : determinación de la profundidad óptica y la densidad columnar}

La transición $J=1-0$ del ${ }^{12} \mathrm{CO}$ genera una línea de emisión cuya frecuencia en reposo, $\nu_{12}$, es $115.271 \mathrm{GHz}$, mientras que la correspondiente al ${ }^{13} \mathrm{CO}$ origina una línea con una $\nu_{13}$ de $110.201 \mathrm{GHz}$.

Usando los criterios de Dickman (1978), obtendremos $T_{e x c}^{12}, \tau_{\nu}^{13}$ y $N_{\text {CO }}^{13}$ que son la temperatura de excitación del ${ }^{12} \mathrm{CO}$, la profundidad óptica y la densidad de columna del ${ }^{13} \mathrm{CO}$, respectivamente. Una vez obtenidas estas cantidades veremos cómo se calcula $N_{\text {total }}(\mathrm{CO})$. Los criterios utilizados se indican a continuación:

- Las distintas especies isotópicas tienen la misma temperatura de excitación, la que a su vez coincide con la temperatura cinética del gas $\left(T_{e x c}^{12} \equiv T_{\text {exc }}^{13} \equiv T_{\text {cin }}\right)$.

- La temperatura de excitación de la transición $J=1 \rightarrow 0$ de las moléculas no presenta un gradiente a lo largo de la línea de la visual.

- El ${ }^{12} \mathrm{CO}$ es ópticamente grueso.

En base a las suposiciones mencionadas, del perfil de emisión de la especie ópticamente gruesa de ${ }^{12} \mathrm{CO}$ puede derivarse la temperatura de excitación (ecuación (3.49)), obteniéndose: 


$$
T_{e x c}=\frac{5.532}{\ln \left(1+\frac{5.532}{T_{b}^{12}+0.818}\right)} \quad \mathrm{K}
$$

Una vez conocida la $T_{\text {exc }}$, usando la ecuación (3.48) se puede despejar la profundidad óptica correspondiente a la parte central de la línea del ${ }^{13} \mathrm{CO}, \tau_{0}^{13}$, resultando:

$$
\tau_{0}^{13}=-\ln \left[1-\frac{T_{L}^{13}[\mathrm{~K}]}{5.289\left(\frac{1}{e^{\frac{5.289}{k T e x c}}-1}-0.164\right)}\right]
$$

Por otro lado, la profundidad óptica de la línea del isótopo ${ }^{13} \mathrm{CO}$ será:

$$
\int_{\nu} \tau_{\nu}^{13} d \nu
$$

que puede aproximarse por:

$$
\tau_{0}^{13} \Delta V_{13} \nu_{13} c^{-1}
$$

donde $\Delta V_{13}$, es el ancho a potencia mitad, en unidades de velocidad, de la línea emitida por el ${ }^{13} \mathrm{CO}$ y $\tau_{0}^{13}$ es la profundidad óptica en el centro de dicha línea. Luego, podemos relacionar la profundidad óptica y la densidad columnar, ya que la ecuación (3.57) puede escribirse como:

$$
\tau_{0}^{13} \Delta V_{13} \nu_{13} c^{-1}=\frac{c^{2} A_{s i}}{8 \pi \nu_{13}^{2}} \frac{g_{s}}{g_{i}}\left(1-e^{-\frac{T_{0}^{13}}{T_{e x c}}}\right) \frac{N_{\mathrm{CO}}^{13}}{Q}
$$

con

$$
T_{0}^{13}=\frac{h \nu_{13}}{k}
$$

donde Q es la función de partición de la molécula de ${ }^{13} \mathrm{CO}$ cuya expresión es

$$
Q=1+\sum_{L=1}^{\infty}(2 L+1) \quad \prod_{J=0}^{L} e^{-\frac{h \nu(J)}{k T_{e x c}(J)}}
$$

siendo $\nu(J)$ y $T_{\text {exc }}(J)$ la frecuencia y la temperatura de excitación de la transición $\mathrm{J} \rightarrow$ J-1. Por simplicidad se supone que $T_{\text {exc }}(J)=T_{\text {exc }}$ y se evalúa como si fuese una integral (Penzias et al. 1971), lo que termina reduciendo la ecuación (3.60) a:

$$
Q=2 \frac{T_{e x c}^{13}}{k T_{0}^{13}}
$$


Si reemplazamos la ecuación (3.61) y las constantes numéricas inherentes a la transición que se observa $\left(g_{s}, g_{i}, A_{s i}, \nu_{13}\right)$ en $(3.58)$, podremos obtener $N_{\mathrm{CO}}^{13}$ como

$$
N_{\mathrm{CO}}^{13}\left[\mathrm{~cm}^{-2}\right]=\frac{2.42 \times 10^{14} \mathrm{~T}_{\text {exc }}[\mathrm{K}] \tau_{0}^{13} \Delta \mathrm{V}_{13}\left[\mathrm{Kms}^{-1}\right]}{\left(1-\mathrm{e}^{\frac{-5.289}{\operatorname{Texc}_{\mathrm{K}}}}\right)}
$$

Una vez encontrada la densidad de columna de esta especie isotópica, la misma se relacionará con la densidad de columna del resto de los isótopos del $\mathrm{CO}$, es decir que la densidad de columna de una especie química dada es la suma de las contribuciones de cada especie isotópica que la conforman,

$$
\begin{array}{r}
N_{\text {total }}(\mathrm{CO})=\mathrm{N}(\mathrm{CO})+\mathrm{N}\left({ }^{13} \mathrm{CO}\right)+ \\
N\left(\mathrm{C}^{18} \mathrm{O}\right)+\mathrm{N}\left({ }^{13} \mathrm{C}^{18} \mathrm{O}\right)+\ldots
\end{array}
$$

Si a modo de ejemplo suponemos que las densidades de columna de las distintas especies isotópicas guardan relación con las abundancias isotópicas de los átomos constituyentes, del monóxido de carbono, que se hallan presentes en la Tierra, tendremos:

$$
\begin{gathered}
\frac{N(\mathrm{CO})}{N\left({ }^{13} \mathrm{CO}\right)}=\frac{N(\mathrm{C})}{N\left({ }^{13} \mathrm{C}\right)} \sim 81 \\
\frac{N(\mathrm{CO})}{N\left(\mathrm{C}^{18} \mathrm{O}\right)} \sim \frac{N(\mathrm{C}) \mathrm{N}(\mathrm{O})}{N(\mathrm{C}) \mathrm{N}\left({ }^{18} \mathrm{O}\right)} \sim 500 \\
\frac{N(\mathrm{CO})}{N\left({ }^{13} \mathrm{C}^{18} \mathrm{O}\right)}=\frac{N(\mathrm{C}) \mathrm{N}(\mathrm{O})}{N\left({ }^{13} \mathrm{C}\right) \mathrm{N}\left({ }^{18} \mathrm{O}\right)} \sim 81 \times 500
\end{gathered}
$$

usando las ecuaciones (3.64), (3.65) y (3.66), se reemplazan las abundancias de $N\left({ }^{13} \mathrm{CO}\right)$ y $N\left({ }^{13} \mathrm{C}^{18} \mathrm{O}\right)$ en función de $N(\mathrm{CO})$ en la ecuación (3.63), resultando

$$
\begin{gathered}
N_{\text {total }}(\mathrm{CO})=\mathrm{N}(\mathrm{CO})+1.23 \times 10^{-2} \mathrm{~N}(\mathrm{CO})+ \\
2 \times 10^{-3} \mathrm{~N}(\mathrm{CO})+2.5 \times 10^{-5} \mathrm{~N}(\mathrm{CO})+\ldots
\end{gathered}
$$

La ecuación (3.67) permite ver que la densidad de columna total a partir de las observaciones puede reducirse a la contribución de los dos primeros términos. Como contamos con el valor $N\left({ }^{13} \mathrm{CO}\right)$, el valor estimado de $N_{\text {total }}(\mathrm{CO})$ será:

$$
N_{\text {total }}(\mathrm{CO}) \sim 81 \times \mathrm{N}\left({ }^{13} \mathrm{CO}\right)+\mathrm{N}\left({ }^{13} \mathrm{CO}\right)
$$

Como la molécula más abundante por masa y número es $\mathrm{H}_{2}$, necesitamos derivar la densidad de columna del $\mathrm{H}_{2}$ a partir de $N_{\text {total }}(\mathrm{CO})$. Para ello, se utiliza la denominada abundancia fraccional del CO $\left(A(\mathrm{CO})=\mathrm{N}_{\text {total }}(\mathrm{CO}) / \mathrm{N}_{\text {total }}\left(\mathrm{H}_{2}\right)\right)($ Lang 1978).

Teniendo en cuenta la definición de abundancia fraccional:

$$
N_{\text {total }}\left(H_{2}\right)=\frac{N_{\text {total }}(\mathrm{CO})}{A(\mathrm{CO})}
$$

De esta forma se obtiene finalmente, $N_{\text {total }}\left(\mathrm{H}_{2}\right)$. 


\section{Líneas de ${ }^{12} \mathrm{CO}$ : determinación de la densidad columnar}

Por otro lado, si contamos sólo con observaciones de ${ }^{12} \mathrm{CO}(1-0)$, que es un isótopo ópticamente grueso, el método anterior no puede ser aplicado ya que no podemos obtener la profundidad óptica $\tau$.

El estudio de la interacción entre los rayos cósmicos (mayormente protones relativistas) con elementos constituyentes nos puede brindar información acerca de ciertos parámetros de una nube molecular. Se sabe que uno de los principales mecanismos de calentamiento es la interacción de los rayos cósmicos con el $\mathrm{H}$ I y el $\mathrm{H}_{2}$, a través de interacciones protónprotón $(p-p)$,

$$
p+p \longrightarrow p+p+a \pi^{0}+b\left(\pi^{+}+\pi^{-}\right)
$$

Esta interacción es más intensa dependiendo de la densidad local de rayos cósmicos y de la densidad ambiental del la nube.

Los piones neutros $\pi^{0}$ son partículas muy inestables, y decaen emitiendo radiación gamma en un amplio rango de energías que van desde $10^{0}$ a $10^{8} \mathrm{MeV}$.

Este tipo de reacciones puede ser utilizado para determinar el cociente entre la densidad de columna del hidrógeno molecular y el ancho equivalente de la emisión de CO $\left(W_{\mathrm{CO}}\right)$, es decir,

$$
X=\frac{N_{\mathrm{H}_{2}}}{W_{\mathrm{CO}}}
$$

donde $X$ depende del sector de la galaxia en el que se encuentra la nube molecular.

\subsubsection{Cálculo de la masa y de la densidad media de una nube molecular}

Conociendo el valor de la densidad de columna $N_{\mathrm{H}_{2}}$ y la distancia $d$ a la nube, podemos obtener la masa molecular

$$
M_{\mathrm{H}_{2}}=m_{\mathrm{H}_{2}} N_{\mathrm{H}_{2}} A_{f}
$$

con $m_{\mathrm{H}_{2}}$ la masa de una molécula de $\mathrm{H}_{2}, \mathrm{~N}_{H_{2}}$ la densidad columnar de hidrógeno molecular y $A_{f}$ el área de la fuente. Recordemos que $\Omega_{f}=A_{f} / d^{2}$ es el ángulo sólido subtendido por la fuente.

Cabe preguntarse si el área de emisión de la línea es representativa de la extensión lineal de la nube. Esto depende de la densidad crítica. Si suponemos que la distribución espacial de las especies es homogénea, transiciones moleculares con menor densidad crítica mostrarán emisión dentro de un área mayor del complejo molecular. Por ende, el ángulo 
sólido que subtiende la fuente será un mejor indicador de la extensión espacial total de la concentración molecular.

\subsection{Distancia cinemática}

Uno de los principales problemas en la radioastronomía es la determinación de la distancia. En general, se utilizan los datos obtenidos de la medición de velocidades radiales de las fuentes, obtenidas de medidas espectoscópicas con las que, a través de modelos, se pueden obtener distancias a esas fuentes. Luego utilizamos modelos de rotación de la galaxia, como por ejemplo, el modelo de rotación circular de la galaxia (MRCG) propuesto por Brand \& Blitz (1993) que basa su determinación en mediciones de posiciones de regiones HiI, nebulosas de reflexión y nubes moleculares distribuidas sobre el plano galáctico. De esta forma obtenemos una distancia llamada distancia cinemática $d_{c i n}$.

Esta distancia tiene un importante factor de dispersión, debido a tres contribuciones:

- Error en la determinación de las velocidades radiales.

- Error en la determinación de la velocidad sistémica.

- Factor de incerteza en el MRCG generado por movimientos aleatorios y sistemáticos.

La determinación de la distancia a una estructura interestelar, observada en diferentes rangos de espectro electromagnético, asociada a estrellas o a cúmulos estelares, surge de considerar tanto la $d_{c i n}$ de la estructura interestelar, como las distancias espectrofotométricas de las componentes estelares. 


\section{Bibliografía}

Allamandola L.J., Tielens A.G.G.M., Barker J.R., 1985, ApJ, 290, 25

Allamandola L.J., Tielens A.G.G.M., Barker J.R., 1989, ApJS, 71, 733

Altenhoff W., Mezger, P.G. Wender H., Westerhout G. 1960, Veröff. Sternwarte, Bonn, No. 59, 48

Brand J., Blitz L., 1993, A\&A, 275, 67

Cappa,C., Niemela V.S., Martín M.C., McClure-Griffiths N.M., 2005, A\&A, 436, 155

Cappa C.E., Arnal E.M., Cichowolski S., Goss W.M., Pineault S., 2003, Massive star odyssey from main sequence to supernova, simposio $\mathrm{N}^{\circ} 212$, IAU

Cappa C.E., Goss W.M., Niemela V.S., Ostrov P.G., 1999, AJ, 118, 948

Chan G., Fich M., 1995, AJ, 109, 2611

Chu Y.-H., 2002, astro-ph/0310311

Chu Y.-H., 1991, "Wolf-Rayet stars and interacctions with other massive stars in galaxies", simposio N 143, IAU, 349

Chu Y.-H., 1982a, ApJ, 254, 578

Chu Y.-H., 1982b, ApJ, 255, 79

Chu Y.-H., 1982c, ApJ, 269, 202

Chu Y.-H., Gull T.R., Treffers R.R., Kwitter K.B., Troland T.H., 1982, ApJ, 254, 562

Chu Y.-H., 1981, ApJ, 249, 195

Chu Y.-H., Treffers R.R., 1981a, ApJ, 249, 586

Chu Y.-H., Treffers R.R., 1981b, ApJ, 250, 615

Churchwell E., Povich M.S., Allen D., Taylor M.G., Meade M.R., Babler B.L., Indebetouw R., Watson C., Whitney B.A., Wolfire M.G., Bania T.M., Benjamin R.A., Clemens D.P., Cohen M., Cyganowski C.J., Jackson J.M., Kobulnicky H.A., Mathis J.S., Mercer E.P., Stolovy S.R., Uzpen B., Watson D.F., Wolff M.J., 2006, ApJ, 649, 759

Cichowolski S., Pineault S., Arnal E.M., Testori J.C., Goss W.M., Cappa C.E., 2001, AJ, 122, 1938

Dickman R.L., 1978, ApJSS, 37, 407

Esteban C., Vilchez J.M., Manchado A., Edmunds M.G., 1990, A\&A, 227, 515

Evans I.N., Dopita M.A., 1985, ApJS, 58, 125

García-Segura G., Mac Low M.-M., Langer N., 1996a, A\&A, 305, 229

García-Segura G., Langer N., Mac Low M.-M., 1996b, A\&A, 316, 133

Hildebrandt, R.H., 1983, Quarterly Journal of the RAS, 24, 267 
Johnson F.S., Hogg D.E., 1965, ApJ, 142, 1033

Lang K.R., 1978, Astrophysical Formulae, 3rd. Eds, eds. Springer-Verlag Berlin Heidelberg

Léger A., Puget J.L., 1984, A\&A, 137, 5

Leung C.M. 1975, ApJ, 199, 340

Marston A.P., ApJ, 366, 181

Mathis J.S., 1985, ApJ, 291, 247

Mathis J.S., 1983, ApJ, 267, 119

Mathis J.S., 1982, ApJ, 261, 195

Mezger P.G, Henderson A.P. 1967, ApJ, 147, 471

Oster L. 1961, Rev. Mod. Phys., 33, 525

Osterbrock D.E., 1965, ApJ, 142, 1423

Puget J.L., Léger A., 1989, ARA\&A, 27, 161

Smith L.J., Clegg R.E.S., 1990, ASPC, 7, 132

Stahler S.W., Palla F., 2004, The formation of stars, WILEY-VCH, 185

Strömgren, B. 1948, ApJ, 108, 242

Terzian Y., Parrish A., 1970, A\&AL, 5, 261

Tielens A.G.G.M., Peeters E., Bakes E.L.O., Spoon H.W.W., Hony S., 2004, Star formation in the interstellar medium, ASP, 323, 135

Tielens A.G.G.N., Hollenbach D., 1985, ApJ, 291, 722

Treffers R.R., Chu Y.-H., 1982, ApJ, 254, 132

Treffers R.R., Chu Y.-H., 1982, ApJ, 254, 569

van de Hulst H.C. 1946, Rech. Astron. Obs. Utretch, 11, 1

van der Hucht K.A., 2001, New Astronomy Rev., 45, 135

Vasquez J., Cappa C.E., McClure-Griffiths N., 2005, MNRAS, 362, 681

Whittet D.C.B., "Dust in the galactic enviroment", 1992, p.214 


\section{Capítulo 4}

\section{El entorno de la nebulosa SG 13}

\section{Resumen}

Hemos investigado la morfología y cinemática del medio interestelar en los alrededores del cúmulo abierto Markarian 50 (Ma 50), que incluye a la estrella WR 157 y a un gran número de estrellas con tipo espectral $\mathrm{B}$. El análisis fue realizado a través de observaciones en la línea de $21 \mathrm{~cm}$ del $\mathrm{H}$ I tomadas del Canadian Galactic Plane Survey, observaciones moleculares de ${ }^{12} \mathrm{CO}(J=1 \rightarrow 0)$ en $115 \mathrm{GHz}$ del Five College Radio Astronomy Observatory y observaciones infrarrojas obtenidas con los satélites IRAS y MSX.

Hemos encontrado correlaciones entre la emisión en el continuo de radio, el infrarrojo y ${ }^{12} \mathrm{CO}$ observándose una estructura de cáscara alrededor de Ma 50. Esta morfología sugiere que la acción de los fuertes vientos de la estrella WR y el resto de las estrellas tempranas han modelado su entorno. Por otro lado se ha encontrado una estructura en $8 \mu \mathrm{m}, \mathrm{H}$ I y ${ }^{12} \mathrm{CO}$ que podría estar asociada con la acción de los vientos de las estrellas tempranas.

\subsection{WR 157 y la nebulosa óptica SG 13}

La región H II Sh2-157 (Sharpless 1959) consiste en dos diferentes regiones identificadas como SG 14 y SG 13 (= Simeiz 274). SG 13 está asociada con el cúmulo abierto Ma 50 (Turner et al. 1983, Lundströn \& Stenholm 1984, Smith \& Willis 1994) ubicado en $(l, b)$ $=\left(111^{\circ} 21^{\prime},-0^{\circ} 12^{\prime}\right), \mathrm{RA}, \operatorname{Dec}(\mathrm{J} 2000)=\left(23^{h} 12^{m},+60^{\circ} 29^{\prime}\right)$. El miembro más brillante de este cúmulo es la estrella WR 157 (= HD 219460, WN 5+B1 II, van der Hucht 2001).

La Fig. 4.1 muestra la parte superior de Sh 2-157. La cruz indica la posición del cúmulo abierto excitatriz Ma 50. La nebulosa anillo en torno a WR 157 tiene aspecto de "herradura" con un tamaño angular de $\simeq 35^{\prime} \times 40^{\prime}$, con el cúmulo abierto proyectado cerca de su sector más brillante. La emisión más difusa a $b \leq-0^{\circ} 30^{\prime}$ corresponde a SG 14 .

Sh2-157 y Ma50 se encuentran en el brazo de Perseo. Van der Hucht (2001) da una distancia espectrofotométrica $d=3.4 \mathrm{kpc}$ para WR 157, tenida en cuenta la asociación 


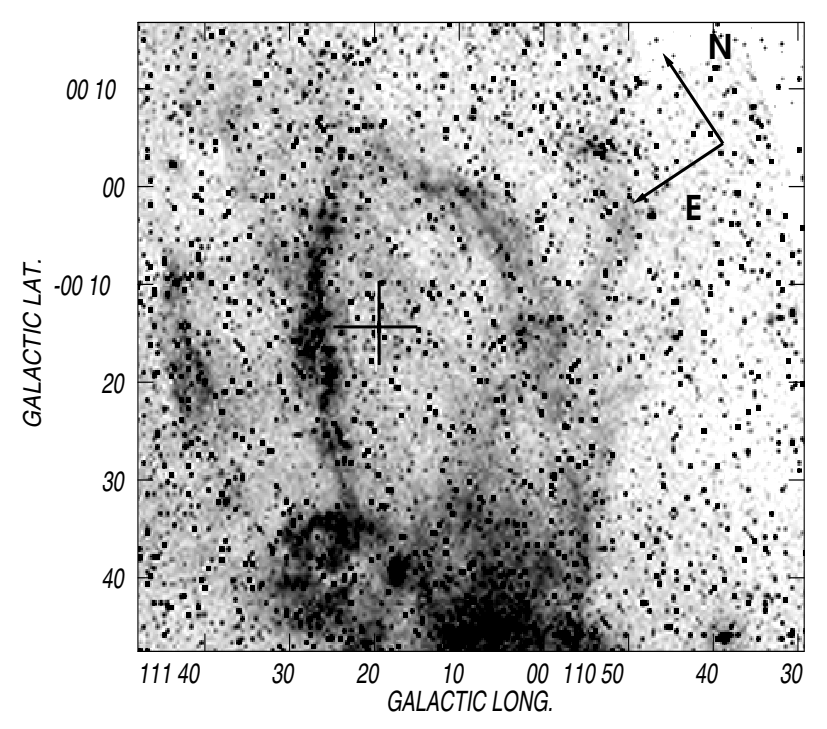

Figura 4.1: Imagen óptica de la región H II Sh2-157 obtenida del Digital Sky Survey, placa roja (DSSR). La cruz indica la posición del cúmulo abierto Ma 50. La escala de grises tiene unidades arbitrarias.

con el cúmulo. Basados en fotometría CCD UBV $(\mathrm{RI})_{C}$, Baume et al. (2004) derivaron una distacia $d_{\text {Ma } 50}=3.46 \pm 0.35 \mathrm{kpc}$ para el cúmulo. Georgelin et al. (1973), Georgelin (1975) y Georgelin \& Georgelin (1976) publicaron una distancia cinemática $d=2.5 \pm 0.4 \mathrm{kpc}$ pa-

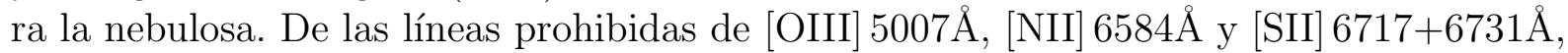
Lozinskaya et al. (1986) determinaron velocidades radiales entre $-53 \mathrm{a}-33 \mathrm{~km} \mathrm{~s}^{-1}$ para al gas ionizado, similares a las obtenidas a partir de observaciones de la línea de recombinación H166a (Pedlar 1980), de observaciones de CO (Blitz et al. 1982) y de observaciones en la línea $\mathrm{H} \alpha$ (Georgelin 1975).

Lozinskaya et al. (1986) realizaron un estudio en líneas de [OIII], [NII] y [SII] de la región Sh2-157. Obtuvieron cocientes de intensidades $\mathrm{I}([\mathrm{SII}] / \mathrm{I}(\mathrm{H} \alpha)=0.11-0.25$, correspondientes a las zonas más intensas de la región. Además determinaron densidades electrónicas medias $n_{e}=100-150 \mathrm{~cm}^{-3}$ para la nebulosa, y un valor $n_{e} \simeq 300 \mathrm{~cm}^{-3}$ para las zonas más intensas de los filamentos. Los autores propusieron un valor para la masa del gas ionizado entre $300-500 \mathrm{M}_{\odot}$, y un valor para el parámetro de excitación entre 25 y $90 \mathrm{pc} \mathrm{cm}^{-2}$ (que incluye WR 157 y cinco estrellas tipo B). Analizando la energética, sugirieron que SG 13 ha sido modelada por los vientos estelares de WR 157 y de las estrellas tipo B pertenecientes al cúmulo abierto Ma 50.

Motivados por una distibución tan particularmente interesante, nos abocamos al estudio multifrecuencia del medio interestelar en dirección a WR 157 para buscar una posible asociación física entre las fuentes mencionadas. Los resultados fueron presentados en Vasquez et al. (2005). 


\subsection{Observaciones}

El estudio encarado se basó en el análisis de observaciones ópticas, IR y de radio. Para el rango 'optico, la imagen del DSS R de Sh2-157 fue extraída de la página del Skyview ${ }^{1}$. La información en radio e infrarrojo está descripta en las siguientes secciones.

\subsubsection{Observaciones en radio}

Para analizar la distribución del gas atómico usamos observaciones del Canadian Galactic Plane Survey (CGPS) obtenidas con el interferómetro del Dominion Radio Astrophysical Observatory (DRAO) ubicado en Canadá. Este instrumento consiste en un arreglo de 7 antenas de $9 \mathrm{~m}$ de diámetro cada una, ubicadas en dirección este-oeste que realiza observaciones en la línea de $21 \mathrm{~cm}$ y en el continuo de radio en las bandas centradas en 408 y 1420 MHz. A las observaciones interferométricas se incorporaron observaciones de disco simple para asegurar la cobertura de la emisión correspondiente a estructuras de todos los tamaños angulares. Las observaciones en continuo fueron obtenidas con un haz sintetizado de $3.4^{\prime} \times 3.9^{\prime}$ y $58^{\prime \prime} \times 67^{\prime \prime}$ en 408 y $1420 \mathrm{MHz}$, respectivamente. El ruido rms en las imágenes es de 5 y $1.5 \mathrm{~K}$ en 408 y $1420 \mathrm{MHz}$, respectivamente. Los detalles acerca de las observaciones de $\mathrm{H}$ I y continuo de radio pueden ser encontrados en Landecker et al. (2000).

Para analizar la distribución de hidrógeno neutro, extrajimos un cubo de datos centrado en $(l, b, v)=\left(111^{\circ} 8^{\prime},-0^{\circ} 23^{\prime},-40.2 \mathrm{~km} \mathrm{~s}^{-1}\right)$ del CGPS. Estas observaciones tienen un haz sintetizado de $1.36^{\prime} \times 1.36^{\prime}$, un ruido $r m s$ de $3 \mathrm{~K}$ y una resolución en velocidad de $\Delta v=0.824 \mathrm{~km} \mathrm{~s}^{-1}$. Estas imágenes han sido convolucionadas a $2^{\prime} \times 2^{\prime}$ para facilitar la identificación de estructuras. La cobertura total en velocidad del cubo de datos abarca el rango de -60 a $163 \mathrm{kms}^{-1}$. Los parámetros observacionales del cubo de H I se han resumido en la Tabla 4.1.

Los datos de ${ }^{12} \mathrm{CO}(J=1 \rightarrow 0)$ en $115 \mathrm{GHz}$ fueron obtenidos con el radiotelescopio del Five College Radio Astronomy Observatory (FCRAO) en EEUU, con una resolución angular de $\simeq 46^{\prime \prime}$. Los detalles acerca del relevamiento de CO se encuentran en el trabajo de Ridge et al. (2006).

\subsubsection{Datos IRAS y MSX}

Para analizar la distribución del polvo interestelar en la región hemos utilizado imágenes IRAS en 60 y $100 \mu \mathrm{m}$ con una resolución angular de $\simeq 1^{\prime}$ y $2^{\prime}$ (HIRES).

El Telescopio Espacial Infrarrojo SPIRITIII a bordo del satélite MSX (del inglés "Midcourse Space Experiment") relevó el plano galáctico en cuatro frecuencias infrarrojas centradas en 8.28, 12.13, 14.65 y $21.3 \mu \mathrm{m}$ (bandas A, C, D y E, respectivamente). La

\footnotetext{
${ }^{1}$ http://www.skyview.gov
} 


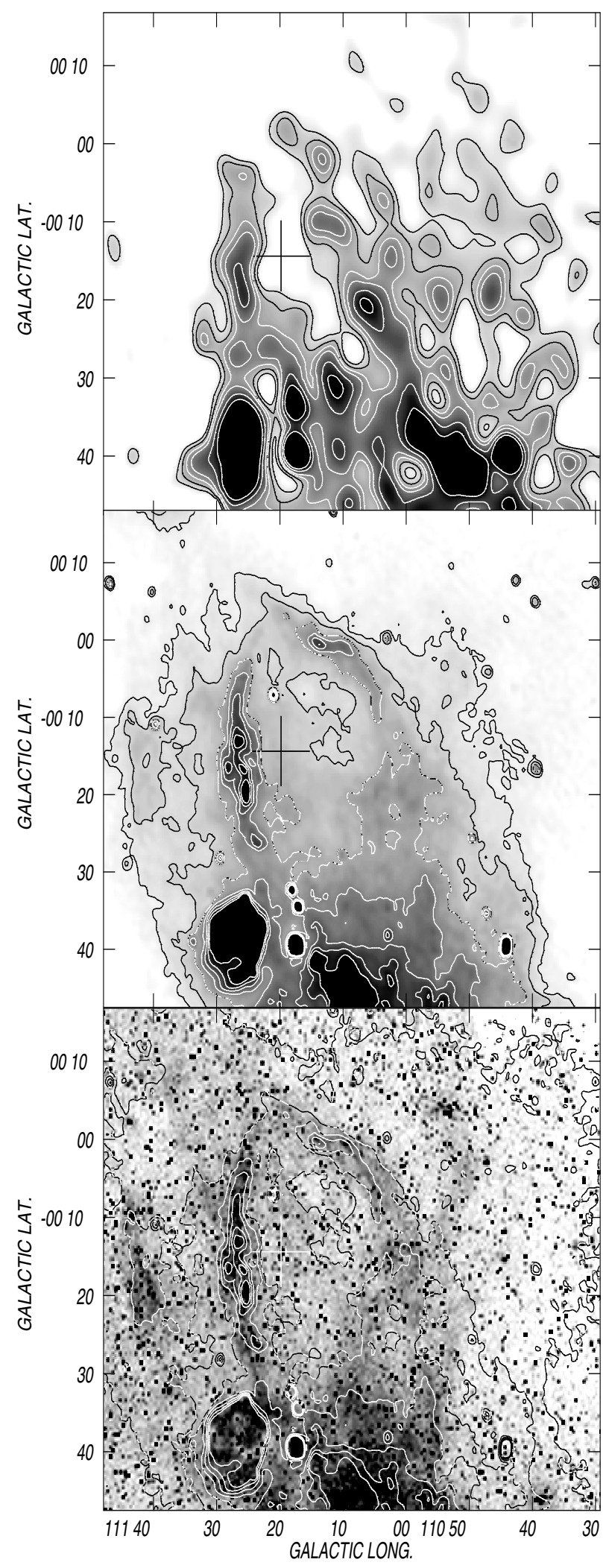

Figura 4.2: Panel superior: Imagen en continuo de radio en $408 \mathrm{MHz}$. La escala de grises representa la temperatura de brillo en un rango de 110 a $150 \mathrm{~K}$. Los contornos son 115, 120, 125, 130, 140 y $150 \mathrm{~K}$. Panel central: Imagen en $1420 \mathrm{MHz}$. El rango en $T_{b}$ va entre 7 y 13 K. Los contornos son de 7, 8, 9, 10, 11, 12 y 13 K. La cruz marca la posición de Ma 50. Panel inferior: Superposición de la imagen óptica en escala de grises, y los contornos correspondientes a $1420 \mathrm{MHz}$. 


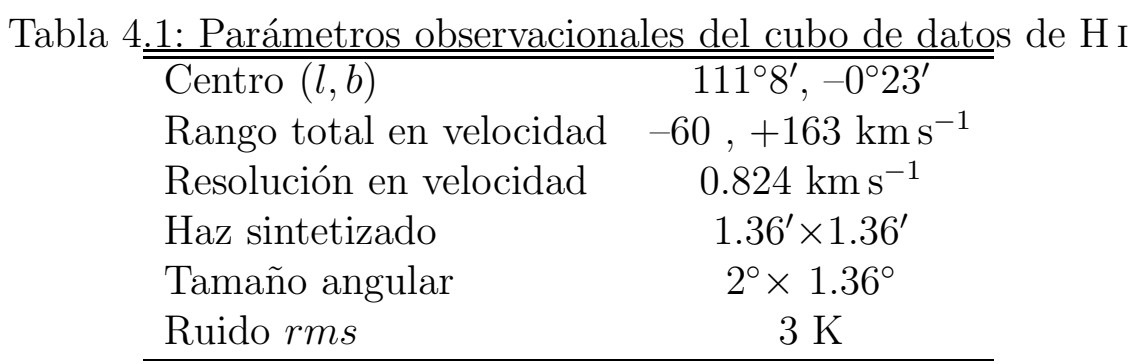

resolución angular en cada una de las cuatro bandas es de 18.4". Nosotros convertimos los flujos promedio a unidades de Jansky a través del factor de conversión provisto por el "Image Server at IPAC" (Egan et al. 1999), entre unidades de radiancia y unidades de densidad de flujo. Este factor depende de cada banda, con valores de $7.133 \times 10^{12}$ para la banda A, $2.863 \times 10^{13}$ para la banda C, $3.216 \times 10^{13}$ para la banda D y $2.476 \times 10^{13}$ para la banda E. Debemos tener en cuenta que este factor asume una relación entre el flujo de la fuente $S_{\nu}$ y la frecuencia de la forma $S_{\nu} \propto 1 / \nu$.

\subsection{Distribución de gas y polvo}

\subsubsection{Emisión del gas ionizado}

Las imágenes en 408 y $1420 \mathrm{MHz}$ están mostradas en la parte superior y central de la Fig. 4.2. La distribución en $1420 \mathrm{MHz}$ se correlaciona muy bien con la emisión óptica (panel inferior de la Fig. 4.2), guardando una coincidencia morfológica casi exacta en ambas ramas de la "herradura". Además, se puede observar emisión en $(l, b) \simeq\left(111^{\circ} 40^{\prime}\right.$,$0^{\circ} 15^{\prime}$ ) coincidente con una región óptica más difusa.

Los estudios previos en alta resolución de Sh 2-157 centraron la atención en la zona inferior de la nebulosa, SG 14, y no incluyeron la región estudiada en este trabajo (Israel 1979). La nebulosa anillo alrededor de WR 157 puede ser identificada también en la imagen en $2700 \mathrm{MHz}$ (Reich et al. 1990) y en $4850 \mathrm{MHz}$ (Condon et al 1991).

Las densidades de flujo $\left(\mathrm{S}_{\nu}\right)$ derivadas en 408, 1420, 2700 y $4850 \mathrm{MHz}$ son $1.8 \pm 0.9$, $3.4 \pm 0.9,3.5 \pm 1.0$ y $1.1 \pm 0.2 \mathrm{Jy}$, respectivamente. Las incertezas en las densidades de flujo provienen del ruido rms de las imágenes y de la estimación de la emisión de fondo. La Figura 4.3 muestra un gráfico $\log \mathrm{S}_{\nu}$ vs $\log \nu$. En la derivación del índice espectral $\alpha$, se encontraron algunos problemas. La imagen en $408 \mathrm{MHz}$ exhibe algunas fuentes muy intensas sobre la nebulosa, por ejemplo las ubicadas en $(l, b)=\left(111^{\circ} 10^{\prime},-0^{\circ} 30^{\prime}\right)$ y $(l, b)=\left(111^{\circ} 5^{\prime},-0^{\circ} 22^{\prime}\right)$, que no pueden ser identificadas en $1420 \mathrm{MHz}$. Las dos fuentes mencionadas estarían asociadas a la fuente de rayos X 1WGA J23138+6024 y a la radiofuente NVSS J231310+601236, respectivamente; todas ellas aparecen listadas en la base 


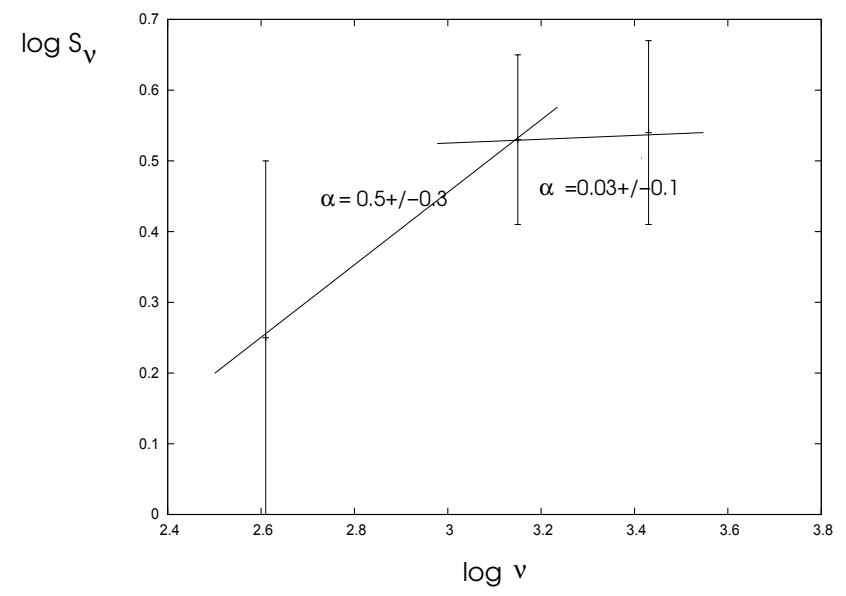

Figura 4.3: Gráfico $\log S$ vs $\log \nu$ para la emisión en continuo de radio de Sh2-157. Las dos rectas indican el comportamiento del índice espectal entre 408 y $1420 \mathrm{MHz}$ y 1420 y $2700 \mathrm{MHz}$.

de datos de la NASA/IPAC Extragalactic Database (NED). Otras "fuentes" detectadas en $408 \mathrm{MHz}$ son "artefactos" originados en la presencia de la intensa radiofuente Cas A, ubicada en $(l, b) \simeq\left(111^{\circ} 42^{\prime},-2^{\circ} 5^{\prime}\right)$. Todos los valores de las densidades de flujo fueron obtenidos restando un nivel de fondo de cada una de las imágenes de $\sim 7 \sigma$ y eliminando las fuentes extragalácticas proyectadas sobre la región. Hemos realizado ajustes a los valores de las densidades de flujo con el fin de determinar el índice espectral $\alpha$, teniendo en cuenta la relación $S_{\nu} \propto \nu^{\alpha}$. De esta manera, determinamos $\alpha_{1}=0.5 \pm 0.3$ entre 408 y 1420 , y $\alpha_{2}=0.03 \pm 0.1$ para 1420 y $2700 \mathrm{MHz}$. Un factor grande de incerteza corresponde a la imagen en $4850 \mathrm{MHz}$ (Condon et al. 1991), en la que se identifican dos pequeñas regiones que no presentan datos, en $(l, b)=\left(111^{\circ} 7^{\prime},-0^{\circ} 15^{\prime}\right)$ y $(l, b)=\left(111^{\circ} 20^{\prime},-0^{\circ} 28^{\prime}\right)$. Además, como se detalla en este relevamiento, se ha restado un fondo en la emisión. Este hecho puede explicar el bajo valor del flujo a esta frecuencia. Por ambos motivos no lo consideramos para ajustar el índice espectral.

El valor de ambos ajustes de los índices $\alpha_{1}$ y $\alpha_{2}$ es compatible con un régimen térmico a frecuencias cercanas a la de turn-over. Como se puede ver en el gráfico 3.6 del Capítulo 3, en este rango de frecuencias la pendiente de la curva se acerca a cero. Por lo tanto, podemos decir que debido al comportamiento hacia frecuencias intermedias, se descarta la posibilidad de emisión no térmica detectable, confirmándose que la radiación de la nebulosa es térmica.

Las fuentes centradas en $(l, b)=\left(111^{\circ} 26^{\prime},-0^{\circ} 40^{\prime}\right),(l, b)=\left(111^{\circ} 18^{\prime},-0^{\circ} 40^{\prime}\right)$ y $(l, b)=$ $\left(111^{\circ} 8^{\prime},-0^{\circ} 46^{\prime}\right)$ en la imagen de $1420 \mathrm{MHz}$ corresponden a las radio fuentes G 111.4-0.7, S 157 A y G 111.2-0.8, listadas por Israel (1977) y pertenecen a SG 14. 


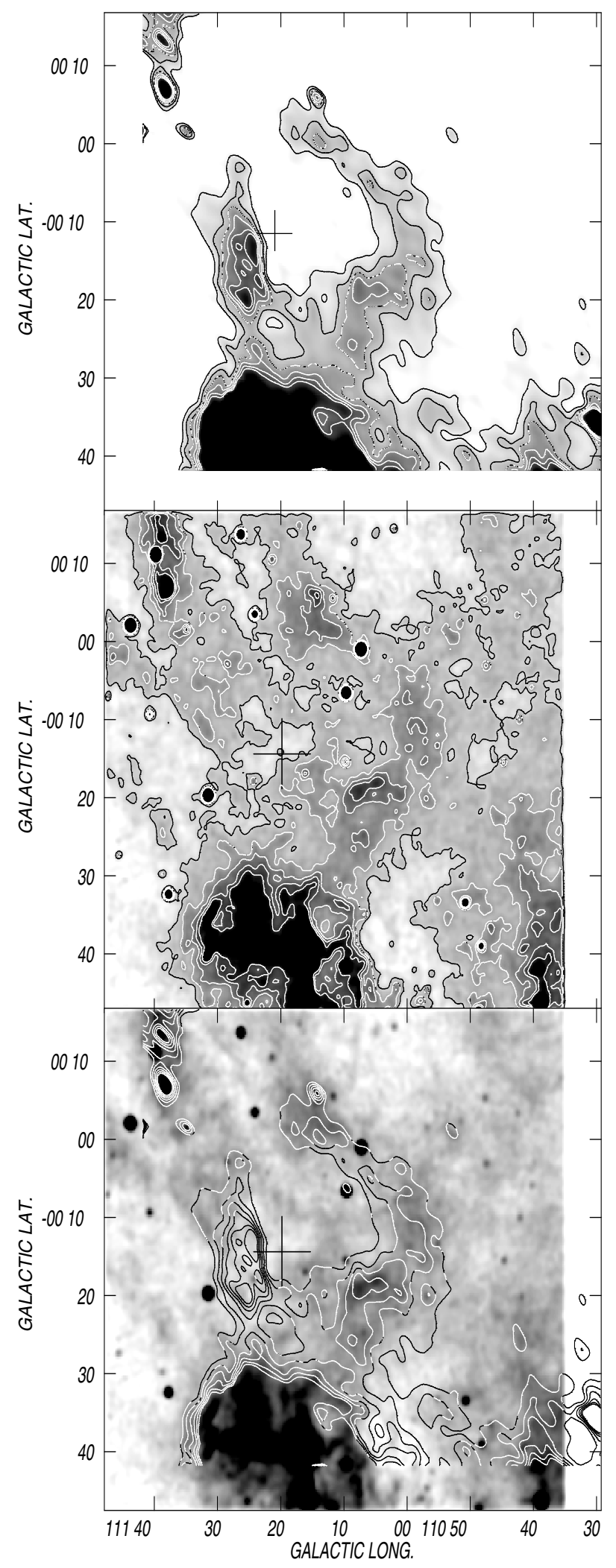

Figura 4.4: Panel superior: Imagen HIRES en $60 \mu \mathrm{m}$. La escala de grises corresponde a 65 - $140 \mathrm{MJy} / \mathrm{sr}$, y las líneas de contorno, a 70, 80, 90, 100, 110 y $120 \mathrm{MJy} / \mathrm{sr}$. Panel central: Imagen en $8.3 \mu \mathrm{m}$ (banda A de MSX). El grisado va de $10.5(7 \sigma)$ a $40 \mathrm{MJy} / \mathrm{sr}$ y las líneas de contorno corresponden a 16, 21, 26, 31 y $36 \mathrm{MJy} / \mathrm{sr}$. Panel inferior: Superposición de la emisión en $60 \mu \mathrm{m}$ (en líneas de contorno) y $8.3 \mu \mathrm{m}$ (en escala de grises). La cruz indica la posición de WR 157. 


\subsubsection{Emisión del polvo interestelar}

La imagen HIRES en $60 \mu \mathrm{m}$ está desplegada en la parte superior de la Fig. 4.4. La distribución de la emisión en el lejano IR presenta una morfología similar a la emisión óptica y a la del continuo de radio. La imagen en $100 \mu \mathrm{m}$, no incluida aquí, muestra la misma distribución que la de $60 \mu \mathrm{m}$. La radiación en el lejano IR se origina principalmente en la emision térmica del polvo interestelar (ver Capítulo 3). La fuerte correlación entre la emisión en el lejano IR y en el continuo de radio sugiere que los granos de polvo y el gas ionizado se encuentran mezclados.

La Fig. 4.4 (panel central) despliega la emisión en la banda A de MSX. El panel inferior de la misma figura muestra una superposición entre las distribuciones en $60 \mu \mathrm{m}$ (contornos) y $8.3 \mu \mathrm{m}$ (escala de grises). Las líneas de 7.6 y $8.6 \mu \mathrm{m}$ de los hidrocarburos aromáticos policíclicos (PAHs) contribuyen fuertemente a la emisión en esta banda. La emisión en 8.3 $\mu \mathrm{m}$ coincide con la de $60 \mu \mathrm{m}$ principalmente a $l \leq 111^{\circ} 20^{\prime}$. Un comportamiento diferente se observa hacia $(l, b)=\left(111^{\circ} 25^{\prime},-0^{\circ} 15^{\prime}\right)$, donde la región más brillante en $60 \mu \mathrm{m}$ coincide con la región más débil en $8.3 \mu \mathrm{m}$. Muy probablemente el polvo responsable de la emisión en $8.3 \mu \mathrm{m}$ haya sido destruido en este sector de la nebulosa.

A $b \sim-0^{\circ} 30^{\prime}$ la emisión IR es muy intensa y está asociada a SG 14.

\subsubsection{Emisión del gas atómico y molecular}

La distribución de la emisión del CO (1-0) está mostrada en la Figura 4.5. En el panel izquierdo está desplegada la imagen promedio dentro del rango de velocidad -58.4 a-43.5 $\mathrm{kms}^{-1}$, mientras que en el panel derecho se ve la superposición de la imagen óptica, en escala de grises, y la emisión molecular, mostrada en contornos. Una serie de nubes moleculares bordean la nebulosa anillo. La región óptica más brillante, la cual se ubica paralelamente a $l=111^{\circ} 25^{\prime}$, aparece libre de material molecular hasta $b \simeq-0^{\circ} 5^{\prime}$. La nube molecular cerca de $(l, b)=\left(111^{\circ} 25^{\prime},-0^{\circ} 32^{\prime}\right)$ coincide con el límite a bajas latitudes de la nebulosa anillo y la separa del gas ionizado perteneciente a SG 14. Notemos que esa zona molecular intensa corresponde a una región cuya emisión óptica es débil. La cadena de nubes descripta delinea una estructura circular de $\sim 35^{\prime}$ de tamaño que encierra a la nebulosa anillo óptica.

El gas molecular en la región $(l, b)=\left(111^{\circ} 30^{\prime},-0^{\circ} 15^{\prime}\right)$ fue detectado con velocidades entre $-43 \mathrm{y}-47 \mathrm{~km} \mathrm{~s}^{-1}$, mientras que las nubes de $\mathrm{CO}$ en $(l, b)=\left(111^{\circ} 25^{\prime},-0^{\circ} 35^{\prime}\right)$ aparecen a $-50 \mathrm{~km} \mathrm{~s}^{-1}$. La cadena de nubes proyectadas entre los filamentos ópticos ubicados en $l \sim 110^{\circ} 50^{\prime}$ y $111^{\circ} 5^{\prime}$, tiene velocidades entre -58 y $-50 \mathrm{~km} \mathrm{~s}^{-1}$. La región a $(l, b)=$ $\left(111^{\circ} 35^{\prime},+0^{\circ} 5^{\prime}\right)$, no correlacionada con SG 13, es detectada en el rango de velocidad 58 to $-48 \mathrm{~km} \mathrm{~s}^{-1}$. La asociación morfológica entre la nebulosa anillo óptica y el CO, y el acuerdo entre las velocidades de las nubes con las del material ionizado indican que el gas molecular y el ionizado están relacionados.

Una gran cantidad de material molecular se encuentra presente en la región superior de la imagen. Con la excepción del CO proyectado sobre la región H II Sh2-159 ubicada en 

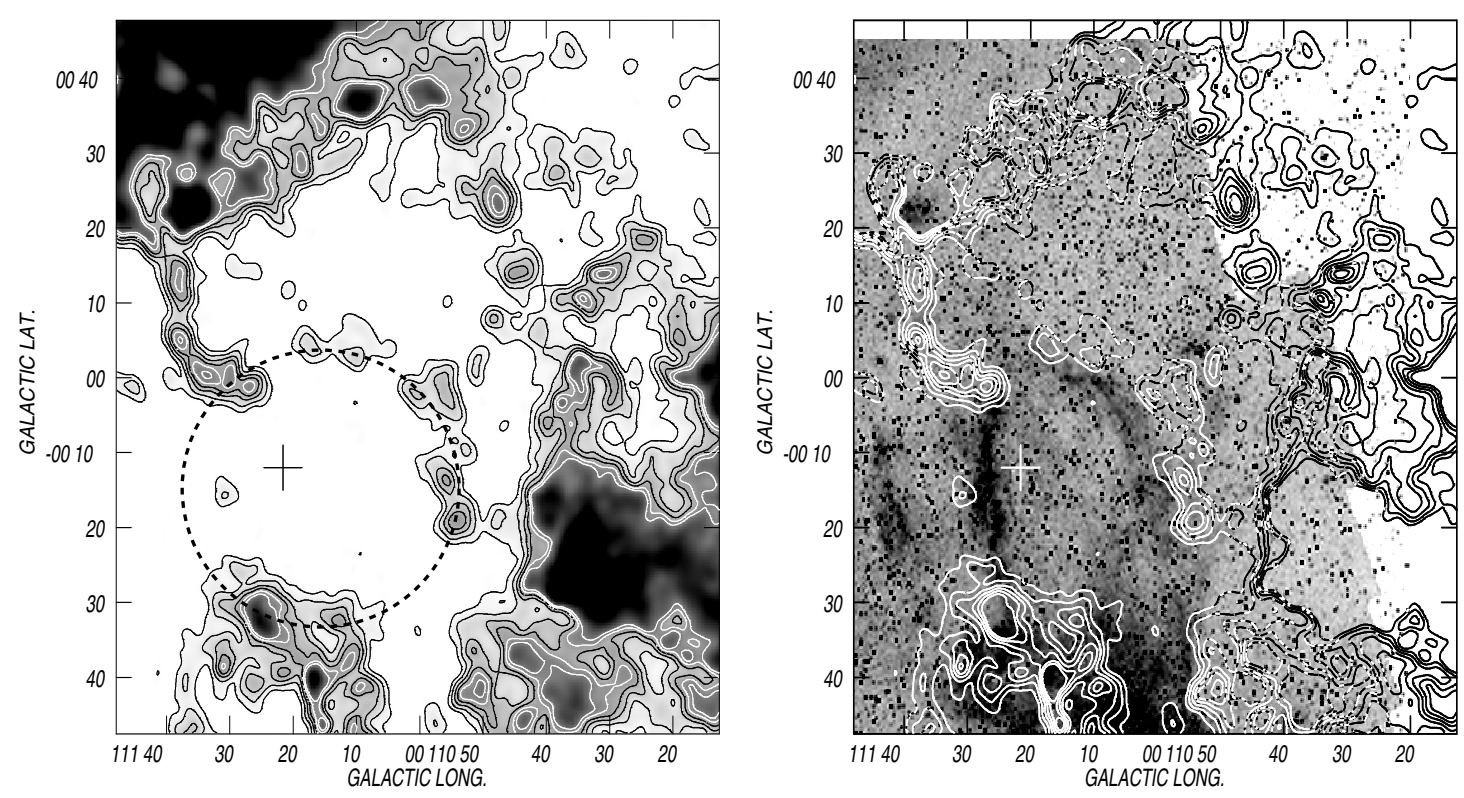

Figura 4.5: Panel izquierdo: Emisión integrada de CO en el rango de velocidad -58.4 a $-43.5 \mathrm{~km} \mathrm{~s}^{-1}$. La escala de grises va entre $1.5-50 \mathrm{~K} \mathrm{~km} \mathrm{~s}^{-1}$. Los contornos representan 2.5, $6,11,16,21$ y $26 \mathrm{~K} \mathrm{~km} \mathrm{~s}^{-1}$. El círculo con línea punteada marca la estructura molecular grumosa. Panel derecho: Superposición entre la imagen óptica del DSS R y los contornos de la distribución molecular. La cruz marca la posición de WR 157.

$(l, b)=\left(111^{\circ} 36^{\prime},+0^{\circ} 22^{\prime}\right)$ (Israel 1977), esta emisión molecular muestra poca correlación con la emisión óptica. La fuerte emisión de CO coincidente con Sh2-159 está asociada a la región H II debido a la coincidencia en velocidad con la línea $\mathrm{H} \alpha$ (Blitz et al. (1982)). La intensa emisión de $\mathrm{CO}$ detectada hacia $l<110^{\circ} 55^{\prime}$ está proyectada fuera de la región óptica más difusa y cerca de su borde en $b<-0^{\circ} 30^{\prime}$.

La comparación entre las distribuciones en 8.3 y $60 \mu \mathrm{m}$ (Fig. 4.4) y la emisión molecular (Fig. 4.5) revela una clara correlación morfológica. Las nubes de CO rodean la emisión IR asociada a SG 13. El círculo con línea punteada en el panel izquierdo de la Fig. 4.5 delinea la cadena de nubes de $\mathrm{CO}$. El diámetro angular de esta estructura es $\sim 35^{\prime}$.

La Figura 4.6 exhibe la superposición de la distribución en $T_{b}$ del H i en el rango de velocidades -48.0 a $-33.2 \mathrm{~km} \mathrm{~s}^{-1}$ (en pasos de a $2.5 \mathrm{~km} \mathrm{~s}^{-1}$ ) con la imagen promediada de $\mathrm{CO}$ en contornos.

El análisis de la emisión del H I permitió la identificación de dos estructuras con velocidades radiales compatibles con las del material ionizado y molecular. La estructura más grande y débil, con un tamaño angular del orden de $67^{\prime} \times 40^{\prime}$ tiene su centro en $(l, b)=$ $\left(111^{\circ} 7^{\prime},+0^{\circ} 8^{\prime}\right)$. A esta estructura la llamamos $\mathbf{A}$, mientras que a la más pequeña e intensa, de cerca de $36^{\prime}$ de diámetro angular y con centro en $(l, b)=\left(110^{\circ} 55^{\prime},-0^{\circ} 35^{\prime}\right)$, la llamaremos B. Ambas estructuras están resaltadas con elipses en la Figura 4.6. 


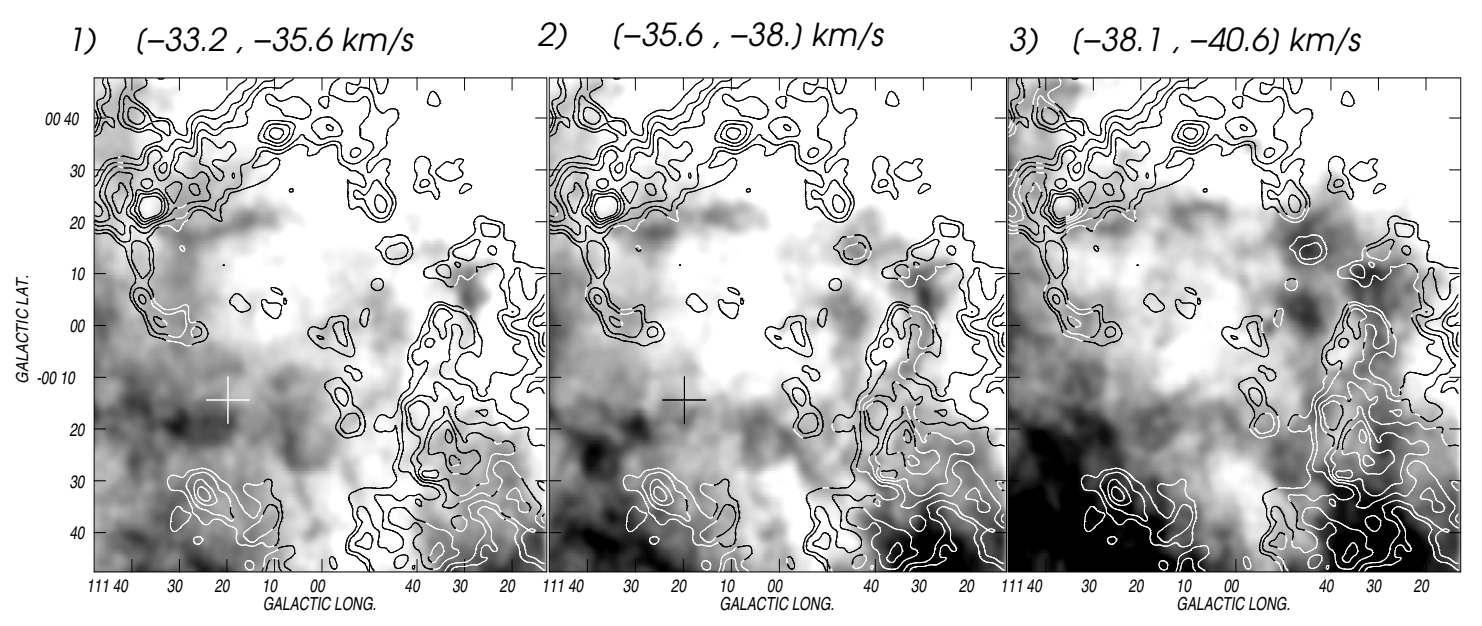

4) $(-40.6,-43.0) \mathrm{km} / \mathrm{s}$

5) $(-43.0,-45.5) \mathrm{km} / \mathrm{s}$

6) $(-45.5,-48.0) \mathrm{km} / \mathrm{s}$

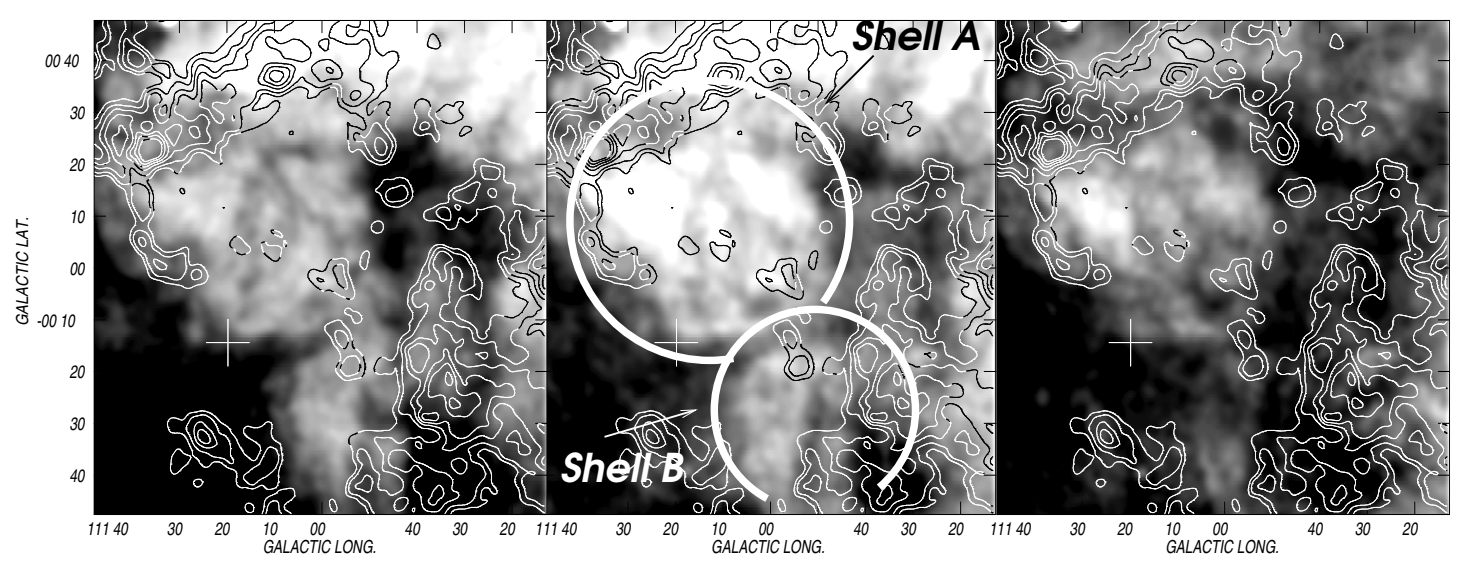

Figura 4.6: Superposición de la distribución de H i en el entorno a Ma 50 (grisados) y la emisión integrada de $\mathrm{CO}$ (contornos). Cada mapa de $\mathrm{H}$ I muestra la $T_{b}$ media en intervalos de $\sim 2.5 \mathrm{~km} \mathrm{~s}^{-1}$. El rango en la escala de grises es 40 a $100 \mathrm{~K}$ para los mapas (1), (2), (3) y (4), y de 70 a $135 \mathrm{~K}$ para los mapas (5) y (6). La cruz marca la posición del cúmulo abierto. 
La estructura A se aprecia más claramente a $\sim-44 \mathrm{~km} \mathrm{~s}^{-1}$. La zona próxima a $b \simeq$ $+0^{\circ} 20^{\prime}$ está asociada con una intensa emisión de CO. La estructura B rodea a SG 14 . El sector ubicado en $l=110^{\circ} 47^{\prime}$ coincide con una región de intensa emisión molecular, mientras que su borde sobre $l=111^{\circ} 10^{\prime}$ se correlaciona con una débil emisión de CO. No se detecta material molecular en la interfase entre ambas estructuras.

Gas neutro aparece asociado morfológicamente con una porción de SG 13 en $(l, b)=$ $\left(111^{\circ} 10^{\prime}, 0^{\circ} 0^{\prime}\right)$ proyectándose cerca del centro de la estructura A. La comparación entre el CO y H i asociados a SG 13 sugieren una débil contraparte atómica.

El panel inferior derecho de la Figura 4.7 muestra la emisión integrada de $\mathrm{H}$ I en el intervalo de velocidad entre -44.0 y $-41.5 \mathrm{~km} \mathrm{~s}^{-1}$, correspondiente a la velocidad sistémica de las cáscaras A y B. El panel superior y el inferior izquierdo de esta misma figura muestran las imágenes $(l, v)$ correspondiente a $b=0.0^{\circ}$ y $(v, b)$ a $l=111^{\circ} 10^{\prime}$, respectivamente. Esas imágenes nos permiten estimar la extensión y la velocidad de expansión de las estructuras.

Para la estructura A, que se detecta entre -32 y $-45 \mathrm{~km} \mathrm{~s}^{-1}$, estimamos una velocidad de expansión de $\simeq 7 \mathrm{~km} \mathrm{~s}^{-1}$, mientras que la velocidad de expansión de la estructura $\mathbf{B}$, que es evidente entre $-33 \mathrm{y}-43 \mathrm{~km} \mathrm{~s}^{-1}$, es de $\simeq 6 \mathrm{~km} \mathrm{~s}^{-1}$.

\subsection{Discusión}

\subsubsection{Análisis del medio interestelar}

Un punto importante para discutir es la asociación o no del H i con la acción de los vientos de WR 157. En la Fig. 4.8 se muestra un esquema con todas las distibuciones de gas y polvo hacia SG 13. La comparación morfológica y dinámica del hidrógeno neutro con las otras componentes interestelares en dirección a SG 13, plantea el siguiente debate:

- De la comparación entre las Fig 4.2 y 4.7 concluimos que no existe una asociación morfológica clara entre la emisión en $1420 \mathrm{MHz}$ del continuo de radio y la distribución de Hi. Podemos ver que la envoltura de la estructura A se cierra hacia $b \sim-0^{\circ} 18^{\prime}$, al igual que la estructura $\mathbf{B}$, y posiblemente a esas latitudes ambas estructuras neutras se conecten. Justamente a esa latitud, los filamentos de SG 13 se extienden perpendicularmente al H I. Es decir, ambas distribuciones se "cruzan" $\mathrm{a} \sim 90^{\circ}$.

- Si cotejamos las distribuciones del gas atómico neutro y molecular (ver Fig. 4.6), vemos que hay una similitud entre la estructura $\mathbf{A}$ y el CO, principalmente en los sectores a $b \simeq 0^{\circ} 30^{\prime}$ y $l \simeq 111^{\circ} 35^{\prime}$. En esa ubicación el CO bordea externamente al H I a lo largo de toda la serie de imágenes.

En cuanto a la distribución de nubes moleculares que guardan una relación morfológica con el continuo de radio y el IR, modelados por los vientos de las estrellas 


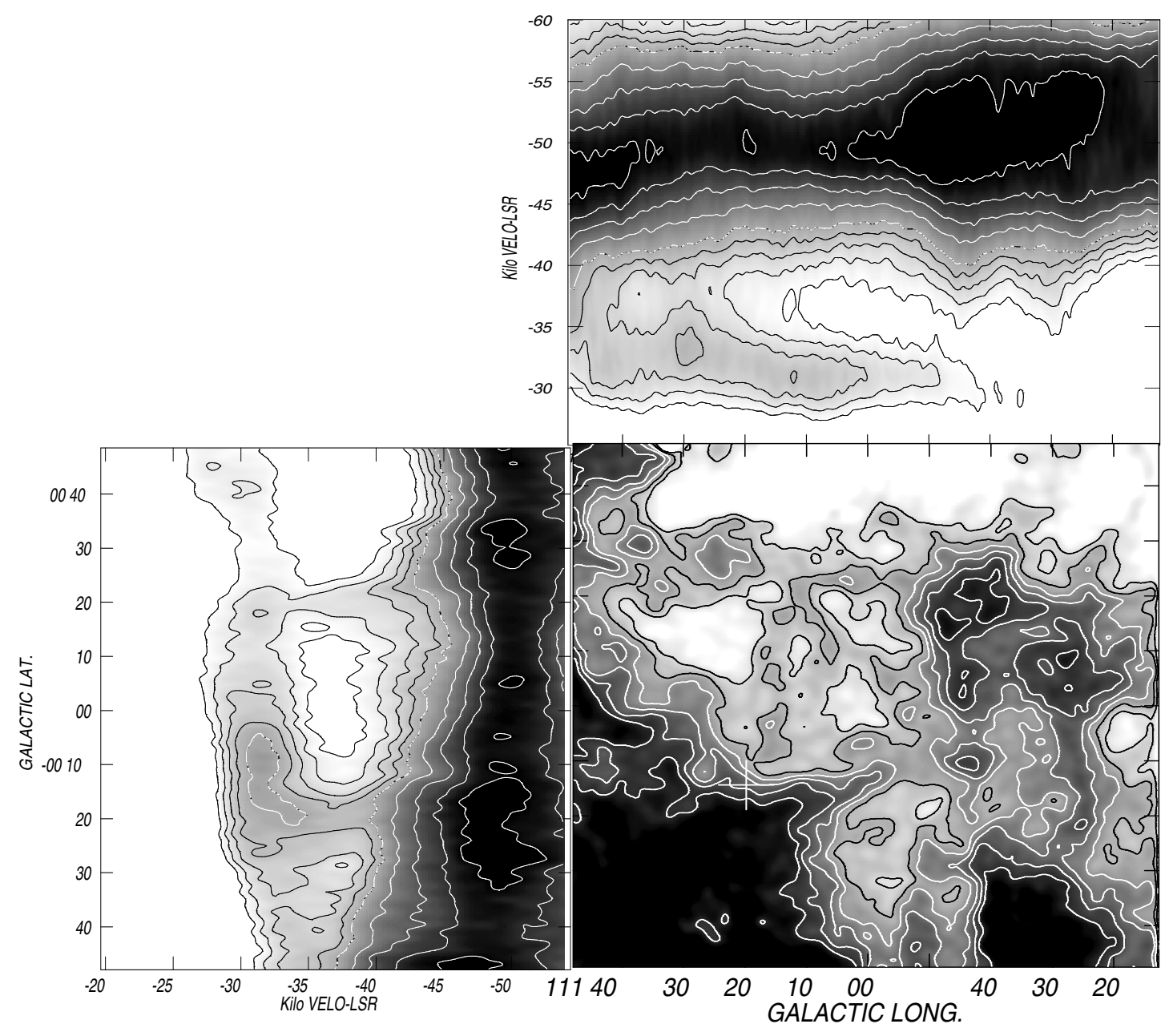

Figura 4.7: Panel inferior derecho: Emisión de H I integrada entre -44.0 to $-41.5 \mathrm{~km} \mathrm{~s}^{-1}$, correspondiente a la velocidad sistémica de ambas estructuras. Panel superior: Imagen integrada $(l, v)$ para $b=0.0^{\circ}$. Panel inferior izquierdo: Imagen integrada $(v, b)$ para $l=$ $111^{\circ} 10^{\prime}$. 


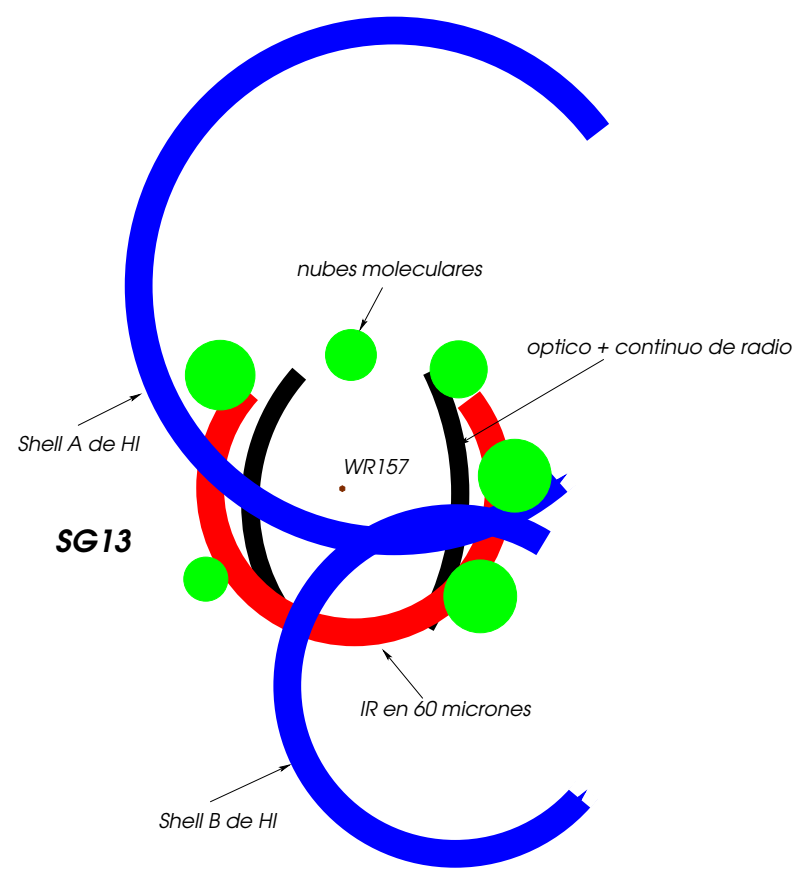

Figura 4.8: Gráfico esquemático con las distribuciones de gas y polvo en dirección a SG 13.

del cúmulo abierto, vemos que no hay asociación posible con ninguna de las dos estructuras atómicas neutras.

- Las velocidades sistémicas del conjunto de nubes de CO asociadas a SG $13\left(v_{\text {sis }}\right.$ $\left.=-47.6 \pm 1.6 \mathrm{kms}^{-1}\right)$ y de las dos estructuras de $\mathrm{Hi}\left(v_{s i s}=-44.5 \pm 1.6 \mathrm{~km} \mathrm{~s}^{-1}\right)$ son similares. Sin embargo, no hay una conexión morfológica clara entre ambas distribuciones en los rangos de velocidad en donde se manifiestan $\left(\Delta v_{\mathrm{HI}}=[-58.4,-\right.$ $43.5] \mathrm{kms}^{-1}$, y $\left.\Delta v_{\mathrm{CO}}=[-48.0,-33.2] \mathrm{km} \mathrm{s}^{-1}\right)$.

Teniendo en cuenta todos estos argumentos morfológicos y cinemáticos, sugerimos que no existe una correlación clara entre la distribución de $\mathrm{H}$ I con el material asociado a WR 157. A diferencia de otras burbujas interestelares alrededor de estrellas WR (ver Capítulo 3), no hay en este caso evidencia observacional de una burbuja de H I asociada a la nebulosa anillo.

Posiblemente la emisión del H I asociado a SG 13 se confunde con la emisión de fondo, o con la emisión de las estructuras A y B, y por ese motivo no vemos ninguna estructura clara en H I asociada a la nebulosa anillo. En cuanto a la emisión de polvo, presenta una gran similud con la de continuo de radio en $1420 \mathrm{MHz}$, y puede ser polvo calentado por la interacción de los electrones libres.

En la Fig. 4.5 se evidencia una estructura molecular más extensa que la distribución de nubes ya mencionada, centrada en $(l, b)=\left(111^{\circ} 5^{\prime},-0^{\circ} 5^{\prime}\right)$ cuya forma es casi circular y tiene 
aspecto de cáscara (ver sección 4.3.3). Como hemos resumido en los párrafos anteriores, esta estructura molecular se correlaciona con la estructura A del H I cuyo origen no estaría asociado con la acción de los vientos de WR 157.

La distribución de material interestelar en los alrededores de Ma 50 puede ser entendida considerando que SG 13 y las contrapartes en continuo, IR y CO han sido "esculpidas" principalmente por los vientos de la estrella WR 157. En lo referente a los filamentos ópticos ubicados en $l \simeq 111^{\circ} 40^{\prime}$, y $l \simeq 110^{\circ} 50^{\prime}$ dos interpretaciones son posibles:

- Están asociados a la nebulosa, habiéndose originado en etapas previas a la actual fase WR. Luego, los filamentos internos más intensos serían el producto de la acción de los vientos en la fase actual de la estrella WR 157. Esos frentes habrían ionizado y disociado el medio cercano a la estrella. Puede considerarse que las nubes moleculares, distribuidas en forma circular, son los "restos" de una nube molecular que habría sido, en su mayor parte, disociada e ionizada. Justamente, esas zonas de conexión entre el material molecular y el ionizado generan regiones de fotodisociación. Esta aseveración puede ser confirmada por la emisión PAH (en $8.3 \mu \mathrm{m}$ ), como se observa en la Fig. 4.4.

- La distribución de las nubes moleculares y la de los filamentos ópticos externos ubicados en $l \simeq 110^{\circ} 50^{\prime}$ no sería coplanar y estaríamos viendo un efecto de la proyección sobre el plano del cielo. En este caso, todos los filamentos podrían estar formando una única estructura de mayor tamaño, originada en ambas etapas.

\subsubsection{Principales parámetros de la nebulosa anillo}

Una de las primeras cuestiones a tratar es la determinación de la distancia. Teniendo en cuenta la velocidad sistémica del CO asociada a SG $13\left(-47.6 \pm 1.6 \mathrm{~km} \mathrm{~s}^{-1}\right)$ y todo el rango de velocidades radiales planteado en la sección 4.1, el ajuste analítico al modelo de rotación circular de la galaxia (MRCG)(Brand \& Blitz (1993)), predice una distancia cinemática de $\simeq 5 \mathrm{kpc}$, en discrepancia con las distancias espectrofotométricas tanto de WR 157 como de Ma 50. No debemos olvidar que en la dirección galáctica en la que se encuentra esta estructura, existen movimientos no circulares de rotación que llevan consigo una incerteza en la determinación de la velocidad radial. Esos movimientos que se "alejan" de los circulares tiene básicamente dos componentes: una aleatoria, debido a la dispersión en la velocidad de las nubes moleculares, y una sistemática, a causa del movimiento del gas en los brazos espirales. De esta forma encontramos una diferencia entre la velocidad radial observada $v_{\text {obs }}$ y la velocidad radial esperada $v_{e s p}$, de acuerdo a este modelo de rotación, llamado velocidad residual $\Delta v_{r e s}=v_{o b s}-v_{e s p}$.

Considerando un valor estimativo de la distancia espectrofotométrica de $\sim 3.4 \mathrm{kpc}$, de acuerdo con el MRCG el gas tendrá una velocidad radial de $\sim-30 \mathrm{~km} \mathrm{~s}^{-1}$. De esta forma, el residuo en la velocidad será $\Delta v_{\text {res }} \sim-17 \mathrm{~km} \mathrm{~s}^{-1}$. Por otro lado, el valor de velocidad residual dado en la figura 10 del trabajo de Brand \& Blitz (1993) da $-20 \pm 5$ $\mathrm{kms}^{-1}$, compatible con $\Delta v_{\text {res }}$, obtenida a partir de la distancia espectrofotométrica. 
Por todo lo expuesto, adoptaremos como distancia a la estructura $3.7 \pm 1.2 \mathrm{kpc}$, dando más peso a las distancias espectrofotométricas.

La Tabla 4.2 muestra los principales parámetros de las estructuras ionizadas, IR y molecular asociadas a SG 13 y WR 157. La densidad electrónica $n_{e}$, la masa ionizada $M_{\text {ion }}$, la medida de emisión $E M$ y el parámetro de excitación observacional $U_{\text {rad }}$ fueron determinados usando las expresiones de Mezger \& Henderson (1967) de la imagen en $1420 \mathrm{MHz}$. Asumimos una geometría esférica para SG 13, con densidad constante; adoptamos una temperatura electrónica $T_{e}=10^{4} \mathrm{~K}$ y suponemos que el He se encuentra una vez ionizado (la masa ionizada derivada de esta forma debe ser multiplicada por 1.27 para tener en cuenta este hecho). Se han incluído densidades electrónicas y masa que corresponden a factores de llenado $f=1$ y $f=0.1-0.2$. Estos últimos tienen en cuenta que SG 13 es un anillo de $14 \pm 3^{\prime}$ de radio, con un espesor de $\sim 5^{\prime}$ y que sólo entre el $10 \%$ y el $30 \%$ de la superficie de la nebulosa está cubierta por plasma.

Basados en las líneas prohibidas del [S II], Lozinskaya et al. (1986) determinaron una densidad electrónica $n_{e}^{\prime}=100-150 \mathrm{~cm}^{-3}$ para la nebulosa (ver sección 4.1), superior a los valores derivados de observaciones en continuo de radio. De acuerdo a Israel (1977), el factor de llenado puede ser estimado como $f=\left(\frac{n e}{n e^{\prime}}\right)^{0.5}$. El resultado indica $f=(2-$ $7) \times 10^{-3}$. Las densidades electrónicas derivadas de cocientes de líneas son más grandes que las obtenidas de observaciones en continuo de radio. Esos valores están asociados a zonas de gran emisividad, mientras que la radiación de continuo proviene de regiones con densidades más bajas. Probablemente el valor real de $f$ se encuentra entre esos dos límites (0.007 y 0.2$)$.

$U_{\text {rad }}$ esta asociado al número de fotones UV usados para ionizar el gas y se obtiene como $U_{\text {rad }}=r n_{e}{ }^{2 / 3}$, donde $r \simeq=15 \pm 5 \mathrm{pc}$, a partir de los datos en continuo de radio. $U_{*}$ está ligado al número de fotones que emiten las estrellas masivas de Ma 50 que ionizan el material neutro $Q\left(\mathrm{H}^{0}\right)$, cuya definición es $U_{*}^{3}=\frac{2 Q\left(\mathrm{H}^{0}\right)}{4 \pi \alpha_{\mathrm{B}}}$, donde $\alpha_{\mathrm{B}}$ es el coeficiente de recombinación a todos los niveles menos al fundamental, que puede ser obtenido de modelos de atmósferas. Para su estimación sólo tomamos la contribución de WR 157 (tipo WN5), ya que el resto de las componentes del cúmulo tiene tipos espectrales más tardíos que B3 (Baume et al. 2004). De acuerdo a Smith et al. (2002), de donde extrajimos el factor $Q_{0}$ que representa la cantidad de fotones capaces de ionizar el $\mathrm{H}, U_{*}=128 \mathrm{pc}$ $\mathrm{cm}^{-2}$. Claramente, $U_{\text {rad }}<U_{*}$, por lo tanto los fotones emitidos por la estrella WR son suficientes para ionizar el gas. Una gran cantidad de fotones UV probablemente escapan al MIE de los alrededores e interactúan con las componentes más frías, como el H i, el medio molecular y las partículas de polvo.

La gran cantidad de gas ionizado involucrado indica que la nebulosa está compuesta principalmente por material del MIE.

Teniendo en cuenta las expresiones obtenidas en el Capítulo 3, hemos determinado las densidades de flujo en 60 y $100 \mu \mathrm{m}$, la temperatura y masa del polvo. También listamos los parámetros físicos del ${ }^{12} \mathrm{CO}(1-0)$, como el centro $(l, b)$ de la estructura, la extensión en velocidad $\Delta v$, la velocidad sistémica, la velocidad de expansión, el radio angular y la densidad columnar. Asumiendo una distancia de $3.7 \pm 1.2 \mathrm{kpc}$, también determinamos el 
radio lineal, y la masa molecular. Los resultados se encuentran en la Tabla 4.2. El cociente gas/polvo derivado teniendo en cuenta las masas listadas en esta tabla es $\sim 150$, superior al valor típico de $\sim 100$ aceptado para regiones H II.

Considerando valores típicos para el viento estelar de una estrella con tipo espectral WN 5, de $\dot{M}=1.75 \times 10^{-5} \mathrm{M}_{\odot}$ años ${ }^{-1}$ y $v_{\infty}=1520 \mathrm{~km} \mathrm{~s}^{-1}$ (Smith et al. 2002), y asumiendo que esta estrella transcurrió por una fase previa de tipo $\mathrm{O}$, con valores $\dot{M}=2.3 \times 10^{-7}$ $\mathrm{M}_{\odot}$ años ${ }^{-1}$ y $v_{\infty}=1950 \mathrm{~km} \mathrm{~s}^{-1}$ (Smith et al. 2002), obtuvimos la luminosidad del viento de WR 157 para ambas fases: $L_{O} \simeq 3.5 \times 10^{35} \mathrm{erg} / \mathrm{seg}$ y $L_{W} \simeq 1.3 \times 10^{37} \mathrm{erg} / \mathrm{seg}$. Teniendo en cuenta los tiempos de quema de $\mathrm{H}$ (fase $\mathrm{O}$ ) $t_{O}=5 \times 10^{6}$ años, y He (fase WR) $t_{W R}$ $=0.4 \times 10^{6}$ años, para una estrella con una masa inicial de $40 \mathrm{M}_{\odot}$ (Meynet et al. 1994), encontramos que la energía mecánica inyectada al medio en la fase $\mathrm{O}$ es $E_{w O} \simeq 5.5 \times 10^{49}$ erg y en la fase $W N, E_{w W R} \simeq 1.6 \times 10^{50} \mathrm{erg}$.

Asumiendo una estructura única (burbuja interestelar), formada por las componentes en continuo de radio, IR y ${ }^{12} \mathrm{CO}$ consideradas en la Tabla 4.2, con una masa total de $(3.8 \pm 2.2) \times 10^{4} \mathrm{M}_{\odot}$, y una velocidad de expansión $v_{\exp }=7 \mathrm{~km} \mathrm{~s}^{-1}$, determinamos la energía cinética de la cáscara de la burbuja interestelar $E_{c}=(2.1 \pm 1.3) \times 10^{49} \mathrm{erg}$. Comparando los valores de energía mecánica del viento y cinética de la burbuja interestelar, encontramos que $\epsilon \simeq 0.01$ y $\pi \simeq 1.8$. Dentro de los errores, esta pareja de valores es compatible con el modelo de consevación de momento. Sin embargo, no puede descartarse completamente que parte de la energía del viento estelar haya drenado a través de la envoltura incompleta.

El tiempo dinámico $t_{d}$ de la burbuja interestelar se obtiene a partir de $t_{d}=\mathrm{C} \frac{R_{\text {bur }}}{v_{\text {exp }}} \times 10^{6}$ años, con $R_{\text {bur }}=16.5 \pm 2 \mathrm{pc}$, radio lineal medio de la burbuja interestelar, y $C=0.55$, constante intermedia entre los valores dados en los modelos de conservación de la energía y del momento. Obtenemos $t_{d} \simeq(1.2 \pm 0.9) \times 10^{6}$ años. Si comparamos este valor con los tiempos de evolución de las distintas fases de la estrella WR 157 dados en los párrafos anteriores, vemos que la edad dinámica es superior al tiempo de evolución de la fase WR. Este hecho estaría evidenciando que la burbuja interestelar ha sido modelada por la estrella WR 157, desde su fase evolutiva previa, es decir, desde la fase O.

Todo lo dicho hasta aquí refuerza la hipótesis de que el principal responsable de la morfología tanto de SG 13, como de las contrapartes IR, en continuo de radio y molecular, es el viento de la estrella WR 157. Consecuentemente, podemos concluir que el entorno del cúmulo abierto ha sido modelado por los fuertes vientos de las estrellas que lo conforman, creando una burbuja interestelar (BI).

\subsection{Conclusiones}

Nuestro análisis del medio interestelar en dirección a SG 13 nos permitió detectar las contrapartes IR y molecular de la nebulosa anillo, así como la emisión en el continuo de radio. Los valores de ajuste del indice $\alpha_{1}$ y $\alpha_{2}$ son compatibles con un régimen térmico a frecuencias en el rango entre 408 y $2700 \mathrm{MHz}$. 
Tabla 4.2: Parámetros físicos de la BI asociada a WR 157

\begin{tabular}{|c|c|}
\hline Distancia adoptada & $3.7 \pm 1.2 \mathrm{kpc}$ \\
\hline \multicolumn{2}{|l|}{ Continuo de radio } \\
\hline $\mathrm{S}_{4850}(\mathrm{Jy})$ & $1.1 \pm 0.3$ \\
\hline $\mathrm{S}_{2700}(\mathrm{Jy})$ & $3.5 \pm 1.0$ \\
\hline $\mathrm{S}_{1420}(\mathrm{Jy})$ & $3.4 \pm 0.9$ \\
\hline $\mathrm{S}_{408}(\mathrm{Jy})$ & $1.8 \pm 0.9$ \\
\hline \multicolumn{2}{|l|}{ Índice espectral $\alpha$} \\
\hline 408 у $1420 \mathrm{MHz}$ & $0.5 \pm 0.3$ \\
\hline 1420 y $2700 \mathrm{MHz}$ & $0.03 \pm 0.1$ \\
\hline Radio angular (') & $14 \pm 3$ \\
\hline Radio lineal (pc) & $15 \pm 5$ \\
\hline$E M\left(\mathrm{pc} \mathrm{cm}{ }^{-6}\right)$ & 570 \\
\hline$n_{e}(f=1)$ & $4 \pm 1$ \\
\hline$n_{e}(f=0.1-0.2)\left(\mathrm{cm}^{-3}\right)$ & 15-9 \\
\hline$M_{\text {ion }}(f=1)\left(\mathrm{M}_{\odot}\right)$ & $3700 \pm 600$ \\
\hline$M_{\text {ion }}(f=0.1-0.2)\left(\mathrm{M}_{\odot}\right)$ & $1100-1500$ \\
\hline$U_{\text {rad }}\left(\mathrm{pc} \mathrm{cm}^{-2}\right)$ & 45 \\
\hline$U_{*}\left(\mathrm{pc} \mathrm{cm}^{-2}\right)$ & $\sim 128$ \\
\hline \multicolumn{2}{|l|}{$I R$} \\
\hline $\mathrm{S}_{60}(\mathrm{Jy})$ & $\sim 6.9 \times 10^{3}$ \\
\hline $\mathrm{S}_{100}(\mathrm{Jy})$ & $\sim 2.25 \times 10^{4}$ \\
\hline Temperatura $(\mathrm{K})(n=1-1.5)$ & 28-31 \\
\hline $\operatorname{Masa}\left(\mathrm{M}_{\odot}\right)$ & $250 \pm 50$ \\
\hline${ }^{12} \mathrm{CO}$ & $(1-0)$ \\
\hline Centro $(l, b)$ & $111^{\circ} 15^{\prime},-0^{\circ} 15^{\prime}$ \\
\hline Rango en velocidad $\Delta v\left(\mathrm{~km} \mathrm{~s}^{-1}\right)$ & $-58.4,-43.5$ \\
\hline Velocidad sistémica $\left(\mathrm{km} \mathrm{s}^{-1}\right)$ & $-47.6 \pm 1.6$ \\
\hline Velocidad de expansión $\left(\mathrm{km} \mathrm{s}^{-1}\right)$ & $7 \pm 1$ \\
\hline Radio angular (' $)$ & $17.5 \pm 3$ \\
\hline Radio lineal (pc) & $18 \pm 5$ \\
\hline Densidad de columna promedio $\left(\mathrm{cm}^{-2}\right)$ & $3.8 \times 10^{21}$ \\
\hline $\operatorname{Masa}\left(\mathrm{M}_{\odot}\right)$ & $(3.7 \pm 2.2) \times 10^{4}$ \\
\hline
\end{tabular}


El polvo asociado presenta una distribución similar al gas ionizado, lo que evidencia que ambos están mezclados.

Nubes de gas molecular rodean las emisiones ionizada y del polvo. La velocidad del gas molecular es compatible con las mediciones para el gas ionizado dadas en la literatura. Este gas molecular representa la componente neutra de la burbuja interestelar.

El flujo de fotones UV de la estrella WR 157 es suficiente para ionizar el gas. Concluimos que esta burbuja interestelar comienza a expandirse ya en la fase $\mathrm{O}$ de la estrella WR 157, debido a que su tiempo dinámico es casi tres veces superior al tiempo de la fase WR de la estrella WR 157.

La evidencia reunida favorece la existencia de una BI con emisión multifrecuencia, generada por los fuertes vientos de la estrella WR 157. 


\section{Bibliografía}

Baume G., Vazquez R.A., Carraro G., 2004, MNRAS, 355, 475

Blitz L., Fich M., Stark A. A., 1982, ApJS, 49, 183

Brand J., Blitz L. 1993, A\&A, 275, 67

Cappa C.E., 2006, RMxAC, 26, 9

Cappa C., Goss W.M., Pineault S., 2002, AJ, 123, 3348

Cappa C. E., Rubio M., Goss W. M., 2001, AJ, 121, 2664

Condon J. J., Broderick J. J., Seielstad G. A., 1991, AJ, 102, 2041

Conti P.S., 1976, MSRSL, 9, 193

Egan M.P., Shipman R.F., Carey S.J., Mizuno D.R., Kuchar T.A., Price S.D., Moshir M, 1999, AAS, 19312203

Elmegreen B.G., ApJ, 2000, 530, 277

Elmegreen B.G., Lada C. J., 1977, ApJ, 214, 725

Georgelin, Y. M., Georgelin, Y. P., 1976, A\&A, 49, 57

Georgelin, Y. M., 1975, CRASB, 280, 349

Georgelin, Y. M., Georgelin, Y. P., Roux S., 1973, A\&A, 25, 337

Israel F.P., 1977, A\&A, 59, 27

Junkes N., Fürst E., Reich W., 1992, A\&AS, 261, 289

Landecker T.L., Dewdney P.E., Burgess T.A., Gray A.D., Higgs L.A., Homann A.P., Hovey1 G.J., KarpaD.R., Lacey J.D., Prowse N., Purton C.R., Roger R.S., Willis A.G., Wyslouzil W., Routledge D., Vaneldik J.F, 2000, A\&AS, 145, 509

Leitherer C, Chapman J.M., Koribalski B., 1997, ApJ, 481, 898

Lumsden S. L., Hoare M. G., Oudmaijer R. D., Richards D., 2002, MNRAS, 336, 621

Lundstrom I., Stenholm B., 1984, A\&AS, 58, 163

Lozinskaia T.A., Sitnik T.G., Lomovskii A.I., 1986, Ap\&SS, 121, 357

Maeder A., 1983, A\&A, 120, 113

Marston A.P., Yocum D. R., García-Segura G., Chu, Y.-H. 1994a, ApJS, 93, 229

Meynet G., Maeder A., Schaller G., Schaerer D., Charbonnel C., 1994, A\&AS, 103, 97

McClure-Griffiths N. M., Dickey J. M., Gaensler B. M., Green A. J., Haverkorn M., Strasser S., 2005, ApJ, in press.

Mezger P.G., Henderson A.P., 1967, ApJ, 147, 471

Oey M.S., 1996, PASP, 108, 547O

Pedlar A., 1980, MNRAS, 192, 179

Reich W., Fuerst E., Reich P., Reif K., 1990, A\&AS, 85, 633

Ridge N.A., Di Francesco J., Kirk H., Li D., Goodman A.A., Alves J.F., Arce H.G., Borkin M.A., Caselli P., Foster J.B., Heyer M.H., Johnstone D.; Kosslyn D.A., Lombardi 
M., Pineda J.E., Schnee S.L., Tafalla M., 2006, AJ, 131, 2921

Shain C.A., 1951, AuSRA, 4, 258

Sharpless S., 1959, ApJS, 4, 257

Smith L., Norris R., Crowther P.A., 2002, MNRAS, 1, 21

Smith L.J., Willis A.J., 1994, Ap\&SS, 221, 189

Sodroski T.J., 1991, ApJ, 366, 95

Turner D.G., Moffat A.F.J., Lamontagne R., Maitzen H.M., 1983, AJ, 88, 1199

van der Hucht K. 2001, New astronomy Rev., 45, 135

Vasquez J., Cappa C. E., Pineault S., 2005, BAAA, 48, 302 


\section{Capítulo 5}

\section{El medio interestelar modelado por los vientos de las estrellas WR 152 y WR 153ab}

\section{Resumen}

En este capítulo analizamos la distribución del material interestelar en las cercanías de las estrellas Wolf-Rayet WR 152 (= HD 211564) y WR 153 ab (= HD 211853) asociadas a la región H II Sh 2-132. Nuestro estudio está basado en observaciones en el continuo de radio, línea de $21 \mathrm{~cm}$ del hidrógeno neutro, línea molecular del ${ }^{12} \mathrm{CO}(1-0)$ en $115 \mathrm{GHz}$ y datos IR de los satélites IRAS y MSX.

Detectamos contrapartes en continuo de radio e IR de las dos cáscaras ionizadas asociadas a WR 152, como así también una estructura de $\mathrm{H}$ I con forma de arco. De esta forma, pudimos obtener los parámetros de la burbuja interestelar asociada.

En el caso de WR 153ab, identificamos las componentes molecular y de polvo contenidas en la nebulosa. La emisión en la banda A del satélite MSX sugiere la presencia de zonas de fotodisociación en el límite entre el frente ionizado y las nubes moleculares. La energía mecánica del viento estelar de ambas estrellas WR es suficiente para impulsar la expansión del material ionizado y neutro de las burbujas.

\subsection{Introducción y antecedentes}

WR 152 y WR 153ab son dos estrellas Wolf-Rayet que se encuentran en el segundo cuadrante de la galaxia, ubicadas sobre el plano galáctico. Su distancia angular es del orden de 30', y el medio interestelar, al menos en dirección hacia estos objetos, presenta emisión desde la región óptica del espectro electromagnético (EE), hasta la zona de radiofrecuencias, indicando el accionar de numerosos procesos físicos. 
WR 152 y WR 153ab están asociadas a Sh2-132 (Sharpless 1959). La Fig. 5.1 muestra la imagen óptica (DSSR) de la región Sh2-132 y de su entorno. Se puede advertir una gran diferencia de brillo entre las zonas a $l>102^{\circ} 35^{\prime}$ respecto al resto.

De la región muy intensa se desprende una serie de filamentos con aspecto arqueado, entre los que se hallan dos estructuras concéntricas que rodean a WR 152, indicada por la cruz negra. Heckathorn et al. (1982) observaron esta región en líneas de [OIII] y H $\alpha$. Ellos asociaron a WR 152 dos estructuras anulares con diámetros de $36^{\prime}$ y $17^{\prime}$. Ambas estructuras se identifican bien en [OIII], mientras que en $\mathrm{H} \alpha+[\mathrm{NII}]$ el anillo interno aparece más difuso. La estrella WR aparece desplazada $3.7^{\prime}$ respecto del centro del anillo interno. Estas estructuras fueron definidas por Marston (1994) como una nebulosa anillo multiple asociada a WR 152. Marston (1996) sugirió la asociación de WR 152 con una estructura IR observada con el satélite IRAS y determinó un diámetro angular para la estructura IR de $21^{\prime}$.

WR 153ab, en cambio, está "enterrada" dentro de una zona con emisión muy intensa. Su ubicación está representada por la cruz roja en la Fig. 5.1. El tamaño de esta región más intensa es de 20.7'. La emisión de [OIII] muestra una región muy brillante cerca de la posición de WR 153ab. Se distingue emisión extendida que parece desprenderse de la región saturada. La imagen $\mathrm{H} \alpha$ muestra una cáscara casi completa de $\sim 34^{\prime}$ de diámetro, centrada en $\left(l_{2}, b_{2}\right)=\left(102^{\circ} 48^{\prime},-0^{\circ} 38^{\prime}\right)$ que no es evidente en la Fig. 5.1 debido a la escala de intensidades.

Massey (1981) da un valor del módulo de distancia de 13.2 para WR 153ab, en buen acuerdo con el propuesto por Crampton (1971) para la nebulosa. Van der Hucht (2001) ubica a WR 153ab a una distancia espectrofotométrica de $2.75 \mathrm{kpc}$.

Posteriormente, Miller \& Chu (1993), llevaron a cabo nuevas observaciones en $\mathrm{H} \alpha$ y [OIII $] \lambda 5007$. Estas observaciones revelaron un arco de $4^{\prime}$ de diámetro hacia el sudeste de la estrella WR 153ab. Los autores sugirieron que esa morfología es similar a la exhibida por el anillo asociado a WR 113. La emisión en [OIII] es difusa. Es posible que el arco observado en $\mathrm{H} \alpha$ y [OIII] represente la emisión de un frente de ionización.

Georgelin \& Georgelin (1976) observaron la línea $\mathrm{H} \alpha$ en dirección a la parte brillante de Sh2-132. Obtuvieron una velocidad radial $v_{L S R}=-50.9 \mathrm{~km} \mathrm{~s}^{-1}$. Reynolds (1988) observó líneas prohibidas de [SII] en $\lambda 6716$ y $\lambda 6731$ y determinó un cociente de intensidad $\frac{\lambda 6716}{H_{\alpha}}=0.056 \pm 0.006$, una $v_{L S R}=-48 \pm 1 \mathrm{~km} \mathrm{~s}^{-1}$ y una medida de emisión $E M=2200$ $\mathrm{cm}^{-6}$ pc. Esteban \& Rosado (1995) observaron la nebulosa en las líneas $\mathrm{H} \beta$, [OIII], H $\alpha$ y líneas de $\mathrm{S}$ y N. A partir de la línea $\mathrm{H} \alpha$, encontraron velocidades en el rango -40 a $-59 \mathrm{~km} \mathrm{~s}^{-1}$, y derivaron densidades electrónicas de $290 \pm 100 \mathrm{~cm}^{-3}$ a partir del cociente de líneas ópticas. En base a su morfología de cáscara, clasificaron a la nebulosa asociada a WR 153ab como tipo $R_{s}$. Quireza et al. (2006), a partir de observaciones de líneas de recombinación de He e $\mathrm{H}$ encontraron $v_{L S R}=-50.46 \mathrm{y}-49.48 \mathrm{~km} \mathrm{~s}^{-1}$, respectivamente, para el gas ionizado. Por otro lado, Churchwell \& Walmsley (1973) observaron la nebulosa en $2695 \mathrm{MHz}$ y reunieron información de densidades de flujo para esta región en otras frecuencias y lograron estimar un índice espectral $\alpha=-0.1$ en la región de alta frecuencia. Además, adoptaron una distancia para WR 153ab de $3.68 \mathrm{kpc}$ en base al tipo espectral 
Tabla 5.1: Estrellas tempranas en dirección a Sh2-132

\begin{tabular}{|c|c|c|c|c|c|}
\hline & \multicolumn{2}{|c|}{ WR152 (=HD 211564) } & \multicolumn{3}{|c|}{ WR153ab (=HD 211853) } \\
\hline$(l, b)\left(^{\circ}\right)$ & $\overline{(102.23,-0.89)}$ & & $(102.78,-0.65)$ & & \\
\hline Tipo espectral & $\mathrm{WN} 3(\mathrm{~h})^{(1)}$ & & $\mathrm{WN} 6 / \mathrm{WC}+\mathrm{O} 6 \mathrm{I}^{(1)}$ & & \\
\hline $\mathrm{A}_{v}$ (mag.) & $1.62^{(2)}$ & & $2.28^{(2)}$ & & \\
\hline$d(\mathrm{kpc})$ & $2.75^{(2)}$ & & $2.75^{(2)}, 3.5^{(3)}$ & & \\
\hline$\dot{M}\left(10^{-5} \mathrm{M}_{\odot} \mathrm{años}^{-1}\right)$ & $4^{(3)}$ & & $<2^{(4)}$ & & \\
\hline $\mathrm{v}_{\infty}\left(\mathrm{km} \mathrm{s}^{-1}\right)$ & $2000^{(5)}$ & & $1785^{(6)}$ & & \\
\hline Nombre & $(l, b)$ & T.E. & $\begin{array}{c}V \\
\text { mag. }\end{array}$ & $(B-V)$ & $\begin{array}{c}d \\
\mathrm{kpc}\end{array}$ \\
\hline$\overline{\mathrm{BD}+552722}$ & $102^{\circ} 48^{\prime} 18^{\prime \prime},-0^{\circ} 40^{\prime} 4.8^{\prime \prime}$ & O9Ve & 9.91 & 0.45 & 2.6 \\
\hline LS III+55 40 & $102^{\circ} 56^{\prime} 16.8^{\prime \prime},-0^{\circ} 42^{\prime} 21.6^{\prime \prime}$ & $\mathrm{O} 9 \mathrm{~V}$ & 12.08 & 0.64 & 5.4 \\
\hline LS III+55 45 & $102^{\circ} 59^{\prime} 13.2,-0^{\circ} 45^{\prime} 28.8^{\prime \prime}$ & O8III & 10.45 & 0.70 & 3.8 \\
\hline
\end{tabular}

(1) Smith et al. (1998), (2) van der Hucht (2001), (3) Nugis \& Lamers (2000), (4) Cappa et al. (2004),

(5) Crowther et al. (1995), (6) Prinja et al. (1990)

WN6+BOI para la estrella, diferente al aceptado en estudios posteriores.

La Tabla 5.1 lista los principales parámetros de las estrellas WR 152 y WR 153ab. En la primer fila figura la posición en coordenadas galácticas, en la segunda su tipo espectral, luego la absorción visual $A_{v}$, la distancia espectrofotométrica, la tasa de pérdida de masa, y en la última fila, la velocidad terminal. Ambas estrellas son posibles miembros de Cep OB1. De acuerdo a Panov \& Seggewiss (1990), WR 153ab presenta dos curvas de luz, que muestran que la estrella es un sistema múltiple formado por dos sistemas binarios. Cada uno de ellos estaría formado por una estrella WR y una estrella O. Se listan en la misma tabla las estrellas en dirección a Sh2-132 (no están incluidas las dos componentes O del sistema WR 153ab). La búsqueda se llevó a cabo utilizando los catálogos de MaízApellániz et al. (2004), Garmany et al. (1982) y Buscombe (1999). En la tabla figuran el nombre de la estrella (columna 1 ), la magnitud $V$, el índice de color $(B-V)$ y su distancia estimada a partir de las magnitudes absolutas de Vacca et al. (1996) y de los índices de color intrínsecos de Wegner (1994).

Uno de los trabajos más interesantes fue el de Harten et al. (1978), que han analizado la región en continuo de radio con observaciones del Westerbork Synthesis Radio Telescope (WSRT) en $610 \mathrm{MHz}$ y $4995 \mathrm{MHz}$ con un haz sintetizado de $56^{\prime \prime} \times 60^{\prime \prime}$ y $6.6^{\prime \prime}$ $\times 7.9^{\prime \prime}$, respectivamente. Ellos encontraron que Sh2-132 es una región H II evolucionada. Detectaron dos estructuras de tipo cáscara que denominaron, Shell A y Shell B. Sugirieron que la Shell B está asociada a WR 153ab y a una estrella tipo O8.5V (BD+55²722, que posteriormente fue clasificada como O9Ve, ver Tabla 5.1). Encontraron que se observa 3 veces más flujo en continuo de radio en la nebulosa que aquel que emiten ambas estrellas WR. Esta diferencia puede deberse a la presencia de estrellas tempranas oscurecidas por 


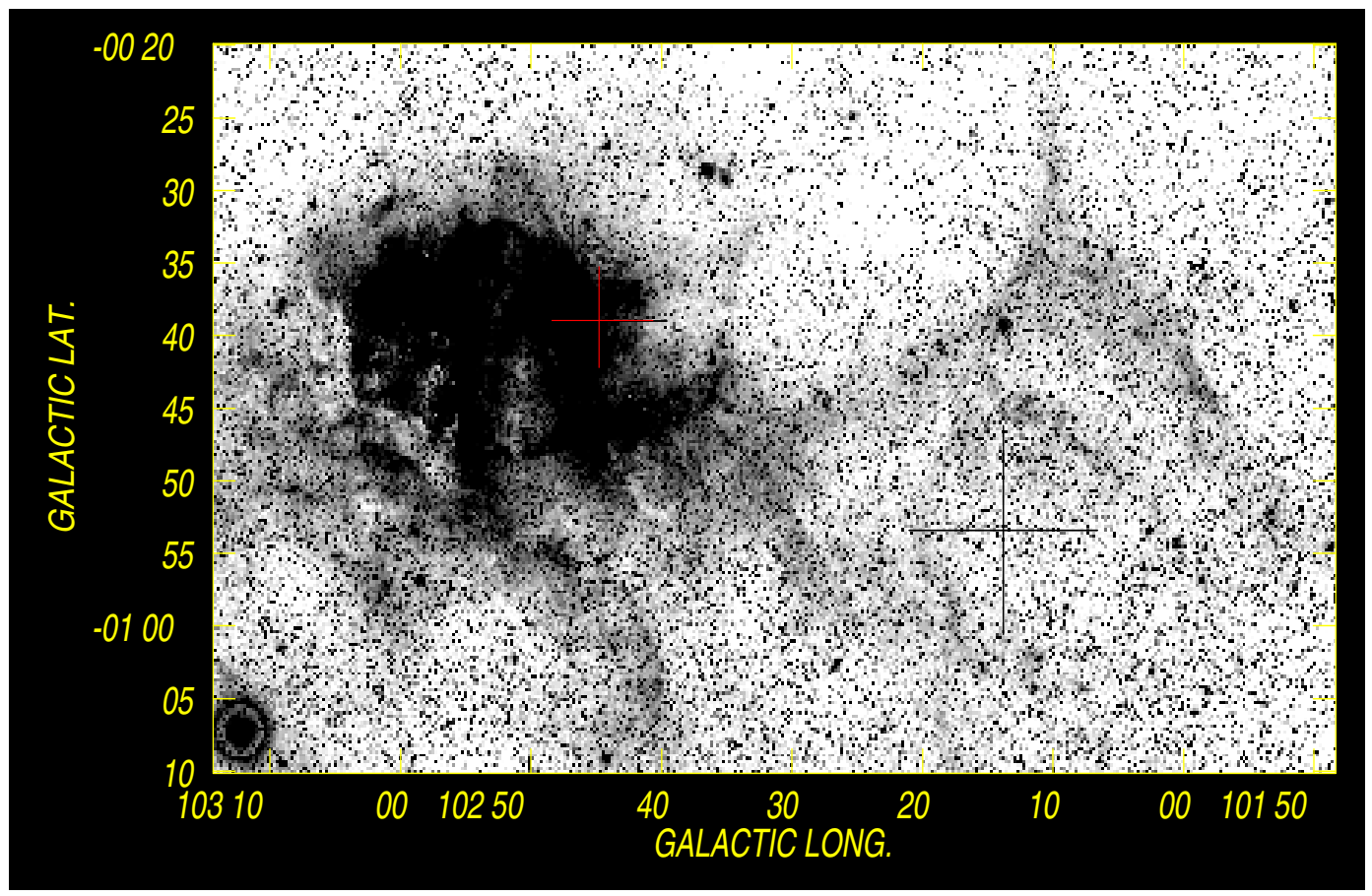

Figura 5.1: Imagen de la nebulosa anillo óptica Sh2-132, obtenida del DSS R. La escala de brillo está en unidades arbitrarias. Las estrellas WR 153ab y WR 152 están indicadas por las cruces roja y negra, respectivamente.

el polvo interestelar (Harten et al. 1978). Además, esta región ha sido observada en 1400 $\mathrm{MHz}$ y $408 \mathrm{MHz}$, con una resolución angular de $\sim 10^{\prime}$ (Felli et al. 1977) y 4.2' $\times 1.9^{\circ}$ (Felli \& Chuchwell 1972), respectivamente. Se determinó un valor de la densidad de flujo en 408 $\mathrm{MHz}$ de $S_{408} \sim 64 \mathrm{Jy}$.

Nuestro objetivo fue determinar si la contribución de la emisión en cada zona del EE se origina en regiones asociadas con las estrellas WR, y de este modo estudiar en forma integral la dinámica y energética de esa región. A partir del análisis de imágenes en 408 y $1420 \mathrm{MHz}$ con una resolución angular aproximadamente 10 veces mejor que la de los datos prexistentes, la idea fue determinar la naturaleza de la emisión en continuo de radio. Además, analizamos las contrapartes IR y molecular de la nebulosa óptica. Los resultados se reunieron en el trabajo Cappa et al. (2006).

\subsection{Base de datos utilizada}

En este trabajo se utilizó para el análisis del hidrógeno neutro en la línea de $21 \mathrm{~cm}$, un cubo de datos de H I de la base de datos del Canadian Galactic Plane Survey (CGPS). Para el estudio del medio molecular se utilizaron datos de la línea de ${ }^{12} \mathrm{CO}(1-0)$ en 115 GHz, obtenidos del Five College Radio Astronomy Observatory (EEUU). Los principales 
Tabla 5.2: Parámetros observacionales de los cubos de datos de $\mathrm{H} \mathrm{I} \mathrm{y}{ }^{12} \mathrm{CO}$

\begin{tabular}{lcc}
\hline & $\mathrm{H}$ & ${ }^{12} \mathrm{CO}(1-0)$ \\
\hline Centro $(l, b)$ & $\left(102^{\circ} 30^{\prime},-1^{\circ} 0^{\prime}\right)$ & $\left(104^{\circ} 45^{\prime},-0^{\circ} 0^{\prime}\right)$ \\
FWHM del haz sintetizado & $1.36^{\prime} \times 1.36^{\prime}$ & $\sim 1^{\prime}$ \\
Cobertura en velocidad (LSR) $\left(\mathrm{km} \mathrm{s}^{-1}\right)$ & $-60,58.6$ & $-60,58.6$ \\
Resolucion en velocidad $\left(\mathrm{km} \mathrm{s}^{-1}\right)$ & 0.824 & 0.824 \\
Ruido rms $(\mathrm{K})$ & 4 & 0.15 \\
\hline
\end{tabular}

parámetros observacionales de los cubos de datos de $\mathrm{H}$ i y ${ }^{12} \mathrm{CO}$ están detallados en la Tabla 5.2. Debemos tener en cuenta que este último no llega a cubrir angularmente la posición de WR 152. La longitud galáctica mínima que alcanza el cubo de CO es $l \simeq$ $102^{\circ} 25^{\prime}$.

Para el estudio del continuo de radio utilizamos datos en 408 y $1420 \mathrm{MHz}$ del CGPS con un haz sintetizado de $3.4^{\prime} \times 3.9^{\prime}$ y $58^{\prime \prime} \times 67^{\prime \prime}$, y un ruido $r m s$ de $\sim 1$ y $1.5 \mathrm{~K}$, respectivamente.

Se estudió la emisión de radiación en el IR medio y lejano, a partir de datos del satélite IRAS en sus cuatro bandas de observación, es decir, en 12, 25, 60 y $100 \mu \mathrm{m}$. Para estas dos últimas bandas se utilizaron datos de alta resolución angular (HIRES). Además contamos con datos del satélite Midcourse Space Experiment (MSX) en el IR medio con una resolución angular de $18.4^{\prime \prime}$, centradas en $8.28 \mu \mathrm{m}$ (banda A), $12.13 \mu \mathrm{m}$ (banda C), $14.65 \mu \mathrm{m}$ (banda D) y en $21.3 \mu \mathrm{m}$ (banda E).

\subsection{Estudio del $\mathrm{H}$ I en gran escala}

En esta sección vamos a realizar el estudio de la distribución del hidrógeno neutro en gran escala en dirección a la nebulosa Sh2-132.

En la Fig. 5.2 se despliega el perfil de H I en dirección a WR 153ab para todo el rango de velocidades radiales que abarca el cubo de H I. Como puede verse claramente, la mayor intensidad en $T_{b}$ se observa en el rango delimitado entre $\sim-75 \mathrm{y}+10 \mathrm{~km} \mathrm{~s}^{-1}$. Los mayores valores son del orden de $65 \mathrm{~K}$ y aparecen en $\sim-55 \mathrm{~km} \mathrm{~s}^{-1} \mathrm{y} \sim 0 \mathrm{~km} \mathrm{~s}^{-1}$. Entre estos "picos" se ve una "depresión" en la intensidad que llega hasta valores del orden de $\sim 20 \mathrm{~K}$ a una velocidad de $-10 \mathrm{~km} \mathrm{~s}^{-1}$. Dentro de esta "depresión" se ven unos picos secundarios con valores que llegan a $50 \mathrm{~K}$ en $-45 \mathrm{~km} \mathrm{~s}^{-1}$ y a $30 \mathrm{~K}$ en $-25 \mathrm{~km} \mathrm{~s}^{-1}$.

Teniendo en cuenta las velocidades observadas a lo largo de la línea de la visual (Brand \& Blitz 1993), las componentes a $-55,-45$ y $-25 \mathrm{~km} \mathrm{~s}^{-1}$ están ubicadas a $\sim 5,3$ y $1.7 \mathrm{kpc}$, respectivamente, correspondiendo al gas en los brazos de Perseo y Cygnus. La componente a $v=0 \mathrm{~km} \mathrm{~s}^{-1}$ está ubicada en el brazo local.

Llevamos a cabo un análisis de la distribución de H i en una región de aproximadamente 


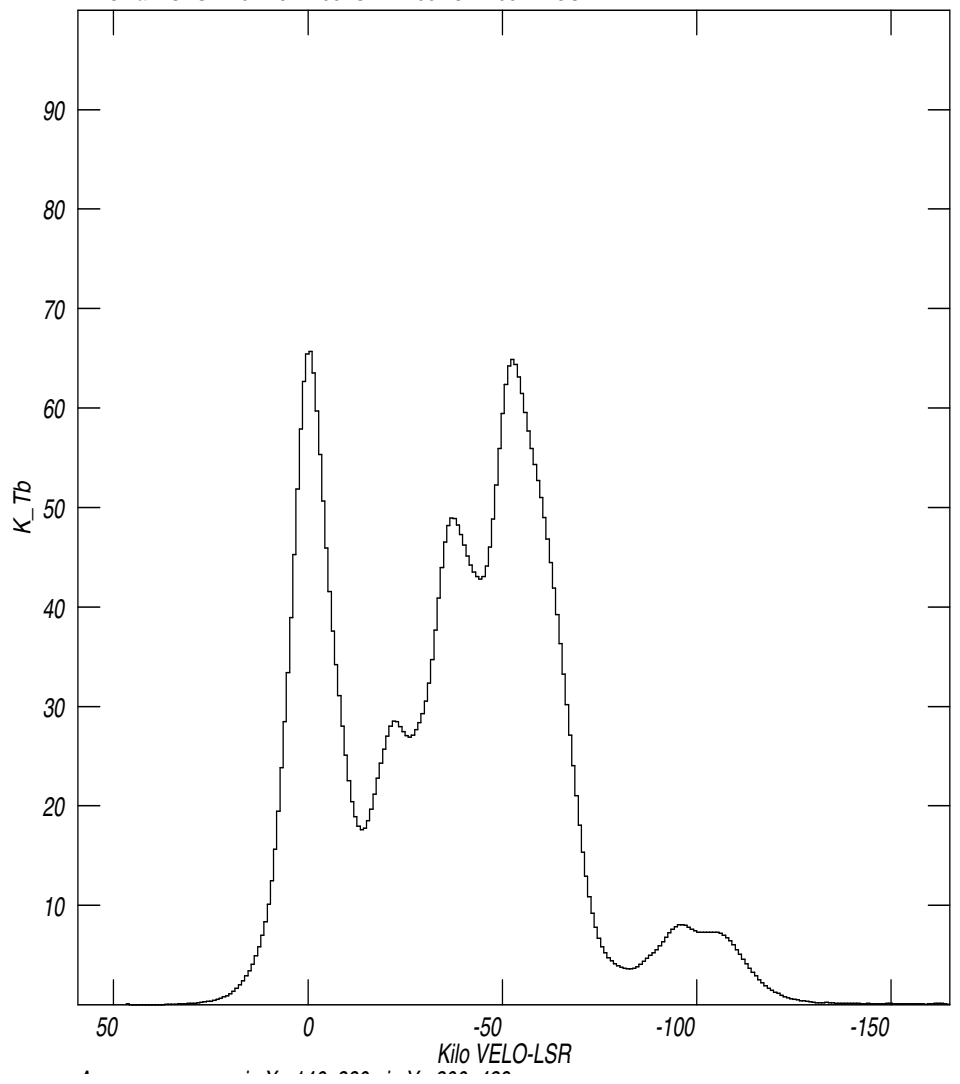

Figura 5.2: Perfil de H I a lo largo de la línea de la visual en dirección a WR 153ab. 


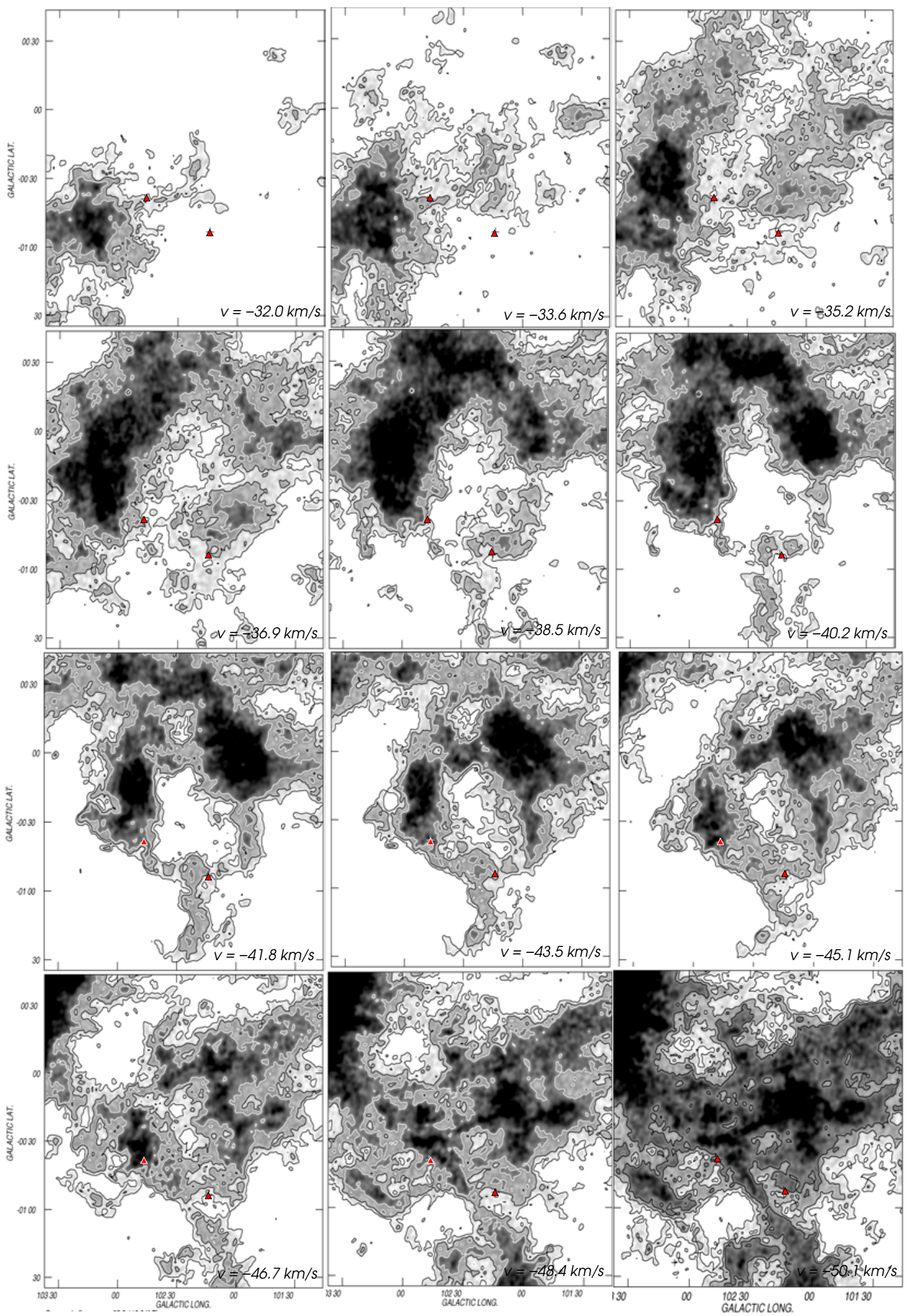

Figura 5.3: Distribución del H I en dirección a las estrellas WR 153ab y WR 152, en el intervalo $v_{r}=[-32.0,-50.1] \mathrm{km} \mathrm{s}^{-1}$, en pasos de $1.64 \mathrm{~km} \mathrm{~s}^{-1}$. Los grisados incluyen el rango entre 65 a $110 \mathrm{~K}$, mientras que las líneas de contorno indican 65, 75 y $85 \mathrm{~K}$. 
$2.5^{\circ} \times 2.5^{\circ}$ centrada en Sh2-132 correspondiente a todo el rango de velocidades radiales en dirección a WR 152 y WR 153ab, y detectamos una estructura con aspecto de cáscara (ver Fig. 5.3), con un diámetro angular de $\sim 60^{\prime}$, obtenido siguiendo los máximos de la distribución del gas neutro. Los rasgos más sobresalientes de esta estructura son sus dos nubes simétricas respecto a una zona libre de material neutro, centrada en $(l, b)=\left(102^{\circ} 30^{\prime}\right.$, $-0^{\circ} 30^{\prime}$ ) cuya distribución es alargada en dirección casi perpendicular al plano galáctico.

Los mapas muestran la distribución del gas neutro en la región de Sh2-132, para las velocidades $v_{L S R}=[-32.0,-50.1] \mathrm{km} \mathrm{s}^{-1}$, en pasos de $1.64 \mathrm{~km} \mathrm{~s}^{-1}$. La estructura que describiremos en esta sección la llamaremos "gran estructura" (GE). La cavidad de H I se distingue en el rango de velocidades desde -33.6 hasta $-46.7 \mathrm{~km} \mathrm{~s}^{-1}$. Sin embargo, el mayor contraste en $T_{b}$ entre la cavidad y la cáscara lo podemos observar entre -38.5 y $-46.7 \mathrm{~km} \mathrm{~s}^{-1}$. La velocidad sistémica de la estructura es $-40.2 \pm 1.6 \mathrm{~km} \mathrm{~s}^{-1}$ y su extensión, $\simeq 1^{\circ}$ de diámetro. La geometría de la cáscara es, en proyección sobre el plano del cielo, circular. La parte superior, es decir, el sector de la cáscara a $b>-30^{\prime}$ presenta las regiones de mayor intensidad y es más "gruesa" que la parte inferior. Desde la imagen a velocidad $-35.2 \mathrm{~km} \mathrm{~s}^{-1}$ hasta aquella a velocidad $-48.4 \mathrm{~km} \mathrm{~s}^{-1}$, las estrellas WR 152 y WR 135ab están proyectadas sobre la parte inferior de la cáscara, en la región más angosta y con emisión relativamente baja. Comparando esta figura con la Fig. 5.1, vemos que no hay elementos morfológicos claros para asociar a Sh2-132 a la GE de H I, salvo el hecho de que está proyectada sobre el sector de menor intensidad de la estructura.

La Fig. 5.4 muestra la emisión de H i integrada en el intervalo -32.0 a $-50.1 \mathrm{~km} \mathrm{~s}^{-1}$ con las estrellas claramente indicadas. Si comparamos esta distribución con el sector más brillante de la Fig. 5.1, es decir, con el sector de la nebulosa Sh2-132, asociada a WR 153ab, vemos que la forma del H i no sigue ni bordea la nebulosa óptica. En lo referente a WR 152, el análisis detallado se encuentra en la sección 5.4.2.

A partir del ajuste analítico al modelo de rotación circular galáctica de Brand \& Blitz (1993), su velocidad radial corresponde a una distancia cinemática $d_{\text {cin }} \simeq 4.7 \mathrm{kpc}$. Como veremos en la sección 5.6, teniendo en cuenta los movimientos no circulares, la distancia a esta estructura es $3.5 \pm 0.5 \mathrm{kpc}$.

En la siguientes secciones haremos un análisis más detallado del medio interestelar en dirección a WR 152 y a WR 153ab.

\subsection{Análisis multifrecuencia en dirección a WR 152}

Como se muestra en la Fig. 5.1, la nebulosa óptica Sh2-132 presenta unos filamentos que se "desprenden" de la región más intensa. La estrella WR 152 se encuentra proyectada entre esos filamentos, que presentan un aspecto semicircular, con un anillo externo de $\sim 30^{\prime}$ de radio y un anillo interno más pequeño de $\sim 20^{\prime}$ de radio. Ambos anillos son concéntricos.

Hasta el momento no se han realizado estudios en líneas ópticas ni en líneas de recombinación en radio en este sector de la región H II que permitan determinar la velocidad radial del gas ionizado. En las siguientes secciones se llevará a cabo un estudio en continuo 


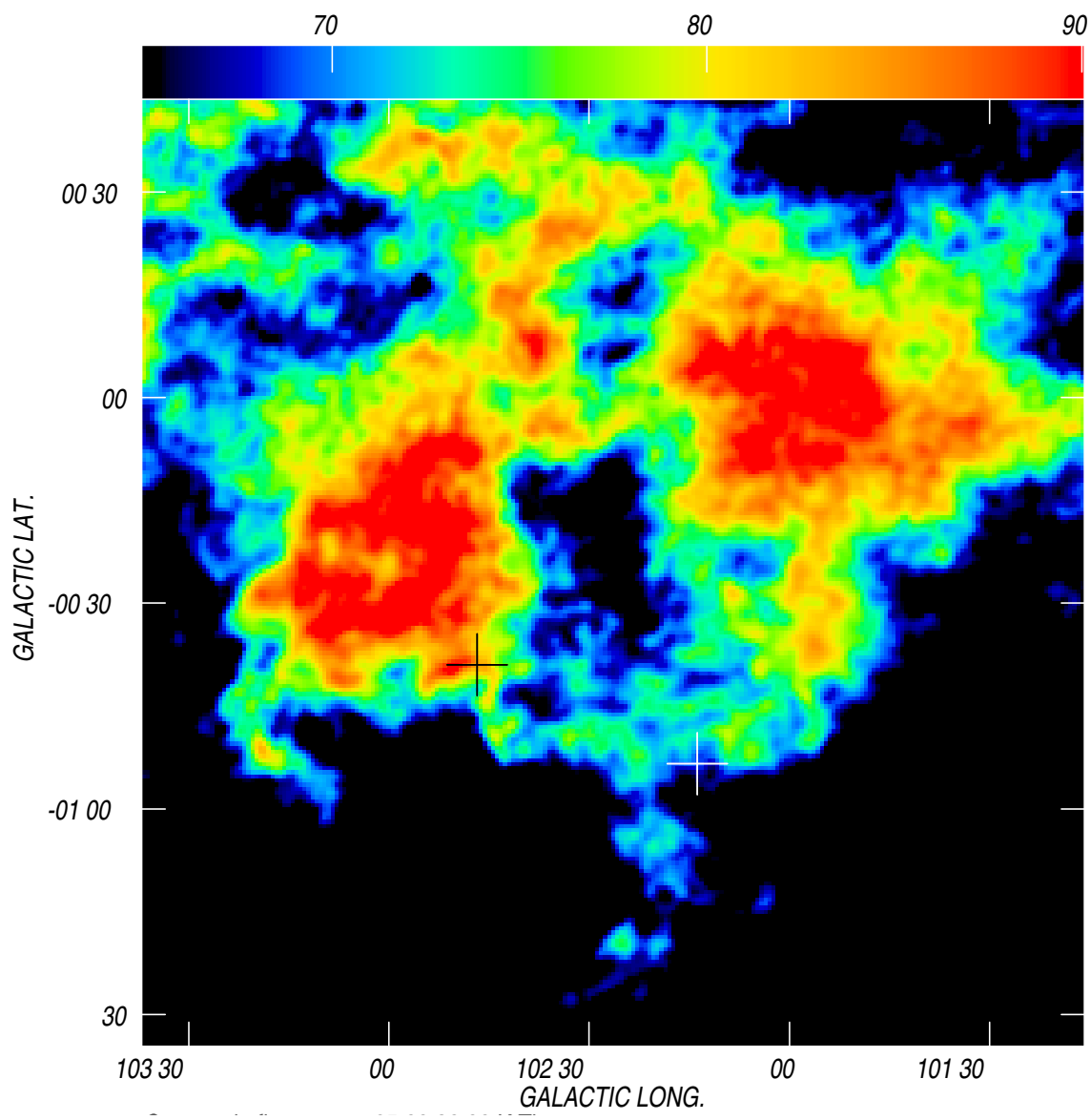

Figura 5.4: Imagen de la temperatura de brillo media entre -32.0 y $-50.1 \mathrm{~km} \mathrm{~s}^{-1}$ de la GE. La barra superior muestra la escala de intensidades en Kelvin. Las estrellas WR están indicadas con las cruces. 
de radio, hidrógeno neutro y en IR, que nos ayudará a comprender los fenómenos físicos responsables de la emisión.

\subsubsection{Radiación en el continuo de radio}

En esta sección analizaremos la emisión en el continuo de radio en la vecindad de WR 152. La Fig. 5.6(a) muestra la imagen en $408 \mathrm{MHz}$ del CGPS. La distribución de la emisión en torno a la posición de WR 152, representada por la cruz, revela la presencia de una estructura semicircular encerrando una zona de baja emisión centrada en la estrella. Sobre esa cáscara se distinguen tres regiones muy intensas en las posiciones $\left(l_{1}, b_{1}\right)=\left(102^{\circ} 22^{\prime},-1^{\circ} 5^{\prime}\right),\left(l_{2}, b_{2}\right)=\left(102^{\circ} 19^{\prime},-0^{\circ} 57^{\prime}\right)$ y $\left(l_{3}, b_{3}\right)=\left(101^{\circ} 59^{\prime},-0^{\circ} 50^{\prime}\right)$. A $b>-0^{\circ} 45^{\prime}$, la cáscara se separa en dos máximos de emisión que los podríamos distinguir como dos "ramas", separadas por una región de baja emisión, ubicada hacia $(l, b)=\left(102^{\circ} 5^{\prime},-0^{\circ} 43^{\prime}\right.$ ) . La región de emisión intensa en $(l, b)=\left(102^{\circ} 30^{\prime},-0^{\circ} 45^{\prime}\right)$ está asociada a la nebulosa óptica Sh2-132, cuya morfología y distribución será discutida en la sección 5.5 de este mismo capítulo.

En la Fig. 5.6(b) se muestra la distribución de la emisión en 1420 MHz. Las dos ramas mencionadas en el párrafo anterior se separan a esta frecuencia, identificándose claramente dos estructuras concéntricas centradas en la posición de WR 152: un arco semicircular muy intenso con un radio angular $\simeq 8^{\prime}$, y una estructura también semicircular, con un radio angular de $\sim 18^{\prime}$. Al igual que en la imagen en $408 \mathrm{MHz}$, se detectan tres fuentes muy intensas en las posiciones $\left(l_{1}, b_{1}\right),\left(l_{2}, b_{2}\right)$ y $\left(l_{3}, b_{3}\right)$, correspondientes a las radiofuentes extragalácticas 87GB 2216+5517, 87GB 221520.4+552034 y NVSS J222006+560546, respectivamente, encontradas en el NASA/IPAC Extragalactic Database (NED). Estas tres fuentes han sido eliminadas en el proceso de la medición del flujo de la nebulosa. Las imágenes en $408 \mathrm{MHz}$ y en $1420 \mathrm{MHz}$ guardan una fuerte correlación morfológica con la imagen óptica.

A fin de conocer el origen de esta emisión, obtuvimos el índice espectral de la región, teniendo en cuenta ambas cáscaras en forma conjunta y niveles mínimos en la emisión de $4 \sigma$ en $1420 \mathrm{MHz}$ y superiores a $7 \sigma$ en $408 \mathrm{MHz}$. Además consideramos las densidades de flujo promedio en la frecuencias $2700 \mathrm{MHz}$ (Reich et al. 1990), y 8350 y $14850 \mathrm{MHz}$ (Langston et al. 2000), restando de estas un fondo de $7 \sigma$. Aplicando la relación entre la densidad de flujo y la frecuencia en continuo de radio $S_{\nu} \propto \nu^{\alpha}$ y restando la contaminación en el flujo provocado por las fuentes extragalácticas, obtuvimos un índice espectral $\alpha=$ $+0.15 \pm 0.08$ entre 408 y $1420 \mathrm{MHz}$, y $\alpha=-0.12 \pm 0.09$, ajustada entre 1420, 2700, 8350 y $14350 \mathrm{MHz}$, compatible con emisión térmica a estas frecuencias.

Un método alternativo para la determinación de índices espectrales es a través del diagrama TT. Teniendo en cuenta que la densidad de flujo es proporcional a la temperatura de brillo $S_{\nu} \propto T_{b}$ y recordando la proporcionalidad entre la densidad de flujo y la frecuencia mencionada en el párrafo anterior, podemos llegar a una relación entre la temperatura de brillo de la fuente $T_{b}$ y el índice espectral $\alpha$, 


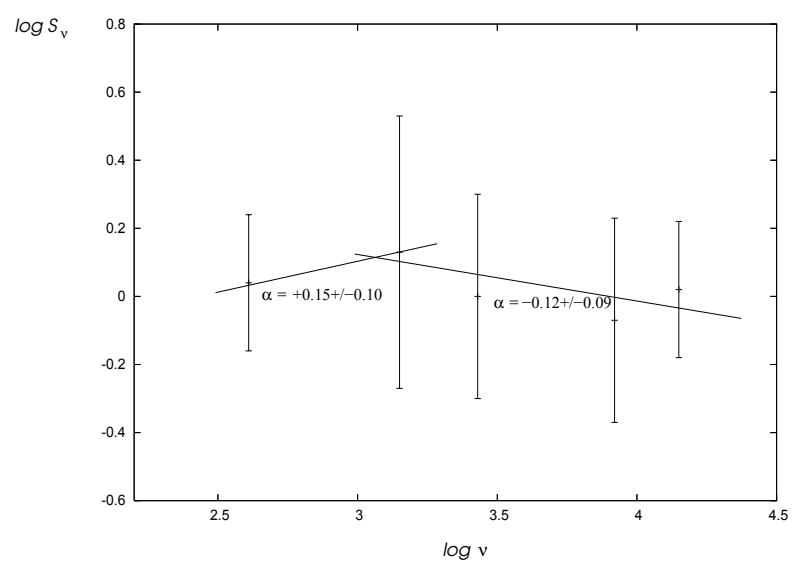

Figura 5.5: Gráfico $\log S$ vs $\log \nu$ para la emisión en continuo de radio de la estructura asociada a WR 152. Las dos rectas indican el comportamiento del índice espectal $\alpha=$ $+0.15 \pm 0.08$ entre 408 y $1420 \mathrm{MHz}$, y $\alpha=-0.12 \pm 0.09$, ajustada entre $1420,2700,8350$ y $14350 \mathrm{MHz}$.

$$
T_{b} \propto \nu^{\alpha-2}
$$

El gráfico de la Fig. 5.7 muestra este diagrama en el que se comparan la temperatura de brillo en 408 y $1420 \mathrm{MHz}$. Esa comparación se llevó a cabo convolucionando la imagen en $1420 \mathrm{MHz}$ a la resolución de la imagen en $408 \mathrm{MHz}$. Una de las principales ventajas de este método es la independencia del fondo de la emisión de las imagenes ya que este diagrama se obtiene de la convolución de ambas imagenes en cuestión a una misma resolución angular. De esta manera se obtuvo un índice espectral, a partir de la pendiente de la recta de ajuste $\alpha=-0.1 \pm 0.1$. Este valor es típico de radiación libre-libre, es decir, de carácter térmico.

\subsubsection{Emisión del H I hacia WR 152}

En la sección 5.3 se llevó a cabo un estudio de la distribución de H i en gran escala en dirección a la nebulosa Sh2-132, encontrándose una estructura de $30^{\prime}$ de radio en esa dirección. Particulamente, se vio que la estrella WR 152 se ubica sobre la región de menor latitud galáctica de la cáscara. Teniendo esto en cuenta, realizamos un análisis detallado del hidrógeno neutro hacia esta estrella, con el fin de buscar emisión de H I asociada a las cáscaras ópticas en una área de $1^{\circ}$ cuadrado, centrada en WR 152. El resultado de la búsqueda fue una estructura centrada en $(l, b) \simeq\left(102^{\circ} 10^{\prime},-1^{\circ} 3^{\prime}\right)$. El rango de velocidades de detección de esta estructura es $[-58.3,-36.9] \mathrm{km} \mathrm{s}^{-1}$. En el panel superior de la Fig. 5.8 se muestra la emisión de H i promediada en este intervalo de velocidades. Se dibujó una línea arqueada para resaltar el aspecto de la estructura de H I. La cruz blanca indica la posición de la estrella, que se ve proyectada sobre el borde de este arco. Los dos segmentos perpendiculares de color rojo indican la posición donde se realizaron los cortes ("slices") 

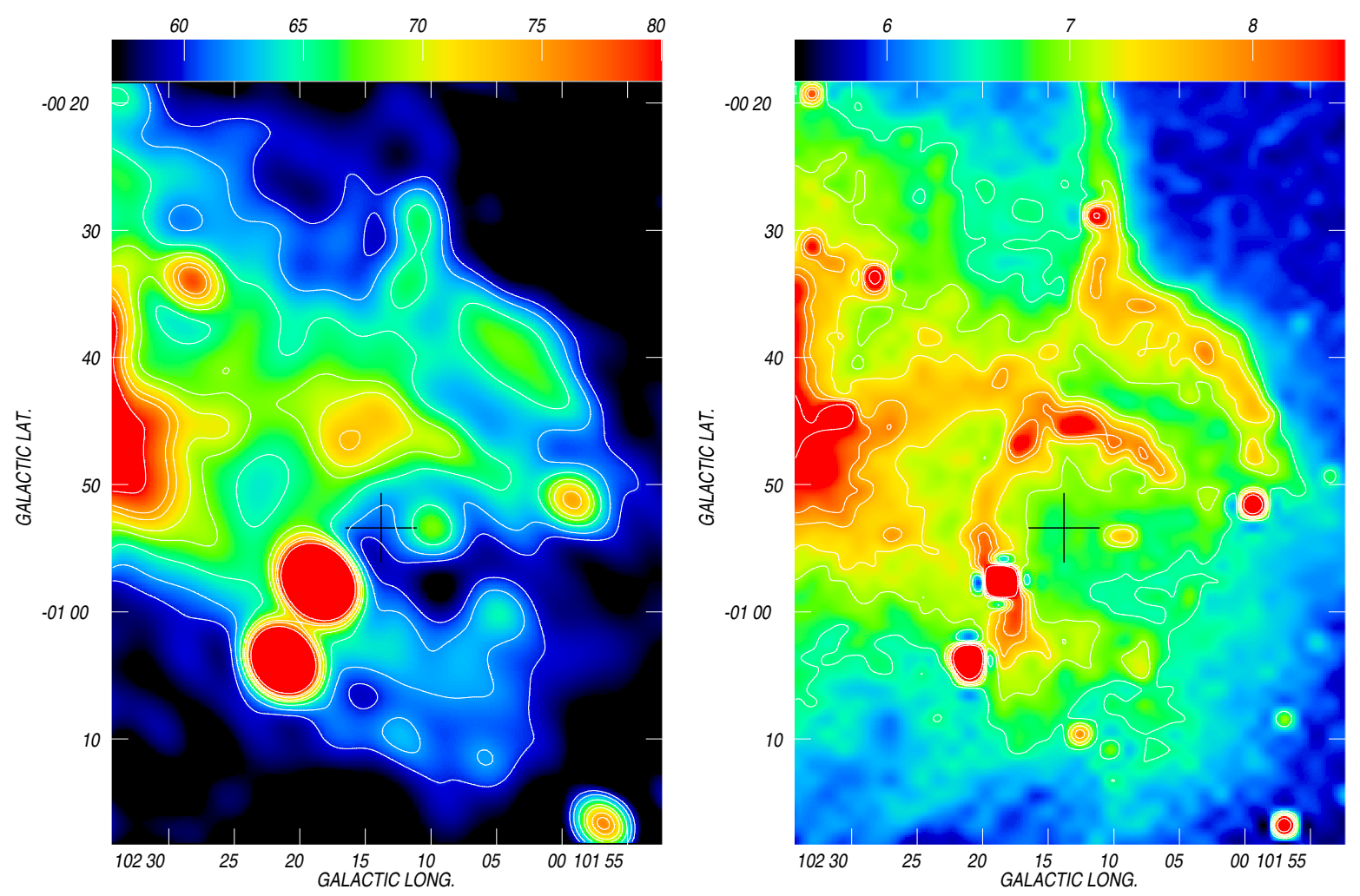

Figura 5.6: Panel (a). Imagen en continuo de radio en $408 \mathrm{MHz}$. Colores: 55 - $80 \mathrm{~K}$. Contornos: 60, 62, 65, 68, 70, 73, 75, $80 \mathrm{~K}$. Panel (b). Imagen en $1420 \mathrm{MHz}$. Colores: 5 9 K. Contornos: 6.6, 7, 7.3, 7.7, 8, $9 \mathrm{~K}$. 


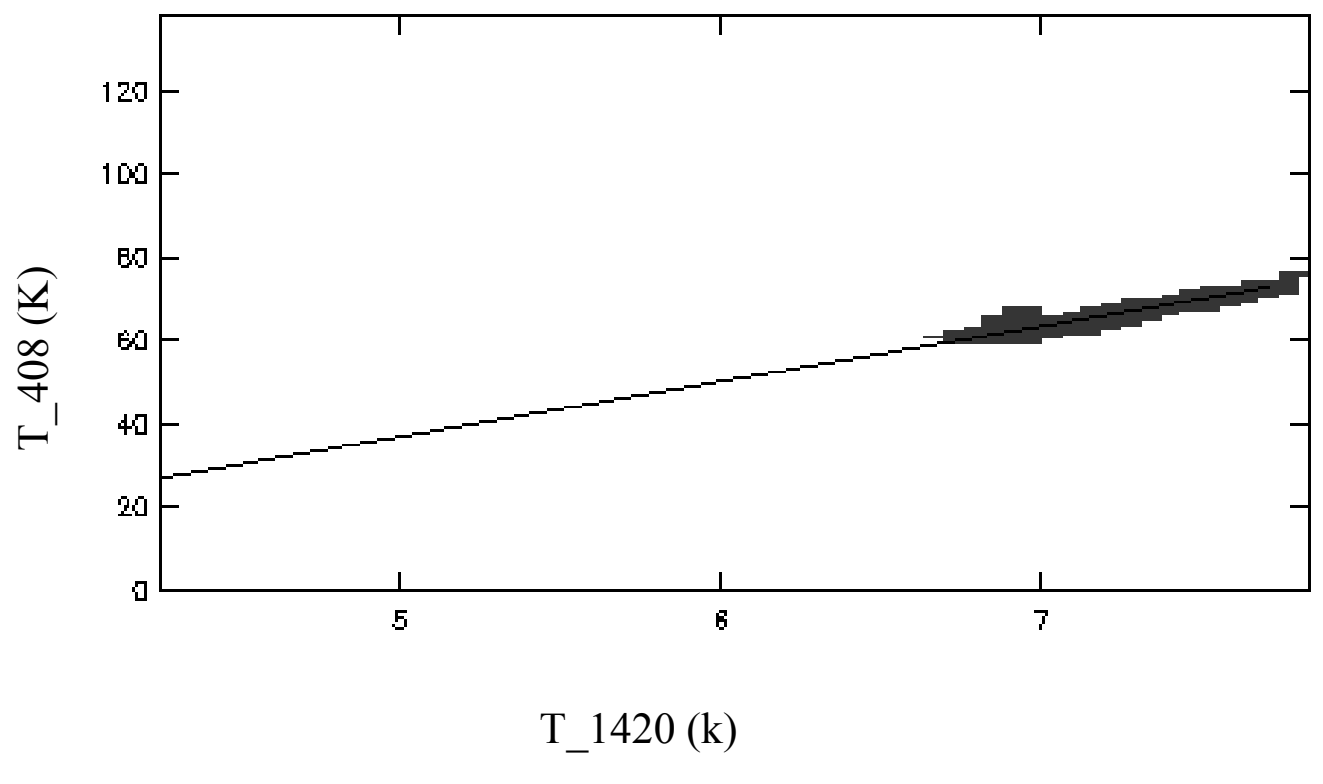

Figura 5.7: Diagrama TT para 408 y $1420 \mathrm{MHz}$. El ajuste de los puntos da una recta con pendiente $\alpha=-0.1 \pm 0.1$.

que aparecen en la parte inferior de la figura y las dos flechas señalan la dirección a la que corresponde cada corte. Las flechas dobles indican la $T_{b}$ correspondiente a la división entre la envoltura y la cavidad de $\mathrm{H}$ i $\left(T_{b}=65 \mathrm{~K}\right)$. Como se puede advertir, el corte correspondiente al eje principal del arco de H I muestra emisión muy intensa a lo largo la mitad de su extensión, con valores de hasta $80 \mathrm{~K}$. Este sector representa la franja más ancha de la envoltura neutra. Luego, la emisión disminuye bruscamente hasta alcanzar valores menores a $60 \mathrm{~K}$. El otro corte, perpendicular al primero, muestra una distribución simétrica respecto de su centro. Puede notarse que aparecen dos picos en la emisión que llegan a valores superiores a $80 \mathrm{~K}$, que encierran una zona central cuya emisión baja hasta casi $60 \mathrm{~K}$. Esa zona es la cavidad de H I. Si comparamos los tres gráficos, vemos que la posición de la estrella está en el borde entre la envoltura y la cavidad.

Para completar y fortalecer el estudio cinemático, la Fig. 5.9 muestra dos gráficos velocidad-posición: $v$ vs $l$, integrado en $\Delta b=\left[-1^{\circ} 35^{\prime},-0^{\circ} 40^{\prime}\right]$ (panel derecho); y $v$ vs $b$, integrado en $\Delta l=\left[101^{\circ} 50^{\prime}, 102^{\circ} 40^{\prime}\right]$ (panel izquierdo). En ambos gráficos se observa una cavidad que se extiende en un rango de velocidades entre $\sim-50$ y $-35 \mathrm{~km} \mathrm{~s}^{-1}$. Los círculos blancos resaltan las cavidades de H I. Esta cavidad coincide con el mínimo exhibido en la imagen integrada que está "encerrada" dentro del arco de la Fig. 5.8. Puede estimarse una velocidad de expansión de $\simeq 8 \mathrm{~km} \mathrm{~s}^{-1}$ para la estructura de $\mathrm{H}$ I.

En la Fig. 5.10 se muestra la superposición de la imagen integrada de H I (colores) y la imagen en continuo de radio a $1420 \mathrm{MHz}$ (contornos). La morfología de ambas emisiones muestra una similitud en cuanto a la forma arqueada que presentan. La cáscara interna 

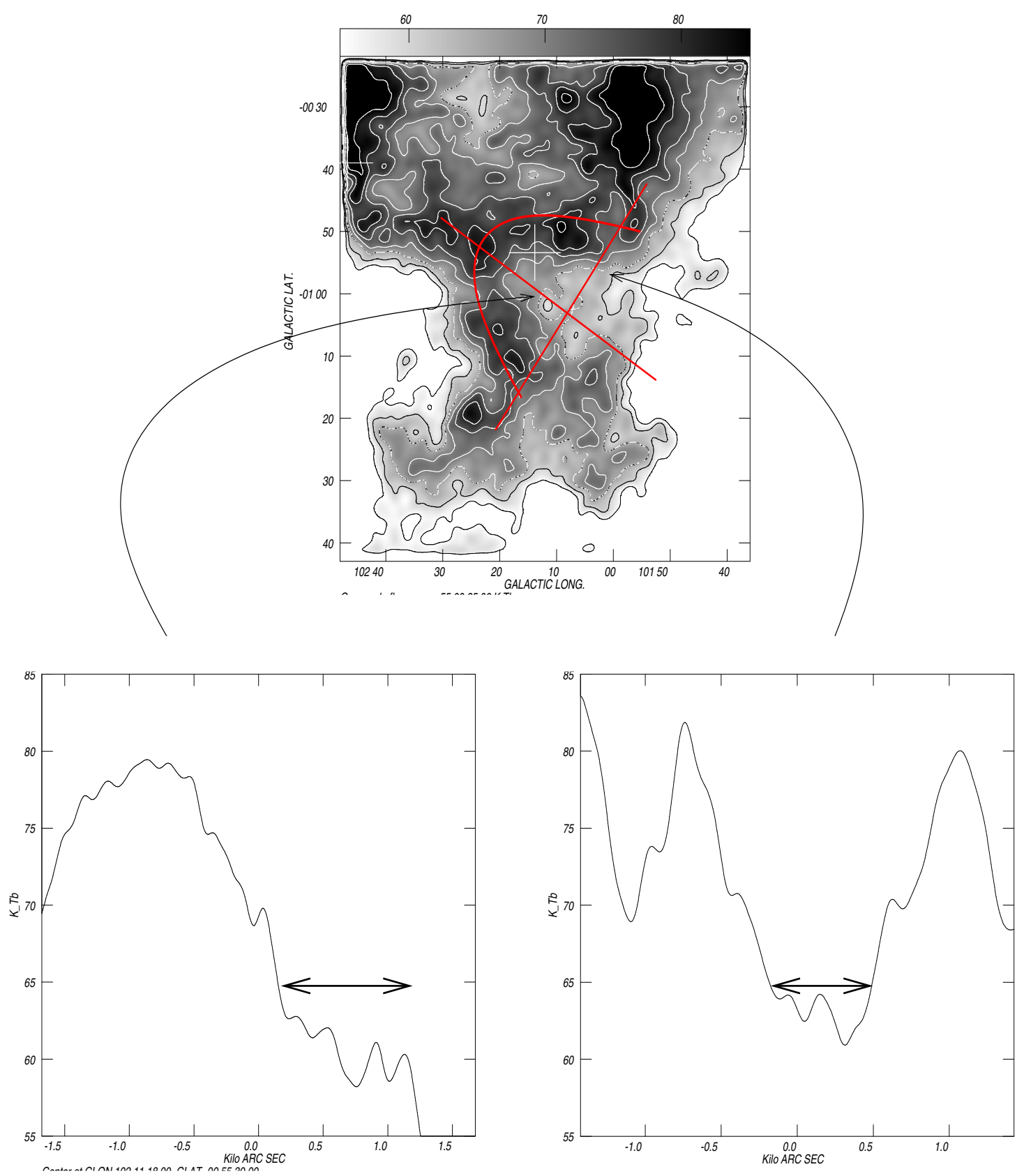

Figura 5.8: Panel superior: Emisión de H I promediada en el intervalo -58 a $-37 \mathrm{~km} \mathrm{~s}^{-1}$. Los segmentos rojos en la imagen de H i indican la posición de los cortes. La cruz blanca indica la posición de la estrella. Panel inferior: Cortes perpendiculares sobre la imagen de H i. Cada corte muestra $T_{b}$ en función de la distancia angular al centro de cada uno de ellos (en kilo segundos de arco). La posición 0.0 corresponde a $(l, b)=\left(101^{\circ} 9^{\prime},-1^{\circ} 4^{\prime}\right)$ en el panel de la izquierda, y a $(l, b)=\left(102^{\circ} 17^{\prime},-0^{\circ} 58^{\prime}\right)$ en el panel de la derecha. 

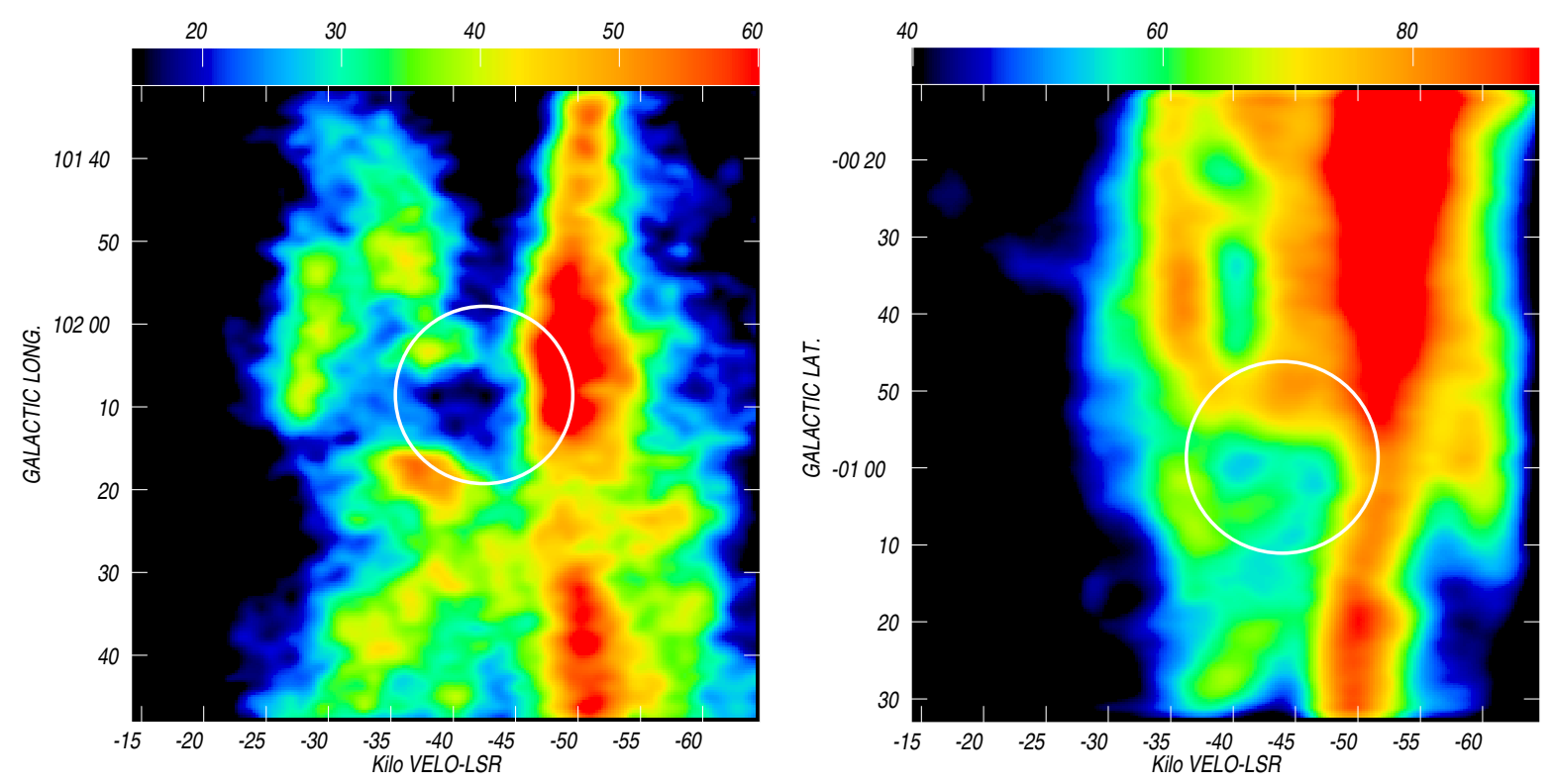

Figura 5.9: Panel izquierdo: Gráfico $l$ vs $v$ de $T_{b}$ del H I promediado entre $b=-1^{\circ} 35^{\prime}$ y $-0^{\circ} 40^{\prime}$. Panel derecho: Distribución $b$ vs $v$ entre $l=101^{\circ} 50^{\prime}$ y $102^{\circ} 40^{\prime}$.

en continuo es bordeada por parte del arco de H I desde $b \simeq-45^{\prime}$ hasta $-1^{\circ} 5^{\prime}$. A $b \geq$ $-0^{\circ} 45^{\prime}$, los máximos de $\mathrm{H}$ i de la envoltura están más cerca de la estrella que la cáscara de continuo.

\subsubsection{Emisión en el lejano IR}

Nuestro interés por determinar los parámetros del polvo interestelar posiblemente asociado a las estructuras encontradas en Hi, nos llevó a analizar las imágenes IR en todas las bandas observadas por los satélites IRAS y MSX. De esta búsqueda y consecuente análisis, sólo encontramos emisión detectable y morfológicamente asociada a WR 152, en las imágenes IRAS.

En el panel izquierdo de la Fig. 5.11 mostramos la distribución de la emisión en 60 $\mu \mathrm{m}$. La imagen en $100 \mu \mathrm{m}$ es similar, por lo que no se incluye.

La estructura IR tiene forma de cáscara coincidente morfológica y espacialmente con la emisión en continuo de radio y H I. Para $l \geq 102^{\circ} 25^{\prime}$ esa cáscara se confunde con la emisión proveniente de la región más intensa de Sh2-132. A latitudes galácticas $b>-0^{\circ} 50^{\prime}$, la cáscara se desmembra y se vislumbran dos "ramas", al igual que el continuo de radio. La estructura encierra una zona de baja emisión que coincide con la posición de la estrella.

Concluimos que morfológicamente, las estructuras en el continuo de radio, IR y H I presentan rasgos claros que permiten asociarlas WR 152. 


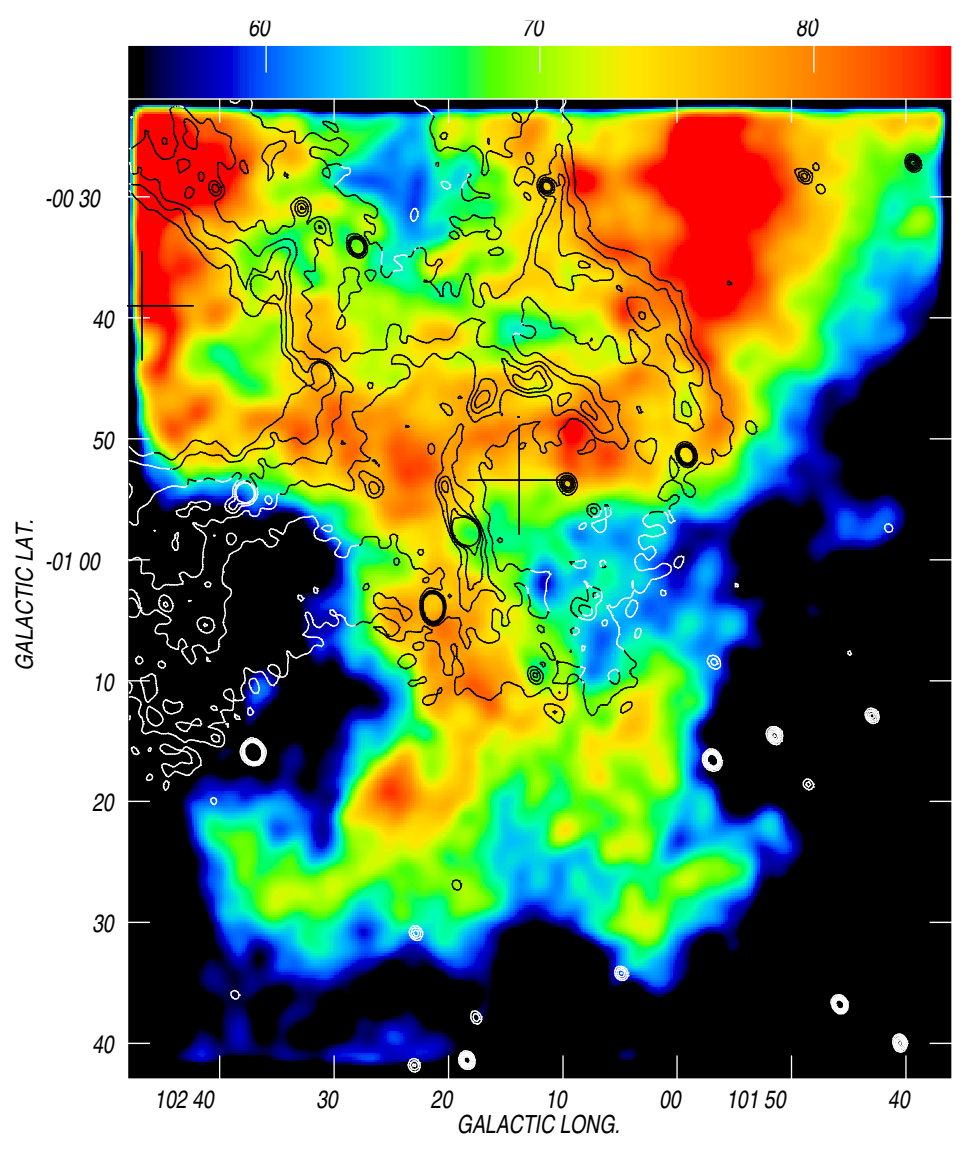

Figura 5.10: Superposición de la imagen integrada de H I (colores) y la distribución en $1420 \mathrm{MHz}$ (contornos). La cruz indica la posición de WR 152. 

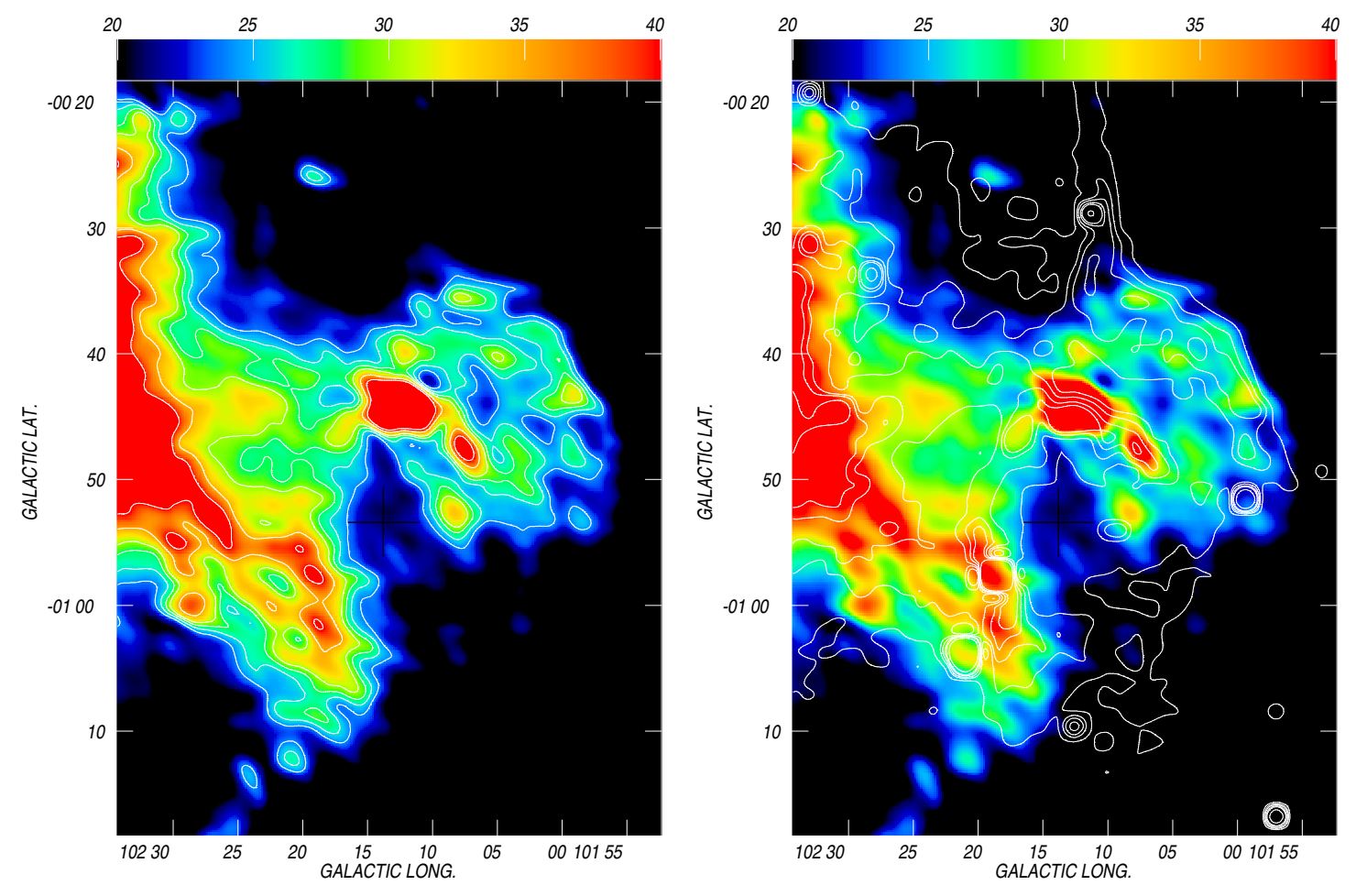

Figura 5.11: Panel izquierdo: Imagen IRAS de alta resolución (HIRES) en $60 \mu \mathrm{m}$. Escala de colores: 20 a $40 \mathrm{MJy} /$ ster. Líneas de contornos: 24, 26, 28, 30, 35 y $40 \mathrm{MJy} /$ ster. Panel derecho: Superposición de la imagen IR en $60 \mu \mathrm{m}$ (colores) y la imagen de continuo en $1420 \mathrm{MHz}$ (contornos). 


\subsection{Análisis multifrecuencia en dirección a WR 153ab}

Como ya mencionamos en la introducción de este Capítulo, esta región ha sido estudiada por diferentes autores. Lo que nosotros estamos llevando a cabo es un estudio integral multifrecuencia con observaciones recientes. Esto nos permite tener una idea global del escenario en donde se desarrolla la interacción entre las diferentes fases del medio interestelar con las estrellas de gran masa asociadas a Sh2-132. En lo que sigue enfocaremos nuestro interés en la morfología, dinámica y energética de las contrapartes en continuo de radio entre el IR y en líneas moleculares.

\subsubsection{Emisión en el continuo de radio e IR}

La imagen en $1420 \mathrm{MHz}$ (Fig. 5.12(a)) exhibe una estructura con forma de "U" invertida. La estructura semicircular está compuesta por dos sectores con emisión intensa que corresponden a las shells A y B de Harten et al. (1978), centradas en $(l, b) \simeq\left(102^{\circ} 34^{\prime} 42.4^{\prime \prime}\right.$,$\left.00^{\circ} 46^{\prime} 9.8^{\prime \prime}\right)$ y en $(l, b) \simeq\left(102^{\circ} 26^{\prime} 35.8^{\prime \prime},-00^{\circ} 43^{\prime} 10.2^{\prime \prime}\right)$, respectivamente. WR $153 a b$, indicada con la cruz, está proyectada sobre la región central intensa de la shell B. La Fig. 5.12(b) muestra la imagen DSS R de la región. La comparación entre las emisiones óptica y de radio muestra que la región más intensa en $1420 \mathrm{MHz}$ es también la más brillante en el rango óptico y que la correlación entre las emisiones es notable. En particular, el arco de $4^{\prime}$ hacia el SE de la estrella WR corresponde al sector más brillante en el continuo de radio en $1420 \mathrm{MHz}$. La imagen en $408 \mathrm{MHz}$ no se muestra por no tener tanto detalle como la correspondiente a $1420 \mathrm{MHz}$, aunque a partir de ambas hemos determinado un índice espectral $\alpha=+0.02 \pm 0.05$. Cabe destacar que no hemos tenido en cuenta los valores en las densidades de flujo de la literatura debido principalmente a la gran diferencia en la resolución angular con nuestros datos, causa por la cual no se había distinguido a la emisión de continuo de radio en dos regiones distintas asociadas a WR152 y WR 153ab, como lo hicimos es este trabajo. Particularmente, los datos en $408 \mathrm{MHz}$ de Felli et al. (1977) tienen una resolución angular casi 3 veces más pobre $\left(\sim 10^{\prime}\right)$ que los datos a esa misma frecuencia que hemos utilizado en esta tesis, y además incluyen una gran contribución de radiación de fondo (Harten et al. 1978).

La Fig. 5.12(c) muestra la distribución de la emisión en $60 \mu \mathrm{m}$ correspondiente al sector de Sh2-132 asociado a WR 153, superpuesta con los contornos de la imagen en $1420 \mathrm{MHz}$. La morfología IR es similar a la que exhibe la distribución en $1420 \mathrm{MHz}$. Se advierte una estructura semicircular abierta hacia $b \simeq-40^{\prime}$, con la estrella WR 153ab ubicada sobre la contraparte infrarroja de la shell B. Los niveles de 16 y $18 \mathrm{~K}$ de la emisión de continuo de radio están proyectados sobre los niveles máximos de la emisión IR. Varias fuentes IR intensas están ubicadas sobre Sh2-132. Aquellas ubicadas en $\simeq$ $\left(103^{\circ} 3^{\prime},-0^{\circ} 42^{\prime}\right)$ y $\left(102^{\circ} 49^{\prime},-0^{\circ} 36^{\prime}\right)$ coinciden con las radiofuentes NVSS J222034+561438 y NVSS J221856+560954, respectivamente. La zona con emisión más intensa rodea la posición de la estrella con valores superiores a los $300 \mathrm{MJy} /$ st. Nuevamente, la región más intensa coincide con el arco de $4^{\prime}$. Cabe destacar que se detecta emisión en las cuatro bandas IRAS. 
(a)
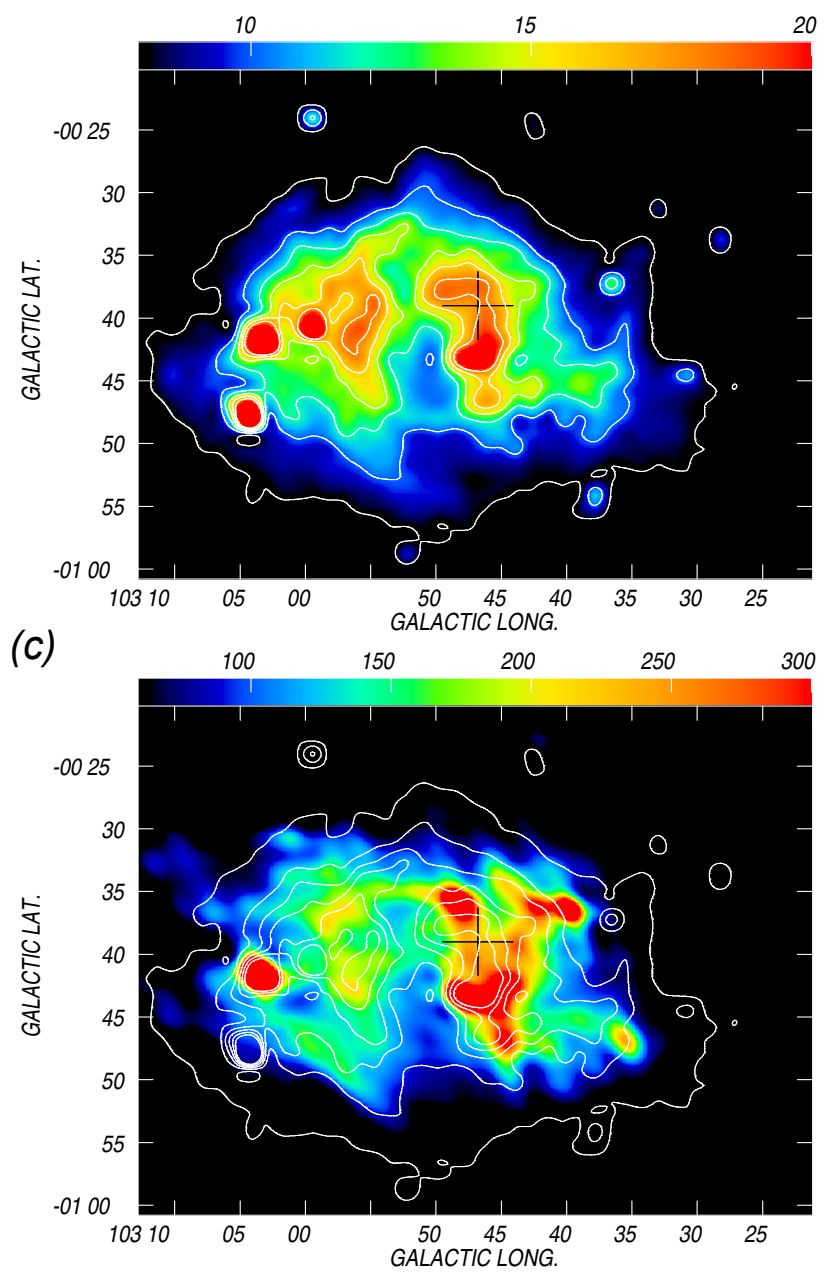

(b)

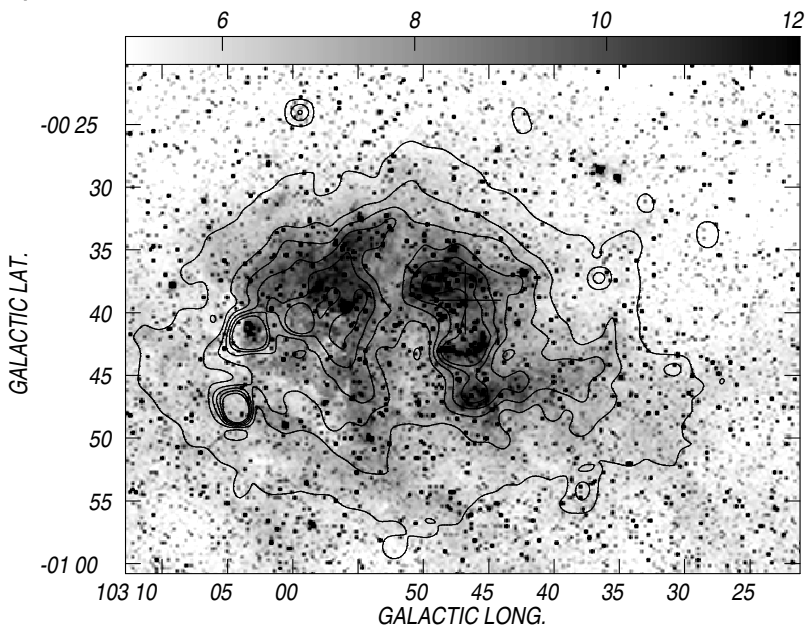

Figura 5.12: (a) Distribución en el continuo de radio en $1420 \mathrm{MHz}$ hacia Sh2-132 y WR 153ab. El rango de colores va desde 8 a $18 \mathrm{~K}$. Los contornos son 8, 10, 12, 14, 16, 18 y 20 K. (b) Imagen DSS R de la misma región. La escala de grises corresponde a unidades arbitrarias. (c) Superposición de la imagen IR en $60 \mu \mathrm{m}$ mostrada en colores y los contornos de la imagen de continuo en $1420 \mathrm{MHz}$. El rango de colores va desde 60 a $300 \mathrm{MJy} / \mathrm{st}$. La cruz indica la posición de la estrella. 
El análisis de las imágenes MSX muestra emisión en la banda A solamente. Como se mencionó en el Capítulo 3, la radiación en esta banda proviene esencialmente de los $\mathrm{PAH}$, y su presencia delata regiones de fotodisociación (PDRs). La Fig. 5.13(b) muestra la emisión en esta banda que presenta un filamento a $b \sim-35^{\prime}$ y una región más intensa hacia $l \sim 101^{\circ} 44^{\prime}$. También se detecta otro filamento alargado y de bajo brillo hacia $(l, b) \sim\left(103^{\circ} 0^{\prime},-0^{\circ} 48^{\prime}\right)$ y una fuente intensa en $(l, b) \sim\left(103^{\circ} 4^{\prime},-0^{\circ} 42^{\prime}\right)$. WR $153 \mathrm{ab}$ se encuentra proyectada sobre una región de baja emisión. La comparación de las emisiones en la banda A y en el continuo de radio en $1420 \mathrm{MHz}$ muestra que la emisión en $8.3 \mu \mathrm{m}$ rodea a ésta última.

En particular, la emisión en la banda A bordea el arco de 4' detectado en líneas ópticas por Miller \& Chu (1993).

\subsubsection{Distribución y morfología del ${ }^{12} \mathrm{CO}$}

Se analizó el cubo de datos de ${ }^{12} \mathrm{CO}$ en todo el rango de velocidades radiales en dirección a Sh2-132, en el sector asociado a WR 153ab y se encontró una estructura entre -50.1 y $-38.6 \mathrm{~km} \mathrm{~s}^{-1}$ asociada espacialmente a Sh2-132. La Fig. 5.13(a) muestra la emisión integrada del ${ }^{12} \mathrm{CO}$ de esa estructura, que se extiende, a $b \simeq-0^{\circ} 35^{\prime}$, desde $\sim 102^{\circ} 35^{\prime}$ hasta $\sim 103^{\circ} 15^{\prime}$, donde se curva hacia latitudes galácticas menores, rodeando a la estrella WR. A lo largo de toda su extensión, se pueden apreciar pequeños grumos de material. El primer nivel de contornos representa $3 \sigma$, siendo el ruido de $0.15 \mathrm{~K}$. La velocidad sistémica de esta estructura molecular es $v_{\text {sis }}=-42.7 \pm 0.8 \mathrm{~km} \mathrm{~s}^{-1}$.

En el panel (c) de esta figura se muestra la superposición de la imagen MSX (colores) y la imagen molecular (contornos). Sorprende la gran similitud entre las emisiones molecular e IR. Hay coincidencia entre las zonas grumosas IR con los núcleos moleculares indicando que ambos tipos de material se encuentran mezclados. La coincidencia entre la emisión molecular y la de los PAHs, y la anticorrelación de estas emisiones con la región más brillante en el continuo de radio indica la existencia de regiones de fotodisociación en la interfase entre el gas ionizado y el neutro.

\subsection{Discusión}

\subsubsection{Distancia a las estructuras}

Una de las primeras cuestiones a resolver es la determinación de la distancia a las estructuras.

Van der Hucht (2001) publicó una distancia espectrofotométrica para WR 152 de 2.75 kpc. Contamos con mediciones propias de velocidades radiales del H I asociado a WR 152. La velocidad sistémica del H I es $v_{s i s}=-47.5 \pm 0.6 \mathrm{~km} \mathrm{~s}^{-1}$.

Por otro lado, las distancias espectrofotométricas para WR 153ab son de $2.75 \mathrm{kpc}$ 
(a)

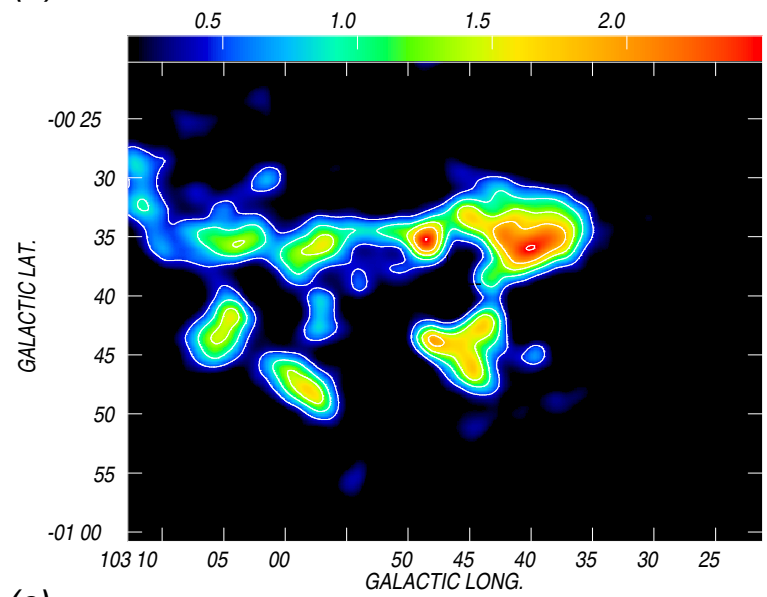

(c)

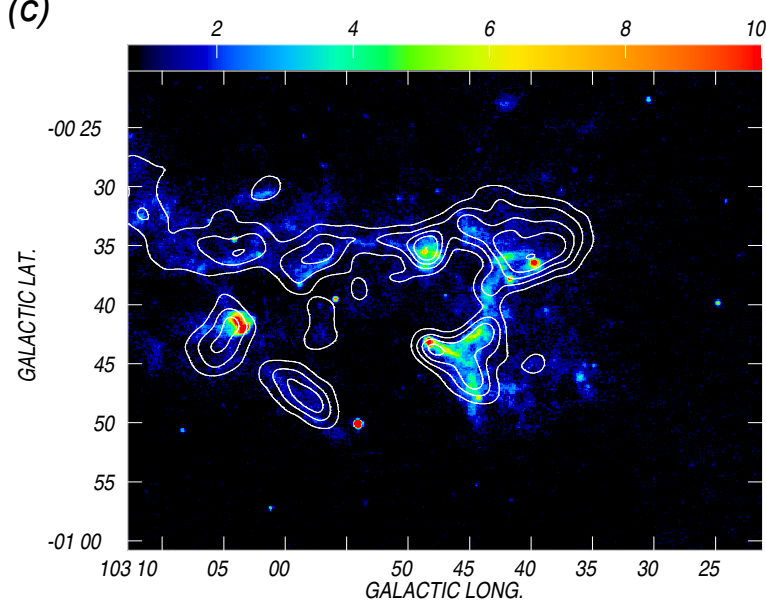

(b)

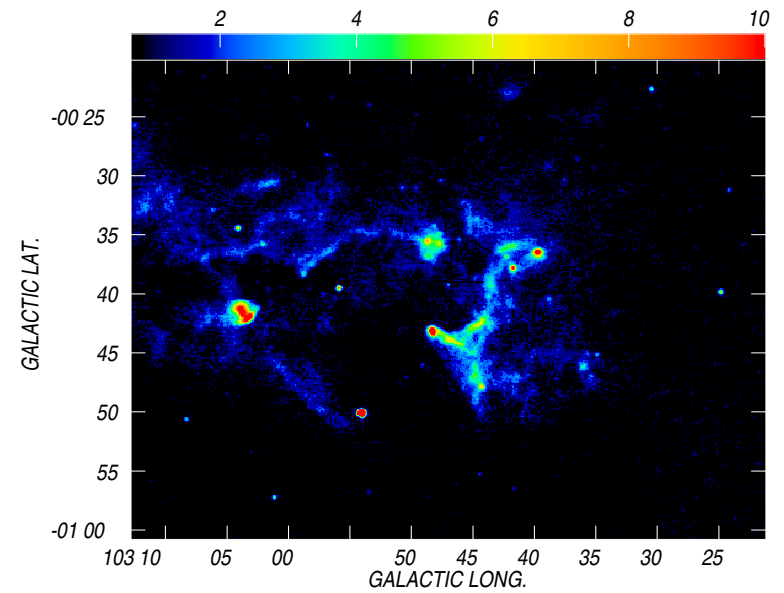

Figura 5.13: (a) Imagen integrada de ${ }^{12} \mathrm{CO}$ entre $-50.1 \mathrm{a}-38.6 \mathrm{~km} \mathrm{~s}^{-1}$. Los colores indican un rango de 0.15 a $2.5 \mathrm{~K}$. Los contornos representan $0.45,0.90,1.35,1.80$ y $2.25 \mathrm{~K}$. (b) Distribución de la emisión en $8 \mu \mathrm{m}$ (banda A del satélite MSX). La escala de colores representa la emisión en un rango entre $7 \times 10^{-7}$ y $1.0 \times 10^{-5} \mathrm{~W}$ ster $^{-1} \mathrm{~m}^{-2} \mathrm{~Hz}^{-1}$. (c) Superposición entre la emisión en $8 \mu \mathrm{m}$, mostrada en colores, con las líneas de contornos de la emisión molecular. 
(van der Hucht 2001) y 3.5 kpc (Nugis \& Lamers 2000). Observaciones de la línea H $\alpha$ de la nebulosa mostraron que el gas ionizado tiene velocidades radiales de $-50.9 \mathrm{~km} \mathrm{~s}^{-1}$ (Georgelin 1975). También contamos con velocidades de líneas de recombinación de He e $\mathrm{H}$ con valores de $-50.4 \mathrm{~km} \mathrm{~s}^{-1} \mathrm{y}-49.4 \mathrm{~km} \mathrm{~s}^{-1}$, respectivamente (Quireza et al. 2006). Reynolds (1988) determinó una $v_{\mathrm{LSR}}=-48 \pm 1 \mathrm{~km} \mathrm{~s}^{-1}$ a partir de observaciones de líneas prohibidas de $[\mathrm{SII}]$ en $\lambda 6716$ y $\lambda 6731$. La velocidad radial de la componente molecular obtenida en este trabajo es $v_{\text {sis }}=-42.7 \pm 0.8 \mathrm{~km} \mathrm{~s}^{-1}$.

Si utilizamos el ajuste analítico al modelo de rotación circular de la galaxia (Brand \& Blitz 1993), vemos que para la longitud galáctica correspondiente a WR $153 \mathrm{ab}$ o WR 152 $\left(l \simeq 102^{\circ}\right)$, este modelo da una distancia cinemática de $5.5 \pm 0.5 \mathrm{kpc}$ (para $v=-45 \pm 5$ $\mathrm{km} \mathrm{s}^{-1}$ ). De esta manera, encontramos una gran discrepancia entre las distancias espectrofotométricas y las cinemáticas. Esta discrepancia ya había sido notada por Harten et al. (1978). No debemos olvidar que en la dirección galáctica en la que se encuentra esta estructura existen movimientos no circulares de rotación (ver Capítulo 4).

Para una distancia de $\sim 3 \mathrm{kpc}$, correspondiente a un valor medio de las distancias espectrofotométricas a WR 153ab y a WR 152, la velocidad radial esperada será de -20.6 $\mathrm{km} \mathrm{s}^{-1}$. Como el rango de velocidades observadas para las estructuras ionizada y molecular está en el intervalo entre $\sim-40 \mathrm{y} \sim-50 \mathrm{~km} \mathrm{~s}^{-1}$, tendremos un valor de $\Delta v_{\text {res }} \sim-25$ $\mathrm{km} \mathrm{s}^{-1}$. Teniendo en cuenta este valor para el residuo, vemos que las distancias cinemáticas obtenidas a través de este modelo no son confiables.

Considerando el campo de velocidades radiales observadas, incluyendo movimientos no circulares (ver figura 2(b) de Brand \& Blitz 1993) la distancia cinemática correspondiente al conjunto de velocidades radiales medidas para la estructura es $3.5 \pm 0.5 \mathrm{kpc}$. Este valor se ajusta muy bien a los valores de distancias espectrofotométricas de las estrellas. Adoptaremos por tanto, esta distancia para las estructuras asociadas a ambas estrellas WR.

\subsubsection{Conexión entre las estructuras de H I}

Otra cuestión a tratar es la vinculación entre la GE y la distribución de H I asociada a WR 152. De la Tabla 5.3 vemos que aunque existe una diferencia en $10 \mathrm{~km} \mathrm{~s}^{-1}$ en la velocidad sistémica de ambas estructuras, el intervalo de velocidad en que se observan ambas estructuras es similar. Desde la imagen a $-35.3 \mathrm{~km} \mathrm{~s}^{-1}$ (Fig. 5.3), hacia velocidades más negativas, se observa la distribución de H I asociada a WR 152 sobre el borde inferior de la "gran estructura". La forma que adquieren ambas distribuciones parece marcar una "fusión" entre ambas, a medida que observamos a velocidades más negativas. En las imágenes con velocidades entre $-39.4 \mathrm{y}-40.2 \mathrm{~km} \mathrm{~s}^{-1}$ las formas de las estructuras son confusas y parece no haber un límite claro entre ambas.

Sugerimos que la estructura de hidrógeno neutro modelada por los vientos de la estrella WR 152, pertenece a una estructura más grande en tamaño a la que llamamos GE, y por lo tanto, se encuentran a la misma distancia. Teniendo en cuenta el rango de velocidad radial de la "gran estructura", $\left(v \simeq-40 \mathrm{kms}^{-1}\right)$, y asumiendo la correlación del H I con 


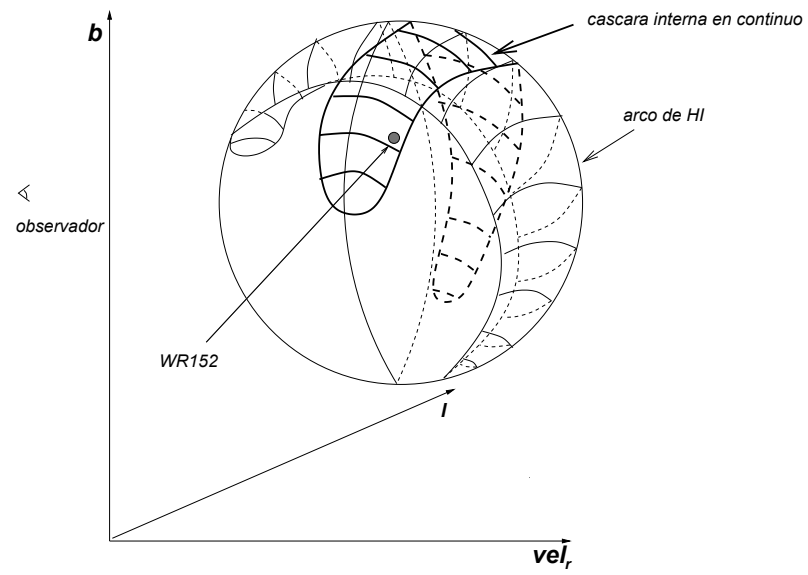

Figura 5.14: Interpretación esquemática de las disposiciones del H I y el continuo de radio asociados a WR 152.

WR 152, adoptamos una distancia de $3.5 \pm 0.5 \mathrm{kpc}$ para todo el complejo de H I.

En la Fig. 5.15 se muestra un mapa con una $v_{r a d}=-40.2 \mathrm{~km} \mathrm{~s}^{-1}$ en donde se indica la posiciń de la GE y el H i asociado a WR 152.

\subsubsection{Parámetos de las estructuras}

En el comienzo de este Capítulo llevamos a cabo el análisis del hidrógeno neutro en dirección a Sh2-132. Detectamos una estructura a la que denominamos "gran estructura" cuya proyección sobre el plano del cielo rodea la posición de las estrellas WR 152 y WR 153ab. En la tercer columna de la Tabla 5.3 se muestran los valores de los parámetros de esta estructura, y en la segunda columa se agregan los mismos parámetros para la estructura de H I asociada a WR 152.

En la tabla se enumeran, para ambas distribuciones neutras analizadas independientemente, la posición de su centro geométrico en coordenadas galácticas, el radio angular y lineal, el intervalo total de velocidades donde se las identifica, la velocidad sistémica, la densidad columnar, y asumiendo una distancia $d=3.5 \pm 0.5 \mathrm{kpc}$, el exceso de masa en la cáscara y la masa faltante en la cavidad.

En la Tabla 5.4 listamos los principales parámetros físicos derivados de la emisión en el continuo de radio en $1420 \mathrm{MHz}$ y en el IR de las nebulosas asociadas a la estrellas WR 152 y WR 153ab. Las dos primeras filas muestran los flujos en 408 y $1420 \mathrm{MHz}$. La tercer fila lista el índice espectral $\alpha$ (determinado a partir de estas dos frecuencias) reflejando en ambas regiones un régimen térmico. Basados en el trabajo de Mezger \& Henderson (1967), para una geometría esférica, una distribución homogénea y una temperatura electrónica de $10^{4} \mathrm{~K}$, obtuvimos la densidad electrónica $n_{e}$ y la masa ionizada $M_{i o n}$.

Para la emisión de continuo de radio asociada a WR 152, consideramos una estructura 


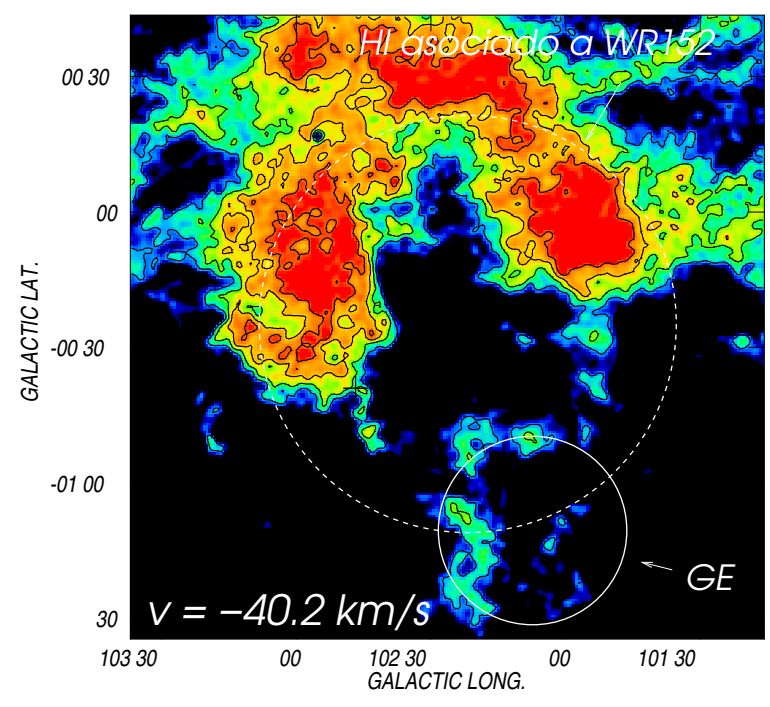

Figura 5.15: Mapa de H I (en $T_{b}$ ) en donde se muestan la GE y el H i asociado a WR 152

de anillo con un radio externo de $r_{\text {ext }} \sim 10 \mathrm{pc}, \mathrm{y}$ un radio interno de $r_{\text {int }} \sim 5 \mathrm{pc}, \mathrm{y}$ valores de $20 \%$ y $40 \%$, que representan el espacio ocupado por el plasma respecto a las dimensiones del anillo. Con estos valores, obtuvimos factores de llenado $f=0.20$ - 0.35 , con los que también obtuvimos la $n_{e}^{\prime}$ y la masa del gas ionizado $M_{i o n}^{\prime}$. Para el caso de la emisión de continuo de radio asociada a WR 153ab, tuvimos en cuenta un $r_{\text {ext }} \sim 12 \mathrm{pc}$ y $r_{\text {int }} \sim 6$ y 8 pc; y valores del $30 \%$ y $40 \%$ para la ocupación porcentual del plasma. Esto arroja los mismos valores de $f=0.20-0.35$.

Las siguientes filas de la tabla indican el radio de la región ionizada $R_{\text {ion }}$, el parámetro de excitación observado $U_{\text {rad }}$ y la medida de emision $E M$. Estos parámetros se obtuvieron de la imagen en $1420 \mathrm{MHz}$. También calculamos el parámetro de excitación teórico $U_{*}$ a partir de modelos de atmósferas estelares, para comparar su valor con $U_{\text {rad }}$.

La parte inferior de la Tabla 5.4 resume los valores de las densidades de flujo en las cuatro bandas IRAS, la temperatura color del polvo $T_{p}$ y masa del polvo $M_{p}$, y la luminosidad en el lejano IR $L_{\mathrm{IR}}$, determinada a partir de las cuatro bandas IRAS.

Debimos agregar el resultado del análisis molecular asociado a la región más intensa de Sh2-132, asociada a WR 153ab. Considerando un intervalo en velocidad de [-38.6,-50.1] $\mathrm{km} \mathrm{s}^{-1}$ y un nivel de fondo de $0.45 \mathrm{~K}$, obtuvimos una densidad columnar de $1.35 \times 10^{21}$ $\mathrm{cm}^{-2} \mathrm{y}$, teniendo en cuenta una distancia a la estructura de $3.5 \pm 0.5 \mathrm{kpc}$, una masa de $(6.5 \pm 2.6) \times 10^{3} \mathrm{M}_{\odot}$.

Para obtener la luminosidad y energía mecánica del viento $L_{w}$ y $E_{w}$, respectivamente, consideramos que WR 152 y WR 153ab han atravesado por una fase O. Asumimos un valor de la tasa de pérdida de masa $\log (\dot{M})=-6.64$ y una velocidad terminal $v_{\infty}=1950 \mathrm{~km} \mathrm{~s}^{-1}$, para una estrella tipo O8.5 (Smith et al. 2002) como valores estándares para las fase O de ambas estrellas WR y para las estrellas O compañeras en cada sistema binario. Además, 
Tabla 5.3: Parámetros de la GE y el H I asociado a WR 152

\begin{tabular}{lcc}
\hline & H I asociado a WR 152 & GE \\
\hline Centro $(l, b)$ & $\left(101^{\circ} 11^{\prime},-1^{\circ} 1^{\prime}\right)$ & $\left(102^{\circ} 26^{\prime},-0^{\circ} 20^{\prime}\right)$ \\
Radio angular medio $\left({ }^{\prime}\right)$ & $\sim 13$ & $\sim 30$ \\
Intervalo total en velocidad $(\mathrm{LSR})\left(\mathrm{km} \mathrm{s}^{-1}\right)$ & $-36.9,-50.1$ & $-32.0,-49.3$ \\
Velocidad sistémica $(\mathrm{LSR})\left(\mathrm{km} \mathrm{s}^{-1}\right)$ & $-47.5 \pm 0.6$ & $-40.2 \pm 1.6$ \\
$N_{H I}$ de la envoltura $\left(\mathrm{cm}^{-2}\right)$ & $(4.3 \pm 0.7) \times 10^{20}$ & $(3.25 \pm 0.8) \times 10^{20}$ \\
$N_{H I}$ de la cavidad $\left(\mathrm{cm}^{-2}\right)$ & $(1.2 \sim 0.5) \times 10^{20}$ & $(1.65 \pm 0.5) \times 10^{20}$ \\
Distancia adoptada $(\mathrm{kpc})$ & \multicolumn{2}{c}{$3.5 \pm 0.5$} \\
Radio lineal medio $(\mathrm{pc})$ & $13.2 \pm 2.5$ & $30.5 \pm 6.1$ \\
Masa de la envoltura $\left(\mathrm{M}_{\odot}\right)$ & $(6.4 \pm 2.5) \times 10^{3}$ & $(2.1 \pm 1.02) \times 10^{4}$ \\
Masa faltante en la cavidad $\left(\mathrm{M}_{\odot}\right)$ & $(1.2 \pm 0.5) \times 10^{3}$ & $(1.6 \pm 1.3) \times 10^{3}$ \\
\hline
\end{tabular}

Tabla 5.4: Parámetros de la emisión en el continuo de radio

\begin{tabular}{|c|c|c|}
\hline & Entorno de WR 152 & Entorno de WR $153 \mathrm{ab}$ \\
\hline$S_{408}(\mathrm{Jy})$ & $1.12 \pm 0.40$ & $10.11 \pm 2$ \\
\hline$S_{1420}(\mathrm{Jy})$ & $1.35 \pm 0.75$ & $10 \pm 3.6$ \\
\hline \multicolumn{3}{|l|}{ Indice espectral $(\alpha)$} \\
\hline $408-1420 \mathrm{MHZ}$ & $+0.15 \pm 0.08$ & $+0.02 \pm 0.05$ \\
\hline $1420,2700,8350$ у $14350 \mathrm{MHZ}$ & $-0.12 \pm 0.09$ & \\
\hline$n_{e}\left(\mathrm{~cm}^{-3}\right)(f=1)$ & $6.2 \pm 2,7$ & $16 \pm 4.0$ \\
\hline$n_{e}^{\prime}\left(\mathrm{cm}^{-3}\right)(f=0.20-0.35)$ & $15 \pm 6.7,10 \pm 4.5$ & $36 \pm 16.2,28 \pm 12.6$ \\
\hline Radio angular(' $)$ & $\sim 10$ & $\sim 10$ \\
\hline$R_{\text {ion }}(\mathrm{pc})$ & $10.8 \pm 3$ & $10.8 \pm 2$ \\
\hline$M_{\text {ion }}\left(\mathrm{M}_{\odot}\right)$ & $(6.8 \pm 2.4) \times 10^{2}$ & $(1.8 \pm 0.5) \times 10^{3}$ \\
\hline$M_{i o n}^{\prime}\left(\mathrm{M}_{\odot}\right)(f=0.20-0.35)$ & $(280 \pm 84),(400 \pm 160)$ & $(8.5 \pm 3.4) \times 10^{2},(1.1 \pm 0.4) \times 10^{3}$ \\
\hline$U_{\text {rad }}\left(\mathrm{pc} \mathrm{cm}^{-2}\right)$ & $10 \pm 4$ & $90 \pm 36$ \\
\hline$M E(\mathrm{pc} \mathrm{cm}-6)$ & $(1.6 \pm 1.2) \times 10^{3}$ & $(5.1 \pm 4.0) \times 10^{3}$ \\
\hline$U_{*}\left(\mathrm{pc} \mathrm{cm} \mathrm{cm}^{-2}\right)$ & $\sim 73.1$ & $\sim 500$ \\
\hline \multicolumn{3}{|c|}{ Parámetros de la emisión IR en las bandas IRAS y del polvo interestelar } \\
\hline$S_{12}(\mathrm{Jy})$ & $(1.0 \pm 0.3) \times 10^{2}$ & $(1.2 \pm 0.8) \times 10^{3}$ \\
\hline$S_{25}(\mathrm{Jy})$ & $(1.6 \pm 0.4) \times 10^{2}$ & $(2.4 \pm 1.2) \times 10^{3}$ \\
\hline$S_{60}(\mathrm{Jy})$ & $(3.9 \pm 1.4) \times 10^{2}$ & $(2.9 \pm 1.1) \times 10^{4}$ \\
\hline$S_{100}(\mathrm{Jy})$ & $(4.7 \pm 1.6) \times 10^{2}$ & $(4.6 \pm 1.2) \times 10^{4}$ \\
\hline$T_{p}(\mathrm{~K})$ & $30 \pm 3$ & $37 \pm 4$ \\
\hline$M_{P}\left(\mathrm{M}_{\odot}\right)$ & $26 \pm 10$ & $40 \pm 15$ \\
\hline$L_{I R}\left(L_{\odot}\right)$ & $(1.4 \pm 0.7) \times 10^{4}$ & $(8.0 \pm 3.2) \times 10^{5}$ \\
\hline
\end{tabular}


teniendo en cuenta que WR 152 es de tipo espectral WN, con valores $\log (\dot{M})=-4.89$ y $v_{\infty}$ $=1240 \mathrm{~km} \mathrm{~s}^{-1}$ (Smith et al. 2002), la luminosidad mecánica entregada por WR 152 al medio durante toda su evolución es $L_{w}=(6.5 \pm 1.3) \times 10^{36} \mathrm{erg} / \mathrm{seg}$. Si consideramos el tiempo de evolución de una estrella que transcurrió por las fases $\mathrm{O}$ y $\mathrm{WN}$, con valores de $3 \times 10^{6}$ años (Conti \& Vacca 1990) y $0.3 \times 10^{6}$ años (Meynet \& Maeder 2003), respectivamente, derivamos la energía mecánica entregada al medio por esta estrella $E_{w}=(8.5 \pm 1.7) \times 10^{49}$ erg. Por otro lado, conociendo la velocidad de expansión de la envoltura de H I (asumiendo que a esta velocidad se expande toda la estructura asociada a WR 152), y con la masa de todas las componentes observadas, podemos obtener la energía cinética de la cáscara $E_{c}=(4.1 \pm 1.6) \times 10^{48} \mathrm{erg}$.

De esta manera, podemos conocer la relación entre la energía cinética de la BI respecto de la energía mecánica del viento estelar $\epsilon=E_{c} / E_{k}=0.05$, valor que es compatible con el hecho de que la estrella WR 152 es capaz de "barrer" las diferentes componentes del medio interestelar circundante.

En cuanto a la región asociada a WR 153ab, consideramos la luminosidad entregada al medio a través del doble sistema binario que representa WR 153ab y las otras estrellas O de la Tabla 5.1. El valor es $L_{w}=(3.1 \pm 0.6) \times 10^{37} \mathrm{erg} / \mathrm{seg}$. Asumiendo los mismos tiempos de evolución para las estrellas O y para la fase WN que adoptamos para el caso de WR152, determinamos un valor de $E_{w}=(1.6 \pm 0.3) \times 10^{51} \mathrm{erg}$. Considerando como contrapartes asociadas a este sector de Sh2-132 a las distribuciones en IR, continuo de radio y ${ }^{12} \mathrm{CO}$, con una masa total $M_{t}=(8.0 \pm 0.6) \times 10^{3} \mathrm{M}_{\odot}$ y una velocidad de expansión, correspondiente al ${ }^{12} \mathrm{CO}$ de $7.4 \mathrm{~km} \mathrm{~s}^{-1}$, conseguimos un valor de la energía cinética de $E_{c}=(3.3 \pm 1.0) \times 10^{49}$ erg. Por lo tanto, $\epsilon=0.02$, lo que aseguraría, a través de los modelos de conservación de momento, que la acción de los vientos generados por las estrellas consideradas son capaces de empujar y modelar el medio que las rodea.

\subsection{Escenario}

Encontramos varias conexiones entre las distribuciones de material asociado a WR 152, en diferentes bandas del espectro. La situación más clara refleja la similitud en la disposición de la emisión óptica, IR en $60 \mu \mathrm{m}$ y el continuo de radio en $1420 \mathrm{MHz}$. En la Fig. 5.11 se ve cómo los máximos en IR coinciden con la cáscara de continuo de radio. Evidentemente esa distribución refleja una interacción entre ambas componentes, es decir, el polvo está siendo calentado, ionizado y en menor medida, destruido por los electrones libres responsables de la radiación en continuo.

Los fuertes vientos de la estrellas WR han barrido y comprimido el material de sus alrededores, formando dos cáscaras de material ionizado observadas tanto en óptico como en continuo de radio.

En la Fig. 5.10 vemos que parte del H i se encuentra distribuido entre la posición de la estrella y las dos cáscaras de continuo. Podríamos postular dos interpretaciones para entender la disposición del material: 
- Las dos cáscaras de continuo son el producto de la acción de los vientos generados en diferentes estados evolutivos de WR 152. Es decir, la cáscara externa estaría asociada a una fase evolutiva previa, probablemente la fase $\mathrm{O}$, mientras que la cáscara interna sería el resultado del viento de la fase WR. El arco de material neutro estaría ubicado detrás o delante de ambas cáscaras ionizadas y también estaría modelada por los vientos de la estrella WR en alguna de sus fases evolutivas.

- Lo que estaríamos observando sería la proyección sobre el plano del cielo de las distribuciones neutra y de continuo, es decir, las cáscaras ionzadas se encontrarían por delante del H I, o posiblemente, su distribución tendría una forma un poco más caprichosa. En la Fig. 5.14 mostramos la distribución de la cáscara interna y el H I. Proponemos un modelo esférico para la región, en la que el H I estaría dispuesto mayormente en dirección de la línea de la visual, mientras que la cáscara interna de continuo, se encontraría a lo largo de una franja semicircular a $\sim 90^{\circ}$ respecto del H I. Lo que vemos es que a $b$ más positivas y $v_{r}$ más negativas, el $\mathrm{H}$ I se encuentra más cerca del observador que el material ionizado. Por otro lado, a $v_{r}$ más positivas, hay casi exclusivamente H I. De esta forma, el material ionizado se encontraría sobre el borde interno del hidrógeno neutro.

No podría excluirse ninguna de las dos explicaciones, y cualquiera de ellas se ajustaría a lo modelos de evolución de BI (ver Capítulo 2), que ubican al material neutro externamente a las cáscaras ionizadas. Además, proponemos que la cáscara externa también puede ser el producto de la proyección sobre el plano del cielo.

Comparando el valor de la densidad de flujo en $408 \mathrm{MHz}$ de la Tabla 5.4 asociado tanto a WR 153ab y a WR 152, y el valor dado en la literatura, encontramos una gran diferencia. Nuestros datos en $408 \mathrm{MHz}$ tienen una resolución angular $\sim 3$ veces mejor que los de la literatura. Este hecho nos ha permitido diferenciar dos sectores de la emisión de continuo, uno asociado a WR 153ab y otro a WR 152. Es decir, con la mejoría en la resolución angular pudimos diferenciar estructuras que no habian sido definidas antes. Posiblemente, con un resolución de $\sim 10^{\prime}$ (Felli et al. 1977) exista una gran contribución de la emisión de fondo de la galaxia que aumente el valor del la densidad de flujo.

A partir de las densidades de flujo en 408 y $1420 \mathrm{MHz}$, determinamos el índice espectral para el entorno de WR $152 \alpha=+0.15 \pm 0.08$, considerando ambas cáscaras ionizadas, que se asemeja al que se determinó a través del diagrama TT. En ambos procedimientos confirmamos la naturaleza térmica en la emisión de continuo de radio teniendo en cuenta una explicación semejante a la dada en el Capítulo 4.

Por otro lado, y analizando la distribución del material asociado a WR 153ab, vemos que está íntimamente relacionado con la acción de las estrellas de gran masa y particularmente a WR 153ab. El alto flujo de fotones UV de estos objetos mantiene al material circundante ionizado. En la Tabla 5.4 se muesta que $U_{*} \gg U_{\text {rad }}$. Una gran parte del flujo de fotones ionizantes se "pierdan" destruyendo o calentando el polvo. Este hecho es justificado por la gran similitud entre la distribución en $60 \mu \mathrm{m}$ y en continuo de radio en 1420 $\mathrm{MHz}$ (ver Fig. 5.11). Alternativamente, la región podría estar limitada por ionización a 
$b \simeq-0^{\circ} 35^{\prime}$ y limitada por densidad hacia $b \simeq-0^{\circ} 45^{\prime}$, por lo que gran cantidad de fotones se dispersaría en el MIE.

También encontramos analogías morfológicas entre la emisión en ${ }^{12} \mathrm{CO}$ y en $8 \mu \mathrm{m}$. Del Capítulo 3 sabemos que esta última es generada por los PAHs, que son delineadores de PDRs, visibles claramente comparando las distribuciones de las Fig. 5.12 y 5.13. En definitiva, el alto valor de $U_{*}$ hace pensar que los fotones estelares con energía mayor a 4.5 eV (potencial de disociación de hidrógeno molecular) podrán disociar el medio molecular.

\subsection{Conclusiones}

Teniendo en cuenta al análisis multifrecuencia en dirección a WR 152 y WR 153ab, podemos mencionar los siguientes puntos:

- Basamos nuestra determinación de la distancia a las estructuras asociadas a WR 152 y WR 153ab, fundamentalmente en las distancias espectrofotométricas de ambas estrellas WR y en las velocidades radiales observadas considerando los movimientos no circulares de la zona. De esa forma obtuvimos una distancia de $3.5 \pm 0.5 \mathrm{kpc}$ para las dos estructuras.

- Las estrellas WR 152 y WR 153ab se encuentran sumergidas en el mismo complejo de hidrógeno neutro, que denominamos "gran estructura".

- El gas atómico asociado a WR 152 es parte de la GE, ya que ambas estructuras se encuentran a la misma distancia.

- Hay semejanza entre las distribuciones en $60 \mu \mathrm{m}$ y en $1420 \mathrm{MHz}$ vinculadas a WR 152, en la que se observa la emisión de dos estructuras arqueadas, una interna y otra externa. El hecho que $U_{*}>U_{\text {rad }}$, estaría indicando que gran parte de los fotones ionizantes se está consumiendo en calentar el polvo.

- De la misma forma, para la región asociada a WR 153ab, el alto flujo de fotones ionizantes de las estrellas de gran masa hace que la región esté en limitada por densidad, al menos en la sección a $b \simeq-0^{\circ} 45^{\prime}$. Este hecho podría explicar la falta de una estructura de H i ligada a la nebulosa óptica.

- Los datos en 408 y $1420 \mathrm{MHz}$ permiten distinguir dos estructura independientes en continuo de radio asociadas a las estrellas WR 152 y WR 153ab. Del estudio del índice espectral en ambas frecuencias se determinó que la emisión es térmica para la estructura asociada a WR 153ab. En el caso de la emisión de la estructura asociada a WR 152, para el cálculo de índice espectral utilizamos además los valores de las densidades de flujo en 2700, 8350 y $14350 \mathrm{MHz}$, debido a discrepancias con el valor de $\alpha$ obtenido con el diagrama TT. De esta manera obtuvimos un ajuste que indica que la emisión también es térmica en esta región. 
- Nuestros resultados de los parámetros del continuo de radio no coinciden con los de Felli et al. (1977). En ese trabajo los autores obtuvieron un valor de la densidad de flujo $\sim 6$ veces superior al nuestro, medido en $408 \mathrm{MHz}$. Una posible causa de esta gran discrepancia con nuestros valores es la baja resolución angular en $408 \mathrm{MHz}$ $\left(\sim 10^{\prime}\right)$ de los datos utilizados por estos autores, en los que se consideró una mayor radiación de fondo de la galaxia que en nuestros datos, aumentando el valor de la densidad de flujo real de la nebulosa. La resolución con la que fueron obtenidos los datos en $408 \mathrm{MHz}$ utilizados en esta tesis $\left(\sim 4^{\prime}\right)$ hizo posible distinguir dos estructuras en continuo asociadas a WR 153ab y WR 152, por lo que pudimos medir la densidad de flujo para cada una de ellas.

- La región de Sh2-132 asociada a WR153ab muestra la existencia de una PDR a través de la emisión en $8 \mu \mathrm{m}$ y de la superposición entre la fuerte emisión en continuo de radio y óptico, con el medio molecular.

- Para las estructuras ligadas a ambas estrellas WR, los valores de $\epsilon$ indican que las estrellas tienen vientos suficientemente intensos como para impulsar la burbuja interestelar y que la expansión se estaría desarrollando en la etapa de conservación del momento. 


\section{Bibliografía}

Blitz M., Fich M., Stark A.A, 1980, "The Galactic Rotation Curve to R=18 kpc" in: Andrew B.H. (ed), IAU Symp. 17, Interstellar molecules, Reidel, Dordrecht, p. 213 Brand J., Blitz L. 1993, A\&A, 275, 67

Buscombe W., Cappa C.E., Vasquez J., Arnal E.M., Cichowolski S., Pineault S., 2006, en prensa

Cappa C.E., Goss W. M., van der Hucht K. A., 2004, AJ, 127, 2885

Churchwell E., Walmsley C.M., 1973, A\&A, 23, 117

Conti P.S., William W.D., 1990, AJ, 100, 431

Crampton D., 1971, MNRAS, 153, 303

Crowther P. A., Smith L. J., Hillier D. J., 1995, A\&A, 302, 457

Fich M., Blitz M., Stark A.A, 1989, ApJ, 342, 272

Garmany C.D., Conti P.S., Chiosi C., 1982, AJ, 263, 777

Georgelin Y. M., Georgelin Y. P., 1976, A\&A, 49, 57

Georgelin Y.M., 1975, PhD Thesis, Observatoire de Marseille

Heckathorn J. N., Bruhweiler F. C., Gull T. R., 1982, ApJ, 252, 230

Harten R. H., Felli M., Tofani G., 1978, A\&A, 70, 205

Langston G., Minter A., D'Addario L., Eberhardt K., Koski K., Zuber J., 2000, AJ, 119,2801

Maiz-Apellaniz J., Walborn N.R., Galue H.A., Wei L.H., 2004, AJSS, 151, 103

Marston A. P., 1996, AJ, 112, 2828

Marston A. P., 1994, A\&AS, 185, 8309

Massey, P., 1981, PASP, 93, 549

Meynet G., Maeder A., 2003, A\&A, 404, 975

Mezger P.G, Henderson A.P. 1967, ApJ, 147, 471

Miller G.,J., Chu Y.-H., 1993, ApJS, 85, 137

Nugis T., Lamers H. J. G. L. M., 2000, A\&A, 360, 227

Panov K.P., Seggewiss W., 1990, A\&A, 227, 117

Prinja R. K., Barlow M.J., Howarth I.D., 1990, ApJ, 361, 607

Quireza C., Rood R.T., Balser D.S., Bania T. M., 2006, ApJS, 165, 338

Reich W., Fuerst E., Reich P., Reif K., 1990, A\&A, 85, 633

Reynolds R. J., 1988, ApJ, 333, 341

Sharpless S., 1959, ApJS, 4, 257

Smith L.J., Norris R.P.F., Crowther P.A., 2002, MNRAS, 337, 1309

Smith L.F., Shara M.M., Moffat A.F.J., 1998, MNRAS, 281, 163

Vacca W.D., Garmany C.D., Shull J.M., 1996, ApJ, 460, 914 
van der Hucht K.A., 2001, New Astronomy. Rev., 45, 135

Wegner W., 1994, MNRAS, 270, 229 


\section{Capítulo 6}

\section{La componente molecular del MIE asociada a WR 113}

\section{Resumen}

Investigamos la distribución y características del gas molecular vinculado a la nebulosa anillo Anon(WR 113). Con ese fin, observamos las líneas ${ }^{12} \mathrm{CO}(J=2-1)$ y ${ }^{12} \mathrm{CO}(J=1-0)$ con el radiotelescopio SEST (Chile), con una resolución angular de $22^{\prime \prime}$ y $45^{\prime \prime}$, respectivamente.

Encontramos estructuras moleculares a distintas velocidades radiales ligadas morfológicamente a la emisión óptica. A través de los valores del cociente $R_{2-1 / 1-0}$, determinamos que el material molecular presenta las condiciones necesarias para ser "very high ratio gas" (VHRG). La morfología que exhiben ambas fases del MIE, ionizada y molecular, y los valores del cociente $R_{2-1 / 1-0}$ del material molecular, sugieren que nos encontramos frente a una región de fotodisociación en la interfase entre ambas fases. La distribución tanto del gas ionizado en Anon(WR 113) como de la contraparte molecular está ligada a la acción de los vientos de la estrella WR 113.

\subsection{Antecedentes}

WR 113 (= HD 168206, WC8d+O8-9IV, van der Hucht 2001) pertenece al sistema binario eclipsante CV Ser, que es un probable miembro de la asociación Ser OB2 (van der Hucht 2001). González y Rosado (1984) descubrieron, en el rango óptico, una estructura doble alrededor de la estrella que consiste en un anillo interno de $4^{\prime}$ de radio y en un arco de $9^{\prime}$ de radio ubicados en el borde más brillante de la región H II Sh2-54 (Sharpless 1959). Ellos sugirieron que el anillo externo fue originado por la acción de los vientos de la estrella en fases previas a la etapa WR. Ambos anillos se ven en imágenes de la nebulosa en la línea H $\alpha$ (Miller y Chu 1993). Esteban y Rosado (1995) observaron la nebulosa óptica en las líneas prohibidas de [NII] 6548 $\lambda, 6584 \lambda$, [SII] 6717 $\lambda, 6731 \lambda$, en H $\alpha 6563 \lambda$ 
Tabla 6.1: Parámertos de la estrella WR 113

\begin{tabular}{lc}
\hline$(\alpha, \delta)(J 2000)$ & $\left(18^{h} 19^{m} 7.36^{s e g},-11^{\circ} 37^{\prime} 59.20^{\prime \prime}\right)$ \\
Tipo espectral & WC $8 \mathrm{~d}+\mathrm{O} 8-\mathrm{O}$ IV \\
$A_{v}(\mathrm{mag})$ & $3.23 \pm 0.1^{a}$ \\
$d(\mathrm{kpc})$ & $1.8^{a}, 2.0^{b}, 2.5^{e, f}$ \\
$\dot{M}\left(10^{-5} \mathrm{M}_{\odot}\right)$ & $<5.6^{g}, 2.0 \pm 0.3^{h}, 2.4^{f}$ \\
$v_{\infty}\left(\mathrm{km} \mathrm{s}^{-1}\right)$ & $1400^{i}, 1890^{j}$ \\
\hline
\end{tabular}

(a) van der Hucht, 2001, (b) Conti \& Vacca (1990), (e) Esteban \& Rosado (1995), ( $f$ ) Nugis \& Lamers (2000), (g) Leitherer et al. (1997), (h) Lamontagne et al. (1996), (i) Koesterge \& Hammann (1995), (j) Nugis et al. (1998).

y en $\mathrm{H} \beta 4861 \lambda$, en cuatro posiciones distintas en torno a $(\alpha, \delta)(J 2000)=\left(18^{h} 19^{m} 7.36^{\text {seg }}\right.$ ,$\left.-11^{\circ} 37^{\prime} 59.20^{\prime \prime}\right)$. Determinaron un rango de velocidades radiales entre $\sim+27 \mathrm{y} \sim+39$ $\mathrm{km} \mathrm{s}^{-1}$, y de esta forma estimaron una distancia cinemática de $2.0 \pm 0.2 \mathrm{kpc}$. Concluyeron que la principal fuente de fotoionización en la zona es la estrella WR, no encontraron evidencia de expansión y sugirieron que la nebulosa es de tipo $R_{s}$. Miller y Chu (1993) [?] no encontraron emisión en [OIII] en esta nebulosa.

En la Fig. 6.1 se observa la imagen $\mathrm{H} \alpha$ obtenida por el UK Schmidt Telescope (UKST) de $1.2 \mathrm{~m}$, de la nebulosa óptica Anon(WR 113). La cruz representa la posición de la estrella WR 113. En la Tabla 6.1 se muestran los principales parámetros de la estrella WR, su posición en coordenadas ecuatoriales $(\alpha, \delta)$, el tipo espectral, la absorción visual $A_{v}$ en dirección a la estrella, la distancia espectrofotométrica obtenida por diferentes autores, la tasa de pérdida de masa $\dot{M}$ y la velocidad terminal $v_{\infty}$.

Cappa et al. (2002) realizaron observaciones en $1465 \mathrm{MHz}$ con el Very Large Array (VLA) en la configuración DnC con una resolución angular de 30" hacia Anon(WR 113). También analizaron imágenes IRAS con $2^{\prime}$ de resolución angular. A partir de su análisis, distinguieron dos estructuras, una interna con forma de anillo, y otra externa con forma de arco, asociadas a esta estrella. Derivaron masas y densidades $M_{\text {int }}=20 \pm 10 \mathrm{M}_{\odot}$ у $n_{e}=$ $180-500 \mathrm{~cm}^{-3}$, y $M_{\text {ext }} \simeq=90 \mathrm{M}_{\odot}$ y $n_{e} \simeq 40 \mathrm{~cm}^{-3}$, para el anillo interno y el arco externo, respectivamente, asumiendo una distancia a toda la estructura de $2.0 \pm 0.6 \mathrm{kpc}$. A través de la relación entre la intensidad en $60 \mu \mathrm{m}$ y el brillo en continuo de radio, confirmaron que la emisión de continuo es térmica. Adoptando un radio $R_{s}=2.3 \mathrm{pc}$ para el anillo interno y una velocidad de expansión $v_{\text {exp }}=5-10 \mathrm{~km} \mathrm{~s}^{-1}$, determinaron un tiempo dinámico $t_{d}$ $=(1.3-2.5) \times 10^{5}$ años. Este valor sugiere que la nebulosa anillo ha sido originada por la acción de los vientos de la estrella en la fase WR. La estructura exterior estaría compuesta de material interestelar barrido, mientras que la interna contiene material expulsado por WR 113. Concluyeron que la nebulosa está en una etapa intermedia entre las fases de conservación de la energía y de conservación de momento. Los resultados fueron reunidos en el trabajo Vasquez et al. (2008). 


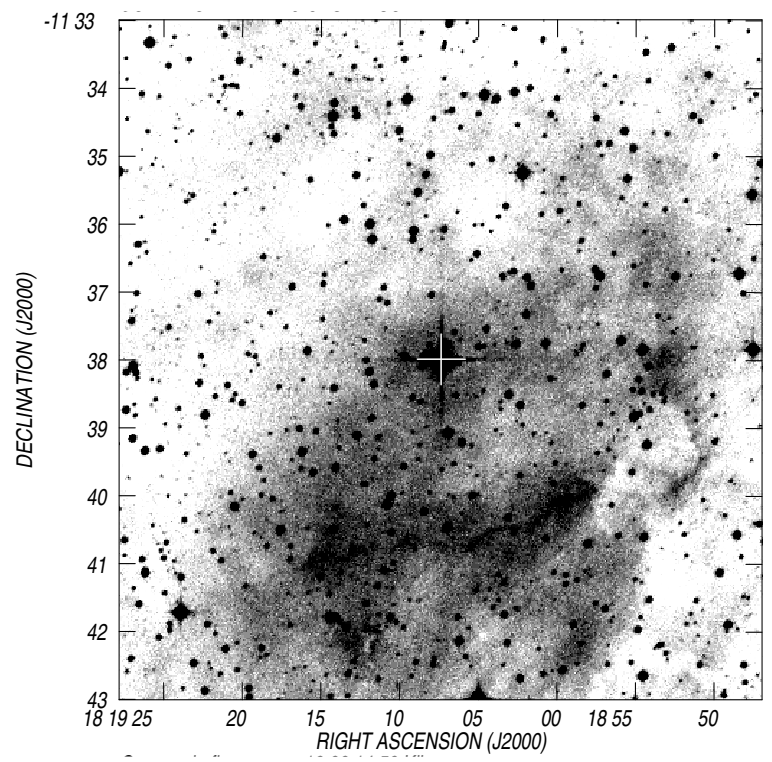

Figura 6.1: Imagen H $\alpha$ de la nebulosa óptica Anon(WR 113).

\subsection{Parámetros observacionales}

Las observaciones de ${ }^{12} \mathrm{CO}(J=1-0)$ y $(J=2-1)$ en 115 y $230 \mathrm{GHz}$, respectivamente, fueron adquiridas con el radiotelescopio de $15 \mathrm{~m}$ del Swedish ESO-Submillimitre Telescope (SEST) con resoluciones angulares de $22^{\prime \prime}$ y 45". Se utilizó un espectrómetro ópticoacústico de alta resolución, que proveía una resolución en velocidad de $0.109 \mathrm{~km} \mathrm{~s}^{-1}$ en 115 $\mathrm{GHz}$ y $0.054 \mathrm{~km} \mathrm{~s}^{-1}$ en $230 \mathrm{GHz}$. La intensidad de las líneas está expresada en temperatura del haz principal $T_{m b}$ (del inglés, main beam), a partir de dividir la temperatura de antena $T_{A}$ con la eficiencia del haz principal $\eta_{m b}$, cuyo valor es 0.70 y 0.50 en $115 \mathrm{GHz}$ y 230 $\mathrm{GHz}$, respectivamente.

Las observaciones fueron realizadas en modo "position switching". Los principales parámetros observacionales están listados en la Tabla 6.2. El proceso de reducción de datos se llevó a cabo con el software CLASS, SURFER, SURFAIPS y el paquete de programas AIPS, para armar cubos de datos en ambas líneas. La antena de $15 \mathrm{~m}$ del radiotelescopio SEST se muestra en la Fig. 6.2.

Las observaciones moleculares se llevaron a cabo en dos turnos de observación en los años 2002 y 2003 y fueron obtenidas por C. Cappa y M. Rubio. Todos los puntos han sido observados en ambas líneas ya que el instrumento permitía observaciones simultáneas. En la coordenada correspondiente a la posición de WR 113, se observaron, además, las líneas ${ }^{13} \mathrm{CO}(1-0)$ y $(2-1)$. 
Tabla 6.2: Parámetros observacionales

\begin{tabular}{lcc}
\hline & ${ }^{12} \mathrm{CO}(2-1)$ & ${ }^{12} \mathrm{CO}(1-0)$ \\
\hline Resolución angular & $22^{\prime \prime}$ & $45^{\prime \prime}$ \\
Cobertura total en velocidad & $(-20,+50) \mathrm{km} \mathrm{s}^{-1}$ & $(-20,+50) \mathrm{km} \mathrm{s}^{-1}$ \\
Resolución en velocidad $\left(\Delta v_{r e s}\right)$ & $0.055 \mathrm{~km} \mathrm{~s}^{-1}$ & $0.110 \mathrm{~km} \mathrm{~s}^{-1}$ \\
Resolución en velocidad (alisada) $\left(\Delta v_{r e s}\right)$ & $0.221 \mathrm{~km} \mathrm{~s}^{-1}$ & $0.332 \mathrm{~km} \mathrm{~s}^{-1}$ \\
Ruido $\Delta T_{r m s, m b}(\mathrm{~K})$ & 0.02 & 0.05 \\
\hline
\end{tabular}

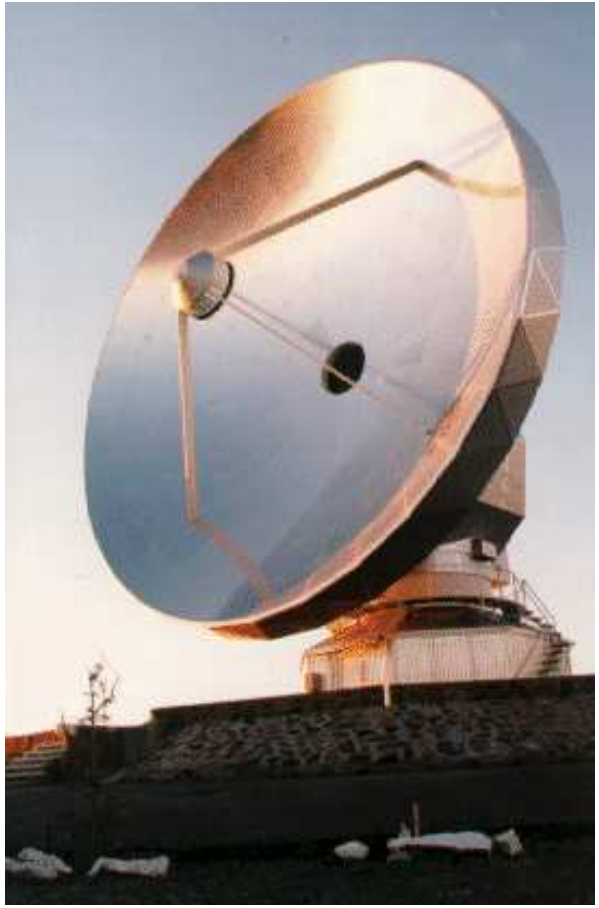

Figura 6.2: Antena de $15 \mathrm{~m}$ del radiotelescopio Swedish-ESO Submillimetre Telescope (SEST), ubicado en La Silla, Chile (hasta hace poco tiempo). 
El proceso de reducción de datos se llevó a cabo de la siguiente manera:

- ajuste de línea de base

- obtención del promedio de los perfiles repetidos en ambos turnos de observación

- alisado en velocidad de los perfiles

- regularización en la distribución de los puntos observados

- armado de cubos de datos de las observaciones de las líneas espectrales del monóxido de carbono correspondientes a $J=1-0$ y $J=2-1$

El primer punto en el proceso de reducción de datos corresponde al ajuste de la línea de base de todos los espectros observados. De esta forma eliminamos las irregularidades sobre la cual está montada la línea espectral. Luego de aplicar esta corrección a todos los espectros (> 300), se realizó el promedio de aquellos perfiles observados en forma repetida en ambos turnos. De esta manera, la cantidad de espectros se redujo a $\sim 170$.

A continuación se llevó a cabo un alisado en velocidad en los espectros de ambas líneas para disminuir el ruido y poder identificar con mayor claridad los detalles de la emisión. Luego del alisado, la resolución en velocidad de los perfiles pasó a ser $\Delta v=0.332 \mathrm{~km} \mathrm{~s}^{-1}$ en $115 \mathrm{GHz}$ y $\Delta v=0.221 \mathrm{~km} \mathrm{~s}^{-1}$ en $230 \mathrm{GHz}$. Hasta aquí, todo el manejo de datos se realizó con el paquete de programas CLASS.

En la Fig. 6.3 se muestran las posiciones observadas en la región. La distribución de los puntos corresponde a una grilla regular, aunque incompleta, con un espaciado igual a 45". Usando el programa SURFER, logramos distribuir estas observaciones en forma equiespaciada a través de interpolaciones de los puntos ya observados. La grilla completa regularizada consiste en un serie de $76 \times 95$ puntos con una separación de $\left(\Delta x=0.12^{\prime} \times\right.$ $\left.\Delta y=0.11^{\prime}\right)$. Posteriormente, se utilizó el programa SURFAIPS para transformar los archivos de salida de SURFER en archivos "legibles" para el programa AIPS. Finalmente se introdujeron todos los archivos en este último programa a través de la tarea "FETCH", para luego armar el cubo de datos correspondiente a cada línea con la tarea "MCUBE".

\subsection{Cálculo de $T_{e x c} \mathbf{y} \tau$}

Contar con datos de ${ }^{12} \mathrm{CO}$ y ${ }^{13} \mathrm{CO}$ nos permite determinar la temperatura de excitación $T_{\text {exc }}$ y la profundidad óptica $\tau$ de las nubes moleculares. La razón física por la cual podemos obtener estos dos parámetros, radica en que el ${ }^{12} \mathrm{CO}$ es ópticamente grueso mientras que el ${ }^{13} \mathrm{CO}$ es ópticamente delgado. O sea, nos dan una idea global del ambiente en el cual se encuentra la nube molecular. En nuestro caso, nosotros contamos con ambas líneas justo en dirección a WR 113.

Realizamos un ajuste de gaussianas con el programa CLASS y obtuvimos la velocidad central de la línea $\left(v_{L S R}\right)$, la temperatura pico $T_{\text {Pico }} \mathrm{y}$ el ancho a mitad de intensidad 


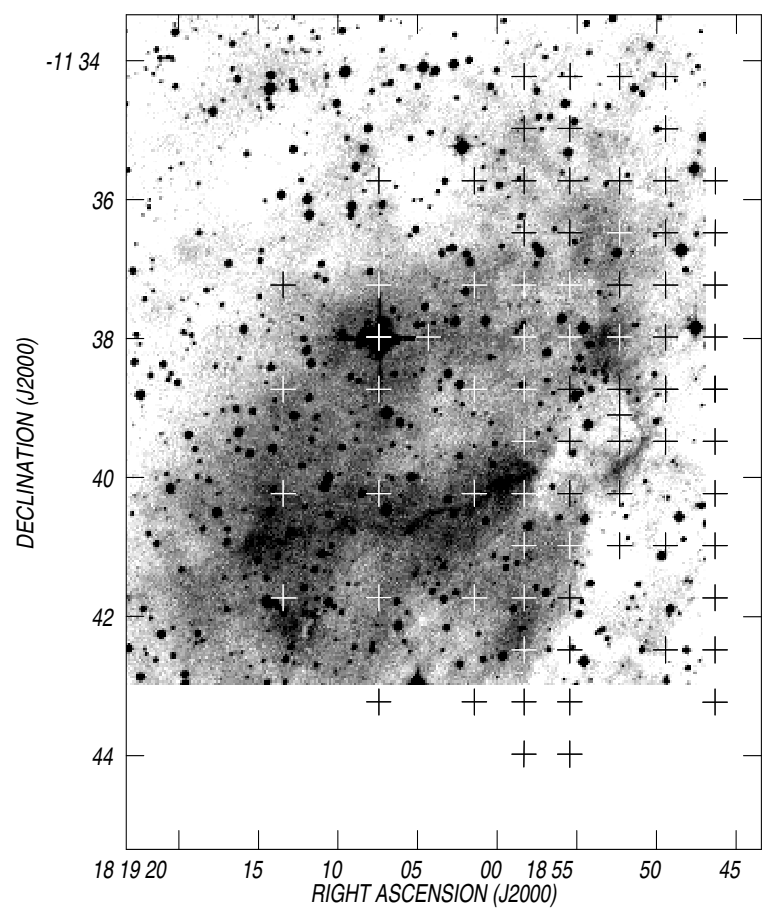

Figura 6.3: Imagen $\mathrm{H} \alpha$ de la nebulosa donde se muestra la grilla de puntos observados.

Tabla 6.3: Líneas de ${ }^{12} \mathrm{CO}(2-1)$ y ${ }^{13} \mathrm{CO}(2-1)$ en dirección a WR 113

\begin{tabular}{ccc|ccc|cc}
\hline \multicolumn{3}{c}{${ }^{12} \mathrm{CO}$} & \multicolumn{3}{c}{${ }^{13} \mathrm{CO}$} & \multicolumn{3}{c}{$\mathrm{T}_{\text {exc }}$} & $\tau^{13}$ \\
\hline$v_{\mathrm{LSR}}$ & $T_{\text {mb,pico }}$ & $\Delta v$ & $v_{\mathrm{LSR}}$ & $T_{m b, p i c o}$ & $\Delta v$ & & \\
$\left(\mathrm{~km} \mathrm{~s}^{-1}\right)$ & $(\mathrm{K})$ & $\left(\mathrm{km} \mathrm{s}^{-1}\right)$ & $\left(\mathrm{km} \mathrm{s}^{-1}\right)$ & $(\mathrm{K})$ & $\left(\mathrm{km} \mathrm{s}^{-1}\right)$ & $\mathrm{K}$ & \\
32.2 & 8.1 & 3.1 & 33.4 & 3.8 & 1.8 & 19.6 & 0.62 \\
\hline
\end{tabular}

máxima de la gaussiana ajustada $(\Delta v)$ para ambas líneas. En la en la Tabla 6.3 se muestran los resultados.

La $T_{\text {exc }}$ es la temperatura que gobierna las transiciones entre dos niveles ligados de energía y la calculamos a través de la expresión (3.54) del Capítulo 3. El cálculo de $\tau^{13} C O$ nos indica cuán opaco a la radiación óptica es este isótopo (en la transición que teníamos como dato) a lo largo de línea de la visual en la nube molecular, y la podemos obtener a través de la expresión (3.55), también del Capítulo 3. Los valores resultantes se encuentran en las columnas 7 y 8 de la Tabla 6.3.

\subsection{Distribución de CO en dirección a WR 113}

En la Fig. 6.4 se muestra el perfil de ${ }^{12} \mathrm{CO}(2-1)$ para la posición de WR 113, que nos da la $T_{m b}$ en función de la velocidad radial. Agregamos la curva de rotación galáctica 
correspondiente a la longitud galáctica de WR 113, para tener una idea clara de las posibles distancias cinemáticas $d_{c i n}$ correspondientes a la nebulosa Anon(WR 113). Recordemos que, según el modelo de rotación circular galáctico (MRCG), existe una ambigüedad en la $d_{\text {cin }}$ para objetos ubicados en el primer cuadrante dentro del círculo solar.

En la búsqueda de estructuras en dirección a WR 113 encontramos emisión extendida a lo largo de la línea de la visual en los rangos de velocidades $\Delta v_{1}=[+18.2,+22.6] \mathrm{km} \mathrm{s}^{-1}$ (que llamaremos estructura 1 [E1]) y $\Delta v_{2}=[+28.2,+37.7] \mathrm{km} \mathrm{s}^{-1}$ (que será la estructura 2 [E2]). La Fig. 6.5 muestra la distribución en $T_{m b}$, integrada dentro del rango de velocidades $\Delta v_{1}$ (panel (a)) y en el rango $\Delta v_{2}$ (panel (c)) en contornos y escala de grises. En ambos casos, el primer contorno corresponde a $3 \sigma$. La cruz indica la posición de la estrella. La distribución del panel (a) muestra que la emisión de $\mathrm{CO}$ a estas velocidades se concentra en máximos a una distancia angular de $4.25^{\prime}$ de la posición de la estrella. El aspecto es grumoso, con un pico intenso en la emisión en $(\alpha, \delta)(J 2000) \sim\left(18^{h} 18^{m} 50^{\text {seg }},-11^{\circ} 38^{\prime}\right)$ y otros dos máximos secundarios en $\sim\left(18^{h} 18^{m} 55^{\text {seg }},-11^{\circ} 37^{\prime}\right)$ y $\sim\left(18^{h} 18^{m} 48^{\text {seg }},-11^{\circ} 37^{\prime}\right)$. Además, pueden observarse tres pequeños grumos cuya emisión aparece justo sobre el nivel de ruido que se ubican en $(\alpha, \delta)(J 2000) \sim\left(18^{h} 19^{m} 00^{s e g},-11^{\circ} 42^{\prime}\right), \sim\left(18^{h} 19^{m} 10^{\text {seg }}\right.$,$\left.11^{\circ} 41^{\prime}\right)$ y $\sim\left(18^{h} 19^{m} 16^{s e g},-11^{\circ} 38^{\prime}\right)$. El panel (b) presenta la superposicion de la emisión en $1465 \mathrm{MHz}$ (Cappa et. al 2002) (contornos) con la misma emisión molecular (escala de grises). Las zonas de máxima emisión en ambos tipos de material aparecen casi superpuestas angularmente, evidenciando zonas de contacto entre ambas fases. La estructura E1 está vinculada al anillo interno ionizado.

La distribución de E2 (panel (c)) exhibe los valores máximos en una región que envuelve parcialmente a la estrella. De hecho, la posición de WR 113 se superpone con la emisión molecular extendida. El rasgo morfológico más sobresaliente es su forma de arco. Su proyección sobre el plano del cielo "contiene" la posición de la estrella central. La forma arqueada de la zona más intensa de la distribución de continuo de radio (panel (d)) "encaja" perfectamente con el arco molecular, envolviéndolo hacia $\alpha$ menores.

Para determinar con precisión las características morfológicas de ambas estructuras moleculares, mostramos toda la extensión en velocidad radial de E1 en una serie de imágenes separadas cada $0.66 \mathrm{~km} \mathrm{~s}^{-1}$ (promedio de dos canales) (ver Fig. 6.6). En la Fig. 6.7 se muestra el mismo detalle para E2, pero en esta figura, cada imagen corresponde a intervalos de $1.32 \mathrm{~km} \mathrm{~s}^{-1}$ (resultado de promediar cuatro canales). Para una presentación más clara, a todos estos mapas se les ha restado el valor medio de cada región encerrada dentro del contorno correspondiente a $T_{m b}=1 \mathrm{~K}$. De esta manera, todos los mapas han sido graficados con el mismo rango de colores y los mismos valores en los niveles de contorno. Cabe aclarar que este tratamiento con las imágenes sólo sirve para su mejor visualización, no para la obtención de parámetros físicos.

En la primer serie (Fig. 6.6), vemos que la forma de la estructura molecular se mantiene en los primeros cuatro mapas. Los pequeños grumos distribuidos alrededor de la posición de la estrella aparecen desde +19.6 hasta $+21.6 \mathrm{~km} \mathrm{~s}^{-1}$. El grumo más intenso se detecta en $(\alpha, \delta)(J 2000) \sim\left(18^{h} 19^{m} 10^{s e g},-11^{\circ} 41^{\prime}\right)$, a $v=+21.6 \mathrm{~km} \mathrm{~s}^{-1}$. En la última imagen de la serie, la estructura se desmembra. 


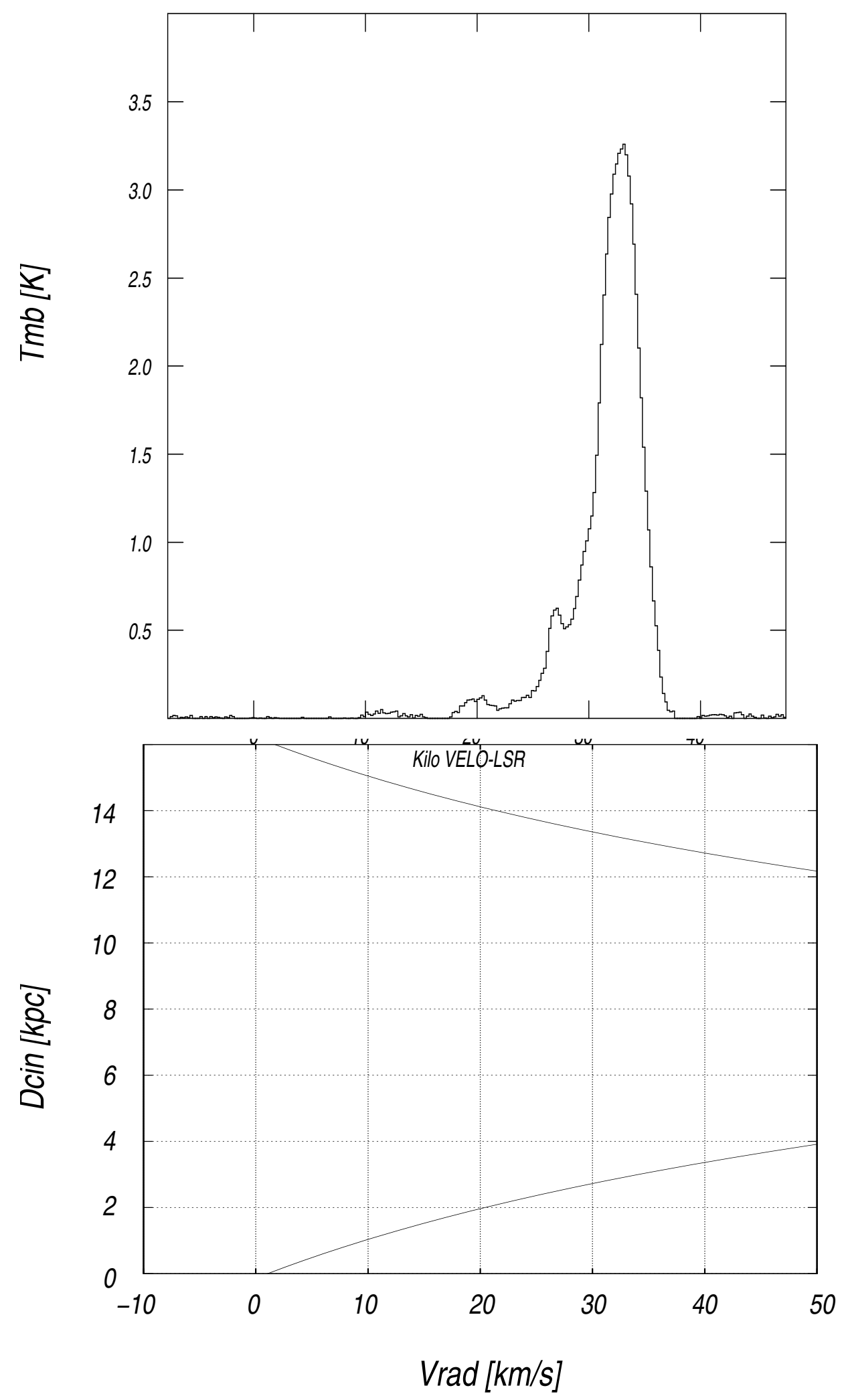

Figura 6.4: Perfil del ${ }^{12} \mathrm{CO}(1-0)$ en dirección a WR 113. La intensidad está dada en $T_{m b}$. En el sector inferior de la imagen se muestra una gráfico $v_{r a d}$ vs $d_{c i n}$, para la longitud galáctica correspondiente a WR 113 . 
En la segunda serie (Fig. 6.7), la emisión más intensa se presenta desde +29.5 hasta $+31.5 \mathrm{~km} \mathrm{~s}^{-1}$. Para velocidades entre $+34 \mathrm{y}+35 \mathrm{~km} \mathrm{~s}^{-1}$, la estructura adquiere forma de arco, cuya máxima extensión aparece a $+31.5 \mathrm{~km} \mathrm{~s}^{-1}$, con dos ramas bien definidas de $\sim 6^{\prime}$ cada una, y otra más pequeña de $\sim 2^{\prime}$. De esta forma, asociamos este mapa con la velocidad sistémica $v_{\text {sis }}$. Los mapas con velocidad $+28.2 \mathrm{y}+37.7 \mathrm{~km} \mathrm{~s}^{-1}$ han sido incluidos para mostrar el fin de la emisión. La distribución en la línea ${ }^{12} \mathrm{CO}(2-1)$ es similar a la de ${ }^{12} \mathrm{CO}(1-0)$, por lo que no se muestra.

La Fig. 6.8 muestra la imagen integrada en ${ }^{12} \mathrm{CO}(2-1)$ entre $+30.3 \mathrm{y}+36.5 \mathrm{~km} \mathrm{~s}^{-1}$. El primer contorno mostrado es $3 \sigma$. Los rasgos generales de la emisión son muy similares a los de la emisión en ${ }^{12} \mathrm{CO}(1-0)$. En la parte inferior de la figura, se muestra la superposición entre la imagen óptica en escala de grises y los contornos de la distribución molecular. El arco filamentoso de la nebulosa óptica en $(\alpha, \delta)(J 2000)=\left(18^{h} 19^{m} 5^{s e g},-11^{\circ} 40^{\prime} 30^{\prime \prime}\right)$ que forma parte del anillo interno bordea la región molecular más intensa, quedando ésta "atrapada" entre ella y la posición de la estrella. Si comparamos la distribución molecular con la emisión óptica vemos que la nube molecular está ubicada entre WR 113 y el anillo interno. La región donde se encuentra la mayor intensidad de CO corresponde a una zona de baja intensidad óptica, sugiriendo que el gas molecular podría estar "tapando" parte de la emisión óptica e interactuando con ella.

A esta figura se agregaron cuatro espectros correspondientes a los puntos indicados con las flechas rojas, que muestran la distribución del ${ }^{12} \mathrm{CO}(2-1)$ en regiones diferentes sobre la misma nebulosa. Elegimos estos puntos ya que, como puede verse en la figura, esas regiones muestran un alto contraste en las condiciones del material. Los dos espectros superiores muestran las emisión de los isótopos de ${ }^{12} \mathrm{CO}$ y ${ }^{13} \mathrm{CO}$ en la misma transición $(J=2-1)$, en dirección a WR 113 .

En principio, la morfología de ambas estructuras moleculares presenta rasgos característicos que sugieren que ambas están relacionadas a la nebulosa.

\subsubsection{Cociente $R_{2-1 / 1-0}$}

Una poderosa herramienta que puede ayudar a determinar las condiciones físicas de una nube molecular es el cociente entre las líneas ${ }^{12} \mathrm{CO}(2-1)$ y ${ }^{12} \mathrm{CO}(1-0)$, comúnmente llamado $R_{2-1 / 1-0}$.

Sakamoto et al. (1997) clasificó el gas molecular en tres categorías de acuerdo a este cociente: cociente muy intenso (VHRG, del inglés "very high ratio gas"), cociente intenso (HRG, del inglés "high ratio gas") y cociente bajo (LRG, del inglés "low ratio gas"). Esta división en diferentes clases la cuantificó en función de $R_{2-1 / 1-0}$. De esta forma tenemos:

- VHRG $\rightarrow R_{2-1 / 1-0}>1$. Las regiones que satisfacen esta condición son aquellas en las que el gas se encuentra a elevada temperatura cinética $\left(T_{\text {cin }} \geq 50 \mathrm{~K}\right)$ y es muy denso $\left(n\left(H_{2}\right) \geq 3 \times 10^{3} \mathrm{~cm}^{-3}\right)$. Tiene una baja opacidad, y las colisiones son el principal mecanismo de emisión de radiación. Estas condiciones se encuentran en 
(a) $\boldsymbol{E} 1 \Delta v 1=[+18.2,+22.6] \mathrm{km} / \mathrm{s}$

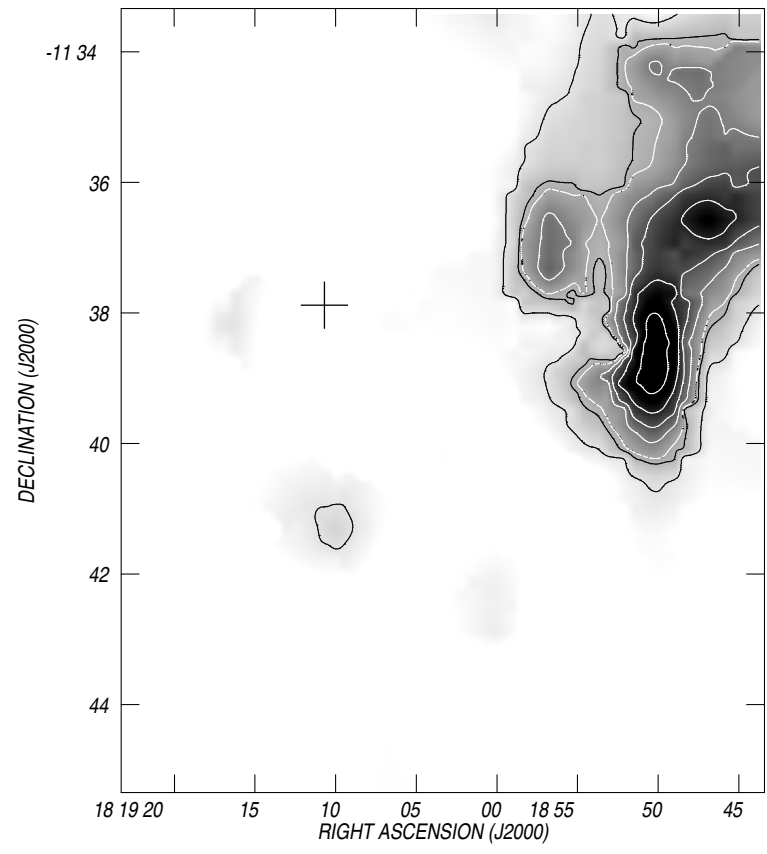

(c) $\quad \boldsymbol{\Delta} 2 \mathrm{v} 2=[+28.2,+37.5] \mathrm{km} / \mathrm{s}$

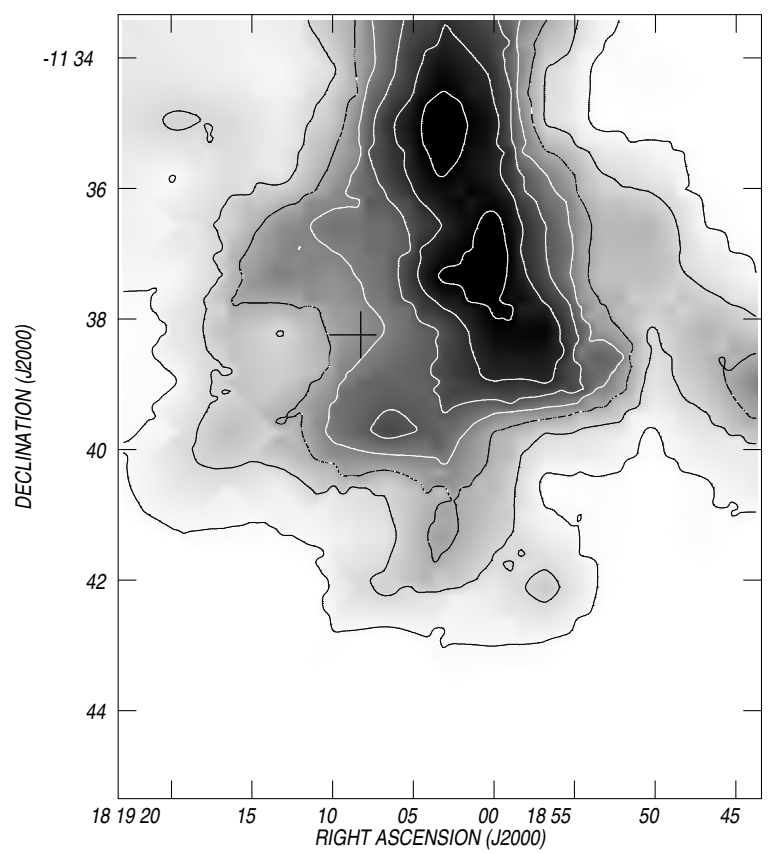

(b)

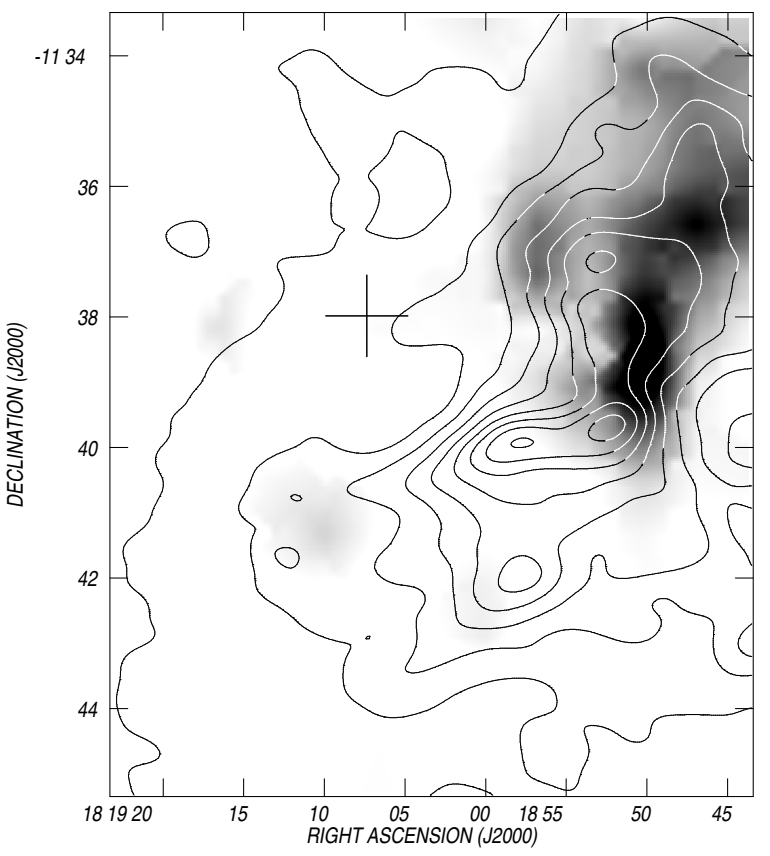

(d)

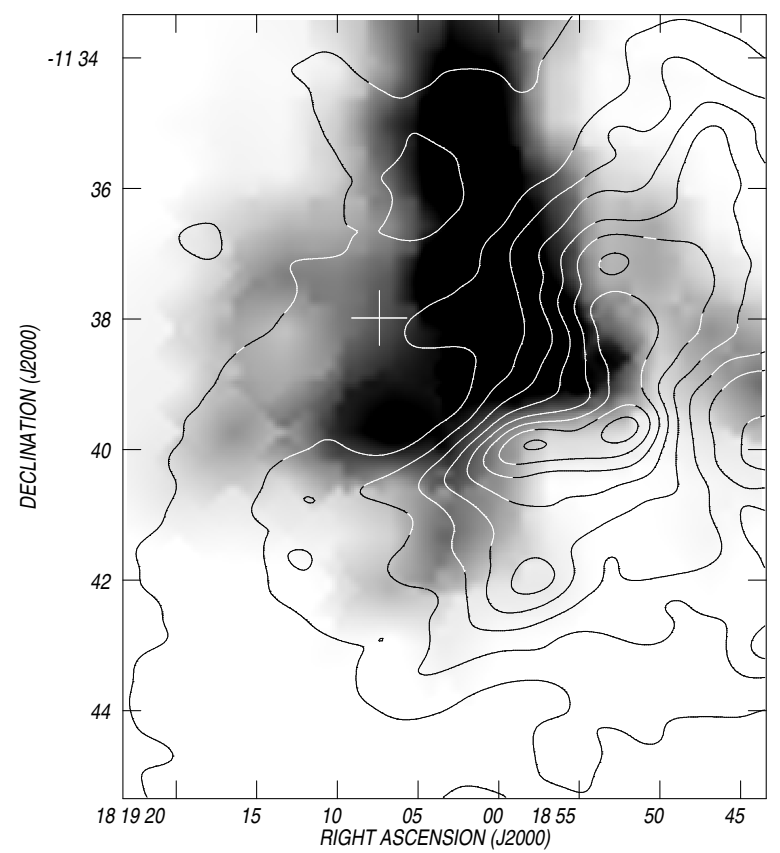

Figura 6.5: Panel superior: (a) Distribución de $\mathrm{CO}(1-0)$ integrada entre +18.2 y +22.6 $\mathrm{km} \mathrm{s}^{-1}$. Escala de grises: 0.08 - $1.5 \mathrm{~K}$, contornos: $0.24,0.48,0.56,0.80,1.04,1.3$ y 1.7 K. (b) Superposición de la misma distribución de $\mathrm{CO}(1-0)$ (grisados) con la emisión en $1420 \mathrm{MHz}$ (contornos). Panel inferior: (c) Imagen de la distribución de CO(1-0) integrada entre 28.2 y $37.5 \mathrm{~km} \mathrm{~s}^{-1}$. Escala de grises: $0.08-5.5 \mathrm{~K}$, contornos: $0.24,1,2,3,4,5$ y $6 \mathrm{~K}$. (d) Superposición de la distribución de CO(1-0) (grisados) con la emisión en $1420 \mathrm{MHz}$ (contornos). 

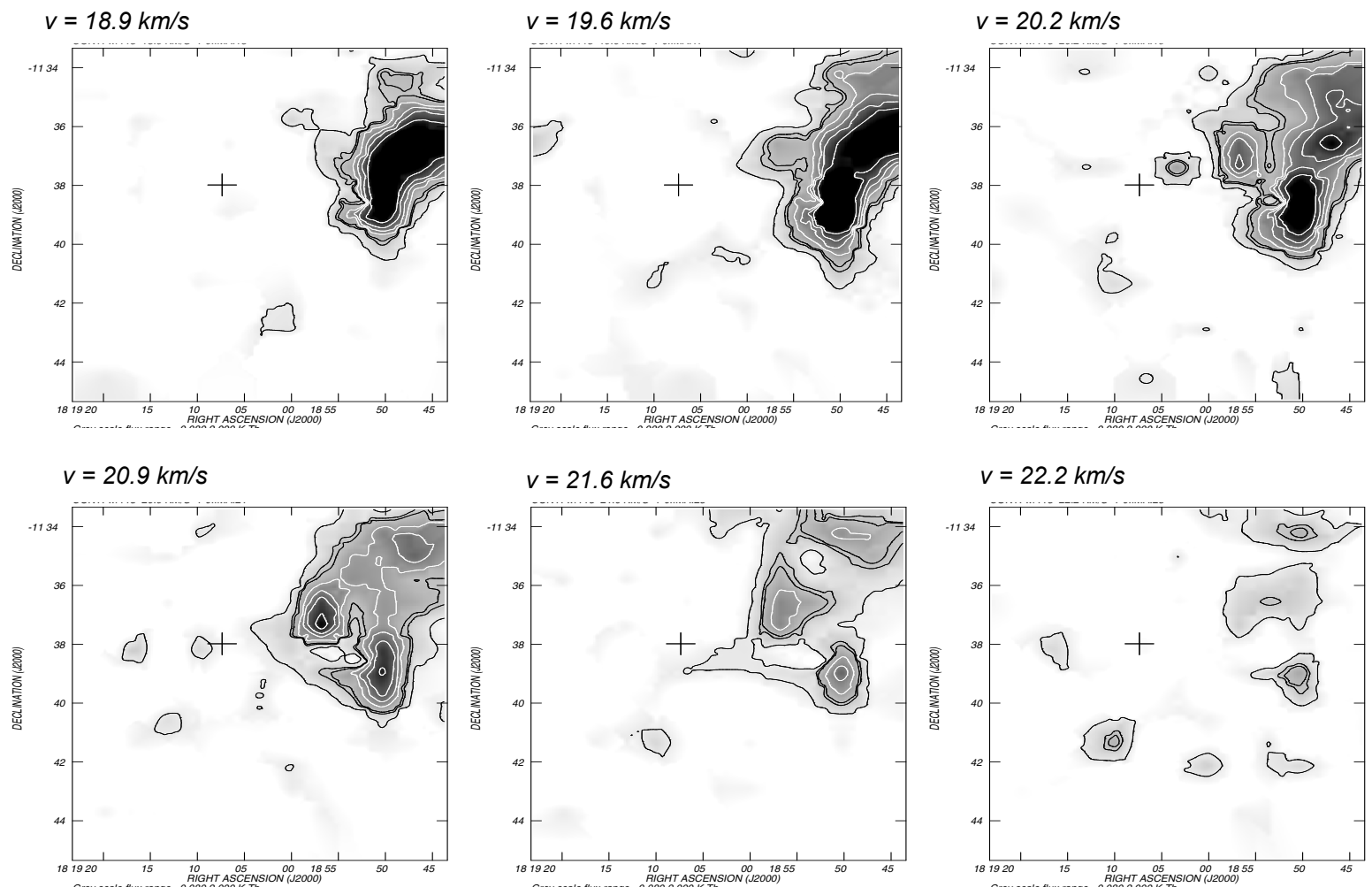

Figura 6.6: Distribución de $\mathrm{CO}(1-0)$ en el mismo rango de velocidades que la Fig. 6.5(a). Cada imagen es el producto de la integración de dos canales consecutivos. 

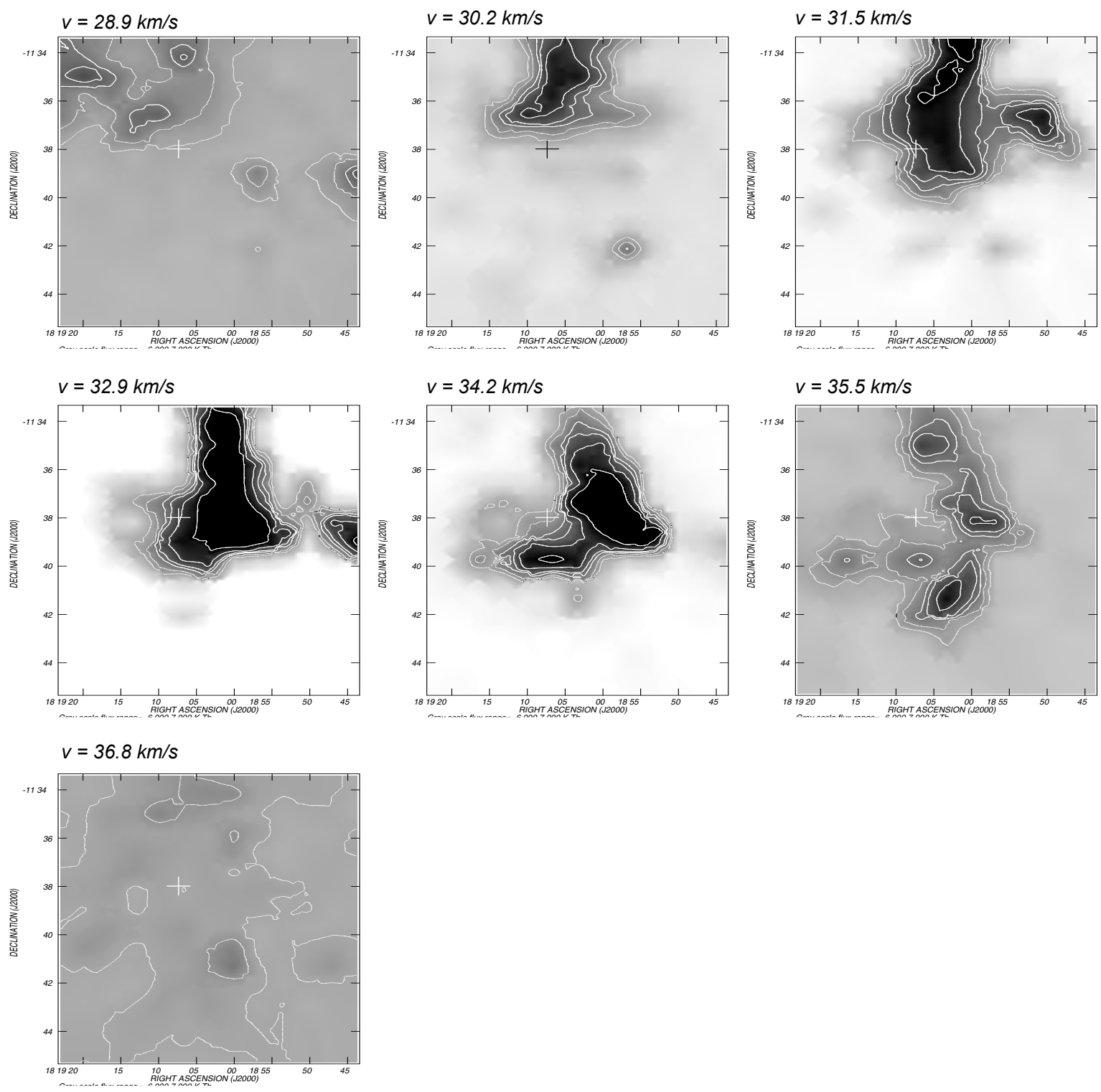

Figura 6.7: Distribución de $\mathrm{CO}(1-0)$ en el mismo rango de velocidades que la Fig. 6.5(a). El intervalo en velocidad entre mapas es $\Delta v=1.32 \mathrm{~km} \mathrm{~s}^{-1}$. 

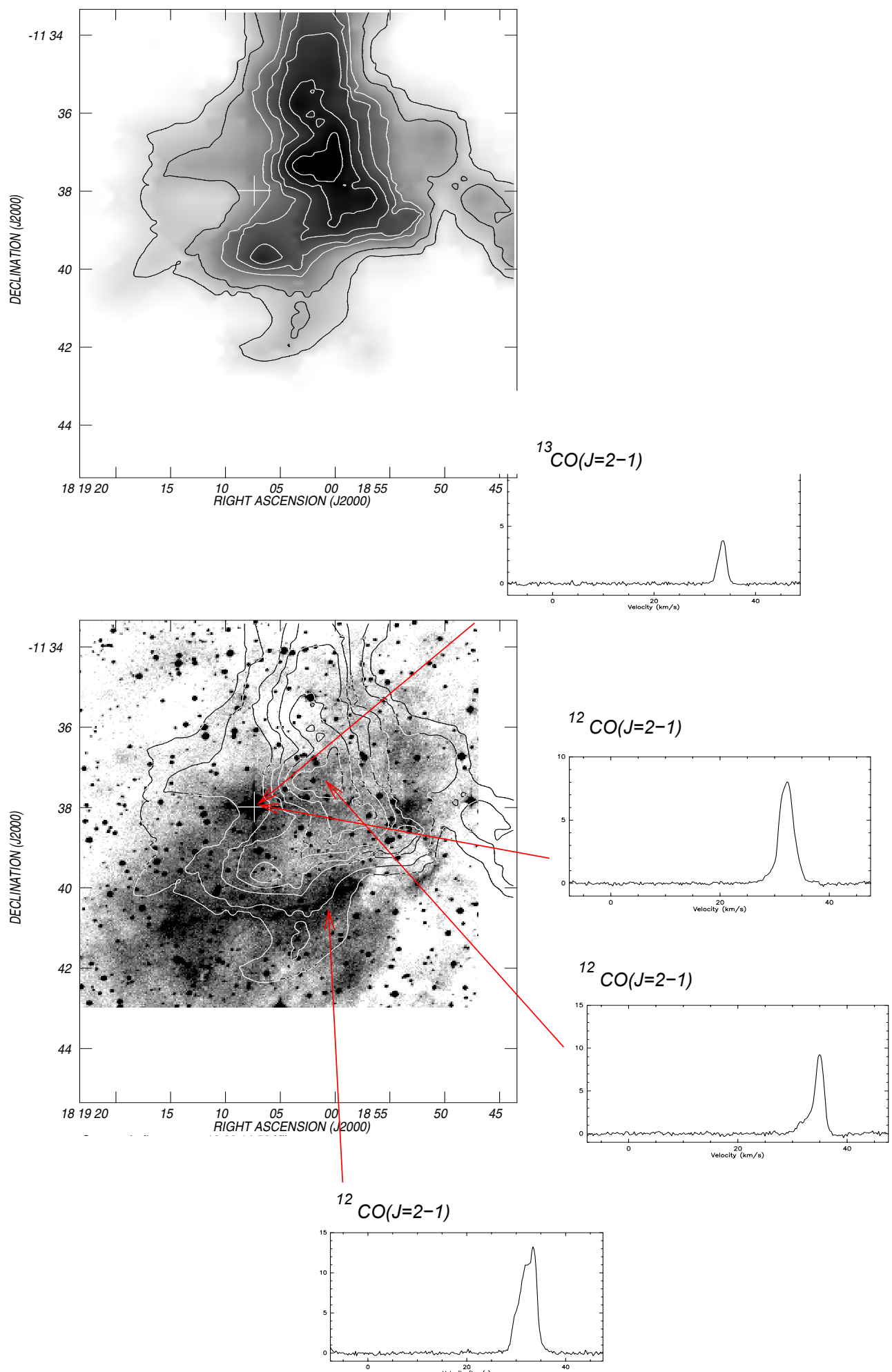

Figura 6.8: Panel superior: Distribución de ${ }^{12} \mathrm{CO}(1-0)$ en el rango de velocidaes entre +30.3 y $+36.5 \mathrm{~km} \mathrm{~s}^{-1}$. Panel inferior: Superposición de la imagen $\mathrm{H} \alpha$ (grisados) y la distribución molecular (contornos). Los espectros muestran la distribución de ${ }^{12} \mathrm{CO}(2-1)$ en diferentes sectores de la nebulosa. Se agregó el espectro en ${ }^{13} \mathrm{CO}(2-1)$ en dirección a WR 113. 
regiones irradiadas por intensos campos de radiación, es decir, regiones H II, regiones de fotodisociación, etc.

- $\mathrm{HRG} \rightarrow 0.7<R_{2-1 / 1-0}<1$. El gas molecular tiene $T_{\text {cin }} \geq 20 \mathrm{~K}$ y densidad $n\left(H_{2}\right) \geq 1 \times 10^{3} \mathrm{~cm}^{-3}$. La radiación está dominada por las colisiones, y, en general, estos valores en el cociente aparecen hacia el centro de nubes moleculares gigantes (Castets et al. 1990, Sakamoto et al. 1994).

- LRG $\rightarrow R_{2-1 / 1-0}<0.7$. Se alcanzan estos valores en el cociente cuando $T_{e x c} \leq 10$ $\mathrm{K}$ y la densidad $n\left(H_{2}\right) \leq 1 \times 10^{3} \mathrm{~cm}^{-3}$. En general, estos valores son observados en los bordes de nubes moleculares gigantes (Sakamoto et al. 1994) y nubes oscuras. En las regiones más externas de la galaxia se da esta situación, ya que la interacción con rayos cósmicos mantiene las nubes a temperaturas $\sim 10 \mathrm{~K}$ (Goldsmith \& Lager 1978). En el interior de la galaxia, este gas tiene baja densidad y es opaco.

La Fig. 6.9(a) muestra el cociente entre las imágenes integradas de ${ }^{12} \mathrm{CO}(2-1)$ y ${ }^{12} \mathrm{CO}(1-$ 0 ) para la componente E2. Para ralizar esto, convolucionamos la imagen con mejor resolución angular $\left({ }^{12} \mathrm{CO}(2-1)\right.$ con $\left.22^{\prime \prime}\right)$ a la resolución angular de la imagen con peor resolución $\left({ }^{12} \mathrm{CO}(1-0)\right.$ a $\left.45^{\prime \prime}\right)$. De esta forma obtuvimos un mapa que nos ofrece el cociente punto a punto. La gama de colores va desde el color negro al color rojo, indicando zonas de menor a mayor valor de $R_{2-1 / 1-0}$, respectivamente (regiones con $R \leq 0.5$ en nuestro mapa tienen gran incerteza, y $R=0$ no tiene sentido). Los contornos muestran la imagen en continuo de radio en $1465 \mathrm{MHz}$. Nuestro interés en la imagen radica principalmente en la zona que ocupa la nebulosa óptica, cuyas dimensiones equivaldrían a la región que encierra el círculo blanco, ya que esa sería la zona de interacción entre el material ionizado y el gas molecular para la componente E2. Vemos que dentro del círculo los valores del cociente van desde $\sim 2.5$ hacia el centro, hasta $\sim 4.5$ hacia los bordes (sobre todo hacia $\alpha \sim 18^{h}$ $18^{m} 52^{s}$ ), justo en donde se encuentra la zona más intensa del continuo de radio. En la Fig. 6.9(b) se exhibe un gráfico que muestra los valores de $R_{2-1 / 1-0}$ en función de la distancia angular, medida en segundos de arco respecto de la posición de la estrella WR 113. Para armar este gráfico tomamos 15 anillos concéntricos en la posición de la estrella WR, con un grosor de $10^{\prime \prime}$ cada uno, de los cuales se obtuvo la intensidad media. Los círculos dibujados en el gráfico indican los límites angulares entre anillos contiguos.

Como puede verse, hasta un radio de $\sim 2^{\prime}$ a partir de WR 113, los valores de $R_{2-1 / 1-0}$ se mantienen en torno a 3 , luego tienen un pico en $\sim 4.5$, un poco más allá de los $2^{\prime}$, pero luego vuelve a valores aún más bajos que los más internos, del orden de 2 .

De esta forma, los resultados sugieren que las condiciones en que se encuentra el gas molecular es VHRG. Estos valores corresponden a regiones moleculares expuestas a intensos campos de radiación. Casos como éste se han presentado por ejemplo en la interacción entre la nube molecular con W 44 y el remanente de supernova IC 443 (Seta et al. 1998). 

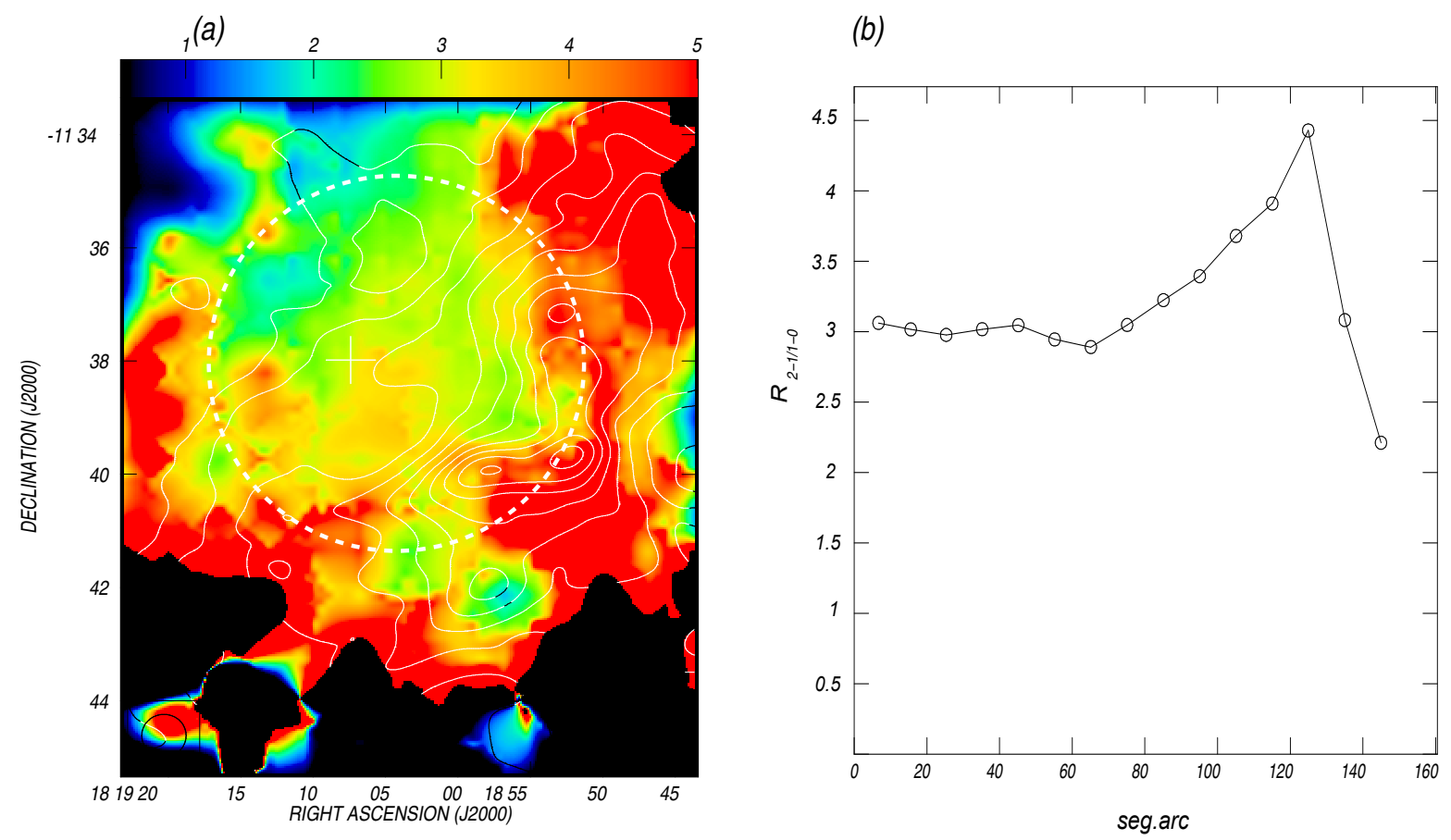

Figura 6.9: Panel izquierdo: Imagen del cociente entre las emisiones integradas de $\mathrm{CO}(2-1)$ y CO(1-0) para la componente E2. El círculo representa la región de interés. Los contornos corresponden a la emision de continuo de la Fig. 6.5(b). Panel derecho: Distribución de intensidad del cociente $R_{2-1 / 1-0}$, en función de la distancia angular, dentro del círculo blanco de $2.5^{\prime}$. 


\subsection{Determinación de la distancia cinemática y parámetros físicos de la estructura}

En esta sección nos dedicaremos a tratar de definir la distancia cinemática $d_{\text {cin }}$ de la estructura molecular. El modelo que nos guía para tal fin, el MRCG (Brand \& Blitz 1993), arroja dos posibles distancias para objetos ubicados en el primer o cuarto cuadrante dentro del círculo solar.

Teniendo esto en cuenta, vamos a establecer algunos criterios para poder ubicar las estructuras encontradas a una $d_{c i n}$ particular y discutir su asociación a la nebulosa:

- Acuerdo entre las $d_{c i n}$ del material molecular con la distancia espectrofotométrica de la estrella asociada

- Correlación morfológica entre el material molecular y el material nebular con $d_{c i n}$ previamente determinada

- Comparación entre la magnitud absoluta para la estrella con la que tendría si su distancia fuese alguna de las $d_{\text {cin }}$ del CO

- Cociente $R_{2-1 / 1-0}>1$

En la sección 6.4 concluimos que tanto la estructura E1 como la E2 presentan rasgos morfológicos que las vinculan a la nebulosa óptica.

En general, vamos a enumerar los principales aspectos que vinculan a E1 con Anon(WR 113):

- La región con emisión de CO más intensa está superpuesta a parte de la emisión intensa en el continuo a $\delta>-11^{\circ} 40^{\prime}$, bordeándola externamente (ver Fig. 6.5)

- La presencia de nubes rodeando la posición de la estrella desde $\sim+20.2$ hasta $\sim+22$ $\mathrm{km} \mathrm{s}^{-1}$.

Por otro lado, también debemos enumerar los rasgos fundamentales que permiten asociar E2 con Anon(WR 113):

- Mantiene una forma de arco a lo largo de $\sim+8 \mathrm{~km} \mathrm{~s}^{-1}$ (ver Fig. 6.6), rodeando la posición de WR 113 desde $\sim+32 \mathrm{~km} \mathrm{~s}^{-1}$ hasta $\sim+36 \mathrm{~km} \mathrm{~s}^{-1}$. El gas molecular está proyectado entre la estrella y la emisión en continuo de radio del anillo interno

- La imagen integrada muestra los máximos de emisión bordeando la posición de WR 113. El gas molecular estaría delante del gas ionizado e interactuando con él

- Similitud entre el rango total en velocidad y velocidades radiales de líneas ópticas medidas por Esteban \& Rosado (1995). 
Por otro lado, recurriendo al MRCG y teniendo en cuenta los efectos de los movimientos no circulares en esta dirección del plano galáctico, que introducen una incerteza en la velocidad radial del orden de $\sim 10 \mathrm{~km} \mathrm{~s}^{-1}$, tendremos un par de valores de distancias cinemáticas por estructura molecular. Para E2, considerando una $v_{\text {sis }}=+34.8 \pm 0.8 \mathrm{~km} \mathrm{~s}^{-1}$, las dos posibles distancias serán $d_{E 2}^{1}=3.0 \pm 1.0 \mathrm{kpc}$ y $d_{E 2}^{2}=13.0 \pm 1.0 \mathrm{kpc}$, mientras que para E1, con una $v_{s i s}=21.8 \pm 0.6 \mathrm{~km} \mathrm{~s}^{-1}$, tendremos $d_{E 1}^{1} \sim=2.0 \mathrm{kpc} \mathrm{y} d_{E 1}^{2} \sim=14.0 \mathrm{kpc}$.

Si calculamos la magnitud visual absoluta $M_{v}$ a partir de la ley de Pogson, $M_{v}-v=$ $5-5 \log (d)-A_{v}$ que tendría la estrella a esas distancias, asumiendo una magnitud visual $v=9.43$ mag y una $A_{v}=3.23 \pm 0.1 \mathrm{mag}$ (van der Hucht 2001), obtendremos las siguientes magnitudes absolutas:

$$
\begin{gathered}
d_{E 2}^{1} \rightarrow M_{v_{1}}=-5.3 \pm 0.3 \mathrm{mag} \\
d_{E 2}^{2} \rightarrow M_{v_{2}}=-9.4 \pm 0.2 \mathrm{mag} \\
d_{E 1}^{1} \rightarrow M_{v_{2}} \simeq=-5.5 \mathrm{mag} \\
d_{E 1}^{2} \rightarrow M_{v_{2}} \simeq=-9.7 \mathrm{mag}
\end{gathered}
$$

Debemos tener en cuenta que van der Hucht (2001) propuso una magnitud absoluta para la estrella WR de -3.30 mag y para el sistema binario de -5.06 mag. En principio, quedan descartadas la distancia $d_{E 2}^{2}$ y $d_{E 1}^{2}$ de ambas estructuras.

De acuerdo con lo mencionado en la sección 6.1, el rango de velocidades radiales medidas para las líneas ópticas [NII], [SII], $H \alpha$ y $H \beta$ (Esteban \& Rosado 1995) va desde $\sim+27 \mathrm{a}+39 \mathrm{~km} \mathrm{~s}^{-1}$, indicando una $d_{\text {cin }} \simeq 3 \pm 0.5 \mathrm{kpc}$ a través del MRCG.

Teniendo en cuenta todos los valores de distancias encontrados en la literatura y nuestras distancias cinemáticas, concluimos que tanto E1 como E2 pueden estar asociadas a la nebulosa. Proponemos $2.8 \pm 0.2 \mathrm{kpc}$ como distancia a todo el complejo de gas molecular e ionizado.

De esta forma, proponemos un escenario donde el fuerte viento de la estrella WR 113 ha formado dos estructuras arqueadas de material ionizado, observadas en la línea $\mathrm{H} \alpha$. Por lo mostrado en las imágenes de CO, la proyección de la región molecular (E2) más intensa se encuentra entre la estrella y el anillo interno, mientras que E1 aparece claramente asociado a la parte $\delta>-11^{\circ} 40^{\prime}$ del mismo anillo. Esta distribución sugiere posibilidades limitadas en cuanto a la ubicación relativa de las diferentes componentes: (i) el material molecular (E1 y E2) se encuentra cerca del frente de ionización, (ii) el frente de ionización disocia e ioniza el material molecular, alentando la formación de regiones de fotodisociación en los alrededores de Anon(WR 113). E1 y E2 podrían formar parte de una estructura de cáscara asociada a la emisión ionizada bordeándola externamente.

En la Tabla 6.5 se resumen los parámetros físicos de E1 y E2 medidos a partir de las observaciones de ${ }^{12} \mathrm{CO}(1-0)$. Se listan el tamaño angular de ambas estructuras a la velocidad sistémica de cada una de ellas, el intervalo total en velocidad, la velocidad sistémica, la densidad columnar y la masa molecular. 
Tabla 6.4: Parámetros físicos de E1 y E2

\begin{tabular}{lcc}
\hline Distancia asumida $(\mathrm{kpc})$ & \multicolumn{2}{c}{$2.8 \pm 0.6$} \\
\hline \multicolumn{2}{c}{$\mathrm{E} 1$} & $\mathrm{E} 2$ \\
\hline Tamaño angular & $\sim 6^{\prime}$ & $\sim 4^{\prime}$ \\
Intervalo total en velocidad $\left(\mathrm{km} \mathrm{s}^{-1}\right)$ & $28.2,37.5$ & $18.2,22.6$ \\
Velocidad sistémica $\left(\mathrm{km} \mathrm{s}^{-1}\right)$ & $34.8 \pm 0.8$ & $21.8 \pm 0.6$ \\
Densidad columnar $\mathrm{N}_{\mathrm{H}_{2}}\left(\mathrm{~cm}^{-2}\right)$ & $(3.5 \pm 0.2) \times 10^{21}$ & $(2.5 \pm 0.2) \times 10^{20}$ \\
Masa $\mathrm{M}_{\mathrm{H}_{2}}\left(\mathrm{M}_{\odot}\right)$ & $(2.6 \pm 1.1) \times 10^{3}$ & $(1.3 \pm 0.5) \times 10^{2}$ \\
\hline
\end{tabular}

Para determinar la densidad columnar $\mathrm{N}_{H_{2}}$ y la masa de hidrógeno molecular asumimos el valor de la distancia discutido en la sección 6.5. Para obtener la $\mathrm{N}_{H_{2}}$ consideramos la expresión 3.71 del Capítulo 3, en la que consideramos un valor para $X=6 \times 10^{20} \frac{\mathrm{molcm}^{-2}}{\mathrm{Kkm} / \mathrm{s}}$ para $60^{\circ}<l<300^{\circ}$ (Sodroski 1991).

\subsection{Conclusiones}

Teniendo en cuenta el análisis que se llevó a cabo del medio molecular en dirección a la nebulosa óptica Anon(WR 113) podemos concluir que existe una interacción física con la estructura molecular E2 detectada en el rango de velocidad $[+28.2,+37.5] \mathrm{km} \mathrm{s}^{-1}$ debido a cuatro factores fundamentales, (i) relación morfológica de la emisión molecular con el continuo de radio en $1465 \mathrm{MHz}$ y con la emisión $\mathrm{H} \alpha$; (ii) el aspecto arqueado de la emisión molecular, anima a pensar que los vientos de las estrellas de gran masa estarían modelando la distribución molecular, (iii) a la distancia derivada del MRCG, la $M_{v}$ de la estrella WR es similar a la propuesta por van der Hucht (2001); (iv) marcada extensión en el ala azul del espectro en dirección hacia el máximo de la emisión molecular (ver Fig. 6.8), respecto al espectro en dirección a la estrella WR, lo que podría evidenciar una interacción entre los fuertes vientos de la estrella con el medio molecular; (v) valores del cociente $R_{2-1 / 1-0}>1$, que mostrarían interacción entre material molecular con el intenso campo de radiación generado por WR 113.

Por otro lado proponemos que la estructura E1 está interactuando con Anon(WR 113), principalmente por su morfología. Su emisión aparece bordeando el máximo de emisión de continuo de radio en un rango amplio de velocidades radiales. Su distancia cinemática es similar a las medidas en líneas ópticas.

Por lo tanto concluimos que ambas estructuras moleculares, E1 y E2, están asociadas a la nebulosa Anon(WR 113) y a WR 113. Proponemos que ambas componentes constituyen una única estructura que, a la manera de una cáscara, bordearía la emisión ionizada del anillo interno. 


\section{Bibliografía}

Brand J., Blitz L., 1993, A\&A, 275, 67

Cappa C. E., Goss W. M., Pineault S., 2002, AJ, 123, 3348

Castets A., Duvert G., Dutrey A., Bally J., Langer W. D., Wilson R. W., 1990, A\&A, 234, 469

Conti P.S., Vacca W.D., 1990, AJ, 100, 431

Esteban C, Rosado M., 1995, A\&A, 304, 491

Goldsmith P.F., Langer W.B., 1978, ApJ, 222, 881

Gonzalez J. \& Rosado M., 1984, A\&A, 134, 21

Koesterke L., Hamann W.-R., 1995, A\&A, 299, 503

Lamontagne R., Moffat A.F.J., Drissen L., Robert C., Matthews J.M., 1996, AJ, 112, 2227

Leitherer C., Chapman J.M., Koribalski B., 1997, ApJ, 481, 898

Miller G.J., Chu Y.-H., 1993, ApJS, 85, 137

Nugis T., Lamers H.J.G.L.M., 2000, A\&A, 360, 227

Nugis T., Crowther P.A., Willis A.J., 1998, A\&A, 333, 956

Sakamoto S., Hasegawa T., Handa T., Hayashi M., Oka T., 1997, ApJ, 486, 276

Sakamoto S., Hayashi M., Hasegawa T., Handa T., Oka T., 1994, ApJ, 425, 641

Seta M., Hasegawa T., Dame T. M., Sakamoto S., Oka T., Handa T., Hayashi M., Morino J.-I., Sorai K., Usuda K.S., 1998, ApJ, 505, 286

Sharpless S., 1959, ApJS, 4, 257

Sodroski, T. J., 1991, ApJ, 366, 95

van der Hucht K.A., 2001, New Astronomy. Rev., 45, 135

Vasquez J., Cappa C.E., Rubio M., 2008, BAAA, en prensa 


\section{Capítulo 7}

\section{Análisis de la posible formación estelar inducida por los vientos de las estrellas WR}

\section{Resumen}

Los vientos estelares viajan a velocidades supersónicas en el MIE. El paso del frente de choque provoca drásticos cambios en las condiciones del medio. La acumulación significativa del material, junto con el fuerte aumento en la temperatura y densidad provoca la formación de grumos de materia en las cáscaras en expansión, generando condiciones óptimas para la formación estelar.

En este capítulo se analiza la posible formación estelar inducida en las cáscaras de las burbujas interestelares asociadas a las estrellas WR 153 ab y WR 157, y la región H II Gum 31. Aunque se han llevado a cabo numerosos estudios de formación estelar en las envolturas alrededor de regiones $\mathrm{H}$ II, pocos se han hecho en las cáscaras alrededor de burbujas interestelares. El objetivo es establecer si la expansión de las BI genera escenarios propicios para la formación estelar inducida.

El estudio se llevó a cabo a través del análisis de las fuentes puntuales IR contenidas en los catálogos 2MASS, IRAS y MSX. Se analizan los resultados teniendo en cuenta el proceso "collect and collapse", que explica la formación estelar en cáscaras en expansión.

\subsection{Introducción}

Los vientos estelares, regiones H II y explosiones de supernova generadas por estrellas de gran masa, barren y comprimen el gas molecular circundante. Así, en las envolturas moleculares asociadas a burbujas interestelares (BI) pueden desarrollarse condiciones para la formación estelar inducida o formación estelar secuencial (FES). Diversos procesos y causas han sido sugeridos por diferentes autores, pero uno de los modelos más difundidos 


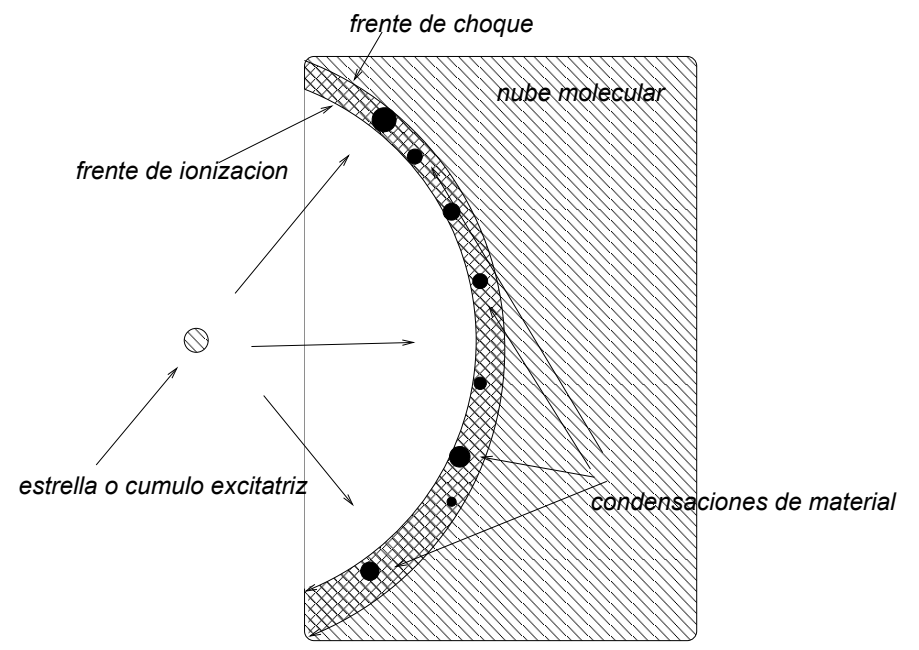

Figura 7.1: Esquema básico de un frente de choque generado por una estrella/s excitatriz/ces a través del intenso campo de fotones UV, interactuando en un medio molecular. Se muestran las condensaciones moleculares que han sido ionizadas y disociadas por el frente de choque.

y convincentes que hoy es tomado en cuenta para la descripción de este fenómeno es el modelo "collect and collapse", propuesto originalmente por Elmegreen \& Lada (1977). En ese trabajo se analiza la estabilidad gravitacional de las cáscaras de material neutro acumuladas entre los frentes de choque y de ionización originados en la interacción de los vientos estelares y la radiación UV de estrellas de gran masa con el gas molecular.

El proceso de FES en las cáscaras en expansión (CE) alrededor de regiones H II (generadas por estrellas de gran masa) puede explicarse de la siguiente manera (ver Fig. 7.1). Las CE se mueven en un medio de nubes moleculares, empujadas por la presión de gas ionizado. El frente de choque modifica drásticamente las condiciones ambientales del material frío, cambiando su estado dinámico y aumentando su temperatura, densidad y presión. De esta manera gran cantidad de gas molecular se disocia y se forman grumos moleculares. Este material comprimido que se encuentra entre el frente de choque y el frente de ionización, con el tiempo, se vuelve dinámicamente inestable. Si esas inestabilidades evolucionan en un tiempo menor al "tiempo de cruce", entonces se forman grumos compactos de material autogravitante, con interiores moleculares y superficies ionizadas, producto de la acción del frente de ionización. Esas estructuras se observan como "glóbulos cometarios" (Bertoldi 1989, Bertoldi \& McKee 1990). Si la acumulación de material no es frenada por las inestabilidades, una gran cantidad de material se acopia en los núcleos. De esta manera, se generan fragmentos altamente densos que permiten la formación de estrellas de gran masa o cúmulos de estrellas.

Para determinar potenciales escenarios en los que se esté llevando a cabo el proceso de FES, se tienen que verificar determinadas condiciones ambientales. Material neutro, como hidrógeno neutro debe rodear las zonas ionizadas, tanto en regiones H II, como en 
BI. Deben existir nubes moleculares adyacentes al gas ionizado. La interacción entre el gas ionizado y el molecular produce regiones de fotodisociación, que se pueden observar a través de la emisión de radiación de los PAH en el cercano y mediano IR. Estas moléculas complejas son excitadas por el campo de radiación estelar de las estrellas excitatrices de regiones H II, emitiendo líneas por el mecanismo de fluorescencia (ver el Capítulo 3). Entre ellas podemos encontrar líneas de emisión centradas en: $\lambda 3.3 \mu \mathrm{m}, 6.2 \mu \mathrm{m}, 7.7$ $\mu \mathrm{m}, 8.6 \mu \mathrm{m}$ y $11.3 \mu \mathrm{m}$. Las nubes en colapso gravitatorio presentan un fuerte exceso de emisión IR con emisión de continuo entre 1 y $5 \mu \mathrm{m}$, principalmente. Esa emisión es generada por el polvo caliente posiblemente ubicado en las regiones más densas de los núcleos autogravitantes. De esta manera, se puede llegar a rescatar información valiosa del proceso de FES observado hacia los bordes de regiones H iा o CE. Se debe tener en cuenta que las regiones vecinas a los grumos moleculares deben tener densidades bajas respecto a las densidades dentro de ellos. Otro aspecto importante a tener en cuenta es que esta nueva "generación" de estrellas debería conservar la velocidad del material del que se formaron.

El proceso de colapso y fragmentación de las nubes moleculares en estrellas ha sido estudiado extensamente por diversos autores (Whitworth et al. 1994, Bhattal et al. 1998, Deharveng et al. 2003, Hennebelle et al. 2004, Hosokawa \& Inutsuka 2005, Deharveng et al. 2006, Zavagno et. al 2006, Hosokawa \& Inutsuka 2007). En la mayoría de los modelos se describen diferentes etapas, entre las que se distingue claramente un estadío en el que se lleva a cabo un proceso de acreción de material, durante el cual la estrella está completamente oculta por el polvo, que emite en el IR lejano. Luego se sugiere la formación de un disco por efecto de la rotación generada en la acreción del material, con la emisión de materia en forma colimada en dirección normal al plano del disco (flujos bipolares), luego una etapa de acreción lenta, y finalmente la formación de una estrella de secuencia principal de edad cero (ZAMS). Simultáneamente, el medio circundante también evoluciona de forma que el hidrógeno molecular es disociado e ionizado formando una región H II ultra compacta que se irá expandiendo gradualmente; algunas capas superficiales del polvo se evaporarán y la concentración natal se irá expandiendo. A medida que disminuye su densidad y su opacidad, el polvo irá absorbiendo la radiación emitida por la estrella y la reemitirá en el infrarrojo cercano y mediano (Romero 2006). Es decir, en todas las etapas en las que se produce la FES, es posible observar la emisión de polvo en distintas bandas del espectro IR.

Se han detectado observacionalmente regiones en las que se está llevando a cabo formación estelar secuencial. Un ejemplo de este evento ha sido reportado por Lefloch \& Cernicharo (2000), quienes encontraron núcleos en $12 \mu \mathrm{m}$, asociados a protoestrellas dentro de grumos moleculares densos vistos en $1.25 \mathrm{~mm}$ en el borde de la nebulosa "Trifid" (NGC 6514). Ellos derivaron un tiempo de expansión para la región $\mathrm{H}$ II de $>0.4 \times 10^{6}$ años y una densidad "preshock" de $2 \times 10^{3} \mathrm{~cm}^{-3}$. Estimaron un "tiempo de inestabilidad" del orden de $0.4 \times 10^{6}$ años. Lada et al. (1991) encontraron dos cúmulos embebidos en la nube de Orión, ubicados en dirección a núcleos densos moleculares. Esos núcleos son las cabezas de glóbulos cometarios, probablemente formados en la expansión de la nebulosa de Orión. Otro ejemplo de FES es presentado en el trabajo de Deharveng et al. (2003). Estos autores analizaron datos milimétricos de diferentes isótopos de monóxido de carbono 
y detectaron cuatro condensaciones moleculares regularmente espaciadas sobre un anillo que rodea el cúmulo excitatriz de la región H II Sh2-104, cuya principal fuente excitatriz es una estrella O6V. Esas condensaciones moleculares contienen gran número de fuentes con exceso IR asociadas a objetos en formación y a regiones H II ultra compactas.

\subsection{Análisis de catálogos infrarrojos para detectar YSOs}

Uno de los objetivos del estudio de formación estelar es detectar objetos estelares jóvenes (YSO, del inglés young stellar objets), que son objetos que todavía no han alcanzado la secuencia principal de edad cero. Estos objetos se caracterizan por tener una emisión IR muy intensa que supera los valores normales de las fotósferas estelares afectadas por el enrojecimiento del polvo interestelar. Ese exceso IR se debe fundamentalmente a que, como ya explicamos en la sección anterior, el medio que los rodea está formado principalmete por polvo circumestelar asociado a la nube primordial en la cual se originaron. No debemos confiarnos sólo en este aspecto, ya que objetos que no están en proceso de formación, como estrellas gigantes rojas de la rama asintótica y nebulosas planetarias también presentan esta particularidad. Por este motivo es que se cuenta con distintos criterios de selección que ayudan a diferenciar entre todos estos objetos. Es muy importante destacar que estos mecanismos de diferenciación no son únicos ni totalmente confiables. Lo que podemos asegurar es que nos dan una cierta certeza de la ubicación de objetos en formación. Para ayudar a su identificación como YSOs se deben hacer correlaciones con catálogos de nubes moleculares, máseres, etc.

En las siguientes tres secciones haremos una pequeña descripción acerca de los criterios de selección utilizados en cada una de las bases de datos utilizadas para encontrar posibles objetos candidatos a protoestrella en las envolturas moleculares originadas en la expansión de las BI asociadas a WR 153ab y WR 157, y a la región H in Gum 31.

\subsubsection{Criterios de selección y análisis de las fuentes 2 MASS}

Una de las bases de datos más extensa y completas de todo el cielo en el infrarrojo cercano es la correspondiente al "Two Micron All Sky Survey" (2 MASS) (Cutri et al. 2003). Cuenta con observaciones en las bandas $J, H$ y $K_{s}$ centradas en $1.25,1.65$ y 2.2 $\mu \mathrm{m}$, respectivamente.

Una de las herramientas más usadas con las fuentes del catálogo 2 MASS para la distinción entre fuentes con exceso IR candidatas a YSOs y estrellas gigantes o de secuencia, son los diagramas color-color (CC) y color magnitud (CM). El primero de estos dos gráficos se basa en la comparación de indices de color $I_{i j}$ en diferentes de bandas, donde

$$
I_{i j}=m_{i}-m_{j}=M_{i}-M_{j}=-2.5 \log \left(\frac{S_{i}}{S_{j}}\right)
$$


$m_{i}$ es la magnitud visual en la banda $i$, siendo $i=J, H$ y $K_{s} ;$ y $M_{i}$ y $S_{i}$ son la magnitud visual absoluta y el flujo en esa banda. El gráfico CM, en cambio, relaciona un $I_{i j}$ con la magnitud visual en alguna de esas bandas. En nuestro estudio, las magnitudes absolutas para las estrellas de la ZAMS en la banda $\mathrm{K}_{S}$ fueron obtenidas de Hanson et al. (1997), y sus correspondientes valores para el diagrama CC, fueron obtenidos de Koornneef (1983).

A fin de probar la existencia de candidatos a YSOs en las cáscaras de BI, se buscaron fuentes IR aplicando criterios de selección. Esos criterios los podemos enumerar de la siguiente manera:

- El radio de búsqueda de YSOs debe contener tanto las cáscaras en expansión ionizadas como la emisión molecular. Como nuestro objetivo final es establecer si la expansión de las BI genera escenarios propicios para la formación estelar, nuestra región de búsqueda debe proyectarse sobre las zonas de contacto entre las envolturas moleculares y el gas ionizado.

- Calidad fotométrica AAA para las fuentes 2MASS. Esto implica una relación señal-ruido óptima, $S / N>10$.

- Corte en magnitud $K_{s}$ para concentrarnos sólo en las fuentes más brillantes. Esto nos permite eliminar de la muestra fuentes débiles cuya asociación con las estructuras estudiadas es dudosa.

- Fuentes con exceso IR. Se establecieron reglas de selección según la posición de las fuentes en el diagrama color-color (CC) a partir de los trabajos de Romero (2006) y Comerón (2005). En estos trabajos se determinó el parámetro $q=(J-$ $H)-1.83 \times\left(H-K_{s}\right)$, cuyo rango de valores distingue básicamente tres tipos de fuentes con naturaleza distinta: objetos de secuencia principal $(-0.15<q \leq 0.10)$, estrellas gigantes de la rama asintótica $(q>0.10)$ y objetos con exceso IR $(q \leq$ -0.15), que son aquellos que se consideran candidatos a YSOs. Nos interesan de manera particular estos últimos. Desde ya que este criterio no es concluyente, ya que otros tipos de objetos, como las estrellas evolucionadas, presentan la misma fenomenología.

Una manera de sortear este inconveniente es buscar una correlación con otras bases de datos de fuentes puntuales IR, como por ejemplo, las de los satétiles MSX o IRAS.

- Ubicación de las fuentes sobre núcleos moleculares o proyectados dentro de la región ionizada. Esto ayudaría a identificar con mayor precisión las fuentes candidatas a protoestrella, ya que los objetos en formación se encuentran, en general, dentro de las nubes moleculares primordiales. Por otro lado, no podemos excluir aquellas fuentes que aparecen proyectadas dentro de la región que envuelve la cáscara en expansión pero no asociados a nubes moleculares. 


\subsubsection{Criterios de selección para las fuentes MSX}

Al igual que para las fuentes 2 MASS, también hemos realizado un extenso análisis de las fuentes puntuales IR observadas por el satélite IR MSX. Básicamente, las observaciones realizadas comprenden el rango del mediano IR en seis bandas, de las cuales nosotros analizamos cuatro, centradas en 8.3, 12.1, 14.7 y $21.3 \mu \mathrm{m}$, llamadas A, C, D y E, respectivamente. Mayor información sobre este relevamiento puede encontrarse en Egan et al. (1999).

En este caso, los criterios usados para identificar fuentes candidatas a protoestrella fueron los establecidos por Lumsden et al. (2002), que permiten distinguir entre objetos con diversas características en base al cociente de flujos en distintas bandas:

- $F_{21} / F_{8}<2 \rightarrow$ objetos evolucionados con exceso IR

- $F_{21} / F_{8}>2$ y $F_{14} / F_{12}<1 \rightarrow$ regiones H II compactas

- $F_{21} / F_{8}>2$ y $F_{14} / F_{12}>1 \rightarrow$ MYSOs (del ingles massive young stellar objets)

Además, nosotros agregamos un criterio fotométrico, quedándonos con fuentes con calidad fotométrica buena en las cuatro bandas, es decir, $q \geq 2$. En cuanto al radio de búsqueda, seguimos los mismos criterios establecidos para las fuentes 2MASS.

Es importante destacar que las fuentes clasificadas como regiones H II compactas también indican formación estelar reciente por lo que serán tenidas en cuenta.

\subsubsection{Criterios de selección para las fuentes IRAS}

La base de datos de fuentes puntuales del satélite infrarrojo IRAS contiene información del mediano y lejano IR. Las bandas que observó el satélite están centradas en 12, 25, 60 y $100 \mu \mathrm{m}$. La información obtenida de estas fuentes nos puede ayudar a encontrar candidatos a protoestrellas en los primeros estadíos de formación, es decir, donde todavía la cantidad de material molecular y polvo en sus alrededores es muy alta.

Junkes et al. (1993) publicó criterios de búsqueda de objetos candidatos a protoestrella, basados tanto en cocientes de flujos en las cuatros bandas IRAS, como en sus calidades fotométricas. Básicamente estos autores trataron de encontrar conexiones entre la formación estelar y el impacto causado por los remanentes de supernova en el medio interestelar circundante. De acuerdo a Wilking et al. (1989), los objetos candidatos a protoestrellas deben cumplir los siguientes criterios:

- deben radiar gran cantidad de energía en el FIR

- no deben estar identificados como regiones H II

- deben estar asociados a discos circumestelares o a "outflows" moleculares 
De acuerdo con estas características físicas, se enumeraron una serie de pautas que debían cumplir los YSOs. Esas condiciones son las siguientes:

- $S_{100} \geq 20 \mathrm{Jy}$

- $1.2<\frac{S_{100}}{S_{60}}<6$, o $24 \mathrm{~K}<T_{p}<45 \mathrm{~K}$

- $\frac{S_{60}}{S_{25}} \geq 1$

- $q_{100}+q_{60} \geq 4$

donde $q_{100}$ y $q_{60}$ son las calidades fotométricas de los flujos en 100 y $60 \mu \mathrm{m}$. Tengamos en cuenta que el rango de calidades va de 1 a 3 , correspondiendo $q=1$, a flujo detectado; $q$ $=2$, a flujo de calidad moderada y $q=3$, a flujo de alta calidad.

Las densidades de flujo en las diferentes bandas no han sido corregidas. El primer criterio elimina las fuentes más débiles, el segundo da una medida de la temperatura de color del polvo $T_{p}$. Este valor puede ser encontrado a partir del espectro de emisión del polvo, como vimos en el Capítulo 3. El límite superior en el cociente de flujo en este criterio excluye nubes interplanetarias y galácticas. El segundo y tercer criterio proveen una clasificación IRAS de acuerdo con la naturaleza de estos objetos, es decir, se relacionan a la distribución espectral de la emisión IR y permiten seleccionar candidatos a protoestella, pero no estrellas evolucionadas o nebulosas planetarias, que tienen su máximo de emisión en longitudes de onda menores. Las fuentes extragalácticas no pueden distinguirse en los núcleos moleculares de las fuentes puntuales IRAS. Para excluirlas hay que realizar suposiciones estadísticas acerca de la distribución de las fuentes IRAS.

Finalmente, recordemos que estos criterios no son concluyentes, y ellos deben estar asociados a emisión molecular, máseres, etc. El criterio referido al radio de búsqueda coincide con el correspondiente a fuentes 2 MASS y MSX.

\subsection{Búsqueda de candidatos a YSOs en la vecindad de nebulosas anillo}

En esta sección analizaremos la existencia de YSOs en las envolturas moleculares asociadas a BI, con el fin de investigar si estas estructuras generan condiciones propicias para la formación estelar. Particularmente, nos centraremos en el análisis de las fuentes puntuales IR en las BI SG 13 y Sh2-132 asociadas a las estrellas WR 157 y WR 153ab, respectivamente. Luego veremos el proceso de formación estelar en la región H iI Gum 31. Finalmente, analizaremos las analogías y diferencias en la formación estelar entre las cáscaras en expansión asociadas a las dos BI y a la región H iI. 


\subsection{1. $\quad$ YSOs asociados a SG 13}

En el panel superior de la Fig. 7.2 se muestra el diagrama CC de las fuentes 2MASS en dirección de SG 13. El radio de búsqueda fue de 30', centrado en la posición del cúmulo Ma 50. La cantidad de fuentes encontradas fue mayor a $2.7 \times 10^{4}$. Aplicando los criterios de selección mencionados en la sección 7.2.1, nos quedamos con sólo 21 fuentes con exceso IR. Esas fuentes están indicadas con cruces rojas en esta figura. Las cruces azules representan estrellas gigantes, los cuadrados de color magenta representan estrellas de secuencia principal no enrojecidas y las cruces verdes, estrellas de secuencia con enrojecimiento. Las rectas de color celeste y amarillo indican la dirección del vector de enrojecimiento. Como se puede advertir claramente, las cruces rojas son minoría. Debemos tener en cuenta que este exceso puede originarse en la emisión de radiación del polvo asociado a las estrellas en formación, sumado a la emisión de radiación del polvo interestelar ubicado a lo largo de la línea de la visual entre el observador y la fuente, que "enrojece" la radiación original. El panel inferior de la Fig. 7.2 muestra un diagrama color-magnitud (CM) asumiendo una distancia a la nebulosa anillo de $3.7 \pm 1.2 \mathrm{kpc}$. Como la cantidad de estrellas gigantes y de secuencia principal es muy grande, sólo graficamos la posición de las fuentes con exceso IR candidatas a protoestrella. Alrededor de la mitad de las fuentes de la muestra presentan una absorción visual $A_{v}>10$ mag. La línea con puntos verdes indica la posición de la secuencia principal de edad cero (ZAMS) de estrellas tempranas de tipo espectral O3 (extemo superior) al B5 (extremo inferior). La recta azul indica la dirección del vector de enrojecimiento y, superpuesto, los valores de $A_{v}$.

La Fig. 7.3 muestra el cociente de flujo para fuentes MSX con calidades fotométricas buenas. Alrededor de 300 fuentes están proyectadas sobre la región, de las cuales once cumplen con los requisitos fotométricos. De esta forma pudimos armar el diagrama CC, donde identificamos tres sectores bien definidos de acuerdo a los criterios de Lumsden et al. (2002). Como se puede adverir, casi la mitad de los objetos presentan cocientes de flujos acordes con MYSOs. La otra mitad corresponde a nebulosas planetarias, estrellas de carbono, etc. Una de las fuentes es candidata a región H II compacta.

Se analizó también la muestra de fuentes IRAS proyectadas sobre la región. De las 31 fuentes puntuales IRAS encontradas, 22 cumplen los requisitos para clasificarlas como YSOs.

En la Tabla 7.1 se enumeran los candidatos a protoestrella encontrados en las tres bases de datos, indicando su posición en coordenadas galácticas y su designación en cada uno de los tres catálogos usados. En el caso de las fuentes 2 MASS se agregaron los valores de magnitud en las bandas $J, H$ y $K_{s}$; para las fuentes MSX, se muestran los cocientes de flujos $\left(F_{21} / F_{8}\right.$ y $\left.F_{14} / F_{12}\right)$ y la clasificación según su naturaleza siguiendo a Lumsden et al. (2002). Finalmente, se listaron los flujos en las cuatro bandas IRAS y la luminosidad en el lejano IR $L_{\mathrm{IR}}$, obtenida de acuerdo a las expresiones de Chan \& Fich (1995).

En la Fig. 7.4 se muestra con cruces la distribución espacial de las fuentes 2 MASS con exceso IR, superpuestas a la imagen en $1420 \mathrm{MHz}$ (grisados) y a la emisión del ${ }^{12} \mathrm{CO}(1-0)$ (líneas de contorno). Con círculos se indica, la posición de las fuentes candidatas a MYSO y la región H iı compacta, y con triángulos, la posición de las fuentes IRAS candidatas a 

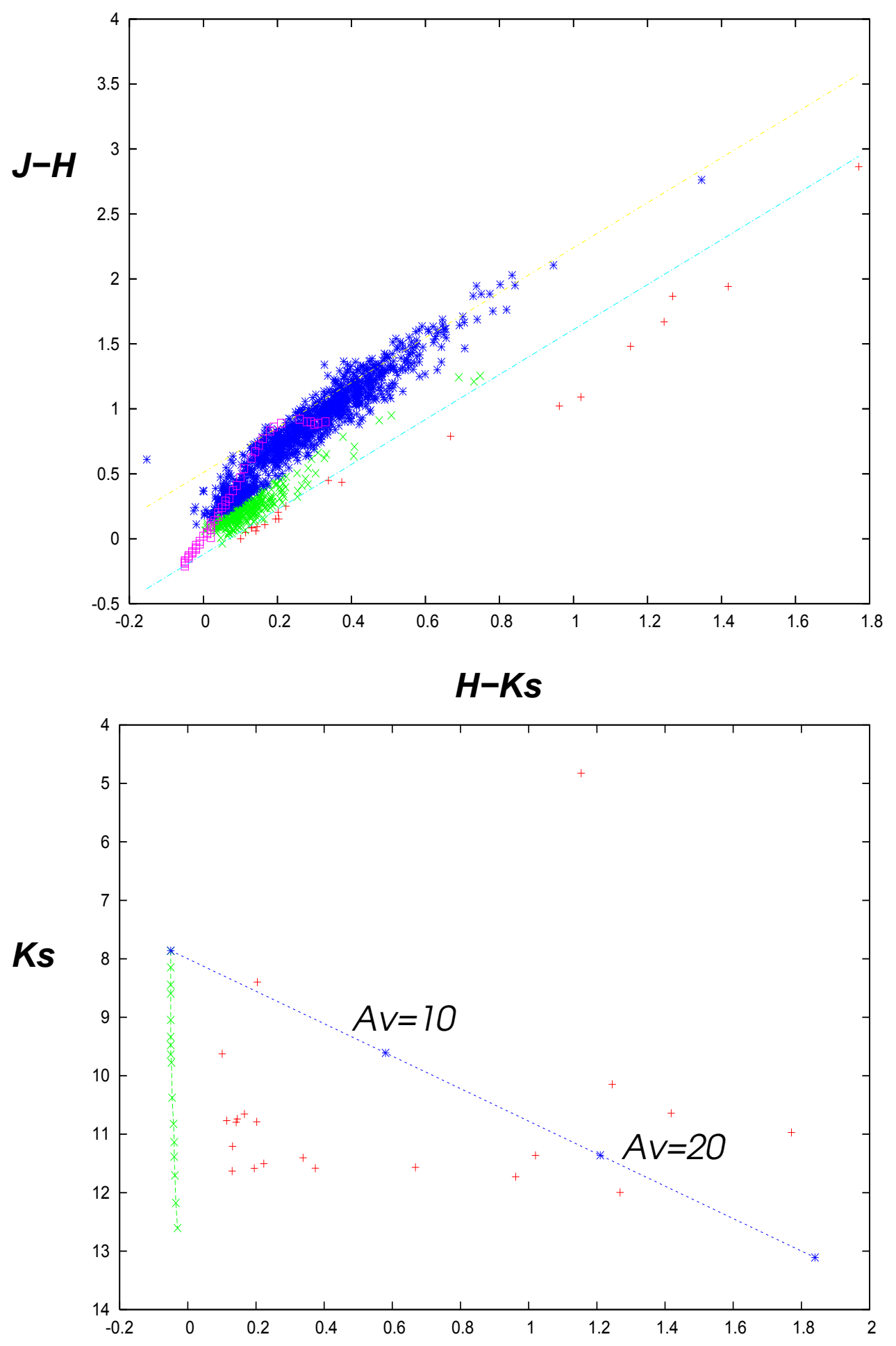

$H-K s$

Figura 7.2: Panel superior: Diagrama CC de las fuentes puntuales 2 MASS en dirección a SG 13. Las fuentes representadas por cruces azules son estrellas gigantes, las verdes, estrellas de secuencia principal, mientras que las rojas son las que presentan exceso IR. Los cuadrados de color magenta representan la SP sin enrojecimiento. Panel inferior: Diagrama CM de las fuentes con exceso IR. 


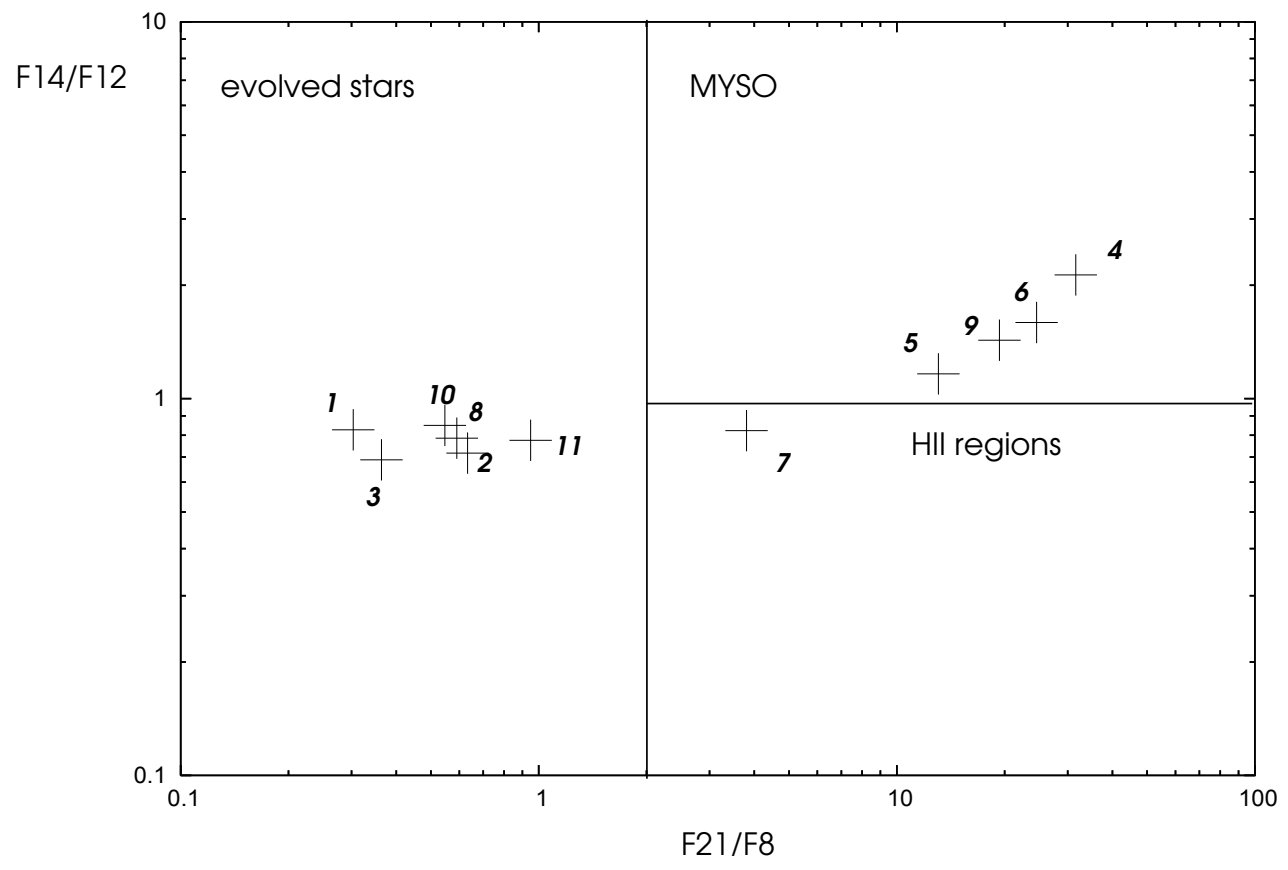

Figura 7.3: Diagrama de cocientes de flujos en las bandas MSX de las 11 fuentes MSX proyectadas sobre la región SG 13. Diferentes sectores en el gráfico corresponden a estrellas evolucionadas, regiones H II compactas y a MYSOs (Lumsden et al. 2002).

protoestrella. Este tipo de gráfico es fundamental para poder asociar las fuentes con exceso IR a grumos moleculares o a los filamentos ionizados de las cáscaras en expansión. Se puede observar que una gran cantidad de fuentes se ubican hacia $(l, b) \simeq\left(111^{\circ} 18^{\prime},-0^{\circ} 42^{\prime}\right)$, proyectadas sobre grumos moleculares pero asociadas a la región H II SG 14. Dada su ubicación, no puede descartarse que la expansión de SG 13 haya contribuido a la formación de estos objetos. De las 22 fuentes IRAS candidatas a protoestrella en toda la región, cinco de ellas se encuentran proyectadas sobre grumos moleculares adyacentes a los filamentos de SG 13 y otras cuatro sobre la cáscara ionizada.

En la Fig. 7.4 se observa que las fuentes \#26 y \#45 coinciden en $\left(l_{1}, b_{1}\right)=\left(111^{\circ} 36^{\prime}\right.$, $\left.0^{\circ} 22^{\prime}\right)$. Estas fuentes están asociadas a la región HiI Sh2-159. Las fuentes \#4 y \#39, coinciden en la coordenada $\left(l_{2}, b_{2}\right)=\left(111^{\circ} 17,-0^{\circ} 40^{\prime}\right)$ y estarían asociadas a una región estudiada en ${ }^{13} \mathrm{CO}(1-0), \mathrm{CS}(2-1)$ y ${ }^{12} \mathrm{CO}(1-0)$ (Ao et al. 2004). Allí, la velocidad del gas molecular es $\simeq-44 \mathrm{~km} \mathrm{~s}^{-1}$.

También encontramos una coincidencia en la posición de una fuente 2 MASS y MSX en la posición $\left(l_{3}, b_{3}\right)=\left(111^{\circ} 45^{\prime}, 0^{\circ} 3^{\prime}\right)$ (fuentes \#14 y \#48). Estas fuentes se encuentran en un sector alejado angularmente de la emisión ionizada y molecular asociadas a la BI, por este motivo no resultan de interés para nuestro estudio. 


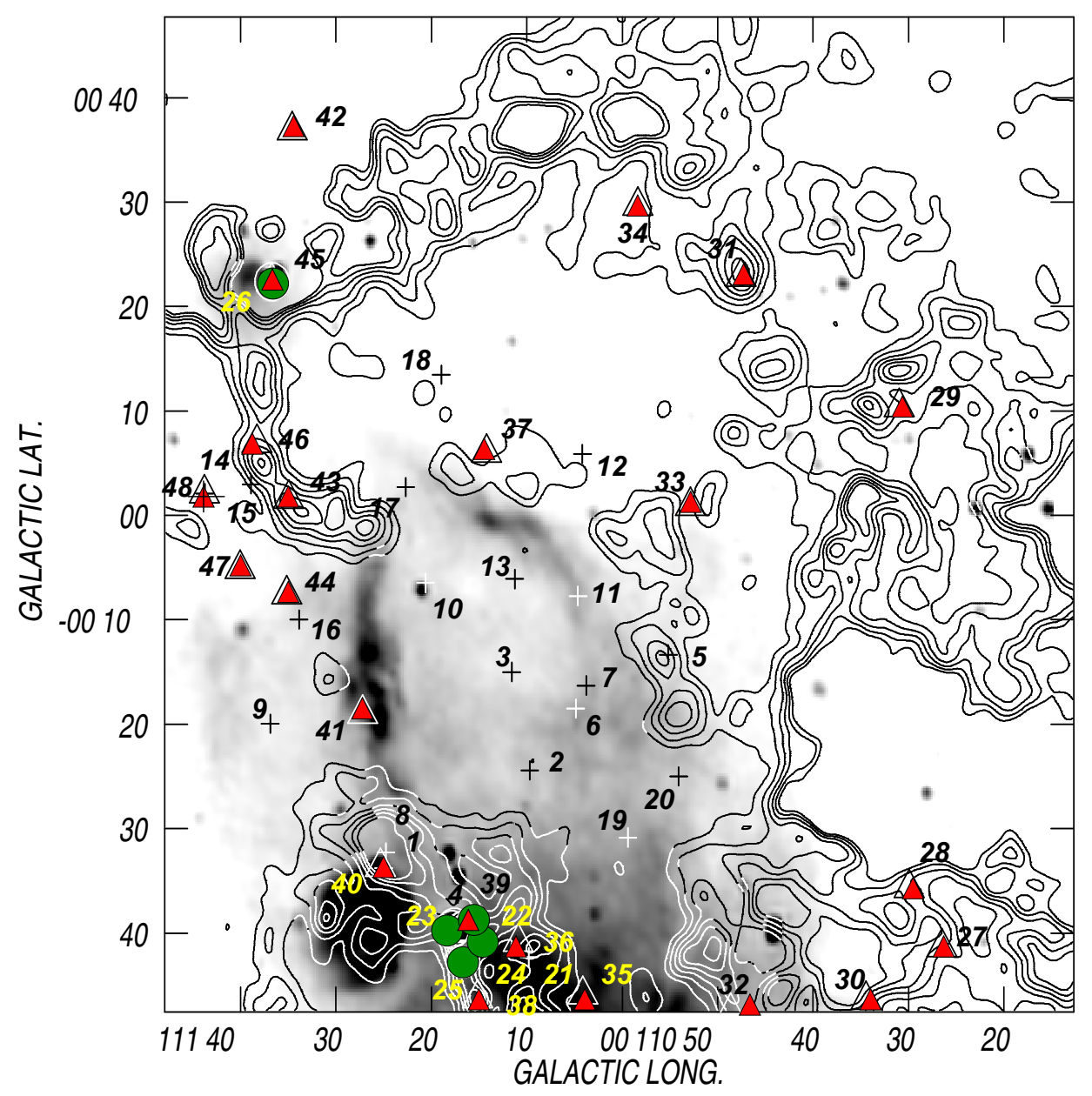

Figura 7.4: Distribución espacial de fuentes puntuales IR candidatas a protoestrellas en dirección a SG 13. Las cruces representan fuentes 2 MASS, los círculos las MSX y los triángulos las fuentes IRAS. 
Tabla 7.1: Fuentes puntuales IR en dirección a SG 13 candidatas a YSOs

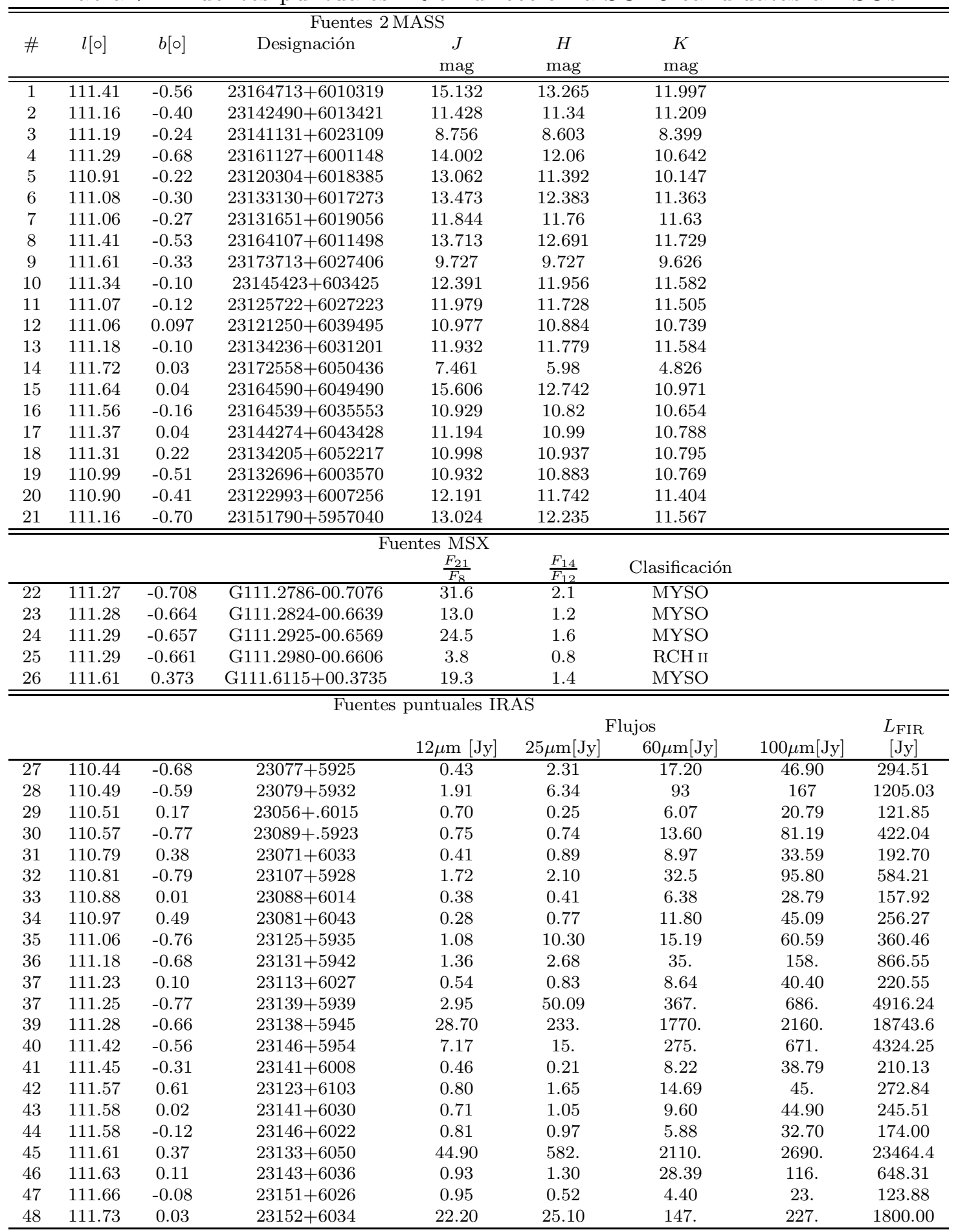

RCH II : región H II compacta 


\subsection{2. $\quad$ YSOs asociados a Sh2-132}

En el panel superior de la Fig. 7.5 se muestra el gráfico CC correspondiente a las fuentes 2MASS proyectadas sobre un área de $25^{\prime}$ de radio, centrada en la posición de la estrella WR 153ab. Luego de aplicar los criterios de selección, encontramos 14 fuentes con exceso IR, que figuran en color rojo. Como puede observarse, muchas de estas fuentes presentan $A_{v}<5$ mag. Si observamos el diagrama CM en el panel inferior de la Fig. 7.5, en el que sólo graficamos los objetos con exceso IR, vemos que para una distancia de $3.5 \pm 0.5 \mathrm{kpc}$, esos objetos evolucionarán como estrellas de gran masa con tipos espectrales más tempranos que B3.

La Tabla 7.2 muestra el listado de las fuentes IR candidatas a protoestellas pertenecientes a los catálogos 2 MASS, MSX e IRAS. Las columnas listan los mismos parámetros que la Tabla 7.1.

En la Fig. 7.6 se revela la distribución de fuentes puntuales IR candidatas a protoestella superpuesta a la imagen óptica y a las líneas de contorno de la emisión molecular integrada. Las cruces representan las fuentes 2 MASS, los círculos llenos las fuentes MSX, y los triángulos las fuentes IRAS. Como puede advertirse, la gran mayoría de la fuentes (excepto la \#1, \#3, \#14, \#21, \#22 y \#29), están proyectadas sobre las componentes ionizada y molecular vinculadas con Sh2-132. Las fuentes \#7 y \#26, \#16 y \#23 y \#8 y \#27, se superponen. La fuente \#23 coincide espacialmente con la fuente \#16 proyectada sobre Sh2-132. Otros estudios muestran que es un objeto protoestelar con "outflows" moleculares, es decir, en proceso de formación de un disco circumestelar. Por lo tanto, podemos confirmar su naturaleza protoestelar.

\subsubsection{Contrapartes moleculares de los YSOs}

Como se mencionó en el comienzo de este Capítulo, los criterios de selección de fuentes puntuales candidatas a protoestrella correspondientes a cada uno de los tres catálogos analizados no son concluyentes. Una de las herramientas que ayudan a confirmar que un objeto es candidato a protoestrella, es su asociación con núcleos moleculares o emisión maser. Por esta razón, buscamos en la literatura estudios adicionales de ${ }^{12} \mathrm{CO}(1-0),{ }^{12} \mathrm{CO}(2$ 1), $\mathrm{C}^{18} \mathrm{O}(2-1), \mathrm{H}^{13} \mathrm{CO}^{*}(1-0), \mathrm{CS}(2-1), \mathrm{N}_{2} H^{+}, \mathrm{N}_{2} \mathrm{D}^{+}$y emisión maser de $\mathrm{H}_{2} \mathrm{O}$, vinculados a las fuentes candidatas a protoestrella. Sólo encontramos asociación con fuentes IRAS. En la Tabla 7.3 se listan estas fuentes. Las columnas 1 y 2 muestran la correspondencia de las fuentes con la numeración de las Tablas 7.1 y 7.2, y el nombre de las fuentes. Las columnas 3, 4 y 5 muestran las velocidades radiales referidas al LSR $v_{L S R}$, la temperatura de brillo del haz principal $T_{m b}$ y el ancho en velocidad $\Delta v$ de la emisión de $\operatorname{CS}(2-1)$, respectivamente. Las columnas 6,7 y 8 muestran la $v_{L S R}$, la distancia cinemática y la luminosidad de la fuente IRAS obtenida del $\mathrm{CO}(1-0)$. En las columnas 9 a 12 se listan la temperatura de antena $\mathrm{T}_{A}^{*}, v_{L S R}, \Delta v$ y la distancia cinemática $d$ de la línea $\mathrm{CO}(1-0)$ obtenidos de Wouterloot \& Brand (1989). Finalmente, en la columnas 13 y 14 se muestran la velocidad $v_{L S R}$ y temperatura pico $\mathrm{T}_{\text {pico }}$ de las concentraciones de $\mathrm{CO}(1-0)$, obtenidas de Kerton et al. (2002). Las distancias son las indicadas por los autores de los trabajos 

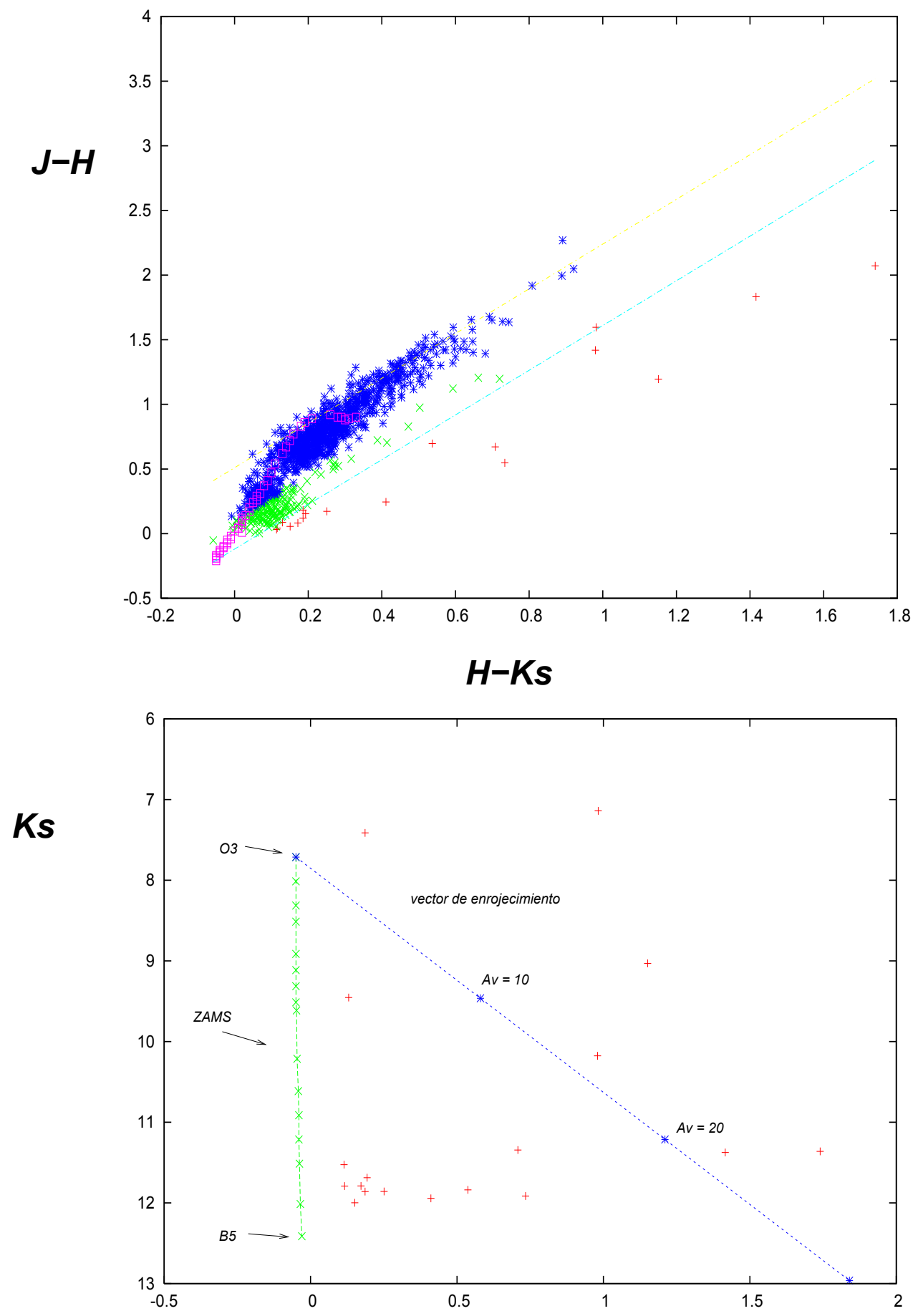

\section{$H-K s$}

Figura 7.5: Panel superior: Diagrama CC de las fuentes puntuales 2 MASS en dirección a Sh2-132. Los colores de los símbolos tienen el mismo significado que en la Fig. 7.2. Panel inferior: Diagrama CM de las fuentes con exceso IR. 


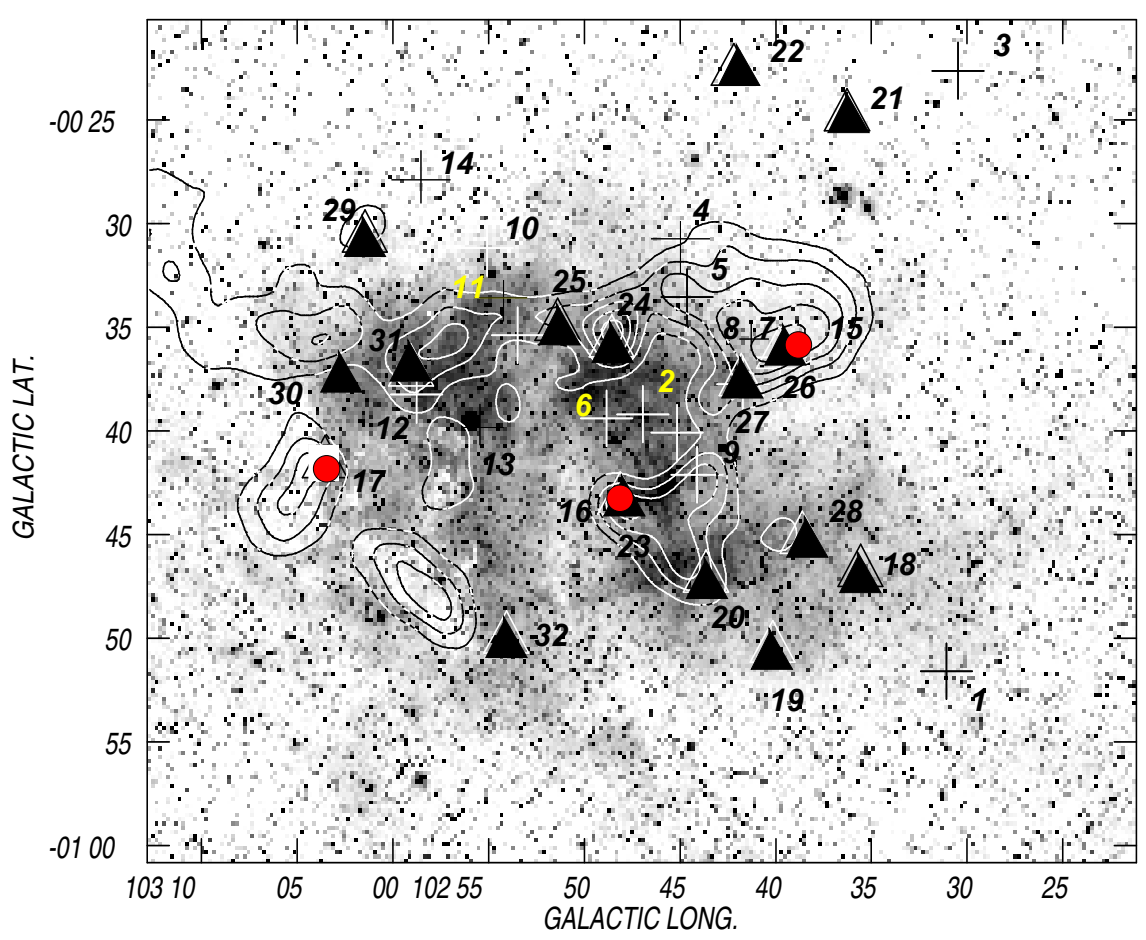

Figura 7.6: Distribución espacial de YSOs y regiones H II compactas en dirección a Sh2132. Los símbolos tienen el mismo significado que en la Fig. 7.4. 
Tabla 7.2: Fuentes puntuales IR en dirección a Sh2-132 candidatas a YSOs

\begin{tabular}{|c|c|c|c|c|c|c|}
\hline \multicolumn{7}{|c|}{ Fuentes puntuales 2 MASS } \\
\hline \# & $l[0]$ & $b[0]$ & designación 2 MASS & $\begin{array}{c}J \\
\mathrm{mag}\end{array}$ & $\begin{array}{c}H \\
\mathrm{mag}\end{array}$ & $\begin{array}{c}K \\
\mathrm{mag}\end{array}$ \\
\hline 1 & 102.51 & -0.86 & $22180090+5548136$ & 12.206 & 12.15 & 11.999 \\
\hline 2 & 102.75 & -0.66 & $22183841+5605497$ & 13.197 & 12.649 & 11.915 \\
\hline 3 & 102.50 & -0.37 & $22160109+5612139$ & 9.719 & 8.123 & 7.141 \\
\hline 4 & 102.74 & -0.55 & $22180942+5611005$ & 12.576 & 11.157 & 10.177 \\
\hline 5 & 102.78 & -0.65 & $22184560+5607338$ & 7.781 & 7.599 & 7.413 \\
\hline 6 & 102.81 & -0.65 & $22185774+5608259$ & 12.724 & 12.053 & 11.345 \\
\hline 7 & 102.66 & -0.60 & $22175177+5605533$ & 13.072 & 12.375 & 11.838 \\
\hline 8 & 102.69 & -0.62 & $22180848+5605531$ & 11.377 & 10.182 & 9.031 \\
\hline 9 & 102.73 & -0.70 & $22184017+5603335$ & 14.623 & 12.791 & 11.375 \\
\hline 10 & 102.91 & -0.51 & $22190286+5618436$ & 12.165 & 12.046 & 11.86 \\
\hline 11 & 102.89 & -0.58 & $22190971+5614203$ & 9.671 & 9.584 & 9.454 \\
\hline 12 & 102.97 & -0.63 & $22195296+5614498$ & 12.599 & 12.354 & 11.943 \\
\hline 13 & 102.93 & -0.67 & $22194560+5611368$ & 15.172 & 13.101 & 11.361 \\
\hline 14 & 102.98 & -0.48 & $22191789+5622553$ & 11.95 & 11.907 & 11.791 \\
\hline
\end{tabular}

\begin{tabular}{|c|c|c|c|c|c|c|c|c|}
\hline \multicolumn{9}{|c|}{ Fuentes puntuales MSX } \\
\hline & & & & $\frac{F_{21}}{F_{8}}$ & $\frac{F_{14}}{F_{12}}$ & clasificación & & \\
\hline 15 & 102.663 & -0.607 & G102.6627-00.6067 & 1.47 & 0.52 & RC H II & & \\
\hline 16 & 102.805 & -0.719 & G102.8051-00.7184 & 3.15 & 0.96 & $\mathrm{RC} \mathrm{H} \mathrm{II}$ & & \\
\hline 17 & 103.062 & -0.691 & G103.0624-00.6911 & 4.29 & 0.84 & RC H II & & \\
\hline \multicolumn{9}{|c|}{$\begin{array}{ll}\text { Fuentes puntuales IRAS } \\
\end{array}$} \\
\hline & & & & \multicolumn{4}{|c|}{ Flujos } & $L_{\mathrm{FIR}}$ \\
\hline & & & & $12 \mu \mathrm{m}$ & $25 \mu \mathrm{m}$ & $60 \mu \mathrm{m}$ & $100 \mu \mathrm{m}$ & \\
\hline & & & & Jy & Jy & Jy & Jy & Jy \\
\hline 18 & 102.5929 & -0.7803 & $22162+5539$ & 0.7022 & 2.494 & 36.64 & 93.46 & 401.553 \\
\hline 19 & 102.6694 & -0.8416 & $22169+5539$ & 0.5645 & 0.2646 & 13.95 & 22.5 & 114.69 \\
\hline 20 & 102.7274 & -0.7849 & $22170+5544$ & 2.109 & 1.284 & 37.75 & 218.1 & 759.37 \\
\hline 21 & 102.6046 & -0.4138 & $22149+5558$ & 0.6892 & 0.5379 & 4.849 & 24.4 & 88.55 \\
\hline 22 & 102.7032 & -0.3775 & $22153+5603$ & 0.434 & 0.5525 & 7.671 & 43.72 & 153.19 \\
\hline 23 & 102.8021 & -0.7222 & $22172+5549$ & 7.798 & 16.13 & 105.9 & 318.1 & 1322.38 \\
\hline 24 & 102.8096 & -0.5957 & $22168+5556$ & 3.323 & 3.447 & 90.3 & 312.5 & 1220.00 \\
\hline 25 & 102.8566 & -0.5826 & $22170+5558$ & 0.9272 & 1.918 & 90.3 & 149.4 & 749.95 \\
\hline 26 & 102.6639 & -0.6052 & $22160+5551$ & 3.033 & 4.275 & 74.13 & 274.3 & 1055.32 \\
\hline 27 & 102.6966 & -0.627 & $22162+5550$ & 1.307 & 3.697 & 74.13 & 328.4 & 1205.78 \\
\hline 28 & 102.6435 & -0.7537 & $22164+5542$ & 0.8211 & 1.546 & 17.91 & 91.48 & 327.80 \\
\hline 29 & 103.0244 & -0.5115 & $22178+5607$ & 0.8001 & 1.326 & 16.6 & 47.46 & 197.50 \\
\hline 30 & 103.0593 & -0.6928 & $22187+5559$ & 7.024 & 17.18 & 243. & 453. & 2193.02 \\
\hline 31 & 102.9843 & -0.6192 & $22179+5600$ & 0.7981 & 0.7612 & 19.02 & 47.64 & 205.45 \\
\hline 32 & 102.9012 & -0.8341 & $22183+5547$ & 5.512 & 2.102 & 13.43 & 77.55 & 279.51 \\
\hline
\end{tabular}

RCH II : región H II compacta 
mencionados.

Uno de los criterios tomados en cuenta para poder emparentar las nubes moleculares con las fuentes candidatas a protoestrellas es la correspondencia en velocidad radial. De la Fig. 7.4 vemos que las fuentes IRAS proyectadas en la vecindad de SG 13 son \#33, \#37, \#41, \#43, \#44, \#46 y \#47. Para las fuentes IRAS \#33, \#43, \#44, \#46 y \#47 (ver Tabla 7.3), la velocidad del gas molecular asociado es compatible con la velocidad del CO vinculado a SG $13\left(\Delta v=-58.4\right.$ a $-43.5 \mathrm{~km} \mathrm{~s}^{-1}$, ver Capítulo 4). Podemos detenernos en el caso de la fuente \#33, cuya $v_{L S R}$ es $-60.7 \mathrm{~km} \mathrm{~s}^{-1}$, pero teniendo en cuenta los errores de medición, puede estar relacionada físicamente con SG 13.

El caso de Sh2-132 es un poco más rico en cuanto a la asociación de las fuentes IRAS candidatas a protoestrella con el gas molecular. Las fuentes proyectadas sobre la región Hir son la \#18, \#19, \#20, \#23, \#24, \#25, \#26, \#27, \#28, \#30, \#31 у \#32 (ver Fig.7.6). De estas, las fuentes \#20, \#23, \#24, \#25, \#26, \#27, \#30 y \#31 están proyectadas sobre la emisión molecular. Sólo la \#30 presenta contraparte molecular con $v_{L S R}$ distinta al rango en velocidad de Sh2-132 (-50.1 a $\left.-38.6 \mathrm{~km} \mathrm{~s}^{-1}\right)$. Fontani et al. (2006), y Fontani et al. (2004) realizaron observaciones milimétricas de un gran ńumero de líneas moleculares hacia la fuente \#23. De estos trabajos se derivó, en 3mm, un radio lineal de 0.04 pc y una masa de $40 \mathrm{M}_{\odot}$ para el núcleo molecular. Pudieron determinar la distribución espectral de energía en el IR, y de esta forma obtuvieron una luminosidad de unas pocas $10^{3} \mathrm{~L}_{\odot}$. A través del análisis de las líneas de ${ }^{12} \mathrm{CO}(2-1)$ y ${ }^{12} \mathrm{CO}(1-0)$ asociaron flujos moleculares con esta fuente YSO. Ellos establecieron que estos eventos moleculares tienen un tiempo dinámico de $\sim 10^{4}-10^{5}$ años y una tasa de pérdida de masa del orden de $10^{-4} \mathrm{M}_{\odot}$ años $^{-1}$. Por otro lado, citan la presencia de jets asociados de esta fuente, a través de observaciones de [FeII]. Finalmente concluyen que este objeto es un YSO donde se está acretando materia desde su capullo molecular.

En conclusión, un total de 43 candidatos a YSO y 4 regiones H II compactas podrían asociarse a SG 13, mientras que 29 candidatos a YSO y 3 regiones H II compactas podrían vincularse a Sh2-132.

\subsection{YSOs en la región H II Gum 31}

En esta sección se desarrolla parte del trabajo "The environs of the HII region Gum 31" (Cappa C.E., Niemela V., Amorín R, y Vasquez J., A\&5A, 2008, 477, 173)

Gum 31 (Gum 1955) es una región H II galáctica ubicada en el brazo de Carina y cuya fuente de energía es el cúmulo abierto NGC 3324. Se encuentra a una distancia de 3.0 \pm 0.5 kpc. El análisis que se llevó a cabo para la búsqueda de candidatos primarios a YSOs fue similar al realizado en los dos casos anteriores. Nos interesa incluir esta región para comparar con la formación estelar en las cáscaras sopladas por vientos. Como inicio del análisis describiremos la distribución del ${ }^{12} \mathrm{CO}$ y de la emisión en las bandas A y E del 


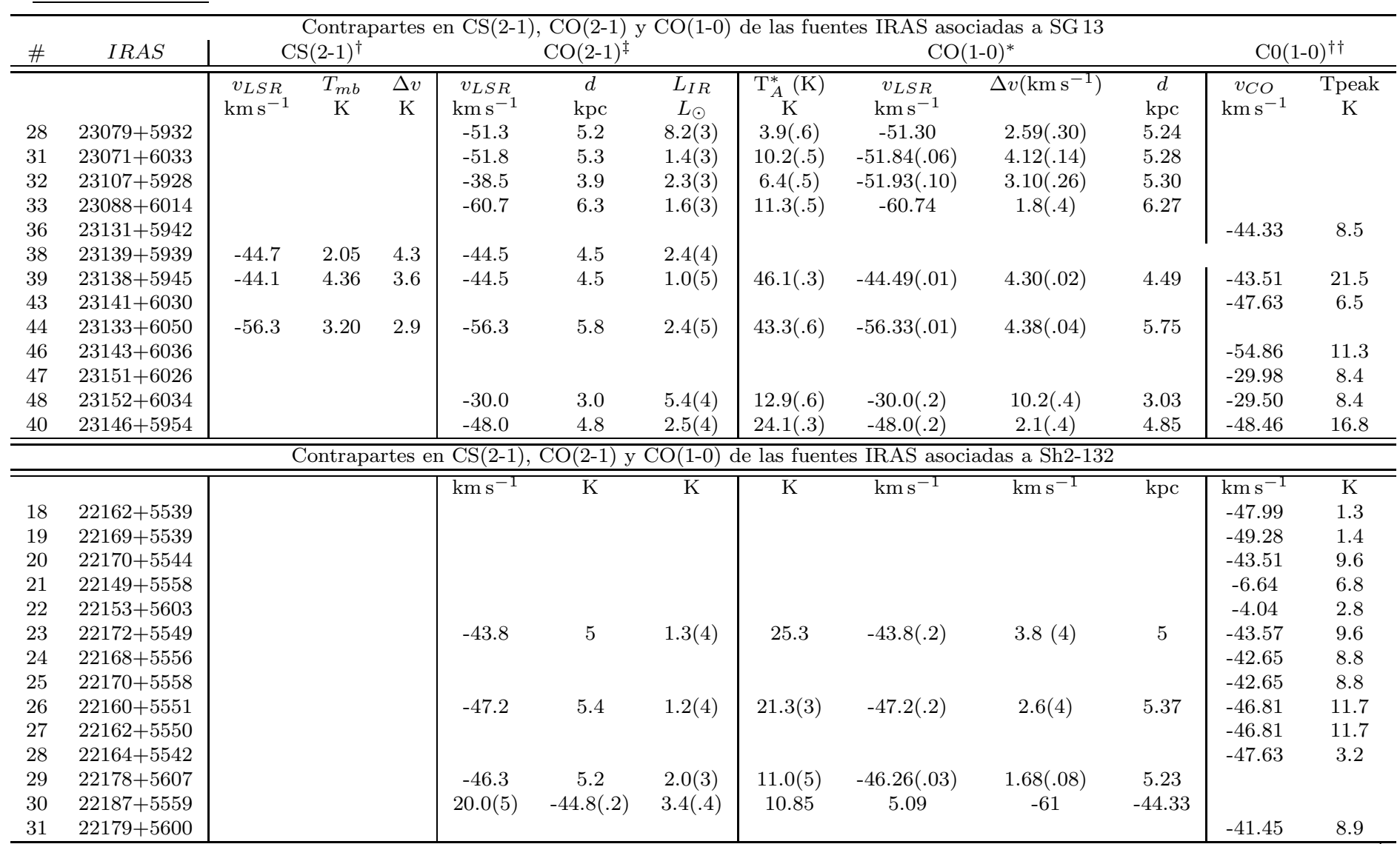

Referencias: $\dagger$ Bronfman et al. 1996, $\ddagger$ Wouterloot et al. 1988, Kömpe et al. 1989, Churchwell et al. 1990, ${ }^{*}$ Wouterloot \& Brand $1989,{ }^{\dagger}$ Kerton et al. 2003. 


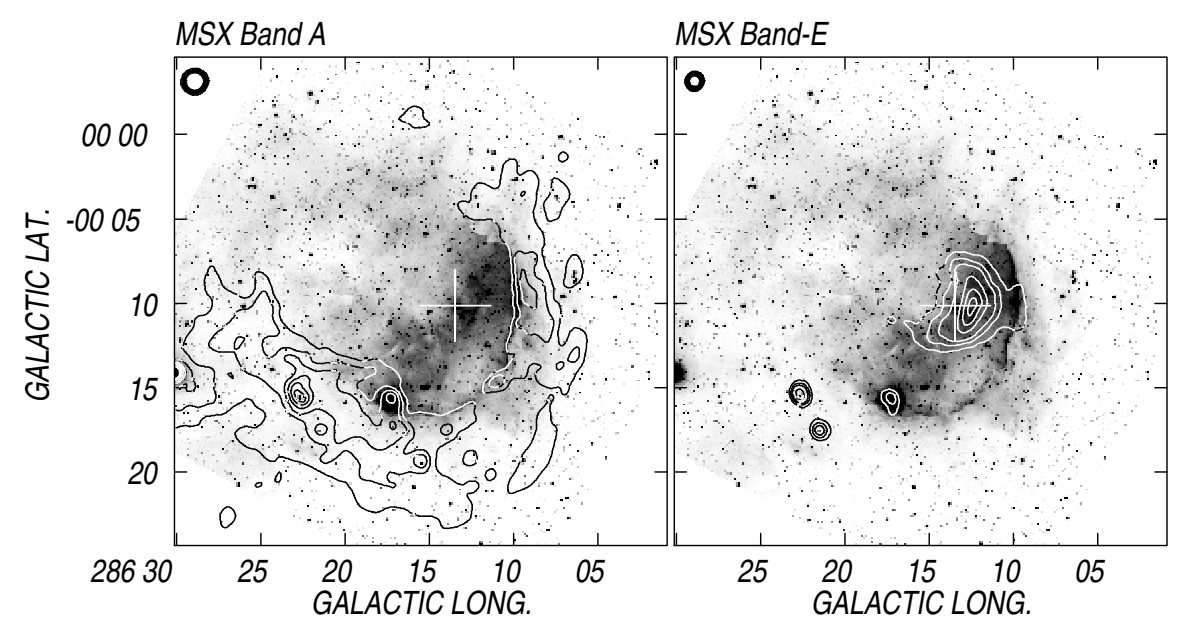

Figura 7.7: Superposición entre la imagen óptica (grisados) con los contornos de 25, 39, 57, 85, 114 y $140 \mathrm{MJy}_{\text {ster }}{ }^{-1}$ para la banda A, y 36, 46, 57, 85, 114 y $140 \mathrm{MJy} \mathrm{ster}^{-1}$ para la banda E.

satélite MSX, para luego hacer un análisis de las fuentes puntuales IR probablemente asociadas a la región H II.

Como ya hemos mencionado en los anteriores capítulos, la emisión en la banda A corresponde principalmente a los PAH, mientras que la emisión en la banda E incluye líneas nebulares y la emisión térmica de pequeños granos de polvo que pueden sobrevivir dentro de la región ionizada (ver por ej. Deharveng et al. 2005). Tielens \& Hollenbach (1985) sugieren que la emisión de los PAH está asociada a PDRs y por este motivo, su emisión IR sería un excelente indicador de regiones de formación estelar.

La Fig. 7.7 muestra la superposición de la emisión óptica en escala de grises con contornos que representan la emisión en las bandas A (panel izquierdo) y E (panel derecho). La emisión en la banda A tiene forma de arco y bordea externamente las secciones más brillantes de la nebulosa óptica. Por otro lado, la emisión en la banda E, se muestra mucho más acotada angularmente y contenida dentro de la nebulosa óptica, es decir, asociada claramente con el gas ionizado. La no coincidencia espacial entre ambas emisiones sugiere la presencia de una PDR en el borde de la nebulosa (Romero 2006), evidenciada por la emisión en la banda A.

\subsubsection{Análisis de la distribución del ${ }^{12} \mathrm{CO}$}

La emisión del gas molecular ha sido estudiada usando datos de la línea de ${ }^{12} \mathrm{CO}(1-0)$ en $115 \mathrm{GHz}$, obtenidos con el radiotelescopio de 4m de NANTEN ubicado en el observatorio Las Campanas en Chile. Estos datos han sido publicados por Yonekura et al. (2005). 
La distribución del gas molecular se muestra en la Figura 7.8. En el panel superior se observa la emisión del ${ }^{12} \mathrm{CO}(1-0)$ integrada en el rango de velocidades [-27.2, -14.0] $\mathrm{km} \mathrm{s}^{-1}$. Las líneas de contornos indican valores superiores a $3 \sigma$. En el panel inferior, los mismos contornos están superpuestos a la imagen óptica obtenida de la base de datos del SuperCOSMOS ${ }^{1}$. Este rango de velocidades es levemente diferente al usado por Yonekura et al. (2005) ([-30,-10] $\left.\mathrm{km} \mathrm{s}^{-1}\right)$, ya que no hemos detectado emisión de esta línea asociada a Gum 31 entre velocidades $v<-27 \mathrm{~km} \mathrm{~s}^{-1}$ y $v>-14 \mathrm{~km} \mathrm{~s}^{-1}$. La emisión molecular más intensa encierra la emisión óptica, con grumos delineando en forma notable el borde brillante en $\left(286^{\circ} 10^{\prime},-0^{\circ} 10^{\prime}\right)$ y cerca de $\left(286^{\circ} 23^{\prime},-0^{\circ} 15^{\prime}\right)$, donde la nebulosa aparece más difusa. Por otro lado, la zona cuya emisión óptica es relativamente poco intensa $[(l, b)$ $\left.=\left(286^{\circ} 20^{\prime},-0^{\circ} 4^{\prime}\right)\right]$ coincide con la zona donde la envoltura molecular está "abierta". El acuerdo morfológico entre ambas emisiones indica que el gas molecular y el ionizado están interactuando. Las líneas gruesas en la Fig. 7.8 delinean los núcleos de $\mathrm{C}^{18} \mathrm{O}$ encontrados por Yonekura et al. (2005) [?]. Comparando esta imagen con la Fig. 7.7, se concluye que los núcleos \#2 y \#6 coinciden con máximos de la emisión IR en la banda A.

\subsubsection{Distribución y características de los candidatos a YSOs}

Al igual que para el caso de las nebulosas anillo SG 13 y Sh2-132, investigamos la presencia de candidatos a protoestrella en la región de Gum 31 a través de bases de datos de fuentes puntuales IRAS, MSX y 2 MASS. Realizamos el análisis con un radio de búsqueda de $20^{\prime}$ centrado en la posición de NGC 3324.

Las fuentes 2 MASS candidatas a YSOs están ubicadas a la derecha del vector de enrojecimiento como en ve en la Fig. 7.9. Muchos de estos objetos se observan proyectados sobre nubes moleculares. Los diagramas CC y CM muestran que gran cantidad de estos objetos son MYSOs, con un alto grado de absorción visual $A_{v}$, lo que indica que están dentro de sus embriones de polvo. Se han identificado, además, 9 fuentes MSX (6 MYSOs y 3 RHII) y 12 fuentes IRAS.

La Tabla 7.4 muestra el listado de todas las fuentes IR candidatas a protoestrella en dirección a Gum 31. La luminosidad IR $L_{\mathrm{IR}}$ es bastante elevada para muchas de las fuentes IRAS, particularmente en las fuentes \#6 y \#9, con valores que justificarían asociar estas fuentes con objetos de gran masa. Por otro lado, es muy interesante ver que la mayoría de las fuentes MSX son candidatos a MYSO. En esta tabla también vemos que las fuentes IRAS, MSX y gran cantidad de fuentes 2MASS, clasificadas como YSO aparecen ubicadas sobre el borde de la región H II, proyectadas sobre la envoltura molecular y muchas de ellas coinciden con la posición de los núcleos densos encontrados por Yonekura et al. (2005) en $\mathrm{C}^{18} \mathrm{O}$.

La distibución de las fuentes candidatas a YSOs se muestra en la Fig. 7.10, superpuestas sobre la imagen óptica y los contornos de la Fig. 7.8.

Analizaremos algunas fuentes particulares:

\footnotetext{
${ }^{1}$ http://www-wfau.roe.ac.uk/sss/
} 

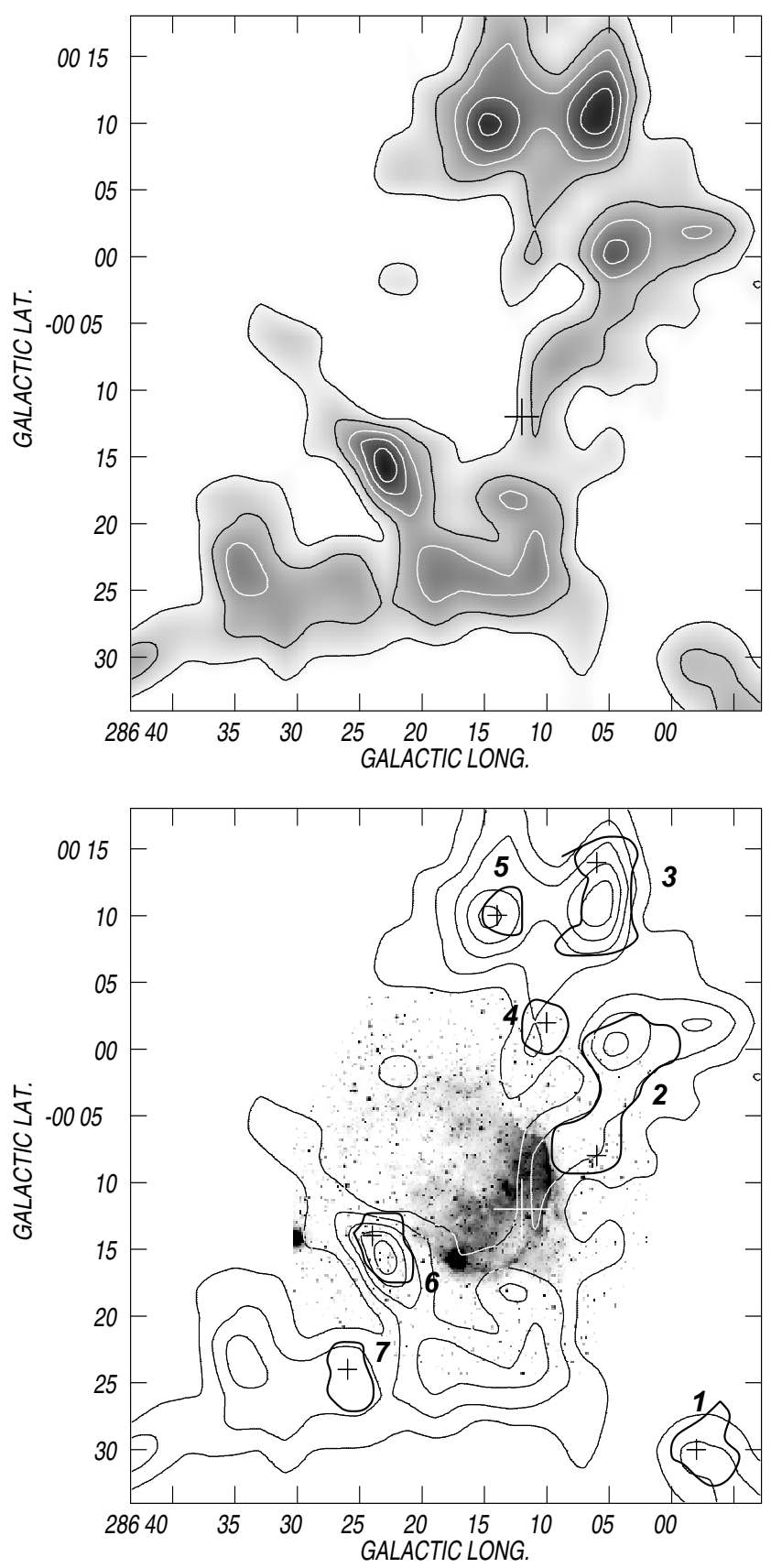

Figura 7.8: Panel superior: Distribución de la emisión del ${ }^{12} \mathrm{CO}(1-0)$ correspondiente al intervalo de velocidad -27.2 a $-14.0 \mathrm{~km} \mathrm{~s}^{-1}$. El rango de grisados corresponde a 15 a $150 \mathrm{~K} \mathrm{~km} \mathrm{~s}^{-1}$. Las líneas de contornos son 20.2, 40.5, 60.7, 81.0 y $101.2 \mathrm{~K} \mathrm{~km} \mathrm{~s}^{-1}$. Panel inferior: Superposición de la imagen óptica obtenida del SuperCOSMOS (grisados) y la distribución molecular (contornos). Las líneas gruesas encierran los núcleos de $\mathrm{C}^{18} \mathrm{O}$ descriptos por Yonekura et al. (2005). Lon números corresponden a la identificación de los núcleos de $\mathrm{C}^{18} \mathrm{O}$ de acuerdo a la Tabla 2 de Yonekura et al.(2005) y las cruces indican el centro de los núcleos. 

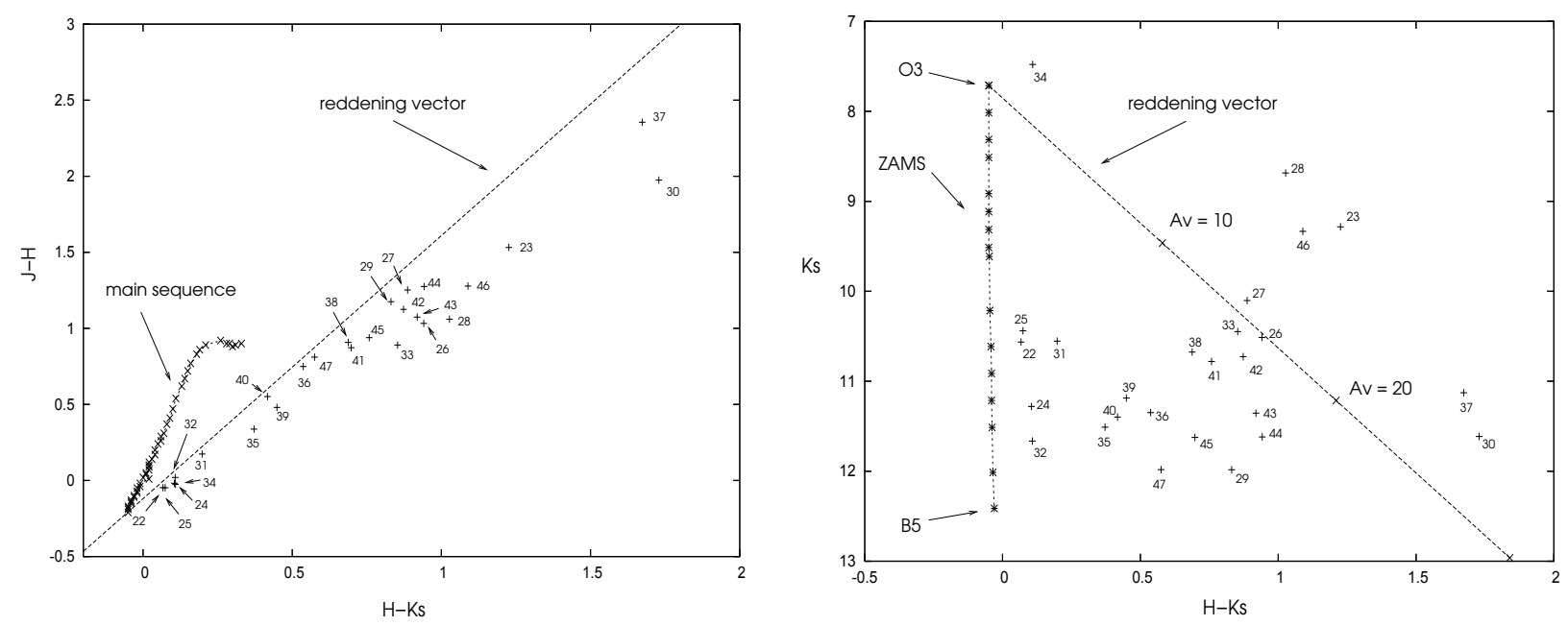

Figura 7.9: Panel izquierdo: Diagrama CC de la fuentes 2 MASS con exceso IR. También está representada la SP. Panel derecho: Diagrama CM de las mismas fuentes. Las cruces corresponden a la ZAMS.

- La fuente IRAS \#9, las fuentes MSX \#19, \#20 y \#21, y las 2 MASS \#38 y \#40 están proyectadas sobre una nube detectada en ${ }^{12} \mathrm{CO}$ y sobre el núcleo \#6 de $\mathrm{C}^{18} \mathrm{O}$. Estos objetos estelares en formación son probablemente objetos masivos o cúmulos de estrellas (Yonekura et al. 2005).

- La fuente MSX \#19 es coincidente con una radiofuente observada en $843 \mathrm{MHz}$ (ver el trabajo original) y con una región brillante observada en la banda E de MSX (ver Fig. 7.7). La radiofuente tiene un tamaño angular del $\sim 48^{\prime \prime} \times 38^{\prime \prime}$, y su densidad de flujo es de alrededor de $30 \mathrm{mJy}$. No se ha estimado la densidad electrónica, pero es altamente probable que la región H II compacta sea ópticamente gruesa a esta frecuencia.

- Las fuentes MSX \#20 y \#21 se ubican proyectadas sobre una región con emisión en las bandas A y E, y sobre el núcleo denso \#6.

- Sobre el frente de ionización observado en la imagen óptica se observan las fuentes \#5, \#13, \#27, \#28, \#29 y \#31. Todas ellas, excepto esta última, también se encuentran proyectadas sobre la emisión molecular. La fuente \#28 se encuentra en el límite del núcleo denso \#2.

- Las fuentes \#6 y \#10 se encuentran proyectadas sobre los núcleos \#5 y \#7, respectivamente.

- Una gran cantidad de objetos protoestelares se encuentran proyectados sobre la posición del cúmulo excitatriz NGC 3324, por ejemplo, las fuentes MSX \#14, \#15 y \#17) y las fuentes 2 MASS \#32, \#33 y \#34. Los diagramas CC muestran que 
esas fuentes no presentan un exceso IR elevado. Algunas de ellas coinciden con el cúmulo IR IC 2599, listado por Dutra et al. (2003). Estos elementos reforzarían la sugerencia de Carraro et al. (2001), quienes concluyen que en la región adyacente a NGC 3324 se estarían formando estrellas.

Los grandes valores en la luminosidad $L_{I R A S}$, estimados para algunas de las fuentes sugieren que ellas son además candidatos a estrellas de gran masa o cúmulos estelares.

Podemos decir que la presencia de objetos protoestelares sobre la cáscara molecular que rodea a Gum 31 indica que la formación estelar ha sido inducida por la expansión de la región H II sobre ésta última. La distribución del gas molecular y el ionizado sugieren que la formación estelar podría deberse al proceso "collect and collapse" (Elmegreen 1977).

\subsection{Discusión}

¿Existen grandes diferencias en cuanto a la formación estelar entre las nebulosas anillo ópticas SG 13 y Sh2-132, respecto a la región H II Gum 31 ?

Nuestro análisis de las tres regiones no es totalmente concluyente al respecto. Si nos remitimos a analizar la cantidad de objetos candidatos a YSOs, seguramente no encontramos grandes diferencias en cuanto a la cantidad de fuentes asociadas a cada una de las tres regiones, más allá que en SG 13 vemos que la densidad de fuentes IR no es alta como en las otras dos regiones.

Un análisis más profundo puede plantearse si proponemos como variable la candidad $\zeta$, en unidades de $\mathrm{YSO} / \mathrm{pc}^{2}$; y las densidades electrónicas $n_{e}$ en cada una de las tres regiones. De esta forma tenemos en cuenta las dimensiones reales de cada estructura. Considerando la densidad electrónica también podemos tener un mejor indicio de las condiciones globales en las que se encuentra el gas cercano a regiones donde se está llevando a cabo la FES.

Sabemos que la emisión molecular en SG 13 tiene un radio lineal de $18 \pm 5$ pc y una $n_{e}=9-15 \mathrm{~cm}^{-3}$, para un factor de llenado $f=0.1-0.2$ (ver Capíulo 4). Considerando 48 fuentes IR listadas (Tabla 7.1) como candidatas a YSO y una geometría circular para SG 13, tenemos un valor de $\zeta=0.04$. Por otro lado, del Capítulo 5 vemos que Sh2-132 tiene un radio lineal de $15.3 \pm 2.5$ pc del gas ionizado (considerándolo como una medida razonable del radio de toda la estructura multifrecuencia). Además, la densidad electrónica es $n_{e}=15-20 \mathrm{~cm}^{-3}$, con $f=0.3-0.2$. Si tenemos 32 fuentes candidatas a YSO, el factor es $\zeta=0.04$.

Gum 31 tiene un radio lineal medio de $13 \pm 5$ pc asociado a la distribución molecular y una densidad electrónica de $34 \pm 3 \mathrm{~cm}^{-3}$. En la Tabla 7.4 de esta tesis listamos 47 objetos candidatos a YSO. Por lo tanto, $\zeta=0.1$.

Vemos que utilizando la variable $\zeta$ y conociendo los valores de las densidades electrónica en cada región, la situación se modifica drásticamente. Existe una diferencia del orden de una magnitud en $\zeta$ entre Gum 31 y las dos BI consideradas, y $n_{e}$ en la región 


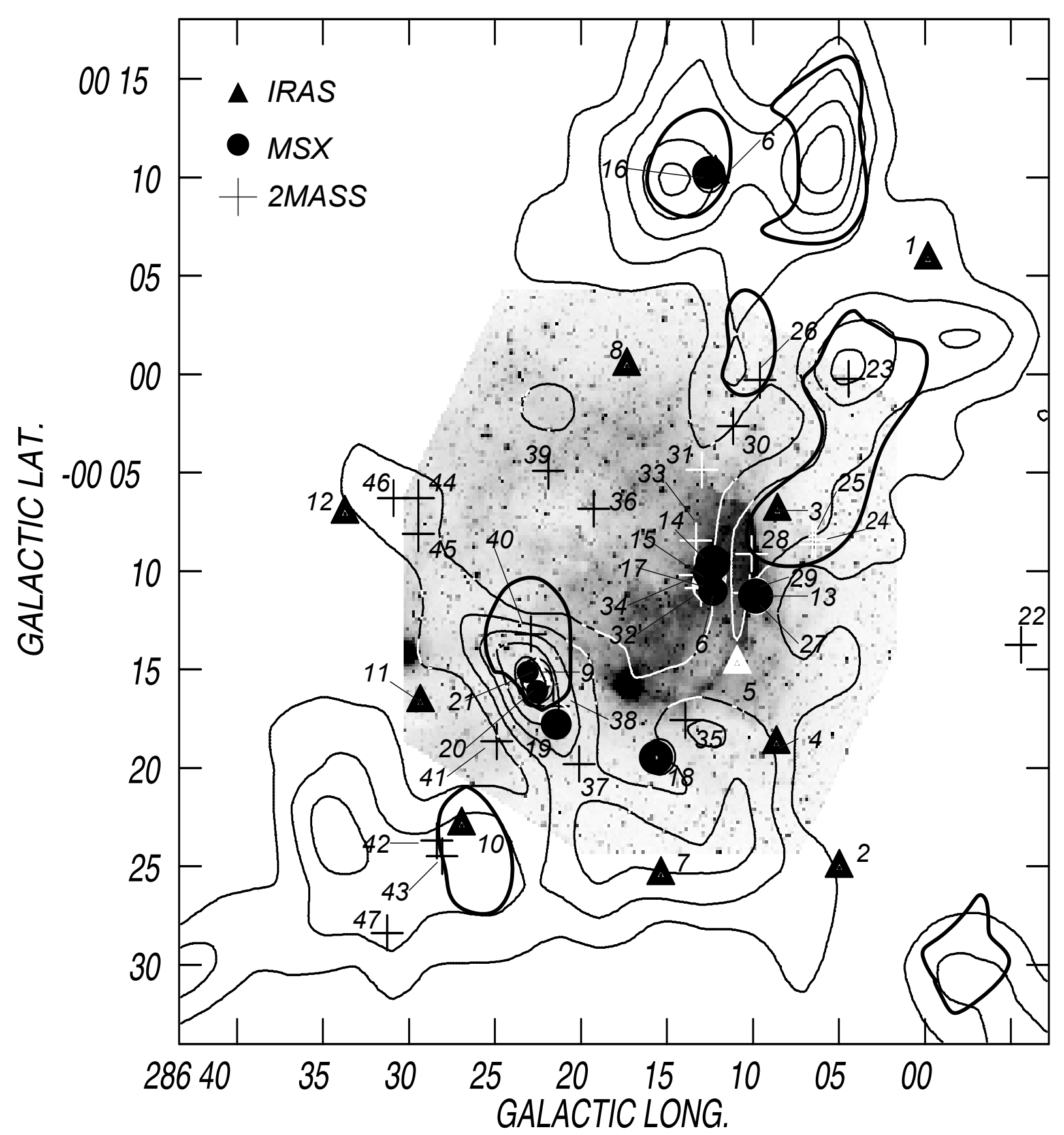

Figura 7.10: Fuentes puntuales IR en dirección a Gum 31. La imagen de fondo corresponde a la nebulosa óptica, los contornos finos a la distribución de ${ }^{12} \mathrm{CO}(1-0)$ y los contornos gruesos a los núcleos de $\mathrm{C}^{18} \mathrm{O}$ (ver Fig. 7.9). Los triángulos indican las fuentes IRAS, los círculos las fuentes MSX y las cruces las fuentes 2 MASS. 
Tabla 7.4: Fuentes puntuales candidatas a objetos YSO en dirección a Gum 31

\begin{tabular}{|c|c|c|c|c|c|c|c|c|}
\hline \multirow[t]{2}{*}{ \# } & \multirow[t]{2}{*}{ 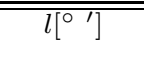 } & \multirow[t]{2}{*}{ 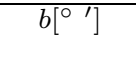 } & \multirow[t]{2}{*}{$\overline{\text { Fuentes } I R A S}$} & \multicolumn{4}{|c|}{$\overline{\text { Flujos [Jy] }}$} & \multirow[t]{2}{*}{$\overline{L_{I R A S}\left[10^{3} L\right]}$} \\
\hline & & & & $12 \mu \mathrm{m}$ & $25 \mu \mathrm{m}$ & $60 \mu \mathrm{m}$ & $100 \mu \mathrm{m}$ & \\
\hline 1 & $285^{\circ} 59^{\prime} 82$ & $+0^{\circ} 05^{\prime} 82$ & $10349-5801$ & 1.6 & 2.5 & 27.9 & 104 & 1.5 \\
\hline 2 & $286^{\circ} 04^{\prime} 98$ & $-0^{\circ} 25^{\prime} 08$ & $10335-5830$ & 0.8 & 3.5 & 22.8 & 111 & 1.5 \\
\hline 3 & $286^{\circ} 08^{\prime} 58$ & $-0^{\circ} 06^{\prime} 96$ & $10351-5816$ & 6.3 & 6.8 & 315 & 1480 & 18 \\
\hline 4 & $286^{\circ} 08^{\prime} 64$ & $-0^{\circ} 18^{\prime} 78$ & $10343-5826$ & 5.5 & 4.3 & 103 & 340 & 5 \\
\hline 5 & $286^{\circ} 10^{\prime} 92$ & $-0^{\circ} 14^{\prime} 7$ & $10349-5824$ & 5.9 & 9.0 & 163 & 1660 & 18 \\
\hline 6 & $286^{\circ} 12^{\prime} 18$ & $+0^{\circ} 10^{\prime} 20$ & $10365-5803$ & 7.2 & 86 & 1170 & 2780 & 43 \\
\hline 7 & $286^{\circ} 15^{\prime} 12$ & $-0^{\circ} 25^{\prime} 44$ & $10346-5835$ & 1.1 & 3.3 & 11.7 & 1430 & 14 \\
\hline 8 & $286^{\circ} 17^{\prime} 34$ & $+0^{\circ} 00^{\prime} 42$ & $10365-5814$ & 2.3 & 1.7 & 85 & 246 & 4 \\
\hline 9 & $286^{\circ} 22^{\prime} 5$ & $-0^{\circ} 15^{\prime} 3$ & $10361-5830$ & 12.4 & 38.4 & 626 & 2160 & 30 \\
\hline 10 & $286^{\circ} 26^{\prime} 94$ & $-0^{\circ} 22^{\prime} 92$ & 10361-5839 & 2.8 & 5.4 & 51.6 & 307 & 4 \\
\hline 11 & $286^{\circ} 29^{\prime} 34$ & $-0^{\circ} 16^{\prime} 68$ & $10368-5835$ & 2.1 & 2.3 & 84 & 271 & 4 \\
\hline 12 & $286^{\circ} 33^{\prime} 72$ & $-0^{\circ} 07^{\prime} 08$ & $10379-5828$ & 1.0 & 2.0 & 13.8 & 540 & 5 \\
\hline \multirow[t]{2}{*}{$\overline{\#}$} & $l\left[\mathrm{o}^{\prime}\right]$ & $b\left[0^{\prime}\right]$ & $\overline{\text { Fuentes } M S X}$ & \multicolumn{4}{|c|}{ Flujos [Jy] } & \\
\hline & & & & $8 \mu \mathrm{m}$ & $12 \mu \mathrm{m}$ & $14 \mu \mathrm{m}$ & $21 \mu \mathrm{m}$ & Class. \\
\hline 13 & $286^{\circ} 09^{\prime} 78$ & $-0^{\circ} 11^{\prime} 28$ & G286.1626-00.1877 & 0.7311 & 1.298 & 1.256 & 2.806 & $\mathrm{CH}$ II \\
\hline 14 & $286^{\circ} 12^{\prime} 36$ & $-0^{\circ} 09^{\prime} 66$ & G286.2056-00.1611 & 0.1585 & 0.9313 & 2.151 & 6.904 & MYSO \\
\hline 15 & $286^{\circ} 12^{\prime} 48$ & $-0^{\circ} 10^{\prime} 32$ & G286.2077-00.1720 & 0.0870 & 0.9481 & 1.764 & 2.9 & MYSO \\
\hline 16 & $286^{\circ} 12^{\prime} 54$ & $+0^{\circ} 10^{\prime} 14$ & G286.2086+00.1694 & 1.353 & 2.882 & 7.182 & 40.57 & MYSO \\
\hline 17 & $286^{\circ} 12^{\prime} 6$ & $-0^{\circ} 10^{\prime} 68$ & G286.2096-00.1775 & 0.2202 & 0.9538 & 1.368 & 7.206 & MYSO \\
\hline 18 & $286^{\circ} 15^{\prime} 42$ & $-0^{\circ} 19^{\prime} 44$ & G286.2566-00.3236 & 2.04 & 2.151 & 1.34 & 4.328 & $\mathrm{CH}$ II \\
\hline 19 & $286^{\circ} 21^{\prime} 48$ & $-0^{\circ} 17^{\prime} 58$ & G286.3579-00.2933 & 0.7126 & 1.815 & 2.677 & 6.065 & MYSO \\
\hline 20 & $286^{\circ} 22^{\prime} 5$ & $-0^{\circ} 15^{\prime} 78$ & G286.3747-00.2630 & 3.591 & 4.756 & 2.409 & 7.577 & $\mathrm{CH}$ II \\
\hline 21 & $286^{\circ} 22^{\prime} 62$ & $-0^{\circ} 15^{\prime} 36$ & G286.3773-00.2563 & 1.628 & 2.918 & 3.855 & 12.1 & MYSO \\
\hline$\overline{\# \#}$ & $\overline{l l\left[\mathrm{o}^{\prime}\right]}$ & $\overline{b\left[\mathrm{o}^{\prime}\right]}$ & $\overline{\text { Fuentes } 2 M A S S}$ & $J[\mathrm{mag}]$ & $H[\mathrm{mag}]$ & $\overline{\overline{K_{s}}[\mathrm{mag}]}$ & $\overline{(J-H)}$ & $\overline{(H-K)}$ \\
\hline 22 & $285^{\circ} 54^{\prime} 42$ & $-0^{\circ} 13^{\prime} 74$ & $10350210-5831039$ & 10.584 & 10.631 & 10.564 & -0.047 & 0.067 \\
\hline 23 & $286^{\circ} 04^{\prime} 44$ & $-0^{\circ} 00^{\prime} 24$ & $10365972-5824186$ & 12.042 & 10.51 & 9.284 & 1.532 & 1.226 \\
\hline 24 & $286^{\circ} 06^{\prime} 36$ & $-0^{\circ} 08^{\prime} 64$ & $10364112-5832326$ & 11.367 & 11.385 & 11.28 & -0.018 & 0.105 \\
\hline 25 & $286^{\circ} 06^{\prime} 54$ & $-0^{\circ} 08^{\prime} 40$ & $10364296-5832267$ & 10.465 & 10.513 & 10.439 & -0.048 & 0.074 \\
\hline 26 & $286^{\circ} 09^{\prime} 60$ & $-0^{\circ} 00^{\prime} 30$ & $10373406-5826540$ & 12.487 & 11.454 & 10.513 & 1.033 & 0.941 \\
\hline 27 & $286^{\circ} 09^{\prime} 78$ & $-0^{\circ} 11^{\prime} 22$ & $10365396-5836293$ & 12.242 & 10.99 & 10.103 & 1.252 & 0.887 \\
\hline 28 & $286^{\circ} 10^{\prime} 08$ & $-0^{\circ} 09^{\prime} 12$ & $10370395-5834489$ & 10.772 & 9.712 & 8.685 & 1.06 & 1.027 \\
\hline 29 & $286^{\circ} 10^{\prime} 20$ & $-0^{\circ} 11^{\prime} 10$ & $10365749-5836366$ & 13.99 & 12.815 & 11.984 & 1.175 & 0.831 \\
\hline 30 & $286^{\circ} 11^{\prime} 16$ & $-0^{\circ} 02^{\prime} 64$ & $10373574-5829405$ & 15.318 & 13.343 & 11.614 & 1.975 & 1.729 \\
\hline 31 & $286^{\circ} 12^{\prime} 96$ & $-0^{\circ} 04^{\prime} 86$ & $10373956-5832311$ & 10.926 & 10.752 & 10.554 & 0.174 & 0.198 \\
\hline 32 & $286^{\circ} 13^{\prime} 02$ & $-0^{\circ} 10^{\prime} 86$ & $10371717-5837460$ & 11.793 & 11.773 & 11.665 & 0.02 & 0.108 \\
\hline 33 & $286^{\circ} 13^{\prime} 32$ & $-0^{\circ} 08^{\prime} 46$ & $10372824-5835492$ & 12.191 & 11.301 & 10.448 & 0.89 & 0.853 \\
\hline 34 & $286^{\circ} 13^{\prime} 38$ & $-0^{\circ} 10^{\prime} 20$ & $10372226-5837229$ & 7.563 & 7.588 & 7.479 & -0.025 & 0.109 \\
\hline 35 & $286^{\circ} 13^{\prime} 92$ & $-0^{\circ} 17^{\prime} 87$ & $10365763-5844052$ & 12.22 & 11.882 & 11.51 & 0.338 & 0.372 \\
\hline 36 & $286^{\circ} 19^{\prime} 26$ & $-0^{\circ} 06^{\prime} 84$ & $10381421-5837192$ & 12.635 & 11.886 & 11.349 & 0.749 & 0.537 \\
\hline 37 & $286^{\circ} 20^{\prime} 10$ & $-0^{\circ} 19^{\prime} 80$ & $10373105-5849026$ & 15.155 & 12.8 & 11.127 & 2.355 & 1.673 \\
\hline 38 & $286^{\circ} 21^{\prime} 06$ & $-0^{\circ} 16^{\prime} 86$ & $10375219-5847133$ & 12.271 & 11.363 & 10.675 & 0.908 & 0.688 \\
\hline 39 & $286^{\circ} 21^{\prime} 90$ & $-0^{\circ} 04^{\prime} 92$ & $10383875-5836566$ & 12.116 & 11.636 & 11.187 & 0.48 & 0.449 \\
\hline 40 & $286^{\circ} 22^{\prime} 92$ & $-0^{\circ} 13^{\prime} 20$ & $10381461-5844416$ & 12.367 & 11.815 & 11.398 & 0.552 & 0.417 \\
\hline 41 & $286^{\circ} 24^{\prime} 92$ & $-0^{\circ} 18^{\prime} 66$ & $10380736-5850240$ & 12.477 & 11.538 & 10.78 & 0.939 & 0.758 \\
\hline 42 & $286^{\circ} 28^{\prime} 11$ & $-0^{\circ} 24^{\prime} 50$ & $10380702-5857039$ & 12.724 & 11.599 & 10.726 & 1.125 & 0.873 \\
\hline 43 & $286^{\circ} 28^{\prime} 44$ & $-0^{\circ} 23^{\prime} 71$ & $10381226-5856318$ & 13.348 & 12.274 & 11.355 & 1.074 & 0.919 \\
\hline 44 & $286^{\circ} 29^{\prime} 46$ & $-0^{\circ} 06^{\prime} 30$ & $10392451-5841486$ & 13.836 & 12.561 & 11.619 & 1.275 & 0.942 \\
\hline 45 & $286^{\circ} 29^{\prime} 46$ & $-0^{\circ} 08^{\prime} 10$ & $10391799-5843257$ & 13.195 & 12.322 & 11.624 & 0.873 & 0.698 \\
\hline 46 & $286^{\circ} 30^{\prime} 90$ & $-0^{\circ} 06^{\prime} 30$ & $10393410-5842321$ & 11.701 & 10.423 & 9.334 & 1.278 & 1.089 \\
\hline 47 & $286^{\circ} 31^{\prime} 27$ & $-0^{\circ} 28^{\prime} 40$ & $10381363-5902003$ & 13.368 & 12.557 & 11.982 & 0.811 & 0.575 \\
\hline
\end{tabular}


H II es el doble (o triple) respecto al valor en las BI.

De esta manera, vemos que aunque existan fuentes candidatas a YSO en nuestras BI, la FES no se da con la intensidad que se da en Gum31. Se pueden proponer algunas explicaciones de por qué ocurre esto:

- Las dimensiones lineales y los tiempos dinámicos de las BI son superiores a los de la región H iI, y por otro lado, las $n_{e}$ de las BI estudiadas son casi la mitad que la de la región H II. Las bajas densidades desfavorecen la generación de núcles moleculares compactos.

- Los altos valores de $\dot{M}$ y $v_{\infty}$ de los vientos de WR 157 y WR 153ab modifican el medio interestelar circundante de tal manera que inhiben la formación y/o destruyen los núcleos moleculares densos.

Una de las posibilidades que podemos plantear para el caso de SG 13, es que los frentes de choque, evidenciados en las dos intensas ramas observadas en continuo de radio y óptico de SG 13, hayan barrido la mayor parte del material molecular y de esta forma hayan impedido la formación de núcleos lo suficientemente densos para la formación estelar en gran escala. La no existencia de una PDR clara o la no asociación distiguible entre las cáscaras en expansión y el hidrógeno neutro serían manifestaciones de este hecho.

Para Sh2-132, el material ionizado de la región H II está interactuando con el hidrógeno molecular de sus alrededores, lo que genera regiones de fotodisociación que se ven claramente superpuestas con las nubes moleculares (ver Capítulo 5). En ese contexto es en donde se observan la mayoría de las fuentes IR candidatas a protoestrella, fundamentalmente fuentes IRAS con contrapartes previamente estudiadas en distintas líneas moleculares. Un hecho notorio acerca de las fuentes MSX asociadas a Sh2-132, es que ninguna de ellas es candidada a fuente YSO. Las tres fuentes MSX están catalogadas como regiones H II compactas. Esas fuentes están en un proceso evolutivo más avanzado al de objetos protoestelares. En ellas, gran parte del material molecular circumestelar y polvo han sido disociados y destruidos por la acción del campo de radiación del objeto central.

En la región H iI Gum 31 se puede ver que el frente de ionización ha disociado parte del material molecular, mientras que otra parte está aún interactuando con los fotones UV. Una de las consecuencias de este hecho es la presencia de PDRs que envuelven casi por completo a la nebulosa. La distribución espacial del $\mathrm{H}_{2}$ presenta un "hueco" que encierra a la región H ir. Esto sería una evidencia de que la nebulosa se formó y está evolucionando dentro de este material molecular. Se puede observar cómo el frente de ionización aún está en contacto con regiones densas de estas nubes. En esas zonas de contacto entre el material ionizado y el molecular es donde conviven gran cantidad de fuentes IR candidatas a protoestrellas, lo que estaría demostrando el desarrollo en pleno de la FES. 


\subsection{Resumen y conclusiones}

Hemos analizado la formación estelar en las nebulosas anillo ópticas SG 13 y Sh2-132. Nuestro interés radica en comprobar si la acción de los fuertes vientos estelares en este tipo de regiones crea condiciones adecuadas para la formación de estrellas. Como parte del trabajo agregamos la región H II Gum 31 (Cappa et al. 2008), donde se realizó un estudio similar. Entre los puntos más sobresalientes de nuestro estudio, vemos que:

- Encontramos un gran número de fuentes 2 MASS y IRAS candidatas a protoestrella proyectadas sobre y dentro de las regiones estudiadas, no así fuentes MSX.

- Existe poca coincidencia espacial entre fuentes de distintos catálogos, lo que sugiere que las fuentes están en etapas de evolución diferentes.

- Hay coincidencia de la mayoría de las fuentes IRAS encontradas con la distribución de gas molecular tanto en SG 13 como en Sh2-132. En particular, es notoria la coincidencia angular de muchas fuentes puntuales con los núcleos de $\mathrm{C}^{18} \mathrm{O}$ en Gum 31.

- Hay evidencias firmes de la presencia de regiones de fotodisociación en Sh2-132, lo que indica que los frentes de ionización y choque están interactuando con las nubes moleculares.

- Una gran cantidad de fuentes MSX y 2 MASS "delinean" los frentes de ionización en Gum 31. Esta característica no es tan marcada en las dos BI.

- Los altos valores de luminosidad IR de algunas fuentes asociadas con Gum 31, sugieren que además de ser candidatos protoestelares, son candidatos a estrellas de gran masa o a cúmulos estelares.

Existe una gran diferencia en cuanto a la formación estelar en la región H II Gum 31 y las nebulosas SG 13 y Sh2-132. Los altos valores en la $n_{e}$ y $\zeta$ de Gum 31 cuantifican este hecho. Por lo tanto, a partir de las observaciones realizadas, éstas dos BI presentan rasgos que muestran que son regiones de FES activa. Sin embargo, la FES se da en mayor escala en Gum 31 con respecto a las dos BI analizadas. Es importante ver si esta tendencia es compartida por otras BI. 


\section{Bibliografía}

Ao Y., Yang J., Sunada K., 2004, AJ, 128, 1716

Bhattal A. S., Francis N., Watkins S. J., Whitworth A. P., 1998, MNRAS, 297, 435

Bertoldi F., McKee Ch. F., 1990, ApJ, 354, 529

Bertoldi F., 1989, ApJ, 346, 735

Bronfman L., Nyman L.-A, May J., A\&ASS, 1996, 115, 81

Cappa C.E., Niemela V., Amorín R, y Vasquez J., A\&A, 2007, 477, 173

Carraro G., Hassan S. M., Ortolani S., Vallenari A., 2001, A\&A, 372, 879

Chan G., Fich M., 1995, AJ, 109, 2611

Churchwell E., Walmsley C. M., Cesaroni R., 1990, A\&AS, 83, 119

Comerón F., Scheneider N, Russeil D., 2005, A\&A, 433, 955

Cutri R. M., Skrutskie M. F., van Dyk S., Beichman C. A., Carpenter J. M., Chester T., Cambresy L., Evans T., Fowler J., Gizis J., Howard E., Huchra J., Jarrett T., Kopan E. L., Kirkpatrick J. D., Light R. M., Marsh K. A., McCallon H., Schneider S., Stiening R., Sykes M., Weinberg M., Wheaton W. A., Wheelock S., Zacarias N., 2003, tmc..book

Deharveng L., Lefloch B., Massi F., Brand J., Kurtz S., Zavagno A., Caplan J., 2006, A\&A, 458, 191

Deharveng L., Zavagno A., Caplan J. 2005, A\&A, 433, 565

Deharveng L., Zavagno A., Salas L., Porras A., Caplan J., Cruz-González I., 2003, A\&A, 399, 1135

Deharveng L., Lefloch B., Zavagno A., Caplan J., Whitworth A. P., Nadeau D., Martín S., 2003, A\&A, 408, 25

Dutra, C.M., Bica, E., Soares, J., \& Barbuy, B. 2003, A\&A, 400, 533

Egan, M. P., Price, S. D., Moshir, M. M., Cohen, M., Tedesco, E., Murdock, T. L., Zweil, A., Burdick, S., Bonito, N., Gugliotti, G. M., \& Duszlak, J. 1999, The Midcourse Space Experiment Point Source Catalog Version 1.2 Explanatory Guide, AFRL-VS-TR-1999-1522, Air Force Research Laborartory

Elmegreen B.G.\&, 2001, astro-ph/0110147v1

Elmegreen B.G.\& Lada C.J., 1977, ApJ, 214, 725

Fontani F., Caselli P., Crapsi A., Cesaroni R., Molinari S., Testi L., Brand J., 2006, A\&A, 460, 709

Fontani F., Cesaroni R., Testi L., Molinari S., Zhang Q., Brand J., Walmsley C. M., 2004, A\&A, 424, 179

Gum, C.S. 1955, MmRAS, 67, 155

Hanson M.M., Howarth L.D., Conti P.S, 1997, ApJ, 489, 698 
Hennebelle P., Whitworth A. P., Cha S.-H., Goodwin S. P., 2004, MNRAS, 348, 687 Hosokawa T., Inutsuka S.-I., 2007, ApJ, 664, 363

Hosokawa T., Inutsuka S.-I., 2005, ApJ, 623, 91

Junkes, N., Fürst, E., \& Reich, W. 1992, A\&A, 261, 289

Kerton C.R., Brunt C.M., 2003, A\&A, 399, 1083

kmpe C., Joncas G., Baudry A., Wouterloot J.G.A., 1989, A\&A, 221, 295

Koornneef J., 1983, A\&AS, 51, 489

Lada Ch.J., Depoy D.L., Merrill K. M., Gatley I., 1991, ApJ, 374, 533

Lefloch B., Cernicharo. J., 2000, ApJ, 545, 340

Lumsden, S.L., Hoare, M.G., Oudmaidjer, R.D., \& Richards, D. 2002, MNRAS, 336, 621

Romero G.A., 2006, Tesis doctoral, p.60

Telesco C. M., Harper D. A., 1980, ApJ, 235, 392

Tielens A.G.G.M., Hollenbach D., 1985, ApJ, 291, 722

Whitworth A. P., Bhattal A. S., Chapman S. J., Disney M. J., Turner J. A., 1994, A\&A, 290, 421

Wilking B.A., Mundy L.G., Blackwell J.H., Howe J.E., 1989, ApJ, 345, 257

Wouterloot J.G.A., Brand J., 1989, ApJ, 340, 265

Wouterloot J.G.A., Henkel C., Brand J., 1988, A\&A, 191, 323

Yonekura, Y., Asayama, S., Kimura, K., Ogawa, H., Kanai, Y., Yamaguchi, N., Barnes, P.J., \& Fukui Y. 2005, ApJ, 634, 476

Zavagno A., Deharveng L., Comerón F., Brand J., Massi F., Caplan J., Russeil D., 2006, A\&A, 446, 171 


\section{Capítulo 8}

\section{Conclusiones}

A lo largo de esta tesis hemos estudiado y analizado la interacción física producida por los vientos de las estrellas WR 157, WR 113, WR 152 y WR 153ab con el medio interestelar (MIE). La mayoría de estas estrellas forman parte de sistemas múltiples y a su vez, pertenecen a cúmulos o asociaciones formadas en general por objetos jóvenes. Todos ellos cooperan con el modelado del MIE, pero aquellos que más influyen por sus altas tasas de pérdida de masa y los fuertes vientos son las estrellas WR. Por este motivo es que en general asumimos que los principales arquitectos del medio circundante son estas estrellas WR.

Llevamos a cabo un análisis multifrecuencia que nos permitió analizar las interacciones entre diferentes componentes del medio interestelar asociado a estas estrellas WR.

Hemos estudiado la formación estelar en las cáscaras de las BI vinculadas a las estrellas WR 157 y WR 153ab, abriendo paso a un campo de la astrofísica todavía pobremente investigado.

La propiedades globales encontradas en todos los casos analizados se pueden resumir comosigue:

- La morfología del gas ionizado observado en continuo de radio es similar a la observada de las nebulosas anillo ópticas (NAO).

- La emisión en continuo de radio de las NAO asociadas a WR 152, WR 153ab y WR 157 se debe a procesos de carácter térmico, es decir, a radiación libre-libre Sin embargo, es necesario contar con más valores de densidades de flujo tanto en bajas como en altas frecuencias para confirmar este hecho.

- Encontramos una buena correspondencia morfológica entre la emisión del gas ionizado, particularmente observada en el continuo de radio en $1420 \mathrm{MHz}$, y la emisión del polvo interestelar, detectada en $60 \mu \mathrm{m}$. Este hecho sugiere que el material ionizado está interactuando con el polvo, ionizándolo, calentándolo y posiblemente destruyéndolo. 
- Se encontró que el parametro de excitación teórico $U_{*}$ es superior al observado Urad, lo que evidencia que el flujo de fotones UV de las estrellas WR mantiene ionizado el gas circundante a ellas. Esta desigualdad indica que gran parte de los fotones ionizantes son absorbidos por el polvo interestelar y luego reemitidos en IR.

- La relación empírica gas-polvo $(\mathrm{G} / \mathrm{P})$ presenta valores entre 160 a 250 superando los valores esperados $\mathrm{G} / \mathrm{P} \sim 100$.

- La distribución de hidrógeno neutro guarda una buena correlación morfológica con el gas y polvo asociado a WR 152. Sin embargo, no existen rasgos claros de asociación ni con el entorno de WR 153ab y ni con WR 157. Encontramos dos posibles razones para este hecho: (i) escaso H I asociado a las NAO y/o (ii) gran cantidad de H i en la línea de la visual que produce confusión en la determinación de alguna posible estructura de Hi.

- La distribución del gas ionizado en torno a WR 153 no es del todo clara y es distinguir si se manifiesta claramente la acción del viento estelar en la actual fase WR o en fases previas.

- Las NAO vinculadas a WR 152 y WR 157 presentan estructuras múltiples con forma arqueada, centradas en la posición de las estrellas WR. Es probable que las cáscaras ópticas asociadas a WR 152 y WR 157 sean el resultado de la acción de diferentes vientos estelares. Este resultado está de acuerdo con el análisis hecho por Cappa (2006) para burbujas de Hi. Es dificil decidir si su origen se debe a la acción de los vientos estelares generados en distintas etapas evolutivas de las estrellas, o si la distribución es simplemente la proyección sobre el plano del cielo de una única estructura formada por la acción de los vientos en la fase WR . Comparando las edades dinámicas $t_{d}$ de las BI, con el tiempo evolutivo de las fases WR $t_{W R}$ de estas estrellas, se ve que $t_{d}>t_{W R}$. Este resultado está de acuerdo con los modelos propuestos por García-Segura et al. (1996) en los que sugiere la acción de tres vientos, uno durante la fase de secuencia principal, el otro en la fase de supergigante roja y el último, en la fase WR. Como este último tiene una velocidad terminal superior al anterior, posiblemente ambos se "fusionen" y lo que veamos sea la acción de los dos simultáneamente.

- Los valores del coeficiente de conversión de energía $\epsilon$ en las estructuras asociadas a WR 152, WR 153ab y WR 157 no se ajustan del todo tanto al modelo evolutivo de conservación del momento ni de energía.

- En todas las estructuras estudiadas se observan regiones de fotodisociación (PDRs) en los límites de las NAO, evidenciadas observacionalmente a partir de (i) la emisión de los PAH en $8 \mu \mathrm{m}$, (ii) la convivencia del gas ionizado y las nubes moleculares.

- Hemos utilizado una amplia gama de herramientas en la búsqueda de candidatos a protoestrella en cada uno de los trabajos. Analizamos fuentes puntuales IR de los relevamientos 2 MASS, MSX e IRAS, determinamos regiones de fotodisociación (PDRs), verificamos la asociación de emisión molecular en diferentes líneas, asociadas a las fuentes IR. En el caso del entorno de la estrella WR 113 utilizamos el 
cociente $R_{2-1 / 1-0}$ como herramienta para estudiar las caracteristicas principales del medio molecular. Los altos valores obtenidos de este cociente evidencian una región propicia para la formación estelar.

La cantidad de fuentes puntuales candidatas a YSOs por unidad de pc en la región H II Gum 31 es un orden de magnitud superior a las observadas en las BI. Creemos que la acción de los vientos de las estrellas WR es tan intensa que no ha permitido el desarrollo de las condiciones óptimas para la formación estelar (densidad electrónica alta y formación de núcleos moleculares) en las cáscara de las BI estudiadas.

Todas estas herramientas nos han llevado a verificar que se esta llevando a cabo la formación estelar inducida en las cáscaras de las NAO generadas por las estrellas WR. Sin embargo es necesario contar con más datos IR y moleculares para confirmar este hecho.

\subsection{Trabajo futuro}

Como ya hemos concluido, las estrellas WR son uno de los principales modeladores de medio interestelar debido a sus fuertes vientos y a su gran tasa de radiación ionizante.

Es necesario contar con mayores estudios de alta resolución que contribuyan a:

- La determinación precisa de regiones de fotodisociación en los límites de las nebulosas anillo ópticas que nos permitan proponer escenarios propicios para la FES.

- La búsqueda de regiones de FES en distintas BI que nos permitan comparar los resultados con los alcanzados en SG 13 y en Sh2-132.

- El estudio en profundidad de la correlación entre la emisión IR en $60 \mu \mathrm{m}$ y el continuo de radio para más herramientasque verifiquen la radiación térmica asociada a las NAO.

- La obtención de factores de llenado más precisos que permitan acotar lo mayor posible los valores de la masa del gas ionizado y la densidad electrónica.

- La búsqueda de estructuras de hidrógeno neutro observado en alta resolución asociadas a estrellas WR. No existen muchos estudios al respecto.

- La búsqueda y el análisis de YSOs asociados a BI con el objetivo de estudiar su distribución en estos ambientes y comparar con regiones H II clásicas.

- El estudio estadístico de las BI asociadas a estrellas WR para poder llegar a inferir correlaciones a nivel estructural o evolutivo de estas estructuras. 


\subsection{Bibliografía}

Cappa C.E., 2006, Rev. Mex. A.A. Serie de conferencias 


\section{Apéndice A}

\section{Conceptos de instrumentación radioastronómica}

\section{Resumen}

Daremos una pequeña reseña acerca de los conceptos generales del instrumental radioastronómico basados en la observación con disco simple e interferómetro.

\section{A.1. Algunas nociones radioastronómicas}

Las antenas pueden definirse como la región de transición entre la ondas electromagnéticas en espacio libre y las ondas guiadas. Las antenas de un radiotelescopio actúan como colectoras de ondas de radio. En particular, son análogas a las lentes o espejos en el caso de telescopios ópticos. El concepto básico de un receptor radioastronómico puede ser clarificado con la ayuda del gráfico de la Fig. A.1. La antena recolecta la potencia en radio proveniente de la fuente celeste. Esa señal pasa por un proceso de predetección donde se traduce como señal eléctrica en el receptor que amplifica, filtra e integra esa señal. Finalmente el último paso es la traducción en señal legible a un analizador analógico o digital.

La potencia recibida por la antena puede expresarse como:

$$
W=k T \Delta B
$$

donde $k$ es la constante de Boltzmann, $\Delta B$ es al ancho de banda del receptor, y $T$ es la temperatura del objeto, medida por ese receptor en particular. Comúnmente esta temperatura se llama temperatura de antena $T_{A}$, que depende del instrumento utilizado y es una medida de la potencia recibida.

Podemos definir la potencia detectada por el instrumento en términos de densidad de 


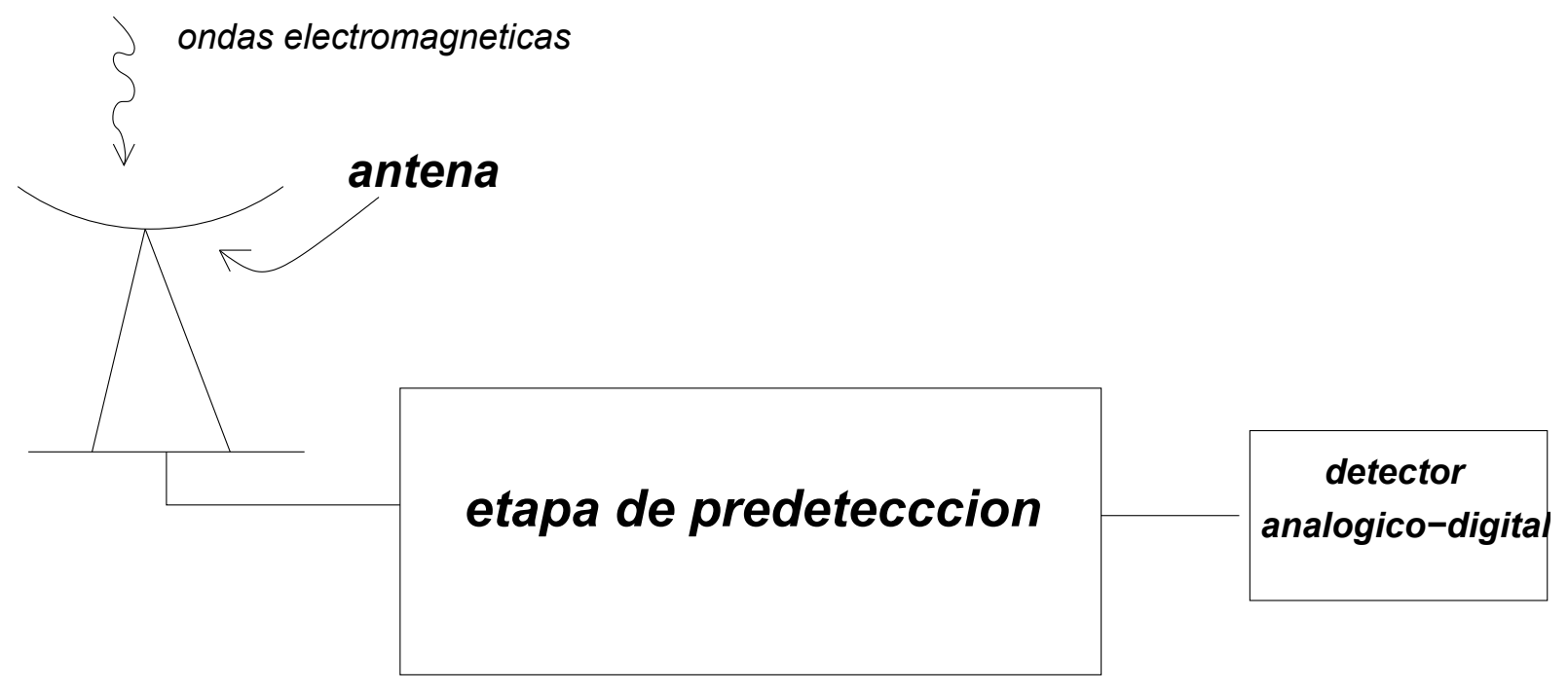

Figura A.1: Esquema de un radiómetro

flujo observada $S_{o b s}$, o simplemente sensibilidad del instrumento, como

$$
\frac{S_{o b s}}{T_{A}}=\frac{2 k}{A_{e f f}}
$$

donde $A_{\text {eff }}$ es el área efectiva de antena, siendo ésta la porción de antena que logra reflejar toda la radiación recibida y $A_{\text {eff }} \leq A_{\text {física }}$, con $A_{\text {física }}$ el área total de la antena.

Toda señal detectada por un radiómetro lleva una componente que presenta fluctuaciones pequeñas y rápidas de intensidad que llamamos "ruido".

Posibles causantes del ruido puden ser son regiones del cielo no asociadas al objeto de interés, ubicados en la misma línea de la visual, radiación proveniente de la Tierra, señales artificiales, etc. Todas estas son fuentes de ruido que se agregan a la componente producida por la fuente de observación. Todas estas contribuciones las medimos como temperatura de antena $T_{A}$.

También la electrónica del radiómetro genera ruido $\left(T_{\text {receptor }}\right)$, que agrega señal en el sistema de medición. De esta forma todas las contribuciones las incluimos en la temperatura del sistema $T_{\text {sis }}=T_{A}+T_{\text {receptor }}+T_{\text {fondo }}+T_{\text {atm }}+$ otras contribuciones.

Entonces se puede caracterizar el ruido como

$$
\Delta T_{r m s}=\frac{K T_{s i s}}{\sqrt{\Delta B t}}
$$

donde $K$ es una constante que depende del modo de observación, $\Delta B$ es al ancho de banda del filtro utilizado para la observación, y $t$ el tiempo de integración de la observación. 


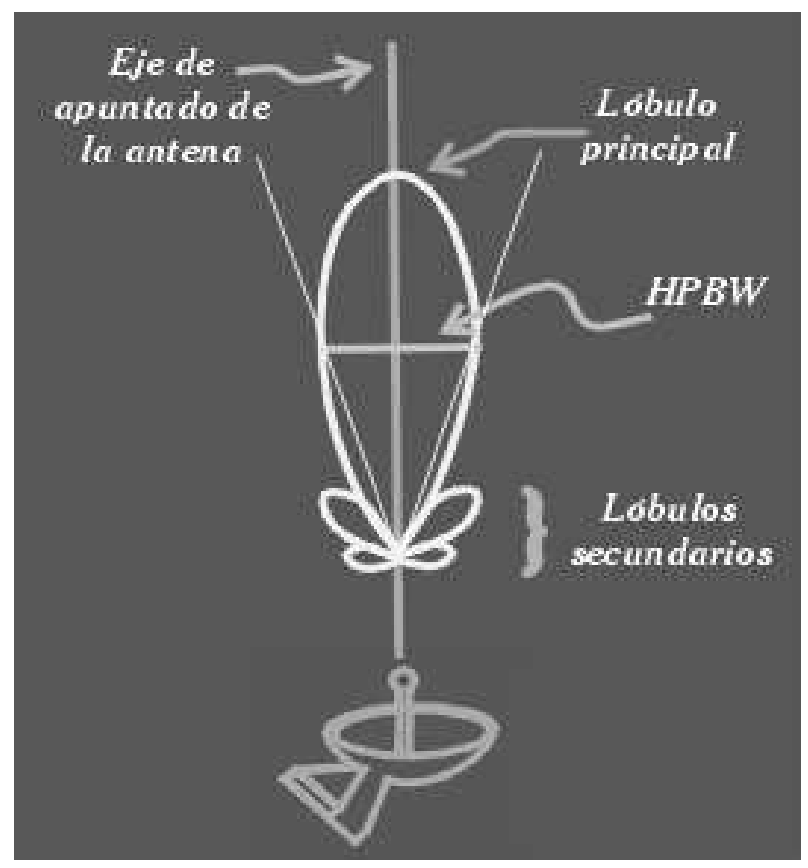

Figura A.2: Diagrama de antena en coordenadas polares.

La respuesta de la antena a la señal recibida en función de la dirección angular está dada por lo que se llama diagrama de antena $P(\phi, \psi)$, donde $\phi$ es el ángulo azimutal y $\psi$ el ángulo cenital en un sistema en coordenadas esféricas. El diagrama puede esquematizarse como está indicado en la Fig. A.2. Como se puede observar, la respuesta de la antena alcanza su valor máximo cuando la fuente se ubica en dirección del eje mayor del haz principal y a medida que el aumenta el ángulo entre el haz principal y la fuente la señal recibida diminuye.

En ambos lados del lóbulo principal aparecen lóbulos secundarios, a través de los que se detecta radiación parásita. Su origen radica principalemte en tres cuestiones, (i) variaciones de intensidad de las líneas observadas, (ii) emisión de otras señales de fuentes celestes ajenas a la observada, (iii) si la montura del telescopio es alta-azimutal, aparecen variabilidades temporales parásitas debido a que el correlador está rotado respecto del cielo. El efecto "parásito" se corrige después de la observación.

Es importante destacar que este efecto se produce cuando una fuente extendida, que se define como tal cuando su extensión angular es mayor que el haz de la antena. Si $\theta$ es al ángulo más pequeño medido por la antena, entonces

$$
\theta \simeq 1.22 \frac{\lambda}{d}
$$

donde $\lambda$ es la longitud de onda y $d$ es el diámetro de la antena. Generalmente, se describe 
a la resolución angular en términos del ancho del diagrama de antena a mitad de su potencia máxima, el HPBW (del inglés half power beam width).

Si queremos medir la distribución de brillo de una fuente extendida, debemos definir la temperatura de brillo $T_{b}$ que es la temperatura que debería tener un cuerpo negro, a una frecuencia de observación dada para que la potencia detectada por un receptor con un ancho de banda $\Delta B$ y un diagrama de antena $P(\phi, \psi)$ sea $k T_{A}$. Suponiendo que un cuerpo negro tiene un espectro de radiación dado por la ley de Planck y sabiendo que para la ondas de radio en la banda centimétrica se satisface $h \nu \ll k T$, a partir de la aproximación de Rayleigh-Jeans, el espectro de la fuente estará dado por

$$
B_{\nu}=\frac{2 k T_{b}}{c^{2}} \nu^{2}
$$

De esta manera, el flujo $S_{\nu}$ de una fuente extendida, con una distribución de brillo $B(\phi, \psi)$ de ángulo sólido $\Omega_{f}$, medido en coordenadas esféricas, será

$$
S_{\nu}=\int_{\Omega_{f}} B(\phi, \psi) d \Omega
$$

No debemos olvidar que la densidad de flujo de la fuente medida por el radiómetro $S_{\text {obs }}$ es la convolución de la distribución real de brillo de la fuente y el diagrama de antena, es decir

$$
S_{o b s}=B(\phi, \psi) * P_{n}(\phi, \psi)=\int_{\Omega_{f}} B(\phi, \psi) P_{n}\left(\phi-\phi_{0}, \psi-\psi_{0}\right) d \Omega
$$

donde $P_{n}(\phi, \psi)$ es el diagrama de antena normalizado.

La ecuación A.4 dice que si queremos mejorar la resolución angular para una frecuencia de observación, debemos aumentar el diámetro del instrumento: una de las formas es aumentar el número de antenas receptoras y que funcionen como una única "gran" antena. De esta forma se abre camino a la interferometría. En la siguiente sección resumiremos los conceptos básicos acerca de esta técnica.

\section{A.2. Conceptos básicos de interferometría}

Si aumentamos el número de antenas se mejora la resolución angular del conjunto. Es por eso que la interferometría es una de las técnicas de observación más usadas en radioastronomía. El concepto de un interferómetro puede entenderse como lo exhibe la Fig A.3.

Aquí se muestra un arreglo de dos antenas donde $s$ representa la distancia entre antenas, llamada "línea de base", a el diámetro de cada una de ellas y $\phi$ el ángulo entre 
(a)

direccion normal al plano de las antenas

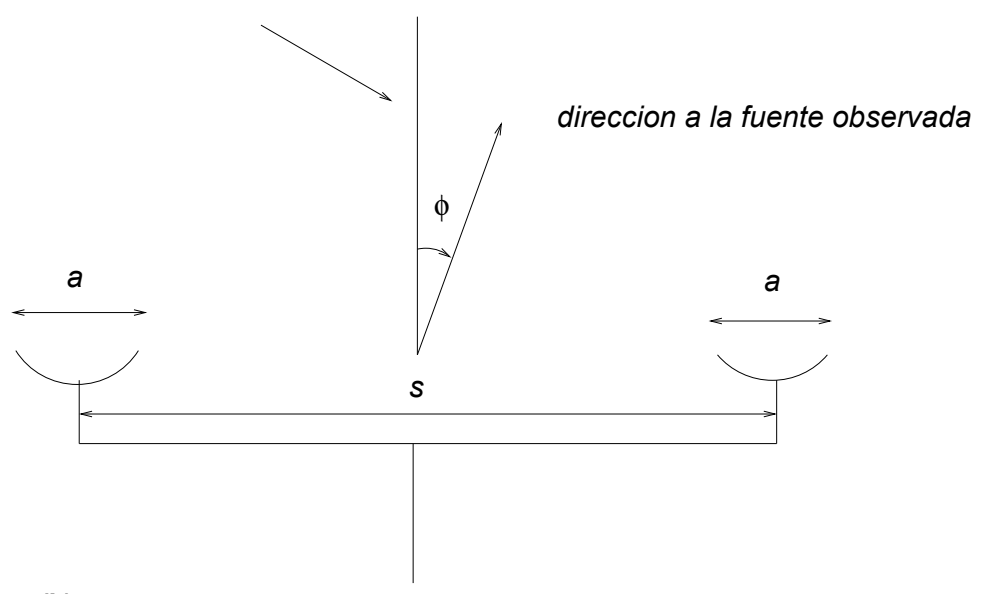

(b)

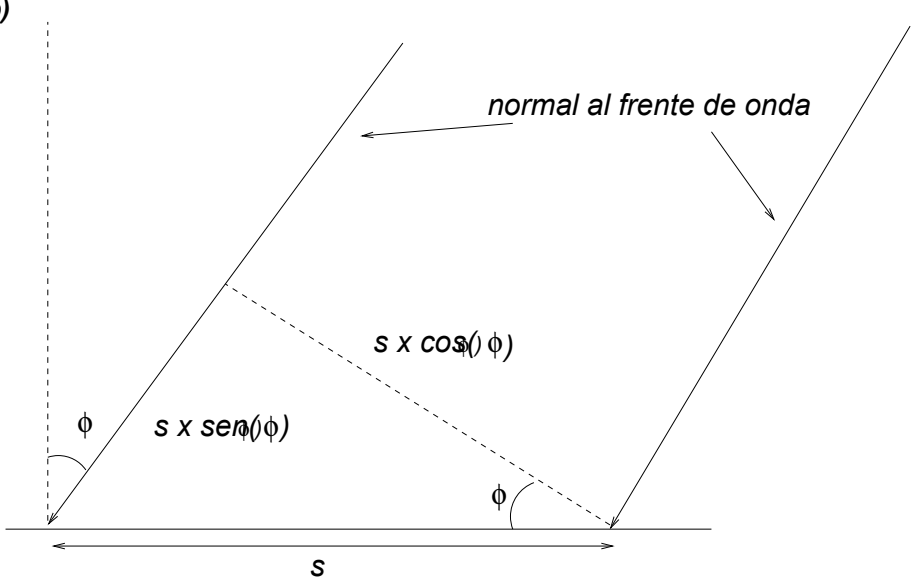

Figura A.3: Esquema básico de un interferómetro de dos antenas. 
la dirección a la fuente observada y la normal al plano de la superficie donde están apoyadas las antenas. Uno de los efectos que se producen al tener este tipo de arreglo son las llamadas "franjas de interferencia". Esto se debe a que el camino recorrido por la radiación desde donde se genera hasta donde es detectada por ambas antenas es diferente. $\mathrm{Si}$ asumimos un frente de onda plano, vemos que esa diferencia en el camino recorrido por el frente de onda en $s \times \operatorname{sen}(\phi)$, que comúnmente se llama "retardo geométrico". Si el retardo es igual a un múltiplo de longitudes de onda, es decir, si $s \times \operatorname{sen}(\phi)=n \lambda$, entonces la interferencia será contructiva, mientras que si no ocurre esto, ambas antenas recibirán fases opuestas y el efecto neto será nulo, o sea, la interferencia será destructiva.

El campo eléctrico del interferómetro será:

$$
E(\phi)=E_{1}(\phi) e^{i \psi / 2}+E_{2}(\phi) e^{-i \psi / 2}
$$

donde $E_{1}(\phi)$ y $E_{2}(\phi)$ son los campos elécticos de cada antena, y $\psi=\frac{2 \pi s}{\lambda} \operatorname{sen}(\phi)$ es la diferencia de fase entre antenas. Si $E_{1}=E_{2}=E_{0}$, y $E_{n}=2=E_{0}$

$$
E(\phi)=2 E_{n} \cos (\psi / 2)
$$

La potencia recibida será

$$
P(\phi)=|E(\phi)|^{2}=\left|E_{n}(\phi)\right|^{2} \cos (\phi / 2)^{2}
$$

a partir de algunas propiedades trigonométricas, llegamos a

$$
P(\phi)=\left|E_{n}(\phi)\right|^{2}\left(\frac{1+\cos (\phi)}{2}\right)
$$

de esta forma, esta expresión representa el diagrama de antena para un interferómetro. Vemos que el primer factor corresponde a la potencia recibida por una única antena, mientras que el segundo factor depende de la diferencia de fase entre antenas. En el panel superior de la Fig. A.4 se muestra la respuesta de una antena individual. El gráfico intermedio corresponde al segundo factor de la ecuación A.11, mientras que el gráfico inferior, el producto de ambos, es decir, la respueta del interferómetro modulada par la antena simple.

La distribución de la densidad de flujo observado $S_{\text {obs }}^{\prime}\left(\phi_{0}, S_{\lambda}\right)$ es igual a la convolución entre la distribución real de brillo de la fuente $\left.B_{(} \phi\right)$ y el diagrama de antena $\left.P_{(} \phi\right)$, es decir

$$
S_{o b s}^{\prime}\left(\phi_{0}, S_{\lambda}\right)=\int_{-\alpha / 2}^{\alpha / 2} B(\phi) P\left(\phi_{0}-\phi\right) d \phi
$$

donde $\phi_{0}$ es la distancia angular respecto del cenit, $S_{\lambda}=s / \lambda$ y $\alpha$ es la extensión de la fuente en el cielo. Si la fuente es puntual, de la ecuación (A.11) $\left(\left|E_{n}(\phi)\right|=1\right)$ y $\alpha \ll S_{\lambda}$, entonces $S_{o b s}^{\prime}$ tendrá la siguiente expresión 


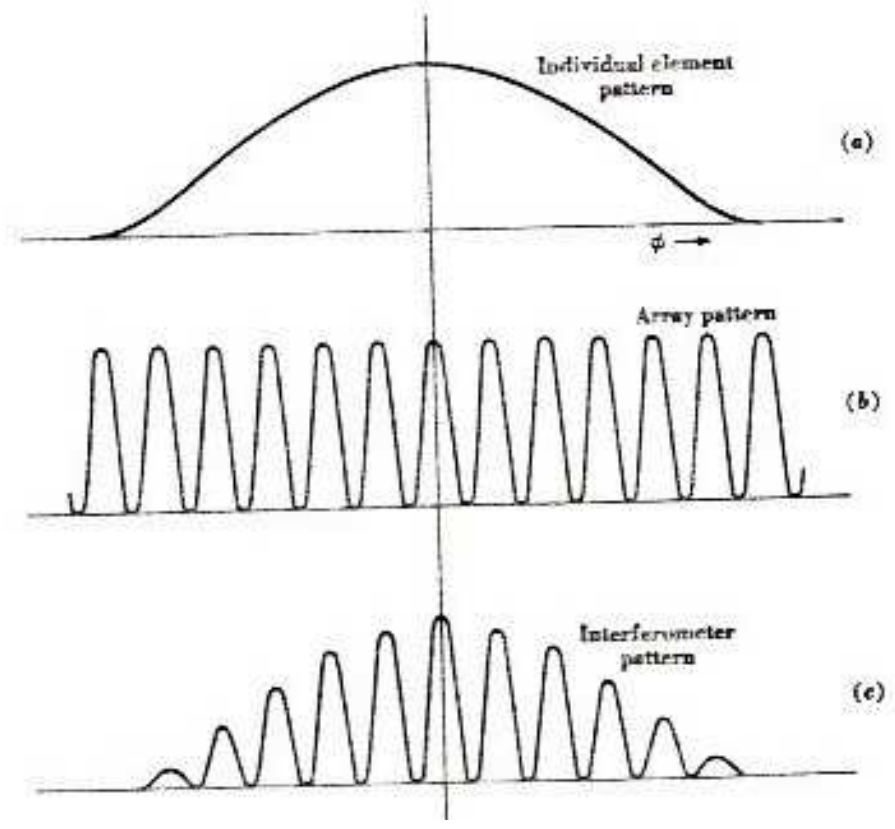

Figura A.4: Panel superior: Respuesta de una disco simple a la radiación. Panel central: Patrón del interferómetro generado por las dos antenas. Panel inferior: Combinación entre ambos componentes. respuesta real del interferómetro (Kraus 1966).

$$
S_{\text {obs }}^{\prime}\left(\phi_{0}, S_{\lambda}\right)=S_{0}+\int_{-\alpha / 2}^{\alpha / 2} B(\phi) \cos \left(2 \pi S_{\lambda}\left(\phi_{0}-\phi\right)\right) d \phi
$$

donde $S_{0}=\int_{-\alpha / 2}^{\alpha / 2} B(\phi) d \phi$ y si $\cos \left(2 \pi S_{\lambda}\left(\phi_{0}-\phi\right)\right) \simeq 1$, entonces

$$
S_{o b s}^{\prime}\left(\phi_{0}, S_{\lambda}\right) \propto S_{0} \pm \int_{-\alpha / 2}^{\alpha / 2} B(\phi) d \phi=S_{0} \pm S_{0}
$$

entonces

$$
S_{o b s}^{\prime}\left(\phi_{0}, S_{\lambda}\right) \propto 2 S_{0}
$$

ó

$$
S_{o b s}^{\prime}\left(\phi_{0}, S_{\lambda}\right) \propto 0
$$

De esta forma definimos la función visibilidad $\mathrm{V}$, como 


$$
V=\frac{S_{\max }-S_{\min }}{S_{\max }+S_{\min }}
$$

para una fuente puntual $S_{\max }=2 S_{0}$ la señal es proporcional al doble del flujo de la fuente, y $S_{\min }=0$ y por lo tanto $\mathrm{V}=1$. Para fuentes extendidas, $\mathrm{V}<1$. No debemos olvidar que la condición de "puntualidad" depende de la línea de base $S_{\lambda}$ con la que se observa.

La función visibilidad, que es lo que mide un interferómetro, se relaciona con la distribución de brillo de la fuente observada, de la siguiente manera

$$
V_{0}\left(S_{\lambda}\right) e^{i 2 \pi S_{\lambda} \Delta \phi_{0}}=\frac{1}{S_{0}} \int_{-\infty}^{\infty} B(\phi) e^{i 2 \pi S_{\lambda} \phi_{0}} d \phi
$$

La cantidad $V_{0}\left(S_{\lambda}\right)$ representa la amplitud del patrón observado. El miembro izquierdo de esta expresión se llama función de visibilidad compleja (FVC). Se asumió que la fuente está contenida dentro de una ángulo pequeño, por eso se extendieron los límites de la integral hasta infinito. En la Fig. A.5 muestra la respuesta del interferómetro a la radiación de una fuente puntual (linea continua). Se observa que el flujo de este tipo de fuente es igual al doble de la señal entrante (panel superior). En el gráfico cental se observa la respuesta del interferómetro a una fuente extendida, pero menor que su resolución. Finalmente, en el panel inferior se observa lo que ocurre cuando la fuente es del orden del haz de interferómetro. Ya la función visibilidad es cero para esta fuente.

De esta manera, la FVC es igual a la transformada de Fourier de la distribución de brillo de la fuente.

La resolución angular o haz sintetizado está determinado por la máxima separación entre las antenas $D$. Por lo tanto , el HPBW será

$$
\theta \simeq 1.22 \frac{\lambda}{D}
$$

Por ejemplo, si estamos observado una fuente en $6 \mathrm{~cm}$, para una línea de base de 36 km (configuración A del Very Large Array, VLA), el HPBW 0.4".

Por otro lado, el campo de vista (FOV, del inglés field of view), está dado por

$$
\theta \simeq 1.22 \frac{\lambda}{a}
$$

es decir, depende del diámetro de las antenas individuales. De esta forma, cuanto máyor es el diámetro, menor será el FOV.

Evidentemente, la menor línea de base corresponde al diámetro de las antenas, por este motivo es que las estructuras angularmente grandes no pueden ser detectadas por un interferómetro. Como se muestra en la Fig A.6, si se hace la autocorrelación entre dos 


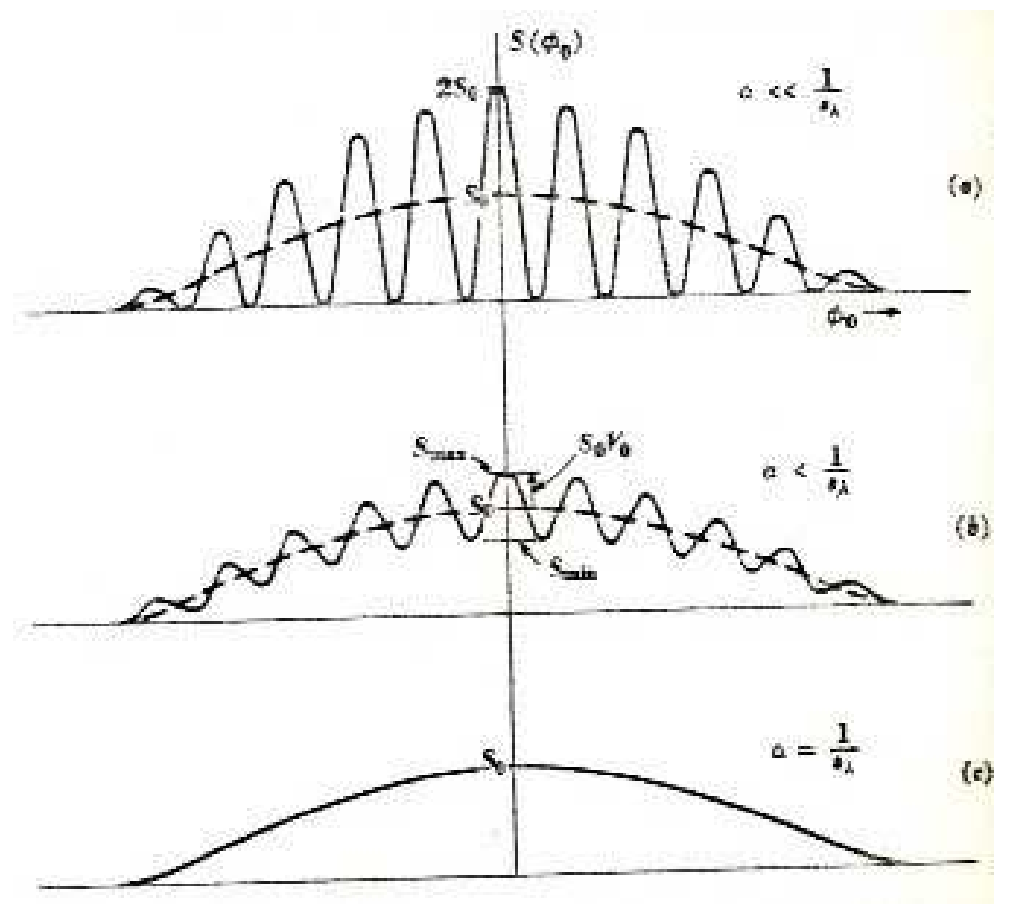

Figura A.5: Panel superior: Respuesta del interferómetro ante una funet puntual. La función visibilidad es igual a la unidad. Panel central: Mismo gráfico anterior, pero la fuente es extendida, aunque menor al haz del instrumento. Panel inferior: Respuesta del instrumento a una fuente extendida con un tamaño angular del orden del haz del interferómetro. En este caso la función visibilidad es cero (Kraus 1966). 


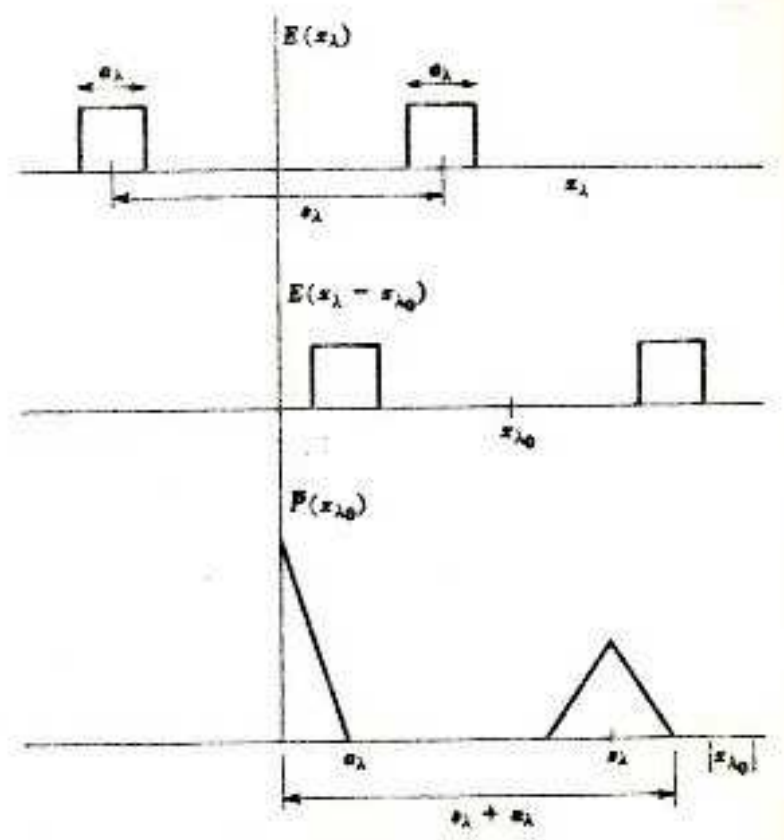

Figura A.6: Panel superior: Función iluminación $E\left(x_{\lambda}\right)$ de ambas antenas con un diametro $a_{\lambda}$. Panel central: Correlación de las iluminaciones de ambas antenas. Panel central: Función de autocorrelación entre dos antenas de un interferómetro (Kraus 1966).

antenas con igual apertura $a_{\lambda}$ (definido como $a_{\lambda}=a / \lambda$, en términos de frecuencias angulares), distanciadas en $S_{\lambda}$, el diagrama resultante será el que se muestra en la Fig. A.6. El sector adyacente al origen corresponde a la autocorrelación de una antena, y la distribución centrada en $S_{\lambda}+a_{\lambda}$ corresponde a la correlación entre la antena 1 y la 2 . Si solo se observa una fuentes extendida con las antenas u interferómetro, las fuentes celestes con estructura angular menor que la centrada en $S_{\lambda}+a_{\lambda}$ no podrán ser detectadas por el interferómetro. Debido a esto, si se llevan a cabo observaciones interferométricas, no podremos observar estructuras en gran escala. Por eso es que muchas veces se agregan las imágenes tomadas por discos simples, llamadas "short spacing", para poder tener una visión completa de las fuentes celestes, si es que presentan estructuras en escala angular pequeña y grande.

El uso secuencial de una serie de líneas de base se llama síntesis de apertura. Los arreglos de síntesis pruducen imágenes a través de la transformada de Fourier de la función visibilidad. 


\section{A.3. Bibliografía}

Kraus J. D., 1966, Radio astronomy, McGraw-Hill 


\section{Apéndice B}

\section{Lista de trabajos publicados}

Trabajos publicados en revistas científicas internacionales con referato:

- An HI interstellar bubble surrounding WR85 and RCW118

J. Vasquez, C. Cappa y N. McClure-Griffiths

Monthly Notices of the Royal Astronomical Society, 2005, 362, 681-688 [astro$\mathrm{ph} / 0507481]$

- The environs of the HII region Gum31

Cappa, V.S. Niemela, R. Amorìn y J. Vasquez

Astronomy \& Astrophysics, 2008, 477, 173 [astro-ph/0711.2458]

Publicaciones en actas de congresos con referato:

- Gas molecular asociado a la región HII Anon(WR113)

J. Vasquez, C.E. Cappa y M. Rubio

BAAA, 2007 (en prensa).

- The complex ISM towards Sh2-157

J. Vasquez, C. Cappa y S. Pineault

2005, BAAA, 48, 302

- Multifrequency study of Gum 31

J. Vasquez, C. Cappa, R. Amorin, V. Niemela y N. McClure-Griffiths 2004, BAAA, 47, 268-271.

- MSX images of stellar wind bubbles

J. Vasquez y C.E. Cappa

RevMxAA, 2006 (en prensa).

Publicaciones en actas de congresos sin referato: 
A multifrequency study of the active star forming region NGC 6357

C.E. Cappa, R. H Barbá, M. Arnal, N. Duronea, E. Fernàndez Lajús, W.M. Goss, J.Vasquez

"Triggered Star Formation in a Turbulent ISM, Simposio No 237 de la IAU, 14-18 de Agosto del 2006, Praga, República Checa.

The ISM around WR stars: WR152 and WR153ab

C. Cappa, J. Vasquez, E.M. Arnal, S. Cichowolski y S. Pineault

Conferencia "Mass loss form stars and the evolution of stellar cluster", 29 de Mayo al 1 de Junio del 2006, Lunteren, Holanda.

The complex ISM towards Sh2-157

J. Vasquez, C. Cappa y S. Pineault

"11th Latin American Regional IAU Meeting", 12-16 de Diciembre de 2005, Pucón, Chile.

Interstellar bubbles and photodissociation regions in NGC 6357

C.Cappa, , R.Barbá, E..M Arnal, N.Duronea, E. Fernández Lajús, W.M. Goss, J. Vasquez

"11th Latin American Regional IAU Meeting ", 12-16 de Diciembre de 2005, Pucón, Chile.

The ISM around the WR star LSS3982 and RCW118

Vasquez J., Cappa C., McClure-Griffiths N.

Conferencia "Diffuse matter in the galaxy: Observations confront theory", 30 de Agosto al 4 de Septiembre del 2004, Arecibo, Puerto Rico. 